\title{
Historic overview and new developments in synthetic methods for preparation of the rare- earth tetrapyrrolic complexes
}

Victor E. Pushkarev, ${ }^{* a}$ Larisa G. Tomilova, ${ }^{\mathrm{a}, \mathrm{b}}$ and Victor N. Nemykin ${ }^{*^{\mathrm{c}}}$

${ }^{a}$ Institute of Physiologically Active Compounds, Russian Academy of Sciences, 142432 Chernogolovka, Moscow Region, Russian Federation.

${ }^{b}$ Department of Chemistry M. V. Lomonosov Moscow State University, 119991 Moscow, Russian Federation

${ }^{c}$ Department of Chemistry \& Biochemistry, University of Minnesota Duluth, Duluth, MN 55812, USA

Keywords: rare-earth, porphyrin, phthalocyanine, naphthalocyanine, tetraazaporphyrin, synthesis

To whom correspondence should be addressed: e-mail: np.ruff@gmail.com (VEP); tom@org.chem.msu.ru (LGT); vnemykin@d.umn.edu (VNN) 


\section{Contents}

1. Introduction

2. Synthetic approaches to single-decker complexes

2.1. Template synthesis from phthalogens

2.2. Rare-earth metal insertion reaction into free-base ligand

2.3. Axial substitution at metal ion

3. Synthetic approaches to homoleptic double-decker complexes

3.1. Template synthesis from phthalogens

3.2. Metallation of free-base ligands

3.3. Axial substitution at the metal center

4. Synthetic approaches to homoleptic triple-decker complexes

4.1. Template synthesis from phthalogens

4.2. Metallation of free-base ligand

4.3. Monophthalocyanine based techniques

5. Synthetic approaches to heteroleptic and mixed-ligand double-decker complexes

5.1. Phthalocyanine-metal-phthalocyanine complexes

5.2. Phthalocyanine-metal-naphthalocyanine complexes

5.3. Phthalocyanine-metal-porphyrin complexes

5.4. Naphthalocyanine-metal-porphyrin complexes

5.5. Porphyrin-metal-porphyrin complexes

6. Synthetic approaches to heteroleptic and mixed-ligand triple-decker complexes

6.1. Heteroleptic phthalocyanine complexes

6.2. Mixed-ligand phthalocyanine and porphyrin complexes 
6.3. Mixed-ligand naphthalocyanine and porphyrin complexes

7. Conclusions

Acknowledgement

\section{List of Abbreviations}

Tetrapyrrole macrocyclic ligands

DAP 2,8,12,18-tetramethyl-3,7,13,17-tetraethyl-5,15-diazaporphyrinate(2-)

Nc general abbreviation for naphthalocyaninate(2-)

OEP $\quad 2,3,7,8,12,13,17,18$-octaethylporphyrinate(2-)

Pc general abbreviation for phthalocyaninate(2-)

PnP 5,10,15,20-tetrapentylporphyrinate(2-)

Por general abbreviation for porphyrinate(2-)

TAP general abbreviation for tetraazaporphyrinate(2-)

${ }^{\mathrm{Ph}}$ TAP 2,3,7,8,12,13,17,18-octaphenyltetraazaporphyrinate(2-)

${ }^{\mathrm{Pr}} \mathrm{TAP} \quad 2,3,7,8,12,13,17,18$-octapropyltetraazaporphyrinate(2-)

TFcP 5,10,15,20-tetraferrocenylporphyrinate(2-)

TPP 5,10,15,20-tetraphenylporphyrinate(2-)

TPyP 5,10,15,20-tetra(4-pyridyl)porphyrinate(2-)

TTP 5,10,15,20-tetra( $p$-tolyl)porphyrinate(2-)

General Abbreviations

acac acetylacetonate(1-)

BNT boron neutron therapy 


\begin{tabular}{|c|c|}
\hline btfa & benzoyl-1,1,1-trifluoroacetonate(1-) \\
\hline$n-\mathrm{Bu}$ & $n$-butyl \\
\hline$t$-Bu & tert-butyl \\
\hline $\mathrm{CD}$ & circular dichroism \\
\hline $1-\mathrm{ClN}$ & 1-chloronaphthalene \\
\hline $\mathrm{dbm}$ & dibenzoylmethanate(1-) \\
\hline DBU & 1,8-diazabicyclo[5.4.0]undec-7-ene \\
\hline$o-\mathrm{DCB}$ & 1,2-dichlorobenzene \\
\hline DFT & density functional theory \\
\hline$\beta$-dik & $\beta$-diketonate(1-) \\
\hline DMAE & $N, N$-dimetylaminoethanol \\
\hline DNA & deoxyribonucleic acid \\
\hline $\mathrm{dpm}$ & dipivaloylmethanate(1-) \\
\hline FAB & fast atom bombardment (MS method) \\
\hline fod & 2,2-dimethyl-6,6,7,7,8,8,8-heptafluoro-3,5-octanedionate(1-) \\
\hline hfbc & 3-heptafluorobutyryl- $d$-camphorate(1-) \\
\hline HOMO & highest occupied molecular orbital \\
\hline HOPG & highly oriented pyrolytic graphite \\
\hline $\mathrm{Ln}$ & lanthanides and yttrium \\
\hline LUMO & lowest unoccupied molecular orbital \\
\hline MALDI-TOF & matrix-assisted laser desorption-ionization, time-of-flight (MS method) \\
\hline MCD & magnetic circular dichroism \\
\hline MS & general abbreviation for mass-spectrometry or mass-spectrum \\
\hline
\end{tabular}




$\begin{array}{ll}\text { NIR } & \text { near infrared spectral region } \\ \text { NPN } & \text { general abbreviation for naphthalonitrile } \\ \text { PDT } & \text { photodynamic therapy } \\ \text { PN } & \text { general abbreviation for phthalonitrile } \\ \text { QN } & \text { quinoline } \\ \text { SOMO } & \text { singly occupied molecular orbital } \\ \text { STM } & \text { scanning tunneling microscopy } \\ \text { TCB } & \text { 1,2,4-trichlorobenzene } \\ \text { TfO }^{-} & \text {triflate anion }\left(\mathrm{CF}_{3} \mathrm{SO}_{2} \mathrm{O}^{-}\right) \\ \mathrm{UV}_{-} \text {-vis } & \text { ultraviolet-visible spectral region }\end{array}$

\begin{abstract}
New developments as well as a historic overview on synthetic strategies for preparation of the rare-earth complexes with porphyrins, phthalocyanines, naphthalocyanines, tetraazaporphyrins, and related systems are discussed in detail with emphasis on selective synthetic pathways for preparation of single-, double, and triple-decker architectures.
\end{abstract}




\section{Introduction}

After their discovery almost 100 years ago, phthalocyanines (Pcs) were predominantly investigated because of their industrial applications as dyes, pigments, and catalysts [1-3]. Similarly, historically, porphyrins (Pors) were intensively studied because of their importance in mimicking biologically relevant atom- and electron-transfer processes as well as light-harvesting mechanisms associated with living cells [4-6]. In addition, porphyrins, phthalocyanines, and their analogues were found to be useful in applications such as redox-driven fluorescence markers and biomarkers, light-harvesting antennas for organic photovoltaics and dye sensitized solar cells, charge carriers for copiers and printers, materials for molecular electronics, as well as redoxactive components in environmental, biological, and industrial sensors as well as active components in photodynamic therapy (PDT) and boron neutron therapy (BNT) of cancer [7-19]. In their initial attempts, researchers focused on rich coordination, redox, and magnetic properties of the metal-free, main-group, and especially transition-metal porphyrinoids. It was soon realized, however, that the rare-earth ions can form unusual systems when coupled with the phthalocyanine ligand.

The first rare-earth Pcs were reported by Russian scientists Kirin and Moskalev in 1965 [20]. Kirin and Moskalev also pointed out that because of the large ionic radii and high coordination numbers of the rare-earth ions, the formation of the double-decker rare-earth phthalocyanine compounds could be achieved under specific reaction conditions [20,21]. During the next 50 years, it was confirmed that rare-earth ions are capable of the formation of phthalocyanine single-, double, and triple-decker complexes and their analogues [22-33]. One of the interesting recent discoveries was the preparation and characterization of heteronuclear (rareearth / cadmium) multiple-decker complexes, which contain up to six Pc ligands [34-42]. 
However, these compounds include no more than two rare-earth ions located at the periphery of such "super-sandwiches". As a result, electronic coupling between the rare-earth centers in these multiple-decker compounds decreases with an increase in the number of Pc ligands and their magnetic properties start to resemble classic rare-earth double-decker systems. These multipledecker systems, with rare-earth ion size-dependent intramolecular electronic coupling between macrocycles, as well as metal-metal interactions (in the case of multinuclear rare-earth compounds), open potential applications for such compounds in electrochromic modules $[30,43,44]$, gas sensors [30, 44-50], metal ion sensors [51], and bio-sensors [51-54], as well as active components of molecular magnets [33, 55-60], materials for multi-bit information storage [61-64], molecular electronics [33,65-67], and non-linear optics [30,68-70].

Synthetic approaches for the high-yield, selective formation of heteroleptic, mixedligand, and heteronuclear rare-earth multiple-decker complexes could potentially result in the preparation of new systems with exciting properties [41,42,71-81]. The most common strategies for the preparation of rare-earth Pcs are: (i) tetramerization reactions of phthalic acid derivatives (usually - PNs) in the presence of respective rare-earth ions (template synthesis) and (ii) metal insertion reactions into pre-formed metal-free macrocyclic system(s). The last method is particularly interesting for the preparation of asymmetric rare-earth multiple-decker systems with different macrocyclic ligands. In this review, we will discuss specific synthetic strategies for the preparation of rare-earth Pcs and their analogues and highlight their advantages and pitfalls. Although several high-quality reviews on rare-earth porphyrinoids are available in the literature, to the best of our knowledge, there is no published comprehensive overview on synthetic methodologies for preparation of such systems. This contribution compiles the work developed on the rare-earth porphyrinoids reported by several groups around the world. 
In order to avoid confusion in terminology [23,25,29], the following definitions will be used in this review: (i) multiple-decker homoleptic complexes are those with identical ligands; (ii) multiple-decker heteroleptic complexes are those that have the same type of ligands (i.e. Pcs) with different substituents, as well as Pc-naphthalocyanine ( $\mathrm{Nc}$ ) and Pc-tetraazaporphyrin (TAP) ligands; (iii) mixed-ligand multiple-decker complexes are those that contain macrocycles with different meso-substituents, i.e. Pc-Por type complexes; (iv) heteronuclear multiple-decker systems are those containing different metals; (v) the definition of dimers and trimers will be used both for multiple-decker systems as well as systems with covalently bridged oligomers; and (vi) the Ln abbreviation will be used for lanthanides and yttrium.

Electronic absorption spectroscopy is known as the most commonly used characterization technique for porphyrinoids. It represents a simple, yet very effective tool and therefore deserves a short introduction, especially since rare-earth planar and sandwich-type tetrapyrrole complexes demonstrate unique features in their absorption spectra depending on the nature, number, and combination of their constituent ligands and metal ions, which affirms this method as the primary one both for identification and purity control purposes.

In this review, we exemplify spectral properties of the rare-earth tetrapyrrolic systems by the generalized Pc- and Nc-containing compounds. UV-vis spectra of the single-decker rareearth Pcs and Ncs characterized by the intense $Q$ - and $B$-(Soret) bands. In the case of tetrapyrrolic systems with effective four-fold symmetry, $Q$-band usually represents the first excited state and predominantly originates from the HOMO $\rightarrow$ LUMO, LUMO+1 single electron excitations. For instance, planar metal-containing Pcs and Ncs reveal a single $Q$ band due to the LUMO degeneracy resulting from higher $\left(D_{4 \mathrm{~h}}\right)$ symmetry of the complex. The LUMO and LUMO+1 degenaracy usually holds in the case of single-decker rare-earth Pcs and Ncs, which 
have effective $C_{4 v}$ symmetry. As a result, these complexes also have a single $Q$-band in their UV-vis spectra. Lowering effective symmetry in Pcs and Ncs results in non-degenerate LUMO and LUMO+1, which leads to splitting of the $Q$-band, similar to free-base Pcs with $D_{2 \mathrm{~h}}$ effective symmetry (Figure 1). Double-decker compounds are typically formed as stable neutral $\pi$-radicals of general formula $\left[\mathrm{Pc}^{2-} \mathrm{Ln}^{3+} \mathrm{Pc}^{-}\right]^{0}$ and the unpaired electron occupies the ligand-centered SOMO level (Figure 2). Single-electron HOMO $\rightarrow$ SOMO transition contributes significantly to the $B V$ (blue valence) band in the $450-500 \mathrm{~nm}$ region and the $I V$ (inter-valence) band observed in the $1200-2100 \mathrm{~nm}$ region. In addition, SOMO $\rightarrow$ LUMO single-electron excitation provides a major contribution to the $R V$ (red valence) band near $900 \mathrm{~nm}$. The spectra of the redox-active species of the double-decker compounds demonstrate significant difference in comparison with their neutral forms (Figure 2). The oxidized double-decker systems have general formula $\left[\left(\mathrm{Pc}^{-}\right)_{2} \mathrm{Ln}^{3+}\right]^{+}$and consist of two antiferromagnetically coupled phthalocyanine cation-radical ligands. Not surprisingly, the UV-vis spectrum of the oxidized form, $\left[\left(\mathrm{Pc}^{-}\right)_{2} \operatorname{Ln}^{3+}\right]^{+}$, shows a series of the typical for phthalocyanine cation-radical absorption bands with the boad band in $800-1000 \mathrm{~nm}$ region having predominantly $2 \mathrm{~b}_{1}(\mathrm{HOMO}) \rightarrow 2 \mathrm{a}_{2}(\mathrm{LUMO})$ character and higher energy bands at $\sim 750$ and $\sim 470 \mathrm{~nm}$ (Figure 2). In the reduced state, $\left[\left(\mathrm{Pc}^{2-}\right)_{2} \operatorname{Ln}^{3+}\right]^{-}$, the SOMO $\left(2 \mathrm{a}_{2}\right)$ orbital of the neutral, radical $\left[\mathrm{Pc}^{2} \mathrm{Ln}^{3+} \mathrm{Pc}^{--}\right]^{0}$ form becomes HOMO, giving rise to the $2 \mathrm{a}_{2}(\mathrm{HOMO}) \rightarrow 6 \mathrm{e}_{1}(\mathrm{LUMO})$ single-electron transition, which mainly contributes to the $Q_{2}$ lowenergy component of the $Q$-band. While the higher-energy $Q_{1}$ band remains predominantly induced by the $2 b_{1} \rightarrow 6 e_{3}$ single-electron transition as in the case of both the neutral and oxidized forms. The UV-vis spectra of the triple-decker rare-earth complexes are similar to those of single-electron reduced forms of the respective double-decker systems due to the same electronic configuration of the constituting ligands (Figure 1). Extension of the $\pi$-system (Figure 
3), increase of the ionic radius of lanthanide, and introduction of the donor substituents typically lead to the low-energy shift of the main absorption bands. Finally, the spectra of heteroleptic compounds generally show intermediate character compared to the corresponding homoleptic relatives (Figure 3). The spectral properties of the sandwich-type tetrapyrrole complexes have already been reviewed in detail along with other common characteristics [26,27,30,33]. Herein, we will discuss UV-vis spectra of the rare-earth complexes only in content of purity of the tartget compounds.

\section{Synthetic approaches to single-decker complexes}

The main characteristics of the single-decker rare-earth Pcs (as compared to the multipledecker systems) is their ability to complete the coordination sphere with a variety of different solvents to form complexes of general formula $\left[\mathrm{Pc}^{2} \mathrm{Ln}^{3+} \mathrm{X}^{-}\right](\mathrm{Solv})_{\mathrm{n}}$, where $\mathrm{X}^{-}$is a counterion and Solv is an additional solvent molecule(s). Thus, in order to enforce the reaction toward the formation of the rare-earth single-decker complexes, one should effectively solvate the Ln ion during such reaction to avoid the formation of unwanted multiple-decker systems. So far, existing methods for preparation of the single-decker rare-earth complexes with Pcs and their analogues can be divided into three groups discussed below.

\subsection{Template synthesis from phthalogens}

The simplest method for preparation of the rare-earth single-decker Pc complexes is the high-temperature template reaction between the respective unsubstituted or substituted PN and a rare-earth salt (Scheme 1, conditions 1). This method was used for synthesis of unsubstituted rare-earth single-decker Pcs $\mathbf{1}[82,83]$ as well as the corresponding crown-ether derivatives $\mathbf{2}$ and 
ytterbium tetrachlorophthalocyanine $\mathbf{3}$ (Table 1) [84,85]. However, the yields of target compounds under these reaction conditions have not been reported, while it is currently generally accepted that the high temperatures used in the original reports could facilitate the formation of the double-decker complexes [85]. As a result, selectivity for the formation of single-decker Pcs is rather poor and the reaction mixtures require extensive purification. According to Smirnov and co-workers [86], up to 76\% yields of tetrachloro- (3) and tetranitro- (4) substituted Pcs can be observed, while yield of the corresponding tetrabromo derivative $\mathbf{5}$ is significantly lower [87] (Table 1). It was suggested in two reports $[88,89]$ that the reaction between sterically hindered PNs and rare-earth salts leads to the selective formation of the single-decker Pc complexes 6-9 (Table 1) in 53-84\% yields with target compounds being characterized by UV-vis spectroscopy. Template synthesis method 1 (Scheme 1) was also employed in the preparation of rare-earth single-decker 1,2-Ncs of general formula 1,2- $\mathrm{NcLnCl}$ (13) [95] and the rare-earth octaphenylsubstituted TAPs of general formula ${ }^{\mathrm{Ph}}$ TAPLnCl (14) [96]. 
Table 1. Reaction conditions and yields in preparation of rare-earth single-decker Pc derivatives (Scheme 1).

\begin{tabular}{|c|c|c|c|c|c|c|}
\hline Cmpd & $\mathrm{R}^{\prime}$ & $\mathrm{Ln}$ & $\mathrm{X}$ & Conditions & $\begin{array}{l}\text { Yield, } \\
\%^{\mathrm{a}}\end{array}$ & Ref. \\
\hline \multirow{3}{*}{1} & \multirow{3}{*}{$\mathrm{H}$} & \multicolumn{2}{|l|}{$\mathrm{Sm}, \mathrm{Gd}, \mathrm{Yb}, \mathrm{Lu}, \mathrm{Y}$} & & & {$[82]$} \\
\hline & & $\mathrm{Nd}, \mathrm{Y}$ & OAc & 1 & - & [83] \\
\hline & & $\mathrm{Lu}$ & & $2 a$ & 5 & [90] \\
\hline \multirow[t]{2}{*}{2} & \multirow[t]{2}{*}{ 15-crown-5 } & $\mathrm{Lu}$ & OAc & 1 & - & {$[85]$} \\
\hline & & $\mathrm{Yb}$ & & & - & [84] \\
\hline \multirow[t]{2}{*}{3} & \multirow[t]{2}{*}{$\mathrm{Cl}$} & $\mathrm{Sm}, \mathrm{Ho}, \mathrm{Lu}$ & $\mathrm{Cl}$ & 1 & $74-76$ & {$[86]$} \\
\hline & & $\mathrm{Y}, \mathrm{Er}$ & & & $32-34$ & [87] \\
\hline \multirow[b]{2}{*}{4} & \multirow[b]{2}{*}{$\mathrm{H}$} & $\mathrm{Nd}, \mathrm{Sm}, \mathrm{Ho}, \mathrm{Lu}$ & \multirow[b]{2}{*}{$\mathrm{Cl}$} & \multirow[b]{2}{*}{1} & $66-74$ & [86] \\
\hline & & $\mathrm{Y}, \mathrm{Er}$ & & & $55-56$ & {$[87]$} \\
\hline 5 & $\mathrm{Br}$ & $\mathrm{Y}, \mathrm{Er}$ & $\mathrm{Cl}$ & 1 & $29-31$ & {$[87]$} \\
\hline 6 & HO- & $\mathrm{Nd}, \mathrm{Eu}, \mathrm{Lu}$ & OAc & 1 & $53-83$ & {$[88]$} \\
\hline
\end{tabular}




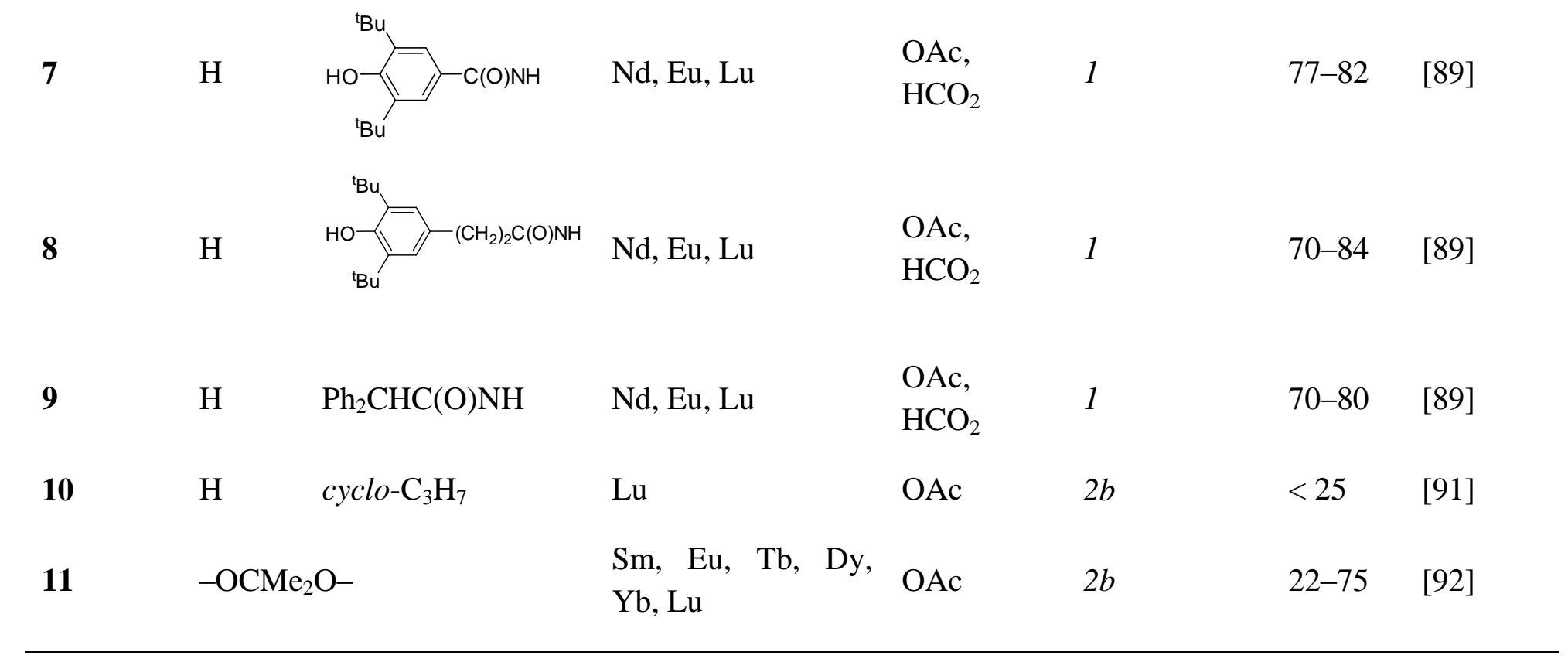

${ }^{a}$ The dash indicates that the yield is not given. 
The reaction temperatures for the preparation of rare-earth single-decker Pcs can be reduced if alcohols are used as solvents in the presence of a strong organic base (i.e. DBU, Scheme 1, conditions 2). Lutetium complexes $\mathbf{1}$ and $\mathbf{1 0}$ with unsubstituted [90] and cyclopropyl group substituted [91] Pcs as well as a series of rare-earth isopropylidenedioxy substituted Pcs 11 [92] have been prepared under these reaction conditions in 5 - $75 \%$ yields.

Isoindolines can also be used as a starting material for the preparation of rare-earth single-decker Pcs (Scheme 2). Indeed, template reaction between isoindolines and rare-earth ions in DMF or DMAE leads to the formation of unsubstituted (1) [93] as well as propyloxysubstituted (12) [94] single-decker Pcs.

\subsection{Rare-earth metal insertion reaction into free-base ligand}

Direct template synthesis of single-decker Pc derivatives by the reaction between PN and the rare-earth ions at elevated temperatures has several disadvantages, with the major one being the relatively low yields on the target compounds and the necessity of further purification step(s). An increase in selectivity toward the formation of rare-earth single-decker Pcs could be achieved using the metal-free macrocyclic ligand or its dianion as a starting material (Scheme 3).

The in situ formation of the corresponding macrocyclic dianions is a key for preparation of the rare-earth single-decker Pcs in high yields. Indeed, short-time (1-5 minutes) reaction between the rare-earth chlorides or acetates and Pc dianion (prepared from the metal-free Pc and $n$-butyl lithium) in DMSO, results in the formation of the single-decker Pc derivatives 1, 15, and 16 (Table 2) in $\sim 90 \%$ yields (Scheme 3, conditions 1) [97-99]. DBU or 1,10-phenanthroline were also used as bases in preparation of the rare-earth single-decker Pcs from the metal-free Pc 
crown-ethers 2 [100,101] or octaalkylphthalocyanines 17, 18 [102] in high yields (Scheme 3, conditions 2$)$. If the rare-earth tris( $\beta$-diketonates) are used as the rare-earth ion source (Figure 4$)$, their reaction with the metal-free Pc could be conducted in DMSO without any organic base (Scheme 3, conditions 3a). Unsubstituted rare-earth Pcs 1 were prepared under these conditions with high, up to $86 \%$, yields (Table 2) [104]. DMSO can be replaced by $o$-DCB (Scheme 3, conditions $3 b$ ) to form erbium single-decker Pcs 16 and 20 in 59 and $61 \%$ yields, respectively [105]. 
Table 2. Reaction conditions and yields in preparation of the rare-earth single-decker Pcs using conditions outlined in Scheme 3.

\begin{tabular}{|c|c|c|c|c|c|c|c|c|}
\hline Cmpd. & $\mathrm{R}$ & $\mathrm{R}^{\prime}$ & M & Ln & $X$ & $\begin{array}{l}\text { Synthetic } \\
\text { pathway }\end{array}$ & $\begin{array}{l}\text { Yield, } \\
\%\end{array}$ & Ref. \\
\hline & & & $\mathrm{H}$ & $\begin{array}{l}\mathrm{Pr}, \mathrm{Nd}, \mathrm{Sm}-\mathrm{Lu} \\
\mathrm{Sm}, \mathrm{Eu}, \mathrm{Gd}, \mathrm{Lu}\end{array}$ & $\begin{array}{l}\mathrm{Cl}, \mathrm{OAc} \\
\text { fod, btfa, hfbc }\end{array}$ & $\begin{array}{l}1 \\
3 a\end{array}$ & $\begin{array}{l}>90 \\
\geq 86\end{array}$ & $\begin{array}{l}{[97,99]} \\
{[104]}\end{array}$ \\
\hline 1 & $\mathrm{H}$ & $\mathrm{H}$ & $\mathrm{Li}$ & $\begin{array}{l}\mathrm{Eu}-\mathrm{Yb}, \mathrm{Y} \\
\mathrm{Eu}-\mathrm{Tm}, \mathrm{Lu}, \mathrm{Y}\end{array}$ & $\begin{array}{l}\text { dbm } \\
\text { dpm, acac }\end{array}$ & $3 c$ & $\begin{array}{l}\geq 90 \\
60-90\end{array}$ & $\begin{array}{l}{[106]} \\
{[107,108} \\
]\end{array}$ \\
\hline 2 & 15-cro & $n-5$ & $\mathrm{H}$ & $\begin{array}{l}\mathrm{Lu} \\
\text { Sm, Dy, Tm }\end{array}$ & OAc & 2 & $\begin{array}{l}>93 \\
>95\end{array}$ & $\begin{array}{l}{[100]} \\
{[101]}\end{array}$ \\
\hline 15 & $\mathrm{Me}$ & $\mathrm{Me}$ & $\mathrm{H}$ & $\mathrm{Pr}, \mathrm{Nd}, \mathrm{Sm}-\mathrm{Lu}$ & $\mathrm{Cl}, \mathrm{OAc}$ & 1 & $>90$ & [98] \\
\hline 16 & $\mathrm{H}$ & $t-\mathrm{Bu}$ & $\mathrm{H}$ & $\begin{array}{l}\mathrm{Pr}, \mathrm{Nd}, \mathrm{Sm}-\mathrm{Lu} \\
\mathrm{Er}\end{array}$ & $\begin{array}{l}\mathrm{Cl}, \mathrm{OAc} \\
\text { acac }\end{array}$ & $\begin{array}{l}1 \\
3 b\end{array}$ & $\begin{array}{l}>90 \\
59\end{array}$ & $\begin{array}{l}{[98]} \\
{[105]}\end{array}$ \\
\hline 17 & Et & $\mathrm{Et}$ & $\mathrm{H}$ & $\mathrm{Eu}, \mathrm{Er} \mathrm{Lu}$ & OAc & 2 & $89-96$ & [102] \\
\hline 18 & $n-\mathrm{Bu}$ & $n-\mathrm{Bu}$ & $\mathrm{H}$ & $\mathrm{Eu}, \mathrm{Er}, \mathrm{Lu}$ & OAc & 2 & $95-97$ & [102] \\
\hline
\end{tabular}




\begin{tabular}{lllllllll}
19 & $\mathrm{Ph}$ & $\mathrm{Ph}$ & $\mathrm{H}$ & $\mathrm{Eu}, \mathrm{Er}, \mathrm{Lu}$ & $\mathrm{OAc}$ & 2 & $60-94$ & {$[103]$} \\
20 & $\mathrm{H}$ & $n-\mathrm{C}_{5} \mathrm{H}_{11} \mathrm{O}$ & $\mathrm{H}$ & $\mathrm{Er}$ & $\mathrm{acac}$ & $3 b$ & 61 & {$[105]$} \\
\hline
\end{tabular}


Alkaline-metal Pcs, and especially commercially available dilithium Pc, can be introduced in the reaction with a variety of the rare-earth derivatives to form the target mononuclear rare-earth complexes (Scheme 3, conditions 3c). High solubility of the dilithium Pc in THF, acetone, and other organic solvents allows the reaction to be conducted at relatively low temperatures and in homogeneous conditions. Indeed, a large number of single-decker Pc complexes 1 with a variety of $\beta$-diketones were prepared under these reaction conditions (Table 2) [106-108].

Choice of the solvent is crucial in preparation of rare-earth single-decker Pcs from rareearth tris( $\beta$-diketonates). For instance, when methanol or DMSO are used as the reaction solvents, the major reaction products have a general formula of $\operatorname{Pc}^{\mathrm{R}} \operatorname{Ln}(\beta$-dik $)(\operatorname{Solv})_{\mathrm{n}}$ [104,106,107]. In some cases, similar complexes could be obtained in THF [107] or upon treatment of the $\operatorname{Li}\left[\operatorname{PcLn}(\operatorname{acac})_{2}\right]$ complexes with water [108]. The $\operatorname{Li}\left[\operatorname{PcLn}(\beta-\mathrm{dik})_{2}\right]$ and $\mathrm{H}\left[\mathrm{PcLn}(\beta \text {-dik })_{2}\right]$ complexes are the major products in the reaction between dilithium Pc and rareearth diketone in acetone [106-109]. In addition, these complexes were also obtained in THF [107] or as a minor reaction product in DMSO [104,110]. Reaction between dilithium Pc and $\mathrm{U}(\mathrm{acac})_{4}$ or $\mathrm{Th}(\mathrm{acac})_{4}$ in $\mathrm{THF}$ leads to the formation of $\mathrm{PcM}(\mathrm{acac})_{2}(\mathrm{M}=\mathrm{U}, \mathrm{Th})$ complexes in $\sim 40 \%$ yield, while a similar reaction with the $\mathrm{MCl}_{4}(\mathrm{M}=\mathrm{U}, \mathrm{Th})$ does not result in the formation of the corresponding single-decker Pcs [111]. Reaction between dilithium Pc and $\operatorname{Ln}(\mathrm{dpm})_{3}$ in boiling THF, followed by the multi-step reaction mixture workup, resulted in the formation of rather unique binuclear single-decker Pcs of general formula $\operatorname{PcLn}_{2}(\mathrm{dpm})_{4}(\mathbf{2 1})$ with two Ln ions and four $\beta$-diketonate ligands per single Pc macrocycle (Figure 5) [107,112,113]. According to two other reports $[104,110]$, the rare-earth single-decker Pcs of general formula Pc(1-)Ln( $\beta$-dik $)_{2}$ 
(22) can be prepared by the reaction between metal-free Pc and rare-earth tris( $\beta$-diketonates) with strong electron-withdrawing groups (fod, hfbc, btfa; Figure 4) in DMSO or TCB in low yields (up to 6.5\%). These complexes are stable in the solid state and their solutions have the characteristic red color of the Pc radical-cations, and show strong EPR signals associated with the singly oxidized Pc ligand [104].

The synthetic approach mentioned above can be extended to the other Pc analogues. Indeed, the general reaction between metal-free Pc analogues or Pors with rare-earth chlorides, acetates, and $\beta$-diketonates results in the formation of the lutetium tetra $(t-\mathrm{Bu})$-substituted pyrazinoporphyrazine 23 [114], lutetium octaphenyl-, octaethythio-, and octadecylthiosubstituted TAPs 24 [114,115], lutetium 1,2-Nc 13 [116,117] and tetra(t-Bu)-substituted 2,3-Nc 25 [118], octaphenoxy- [119] and octaphenyl- [103] substituted 2,3-Ncs 26 and 27, lutetium 1,2,3,4,19,20,21,22-octaphenyldiphthalo-11(12),29(30)-di(tert-butyl)

dinaphthalotetraazaporphyrin 28 [120] (Figure 6), as well as a variety of rare-earth mesosubstituted single-decker Por complexes [121-124]. DMF [114], DMSO [114,115,118,120], or octanol [115] were used as solvents in these reactions. Interestingly, lutetium insertion into the octaalkyl-substituted TAP macrocycle resulted in the formation of complex $\mathbf{2 4}$ even at room temperature. The formation of single-decker Pcs $\mathbf{2 6}$ and $\mathbf{2 7}$ were reported with $77-88 \%$ yields at conditions similar to those used for the preparation of Pcs 17-19 (Scheme 3, conditions 2) $[103,119]$. Both change in the ratio of reactants and longer reaction time do not lead to the formation of the double-decker Pc complexes. This observation could be indicative of the influence of the temperature and/or coordinating ability of the solvent, which prevents the formation of the double-decker derivatives and thus allows the use of this method as a selective approach for preparation of rare-earth single-decker Nc compounds [29,125]. Thus, insertion of 
the rare-earth ions into metal-free macrocycles and their dianions is, indeed, a highly selective method for preparation of the single-decker rare-earth complexes, which leads to the formation of the target compounds in high yield and purity.

\subsection{Axial substitution at metal ion}

Axial ligand(s) substitution reaction in rare-earth complexes of aromatic macrocycles was reported for Pors [126-129], N-confused Pors [130], and Pcs [131-137]. In the case of singledecker Pc derivatives similar reactions were also described for zirconium, hafnium [138,139], and indium [140-142] complexes. Besides the obvious reasons for axial ligand(s) functionalization, stability of the rare-earth single-decker Pcs can also be significantly improved using this method. In the case of rare-earth single-decker Pors, the tridentate ligand suggested by Kläui (Scheme 4) [126-129], as well as tris(1-pyrrazolyl)borohyrides (Scheme 5) [127], are quite commonly used to stabilize a single-decker structure via saturation of the first coordination sphere of the central metal ion. Such axial ligand exchange reactions are usually conducted at room temperature and result in the formation of the target compounds in fairly high yield (30 96\%). Notably, yields of the products generally tend to increase with the Ln ions contraction.

Since stability of rare-earth single-decker Pcs with tridentate axial ligands is very good, such complexes can be used for further transformation located at the Por macrocycle. Indeed, ytterbium complex 35 (Scheme 6) can be prepared using this synthetic approach in four steps with high yields (60-90\%) in individual reactions [128].

Because of the presence of an additional transition-metal ion in heteronuclear complex 35, its photophysics and specifically luminescent properties in the NIR region are significantly improved compared to the dinuclear ytterbium-containing starting material [128]. The low yield 
(5\%) of the starting asymmetric metal-free hydroxy-substituted Por, however, limits the potential use of complex 35 in imaging and bioimaging applications. Water-soluble dinuclear complexes 37 can be prepared by quaternization of the corresponding tetra-(4-pyridyl)-substituted Pors $\mathbf{3 6}$ (Scheme 7). Target compounds 37 can intercalate with DNA fragments similar to the other cationic water-soluble Pors [129].

A similar synthetic approach was used in transformation of the N-confused dinuclear Por 38 into water-soluble quaternized derivative 39 [130]. Starting compound 38 was prepared from the corresponding metal-free N-confused Pors in two steps in 40-78\% yield (Scheme 8).

Axial ligand substitution reactions with Kläui's ligand can also be achieved in the case of rare-earth single-decker Pcs to form target dinuclear complexes 40 and 41 [131,132] (Scheme 9). Yield of the dinuclear complexes 40 (9-30\%), however, are significantly lower compared to the dinuclear complexes 41 (63-66\%), perhaps because of the low solubility of the former systems in common organic solvents. X-ray structures of symmetric dinuclear complexes $\mathbf{4 0}$ (Figure 7) have been correlated with their individual magnetic properties [132].

Synthetic strategies for the preparation of rare-earth mixed ligand (Schiff base / Pc) single-, double-, triple-, and quadruple-decker complexes $\mathbf{4 2 - 4 5}$ has been described recently [133-136] (Scheme 10). Although reactions can be easily conducted at room temperature, increasing the reaction temperature to $80{ }^{\circ} \mathrm{C}$ in a sealed vial allows better (up to $\sim 40 \%$ ) yields of the target compounds [135]. Polynuclear complexes $\mathbf{4 2 - 4 5}$ can be obtained in a pure form upon slow crystallization of the reaction mixture. Polynuclear complexes 42-45 have optical and magnetic properties close to those observed for the single-decker Pc systems, which is indicative of a weak inter-ligand electronic coupling (Figures 8 and 9). For instance, minor splitting of the low-energy $Q$-band and its energy, which is close to the $Q$-band energy in rare-earth single- 
decker Pcs in the case of systems $\mathbf{4 2}$ and $\mathbf{4 4}$, is indicative of effective $C_{4 \mathrm{v}}$ symmetry in these compounds and degeneracy of the Pc-centered LUMO and LUMO+1.

Reaction between single-decker PcLuOAc or $\mathrm{PcMCl}_{2}(\mathrm{M}=\mathrm{Zr}$, Hf) complexes with iron(II) chlathrochelate precursors in methanol/ $\mathrm{CH}_{2} \mathrm{Cl}_{2}$ mixture allows the preparation of the hybrid binuclear Pc-chlathrochelate complexes of general formula of PcM(Clat) $(\mathrm{M}=\mathrm{Lu}, \mathrm{Zr}$, Hf; Clat = chlathrochelate anion) [137,138]. UV-vis and MCD spectra of these complexes are a superposition of the UV-vis and MCD spectra of the corresponding Pcs and chlathrochelates, which is indicative of a lack of electronic interactions between them. Electro- and spectroelectrochemical data as well as DFT calculations are suggestive that the HOMO is Pccentered MO [143].

Single-decker Pcs of general formula $\mathrm{PcMCl}_{2}(\mathrm{M}=\mathrm{Zr}$, Hf) can also be introduced into the axial ligand substitution reaction with a variety of $\beta$-diketones with the formation of the target $\operatorname{PcM}(\beta \text {-dik })_{2}$ complexes [139]. The PcInCl complex can react under mild conditions with $\mathrm{Bu}_{4} \mathrm{~N}^{+} \mathrm{X}^{-}(\mathrm{X}=\mathrm{F}, \mathrm{Cl}, \mathrm{Br}, \mathrm{CN}, \mathrm{HCOO})$ salts in $\mathrm{CH}_{2} \mathrm{Cl}_{2}$ or THF with the formation of singledecker $\left.\left[\mathrm{NBu}_{4}\right]^{+}[\mathrm{PcInX}]_{2}\right]^{-}$compounds in high yield [140]. Organometallic indium Pc complexes of general formula ${ }^{\mathrm{R}} \mathrm{PcInR}$ ' can be prepared in $12-70 \%$ yields by the reaction between substituted chloroindium Pcs, namely ${ }^{\mathrm{R}} \mathrm{PcInCl}(\mathrm{R}=$ alkyl or alkoxy group), with Grignard reagents of general formula $\mathrm{R}^{\prime} \mathrm{MgCl}\left(\mathrm{R}^{\prime}=\mathrm{Me}, \mathrm{Ph}, p-\mathrm{FC}_{6} \mathrm{H}_{4}, p-\mathrm{CF}_{3} \mathrm{C}_{6} \mathrm{H}_{4}, m-\mathrm{CF}_{3} \mathrm{C}_{6} \mathrm{H}_{4}, \mathrm{~F}_{5} \mathrm{C}_{6}\right)$ in ether or THF [141,142]. Similarly, the pentaferrocene-containing FcIn(TFcP) complex $\left(\mathrm{TFcP}^{2-}=5,10,15,20-\right.$ tetraferrocenylporphyrinate), with one of the ferrocene groups located in the axial position, can be prepared by the reaction between $\mathrm{CIIn}(\mathrm{TFcP})$ and ferrocene lithium [144]. All five ferrocenes in the $\mathrm{FcIn}(\mathrm{TFCP})$ compound can be oxidized at different potentials and this organometallic Por can form highly ordered "channel" structures with the $\mathrm{C}_{60}$ fullerene. 


\section{Synthetic approaches to homoleptic double-decker complexes}

The most common group of the double-decker rare-earth complexes belongs to doubledecker Pc derivatives, which were first reported in 1965 by a group of Russian scientists [20]. Major synthetic approaches for preparation of the rare-earth double-decker Pcs can be classified based on the type of starting materials involved in their preparation. Following such classification, PN-based template synthesis and metal insertion reactions into metal-free Pc or its dianion will be discussed below.

\subsection{Template synthesis from phthalogens}

Template synthesis of double-decker Pcs from derivatives of phthalic acid, and specifically $\mathrm{PN}$ is one of the most common synthetic strategies for preparation of the doubledecker complexes. Although this method is simple, its selectivity is very sensitive to the reaction conditions as rare-earth ions can form stable single-, double-, and triple-decker compounds. The most important reaction parameters are the reaction temperature, reaction time, the type of precursor rare-earth salt or complex, the type of phthalic acid derivative (most commonly PNs), and the ratio of reactants. For instance, elevated temperatures, longer reaction time, and use of heavier Ln ions would favor the formation of the double-decker Pcs compared to the singledecker Pc derivatives. Introduction of bulky substituents into the PNs, however, will favor the formation of the single-decker Pc derivatives. The first rare-earth double-decker Pc complexes 46 (Table 3) were prepared by Kirin and Moskalev by the reaction between the rare-earth acetates and PN at $280-290{ }^{\circ} \mathrm{C}$ with $1: 4-8(\mathrm{~mol} / \mathrm{mol})$ ratio [20,21]. New double-decker complexes were obtained in $10-15 \%$ yields and characterized by UV-vis spectroscopy (Scheme 
11, conditions 1). This method was further optimized by several research groups for preparation of a large variety of the rare-earth double-decker Pcs $\mathbf{4 6}$ with unsubstituted macrocyclic ligands [145-148] as well as substituted double-decker Pcs 47-57 [85,94,148-155].

Note that along with the regular double-decker Pc complexes 56 [85], one research group was able to isolate and characterize new $\mathrm{Gd}, \mathrm{Yb}$, and $\mathrm{Lu}$ double-decker complexes with covalent $\mathrm{C}-\mathrm{C}$ bonds between $\alpha$-pyrrolic atoms of neighboring macrocycles, although yields of these systems were quite low ( 1\%) [156]. Because of the direct C-C bonds between Pc ligands and thus the loss of the conjugation in the macrocyclic $\pi$-system, no usual low-energy $Q$-band was observed in these complexes. Similar covalently linked Pcs have also been reported for titanium [157] and niobium [158] ions.

Depending on the nature of the Ln ion, yields of the rare-earth double-decker Pcs 46 can vary between 5 and $60 \%$ when the template reaction was conducted at $300-310{ }^{\circ} \mathrm{C}$ followed by a vacuum sublimation of the crude product [146,147]. Under these conditions, yields of the target double-decker Pc increase and the yields of the reaction by-product (metal-free Pc) monotonically decrease (from 75 to $2 \%$ ) with light to heavy Lns. In order to improve yields of the double-decker Pcs with the early rare-earth ions, it was suggested [148] to conduct the template reaction in a sealed tube applying chromatographic purification instead of sublimation. In this case, target double-decker complexes $\mathbf{4 6}$ were isolated in 50-60\% yield. This reaction modification was used later for a template synthesis of double-decker complexes 47-51 (Table 3) [148-152]. It was also mentioned that although the first step in this reaction is the formation of the single-decker Pc derivative $[148,153,159,160]$, the formation of double-decker Pcs could be achieved for the early $\mathrm{Ln}$ ions in 5-10 minutes, while late $\mathrm{Ln}$ ions require longer reaction time for preparation of target double-decker systems. Similar to Lns, zirconium(IV) and hafnium (IV) 
double-decker Pcs can be obtained in 60-70\% yields upon heating PN or 4-tertbutylphthalonitrile and the corresponding metal chlorides [168,169].

If template condensation between PN and rare-earth salt is conducted in the presence of an inorganic base (i.e. $\mathrm{Na}_{2} \mathrm{CO}_{3}, \mathrm{KOH}$, or $\mathrm{KOCH}_{3}$ etc.) at $270-280{ }^{\circ} \mathrm{C}$, the formation of the ionic double-decker Pcs 46 of general formula $\mathrm{M}^{+}\left[\mathrm{Pc}_{2} \mathrm{Ln}\right]^{-}(\mathrm{Ln}=\mathrm{La}, \mathrm{Pr}, \mathrm{Nd}, \mathrm{Sm}-\mathrm{Lu}, \mathrm{Y} ; \mathrm{M}=\mathrm{Na}, \mathrm{K})$ was documented in 36-41\% yields [161-164]. Alkaline cations in these systems can be replaced by tetraalkyl ammonium cations using simple metathesis reactions with tetraalkyl ammonium bromides in quantitative yields. New systems of general formula of $\left[\mathrm{NAlk}_{4}\right]^{+}\left[\mathrm{Pc}_{2} \mathrm{Ln}\right]^{-}$are easily soluble in a variety of organic solvents, which significantly simplifies their characterization. Electrochemical oxidation of the anionic form of double-decker Pc derivatives in $\mathrm{CH}_{2} \mathrm{Cl}_{2}$ results in the formation of neutral radical double-decker compounds of general formula $\left[\mathrm{Pc}^{2} \mathrm{LnPc}^{1}\right]$. Similar oxidation of neutral double-decker Pcs from the corresponding anionic form can also be achieved under UV light irradiation of a solution of $\left[\mathrm{NAlk}_{4}\right]^{+}\left[\mathrm{Pc}_{2} \mathrm{Ln}\right]^{-}$in $\mathrm{CH}_{2} \mathrm{Cl}_{2}$ /acetonitrile [165].

Ln metals can also be used for preparation of double-decker Pcs. For instance, heating a mixture of ytterbium, $\mathrm{PN}$, and iodine (molar ratio of $1: 8: 2$ ) in a sealed tube at $200{ }^{\circ} \mathrm{C}$ results in the formation of dark violet crystals of ytterbium double-decker $\mathbf{4 6}$ of formula $\left[\mathrm{Pc}_{2} \mathrm{Yb}\right] \mathrm{I}_{2}$ [166]. In this case, both $\mathrm{Pc}$ ligands are present in the single-electron oxidized radical form $\left(\mathrm{Pc}^{1-}\right)$. Similar complexes have been obtained using these reaction conditions also for zirconium(IV) and indium(III) metals, although in the case of indium, it has to be introduced in the reaction as an indium/thallium alloy [167].

Microwave radiation has also been used for a template synthesis of rare-earth doubledecker Pc complexes (Scheme 11, Table 3) [170]. The main advantage of microwave radiation 
for template condensation of Pcs is that the reaction time is reduced from hours to minutes. For instance, unsubstituted $\mathrm{Pc}_{2} \mathrm{Ln}$ complexes $46(\mathrm{Ln}=\mathrm{Tb}$, Dy, and $\mathrm{Lu})$ were prepared in more than $70 \%$ yields upon microwave irradiation $(650-700 \mathrm{~W})$ of the reaction mixture of $\mathrm{PN}$ and the corresponding rare-earth salts for only 6-10 minutes [170]. However, respective $t$-Bu-substitited analogues 47 can only be obtained in low (less than 10\%) yields under the same reaction conditions. In a more recent report [154], the reduction of the microwave power to $300-450 \mathrm{~W}$ as well as a shorter reaction time (5-8 minutes) resulted in improved yields of $t$-Bu-substituted rareearth double-decker Pcs 54 (Table 3). 
Table 3. Yields of the rare-earth double-decker Pcs under template condensation reaction conditions shown in Scheme 11.

\begin{tabular}{|c|c|c|c|c|c|c|c|}
\hline Cmpd & $\mathrm{R}$ & $\mathrm{R}^{\prime}$ & $\mathrm{Ln}$ & $X$ & $\begin{array}{l}\text { Synthetic } \\
\text { route }\end{array}$ & Yield, \% & Ref. \\
\hline \multirow{6}{*}{46} & \multirow{5}{*}{$\mathrm{H}$} & \multirow{5}{*}{$\mathrm{H}$} & $\mathrm{La}, \mathrm{Pr}, \mathrm{Nd}, \mathrm{Sm}-\mathrm{Lu}$ & \multirow{5}{*}{ OAc } & 1 & $10-15$ & $\begin{array}{l}{[20,21,14} \\
5]\end{array}$ \\
\hline & & & $\mathrm{Lu}$ & & $3 a$ & 10 & {$[90]$} \\
\hline & & & $\mathrm{Nd}, \mathrm{Sm}, \mathrm{Er}, \mathrm{Lu}$ & & 1 & $50-60$ & [148] \\
\hline & & & $\mathrm{Pr}, \mathrm{Nd}, \mathrm{Sm}-\mathrm{Lu}$ & & 1 & $5-60$ & {$[146,147]$} \\
\hline & & & $\mathrm{Tb}, \mathrm{Dy}, \mathrm{Lu}$ & & 2 & $>70$ & {$[170]$} \\
\hline & \multirow{4}{*}{$\mathrm{H}$} & \multirow{4}{*}{$t$-Bu } & $\mathrm{La}, \mathrm{Pr}, \mathrm{Nd}, \mathrm{Sm}, \mathrm{Gd}, \mathrm{Er}, \mathrm{Lu}$ & OAc & 1 & $60-80$ & {$[148,149]$} \\
\hline \multirow{3}{*}{47} & & & $\mathrm{Er}, \mathrm{Gd}, \mathrm{Lu}$ & $\mathrm{HCOO}, \mathrm{Cl}$ & 1 & 70 & {$[150]$} \\
\hline & & & $\mathrm{Ce}$ & $\mathrm{OBz}$ & 1 & 52 & {$[151]$} \\
\hline & & & $\mathrm{Er}$ & acac & $3 c, 12 \mathrm{~h}$ & 24 & {$[105]$} \\
\hline 48 & $\mathrm{H}$ & $\left(\mathrm{CF}_{3}\right)_{3} \mathrm{C}$ & $\mathrm{Lu}$ & OAc & 1 & - & {$[152]$} \\
\hline 49 & $\mathrm{H}$ & $\mathrm{Ph}$ & $\mathrm{Lu}$ & $\mathrm{HCOO}$ & 1 & up to 70 & {$[150]$} \\
\hline 50 & $\mathrm{H}$ & $\mathrm{PhO}$ & $\mathrm{Lu}$ & $\mathrm{HCOO}$ & 1 & 70 & {$[150]$} \\
\hline 51 & $\mathrm{Br}$ & $t-\mathrm{Bu}$ & $\mathrm{Lu}$ & $\mathrm{HCOO}$ & 1 & 70 & {$[150]$} \\
\hline 52 & $\mathrm{H}$ & $\mathrm{PrO}$ & $\mathrm{Lu}$ & OAc & 1 & - & [94] \\
\hline \multirow[t]{2}{*}{53} & $\mathrm{H}$ & $\left(\mathrm{CH}_{3}\right)_{3} \mathrm{CCH}_{2}$ & $\mathrm{Lu}$ & OAc & 1 & - & {$[94]$} \\
\hline & $\mathrm{C}_{\mathrm{n}} \mathrm{H}_{2 \mathrm{n}+1}, \mathrm{n}=1$ & $\mathrm{C}_{\mathrm{n}} \mathrm{H}_{2 \mathrm{n}+1}, \mathrm{n}=1$ & $\mathrm{~Tb}, \mathrm{Lu}$ & OAc & 1 & - & [153] \\
\hline \multirow[t]{2}{*}{54} & $\mathrm{n}=2$ & $\mathrm{n}=2$ & $\mathrm{Eu}, \mathrm{Dy}, \mathrm{Lu}$ & OAc, acac & $\begin{array}{l}3 b, 15-20 \\
\mathrm{~h}\end{array}$ & $11-53$ & {$[154]$} \\
\hline & $\mathrm{n}=4$ & $\mathrm{n}=4$ & $\mathrm{Eu}, \mathrm{Dy}, \mathrm{Lu}$ & OAc, acac & $1,2-8 \mathrm{~h}$ & $22-49$ & {$[154]$} \\
\hline
\end{tabular}




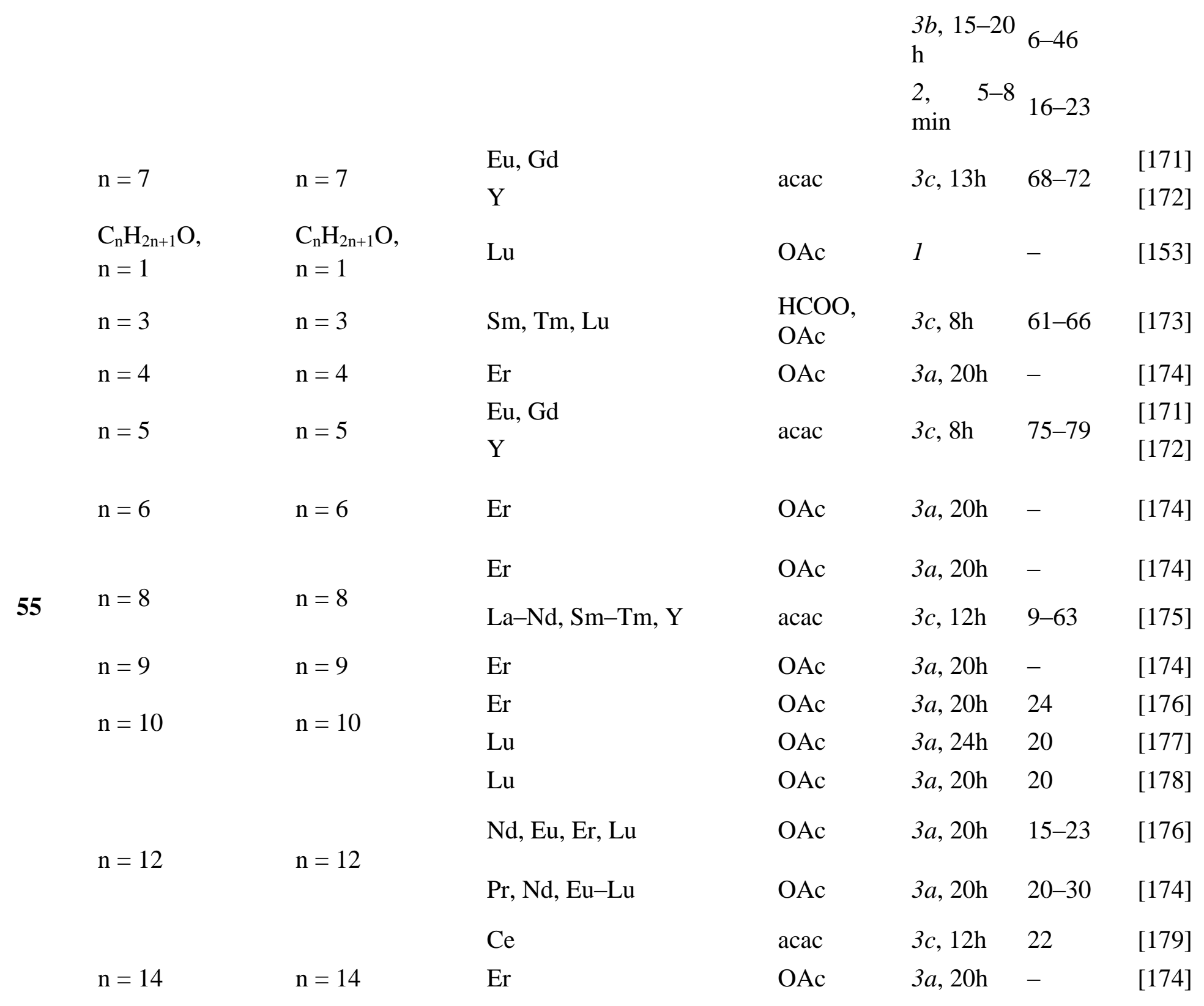




$\begin{array}{lll} & & \mathrm{Lu} \\ \mathrm{n}=16 & \mathrm{Er} \\ \mathrm{n}=16 & \mathrm{Lu} \\ & & \mathrm{Er} \\ \mathrm{n}=18 & \mathrm{Lu}\end{array}$

56

15-crown-5

$\mathrm{Lu}$

$\mathrm{Pr}, \mathrm{Nd}, \mathrm{Eu}-\mathrm{Lu}$

$57 \quad \mathrm{H}$

58 18-crown-6

$\begin{array}{lll}\mathrm{MeO}\left[\left(\mathrm{CH}_{2}\right)_{2} \mathrm{O}\right]_{\mathrm{n}} & \mathrm{MeO}\left[\left(\mathrm{CH}_{2}\right)_{2} \mathrm{O}\right]_{\mathrm{n}} & \mathrm{Lu} \\ (\mathrm{n}=1,2,3,4) & (\mathrm{n}=1,2,3,4) & \end{array}$

59

$$
\mathrm{n}=2
$$$$
\mathrm{n}=2
$$

$\mathrm{Eu}$

60

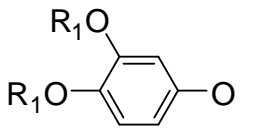

$\mathrm{R}_{1}=\mathrm{C}_{\mathrm{n}} \mathrm{H}_{2 \mathrm{n}+1}$,

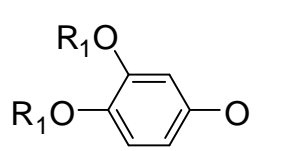

(n=12,13)

61

$\mathrm{BnO}$

$\mathrm{BnO}$

Nd, Sm, Dy, Lu

$\mathrm{C}_{\mathrm{n}} \mathrm{H}_{2 \mathrm{n}+1} \mathrm{~S}$

$\mathrm{C}_{\mathrm{n}} \mathrm{H}_{2 \mathrm{n}+1} \mathrm{~S}$

62

$(\mathrm{n}=8,10,12,(\mathrm{n}=8,10,12, \mathrm{Eu}, \mathrm{Tb}, \mathrm{Lu}$
$n=6$
$\mathrm{n}=6$
Sm, Gd, Dy

$\begin{array}{llll}\text { OAc } & 3 a, 24 \mathrm{~h} & 14 & {[177]} \\ \text { OAc } & 3 a, 20 \mathrm{~h} & - & {[173]} \\ \text { OAc } & 3 a, 24 \mathrm{~h} & 11 & {[177]} \\ \text { OAc } & 3 a, 20 \mathrm{~h} & 27 & {[176]} \\ \text { OAc } & 3 a, 24 \mathrm{~h} & 12 & {[177]} \\ & 3 a, 20 \mathrm{~h} & - & {[180]} \\ \text { OAc } & 1 & 35 & {[181]} \\ & & & {[85]} \\ \text { OAc } & 1,1 \mathrm{~h} & 30-50 & {[155]} \\ & & & {[181]} \\ \text { OAc } & 3 a, 20 \mathrm{~h} & 7 & {[181,182]} \\ \text { OAc } & 3 a, & 6-12 & {[183]} \\ \text { acac } & 3 c, 8 \mathrm{~h} & 31 & \\ & & & \end{array}$

$\mathrm{HCOO}, \quad 3 a, 8 \mathrm{~h} \quad 37-55 \quad$ [185]
OAc

$\begin{array}{llll}\text { OAc } & 3 a, & 22-44 \mathrm{~h} & 26-44\end{array}$

OAc $\quad 3 a, 48 \mathrm{~h} \quad 29-36 \quad$ [187] 


\begin{tabular}{|c|c|c|c|c|c|c|c|}
\hline & & & $\mathrm{Lu}$ & & $3 c, 48 \mathrm{~h}$ & 12 & [188] \\
\hline 63 & $\mathrm{H}$ & ${ }^{n} \mathrm{C}_{12} \mathrm{H}_{25} \mathrm{~S}$ & $\mathrm{Lu}$ & OAc & $3 a, 20 \mathrm{~h}$ & 8.1 & [189] \\
\hline 64 & $\mathrm{H}$ & cyclo- $\mathrm{C}_{3} \mathrm{H}_{7}$ & $\mathrm{Lu}$ & OAc & $3 b$ & $<25$ & [91] \\
\hline 65 & $\mathrm{H}$ & ${ }^{n} \mathrm{C}_{5} \mathrm{H}_{11} \mathrm{O}$ & Er & acac & $3 c, 12 \mathrm{~h}$ & 30 & [105] \\
\hline 66 & $\mathrm{PhO}$ & $\mathrm{PhO}$ & $\mathrm{Eu}, \mathrm{Ho}, \mathrm{Lu}$ & acac & $3 c, 8 \mathrm{~h}$ & $36-43$ & [190] \\
\hline 67 & $\mathrm{PhS}$ & $\mathrm{PhS}$ & $\mathrm{Eu}$ & acac & $3 c, 8 \mathrm{~h}$ & 42 & [190] \\
\hline 68 & $\mathrm{Me}^{(\mathrm{a})}$ & $\mathrm{Me}^{(\mathrm{a})}$ & Dy, Er, Tm, Lu & $\begin{array}{l}\mathrm{HCOO} \text {, } \\
\text { OAc }\end{array}$ & $3 a$ & $66-72$ & [191] \\
\hline 69 & $\mathrm{CN}$ & $\mathrm{CN}$ & $\mathrm{Nd}$ & OAc & $3 d$ & - & [192] \\
\hline 70 & & & $\mathrm{Gd}, \mathrm{Lu}$ & OAc & $\begin{array}{l}3 c^{(\mathrm{b})}, \\
20-30 \mathrm{~h}\end{array}$ & $2-17$ & [70] \\
\hline 71 & $\mathrm{H}$ & & $\mathrm{Lu}$ & OAc & $3 a, 6 \mathrm{~h}$ & 49 & [69] \\
\hline 72 & $\mathrm{HO}\left[\left(\mathrm{CH}_{2}\right)_{6} \mathrm{~S}\right]$ & $\mathrm{HO}$ & $\mathrm{Eu}, \mathrm{Yb}, \mathrm{Lu}$ & acac & $\begin{array}{l}3 a, \\
8-10 \mathrm{~h}\end{array}$ & $10-13$ & [51] \\
\hline 73 & $\mathrm{H}$ & & $\mathrm{Lu}$ & OAc & $3 a, 24 \mathrm{~h}$ & 27 & [44] \\
\hline 74 & $\mathrm{H}$ & & $\mathrm{Lu}$ & OAc & $3 a, 24 \mathrm{~h}$ & 12 & [193] \\
\hline
\end{tabular}




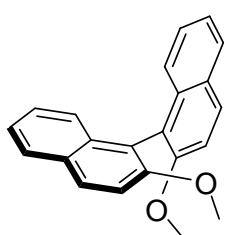

(a) Substituents at 1,3,8,10,15,17,22,24 positions of Pc ligand;

(b) Lithium alkoxide was used as a base. 
The third synthetic strategy for preparation of the rare-earth double-decker Pcs using a template condensation reaction is boiling the mixture of the corresponding PN, rare-earth precursor, DBU (as a strong organic base), and a long-chain alcohols (usually pentanol or hexanol) as shown in Scheme 11, condition 3. The target double-decker compounds can be purified by standard column chromatography approaches. Yield of the unsubstituted (46) [90] as well as substituted (47, 54-75, Table 3) $[44,51,69,70,91,105,154,156,171-194]$ rare-earth double-decker Pcs prepared using this method depends on the nature of substituents in the Pc macrocycle as well as the type of $\mathrm{Ln}$ ion used for the reaction and varies between 2 and $79 \%$. For instance, lutetium salts tend to result in the lowest yields, while the higher yields were observed for europium and gadolinium complexes. Similarly, the presence of bulky substituents in the Pc macrocycle leads to a reduction of the rare-earth double-decker Pcs yields (Table 3).

Template synthesis has also been used in preparation of a variety of the rare-earth doubledecker Nc complexes (Scheme 12) [119,125,195-198]. For instance, high-temperature template condensation reaction between 5-bromo-7-tert-butylnaphthalonitrile [195] or 6,7diphenoxynaphthalonitrile $[119,196,197]$ (Scheme 12, condition 1) results in the formation of the rare-earth double-decker compounds $\mathbf{7 6}$ or $\mathbf{7 7}$ in $41-55 \%$ yields without any single-decker complexes formed as byproducts. Optimization of the reaction temperatures can significantly improve yields of the target compounds [199]. Europium and erbium double-decker Ncs 77 also can be prepared using microwave radiation (Scheme 12, condition 2) similar to a synthesis of double-decker Pcs 54 (Scheme 11) [154,171,172]. The best yields of europium and erbium 
double-decker complexes 77 (39 and 33\%, respectively) can be achieved using 700 W microwave power and 5-7 minutes reaction time [199].

High-boiling solvents can be utilized in template preparation of the double-decker Ncs. For instance, complexes $\mathbf{7 8}$ and $\mathbf{7 9}$ were prepared in $35-79 \%$ yield using the rare-earth acetylacetonates and the corresponding naphthalonitriles in boiling $n$-octanol in the presence of DBU (Scheme 12, condition 3). In this approach, yields of the target complexes decrease upon Ln ion contraction $[125,198]$. The choice of $n$-octanol as a solvent for this reaction is critical as its replacement with lower boiling point $n$-pentanol or $n$-hexanol as well as high boiling point chlorinated aromatic solvents (TCB or 1-CIN) did not result in the formation of the target compounds [125].

\subsection{Metallation of free-base ligands}

Synthesis of the double-decker rare-earth Pcs using the corresponding metal-free Pc macrocycles avoids many unwanted side reactions, especially the formation of linear oligomers from the corresponding PNs. The formation of the target double-decker complexes using this method, however, is complicated by steric interactions between the initially formed rare-earth single-decker Pc and the incoming metal-free macrocycle. This results in lower yields of the target double-decker compounds compared to the template synthesis method, especially, for heavy Ln cations. Rare-earth acetates or acetylacetonates are usually used as the metal precursors in this approach (Scheme 13, Table 4). Reactions are carried out using lithium or sodium Pcs as well as metal-free Pc in QN, TCB, or n-octanol. A variety of the unsubstituted rare-earth doubledecker Pcs 46 was prepared using this method in QN or TCB (Scheme 13, conditions $1 a$ and $1 b$ ) in $9-33 \%$ yields $[171,172,200,201]$, while alkoxy-substituted complexes $\mathbf{5 5}$ and $\mathbf{8 0}$ can be 
synthesized using $n$-octanol (Scheme 13, condition 1c) [202,203]. Attempts to prepare hexadeca$n$-heptyl- and hexadeca- $n$-pentoxysubstituted double-decker europium and gadolinium Pcs $\mathbf{5 4}$ and 55 using $n$-octanol at $190{ }^{\circ} \mathrm{C}$, on the other hand, (Scheme 13, conditions 1 b) completely failed [171]. The selective formation of double-decker alkylsubstituted Pcs 54 in high yields $(\mathrm{R}=$ Et, $n$-Bu, Table 4) can be facilitated by addition of the strong organic base (DBU) to $n$-hexanol (Scheme 13, condition 2a), or by increase of the reaction temperature (Scheme 13, conditions 1d) [102]. Combination of the alcohol and DBU allows the formation of the double-decker complexes of $1,4,8,11,15,18,22,25$-octabutoxyphthalocyanine $(\mathbf{8 1})$ as well as chiral tetrasubstituted $(D)$ - and $(L)$-mentol compounds 82 (Scheme 13, conditions $2 b$ and $2 c$ ) [204,205]. Moreover, the use of equimolar amounts of Pc and dibenzo-18-crown-6 increases yield of the target double-decker complexes $\mathbf{8 1}$ from $1-2 \%$ to $24-38 \%$ under the same reaction conditions [204]. An approach mentioned in this section was also used in preparation of the rareearth double-decker complexes $\mathbf{8 3}$ with electron-withdrawing groups, which were used as model platforms for characterization of multi-electron reduced forms, although no detailed experimental conditions have been provided [206]. Proposed by Tomilova and co-workers, the synthetic approach for preparation of the single-, double-, and triple-decker rare-earth Pcs in an alcohol/TCB mixture allows the preparation of phenyl-containing double-decker Pcs $\mathbf{8 4}$ in 4996\% yields [103], which are higher than the most of the reported yields for similar systems. 
Table 4. Yields of the rare-earth double-decker Pcs prepared using Scheme 13 reaction conditions.

\begin{tabular}{|c|c|c|c|c|c|c|c|c|}
\hline Cmpd & $\mathrm{R}$ & $\mathrm{R}^{\prime}$ & $\mathrm{M}$ & $\mathrm{Ln}$ & $\mathrm{X}$ & $\begin{array}{l}\text { Rxn. } \\
\text { Cond. }\end{array}$ & Yield, \% & Ref. \\
\hline \multirow{4}{*}{46} & \multirow{4}{*}{$\mathrm{H}$} & \multirow{4}{*}{$\mathrm{H}$} & $\mathrm{H}$ & $\mathrm{Lu}$ & OAc & $1 a, 22 \mathrm{~h}$ & 9 & [200] \\
\hline & & & $\mathrm{Li}$ & $\mathrm{La}, \mathrm{Pr}, \mathrm{Nd}, \mathrm{Sm}-\mathrm{Lu}$ & acac & $1 b, 4 \mathrm{~h}$ & $12-33$ & [201] \\
\hline & & & $\mathrm{Li}$ & $\mathrm{Eu}, \mathrm{Gd}$ & acac & $1 b, 10 \mathrm{~h}$ & 32,25 & {$[171]$} \\
\hline & & & $\mathrm{Li}$ & $\mathrm{Y}$ & acac & $1 b, 10 \mathrm{~h}$ & 27 & {$[172]$} \\
\hline 47 & $\mathrm{H}$ & ${ }^{t} \mathrm{Bu}$ & $\mathrm{H}$ & La, Tb, Dy & OAc & 3 & $61-63$ & {$[207,208]$} \\
\hline \multirow[t]{2}{*}{54} & $\begin{array}{l}n-\mathrm{C}_{\mathrm{n}} \mathrm{H}_{2 \mathrm{n}+1} \\
\mathrm{n}=2,4\end{array}$ & $\begin{array}{l}n-\mathrm{C}_{\mathrm{n}} \mathrm{H}_{2 \mathrm{n}+1} \\
\mathrm{n}=2,4\end{array}$ & $\mathrm{H}$ & $\begin{array}{l}\mathrm{Eu} \\
\mathrm{Er}, \mathrm{Lu}\end{array}$ & OAc & $\begin{array}{l}2 a \\
1 d\end{array}$ & $\begin{array}{l}87-95 \\
85-90\end{array}$ & [102] \\
\hline & $\mathrm{n}=8,12,18$ & $\mathrm{n}=8,12,18$ & $\mathrm{H}$ & $\mathrm{Lu}$ & OAc & 4 & - & {$[214,215]$} \\
\hline 55 & ${ }^{n} \mathrm{C}_{4} \mathrm{H}_{9} \mathrm{O}$ & ${ }^{n} \mathrm{C}_{4} \mathrm{H}_{9} \mathrm{O}$ & $\mathrm{H}$ & $\mathrm{Yb}, \mathrm{Lu}$ & OAc & $1 c$ & - & {$[202]$} \\
\hline \multirow{3}{*}{56} & \multirow{3}{*}{ 15-crown-5 } & & $\mathrm{H}$ & $\mathrm{Gd}, \mathrm{Yb}, \mathrm{Y}$ & OAc & $2 d, 2 \mathrm{~h}$ & $15-35$ & [209-212] \\
\hline & & & $\mathrm{H}$ & $\mathrm{La}$ & OAc & $2 d, 1 \mathrm{~h}$ & 70 & {$[212,213]$} \\
\hline & & & $\mathrm{H}$ & Sm, Dy, Tm & OAc & $2 d, 2 \mathrm{~h}$ & $40-45$ & {$[101]$} \\
\hline 80 & $\left(\mathrm{C}_{2} \mathrm{H}_{5}\right)_{2} \mathrm{CHO}^{(\mathrm{a})}$ & $\mathrm{H}$ & $\mathrm{H}$ & $\mathrm{Eu}, \mathrm{Lu}, \mathrm{Y}$ & acac & $1 c, 9 \mathrm{~h}$ & $21-49$ & [203] \\
\hline 81 & ${ }^{n} \mathrm{C}_{4} \mathrm{H}_{9} \mathrm{O}^{(\mathrm{c})}$ & ${ }^{n} \mathrm{C}_{4} \mathrm{H}_{9} \mathrm{O}^{(\mathrm{c})}$ & $\mathrm{H}$ & $\mathrm{Eu}, \mathrm{Y}$ & acac & $\begin{array}{l}2 c^{(\mathrm{d})} \\
10 \mathrm{~h}\end{array}$ & $24-38$ & [204] \\
\hline 82 & $\mathrm{Me}-\mathrm{Me}$ & $\mathrm{H}$ & $\mathrm{H}$ & $\mathrm{Eu}, \mathrm{Lu}, \mathrm{Y}$ & acac & $\begin{array}{l}2 b \\
8-12 \mathrm{~h}\end{array}$ & $9-10$ & [205] \\
\hline 83 & ${ }^{n} \mathrm{C}_{3} \mathrm{~F}_{7} ; \mathrm{F}^{(\mathrm{c})}$ & ${ }^{n} \mathrm{C}_{3} \mathrm{~F}_{7} ; \mathrm{F}^{(\mathrm{c})}$ & $\mathrm{H}$ & $\mathrm{Tb}, \mathrm{Lu}$ & - & - & - & [206] \\
\hline
\end{tabular}


$84 \quad \mathrm{Ph}$

$\mathrm{Ph}$

Li Eu, Er, Lu

85
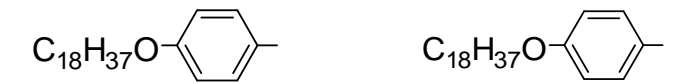

$\mathrm{H} \quad \mathrm{Lu}$

$\mathrm{C}_{\mathrm{n}} \mathrm{H}_{2 \mathrm{n}+1} \mathrm{OCH}_{2}$

$(\mathrm{n}=8,12,18)$

$\mathrm{H} \quad \mathrm{Lu}$

$86 \quad(\mathrm{n}=8,12,18)$

$l^{(\mathrm{b})}$,

OAc $\quad 5-10$

49-96 [103]

$\min$

OAc 4

[216]

(a) Substituents at 1,8,15,22-positions of Pc ligand;

(b) Mixture of $n-\mathrm{C}_{16} \mathrm{H}_{33} \mathrm{OH} / \mathrm{TCB}(1: 1 \mathrm{v} / \mathrm{v})$;

(c) Substituents at 1,4,8,11,15,18,22,25-positions of Pc ligand;

(d) Equimolar amount of crown-ether was used. 
DBU is quite often used as a strong organic base in preparation of substituted doubledecker rare-earth Pc complexes (Scheme 13, conditions 2a, 2d, and 3) [101, 207-213]. For instance, the preparation of octa-t-Bu-substituted complexes of lanthanum, terbium, and dysprosium 47 was suggested to produce target compounds in good (61-63\%) yields using DBU under $240 \mathrm{~W}$ microwave radiation (Scheme 3, conditions 3; Table 4), although reported UV-vis spectra of the target compounds are close to those of the corresponding single-decker rare-earth Pcs [207,208]. On the other hand, Ln double-decker octa-15-crown-5-substituted Pcs 56 were prepared using the metal-free Pc, rare-earth precursor, and DBU (1.5:1:2 molar ratio) in 1-CIN as solvent (Scheme 13, conditions $2 d$ ) in 15-45\% yield [101,209-212]. In this case, structures of the target compounds were confirmed by spectroscopic methods as well as crystallography [211]. Further optimization of the reaction conditions and specifically use of the 1:1.5:10 molar ratios between Pc ligand, rare-earth precursor, and DBU allowed the preparation of double-decker lanthanum octa-15-crown-5-substituted Pcs 56 (as a mixture of neutral radical and reduced anion forms) in $70 \%$ yield (Table 4) [212,213].

Several double-decker lutetium Pcs 54, 85, and 86 with long-chain substituents have liquid crystal properties [214-218]. These complexes were prepared in up to $40 \%$ yield using amyl alcohol as a solvent and generated in situ from potassium and alcohol alkoxide anion as a base (Scheme 13, conditions 4; Table 4). Asymmetric double-decker rare-earth Pcs 87 and 88 (Scheme 14) have been prepared using synthetic conditions [219] developed for systems 54 [102]. These complexes were further used as precursors for preparation of the nano-sized rareearth systems. 
Planar diphthalocyanines 89-91 with extended $\pi$-system can be transformed into the corresponding mono- as well as trinuclear double-decker "sandwich-planar" complexes 92-94 (Scheme 15) [220]. Mononuclear complex 94 was prepared from trinuclear 92 by demetalation reaction in acidic media. In the case of complexes 92-94, both halves of the sandwich fragments have extended $\pi$-conjugation, which leads to unusual optical properties of the target compounds. Interesting "sandwich-clamshell" trinuclear tetraphthalocyanine-containing complex 96 was prepared from asymmetric zinc "clamshell" Pc 95 and lutetium acetate in $n$-hexadecanol using catalytic amounts of lithium methoxide in $45 \%$ yield (Scheme 16) [221].

Reaction of the metal-free "clamshell" asymmetric Pc 97 with the rare-earth ions resulted in the formation of the bridged "sandwich-clamshell" double-decker Pcs 98 (Scheme 17) [222]. Availability of the synthetic strategies for preparation of tetrabenzotriazoporphyrins [223-226] led to preparation of the first double-decker lutetium tetrabenzotriazoporphyrin complex 99 (Scheme 18) [227].

The first lutetium double-decker tetradiazepinoporphyrazine based complex $\mathbf{1 0 0}$ can be prepared using either template condensation of the dicyanodiazepine with lutetium acetate or by metallation of the metal-free diazepine-containing macrocycle (Scheme 19) [228]. Note that the formation of double-decker system $\mathbf{1 0 0}$ was achieved under conditions typical for preparation of the single-decker rare-earth Pcs (Scheme 3, conditions 2) [102].

Metal insertion reactions can be used in the formation of the double-decker systems, which contain not only rare-earth ions, but also actinides and titanium. For instance, reaction between $\mathrm{UCl}_{4}$ or $\mathrm{ThCl}_{4}$ with disodium $\mathrm{Pc}$ in 1-ClN results in the formation of the double-decker $\mathrm{Pc}_{2} \mathrm{M}(\mathrm{M}$ $=\mathrm{U}, \mathrm{Th}$ ) complexes $\mathbf{1 0 1}$ in 8 and 6\% yields, respectively [229]. Similar reaction between $\mathrm{TiCl}_{4}$ 
and $\mathrm{PN}$ or 4-tert-butylphthalonitrile in boiling DMSO results in the formation of ${ }^{\mathrm{R}} \mathrm{Pc} \mathrm{c}_{2} \mathrm{Ti}(\mathrm{R}=\mathrm{H}$, $t$-Bu) complexes $\mathbf{1 0 2}$ in up to $40 \%$ yield [230].

Reaction between lutetium acetate and unsubstituted dilithium 2,3-Nc or 1,2-Nc in QN or 1-ClN leads to the formation of the corresponding double-decker systems 103 [231] and 104 [196] in 47 and 60\% yields, respectively (Figure 10). In the case of 1,2-Nc derivatives, each of the individual macrocycles can form four positional isomers of $C_{4 \mathrm{~h}}, D_{2 \mathrm{~h}}, C_{2 \mathrm{v}}, C_{\mathrm{s}}$ symmetry and thus complex 104 should also consist of numerous positional isomers, which will be challenging to separate using conventional purification methods. Neodymium and europium double-decker 1,2-Ncs 104 are also discussed in [95], but synthetic conditions and yields of the target compounds were not clearly reported. Phenyl-substituted double-decker 2,3-Ncs 105 could be prepared in 55-63\% yields [124] using a general method developed for the preparation of their unsubstituted analogues 84 (Table 4).

Interestingly, double-decker Pors 106-108 and TAPs $(109,110)$ have so far only be prepared from the corresponding metal-free macrocycles and the corresponding metal salts (Figure 10). For instance, complexes 106 [232], 107 (M = La-Nd, Sm-Gd) [233,234], and 109 $(\mathrm{M}=\mathrm{Ce})$ [235] were prepared in up to $80 \%$ yields by the reaction of the metal-free Pors or TAPs with rare-earth acetylacetonates in boiling TCB. Similar reaction with $\mathrm{M}\left(\mathrm{NEt}_{2}\right)_{4}(\mathrm{M}=\mathrm{Zr}$, Hf) in toluene leads to the formation of complexes $\mathbf{1 0 8}$ and $\mathbf{1 1 0}$ in 54-61\% yields [236, 237]. The preparation of double-decker TAPs $\mathbf{1 0 9}(\mathrm{M}=\mathrm{Eu}, \mathrm{Lu})$ could be achieved using $n$-hexanol in 36 and 44\% yields, respectively [235]. Finally, double-decker Por systems 107 ( $\mathrm{M}=\mathrm{Tb}-\mathrm{Lu}, \mathrm{Y})$ can be prepared in 60-80\% yields using the "raise-by-one-story" approach described in section 3.3 [234]. 


\subsection{Axial substitution at the metal center}

In this approach, the pre-formed single-decker complex reacts with an appropriate metalfree macrocycle to form the double-decker compound. It is commonly abbreviated as the "raiseby-one-story" method and usually used for the preparation of heteroleptic and mixed-ligand compounds discussed in the next chapters. However, it also was used in several cases for the preparation of homoleptic double-decker complexes. For instance, the reaction between tin(IV) single-decker $\mathrm{Pc}, \mathrm{PcSnCl}_{2}$, and disodium $\mathrm{Pc}$ in boiling 1-ClN afforded a double-decker $\mathrm{Pc}_{2} \mathrm{Sn}$ complex [238], while the reaction between $(\mathrm{TPyP}) \operatorname{Ln}(\mathrm{acac})\left(\mathrm{Ln}=\mathrm{Sm}, \mathrm{Eu}, \mathrm{Gd}\right.$; $\mathrm{TPy}^{2-}=$ 5,10,15,20-tetra(4-pyridyl)porphyrinate) and $[\mathrm{TPyP}]^{2-}$ in boiling TCB resulted in the formation of double-decker $(\mathrm{TPyP})_{2} \mathrm{Ln}$ complexes [239]. Octaethylporphyrin $(\mathrm{OEP})_{2} \mathrm{Ln}$ derivatives 107 (Ln $=\mathrm{Tb}-\mathrm{Lu}, \mathrm{Y})$ were also prepared using the corresponding single-decker rare-earth OEPs and dilithum OEP in $60-80 \%$ yields [234].

\section{Synthetic approaches to homoleptic triple-decker complexes}

\subsection{Template synthesis from phthalogens}

The first hypothesis on the formation of triple-decker rare-earth Pcs was reported by Russian scientists in 1967 [21,240]. The reaction between PN and rare-earth acetates at 280-290 ${ }^{\circ} \mathrm{C}$ led to the formation of not only double-decker complexes, but also compounds which, based on spectroscopic data and elemental analysis, were assigned as dinuclear triple-decker Pcs $\mathbf{1 1 1}$ of general formula $\mathrm{Pc}_{3} \operatorname{Ln}_{2}(\mathrm{Ln}=\mathrm{Pr}, \mathrm{Nd}, \mathrm{Er}, \mathrm{Lu}$; Scheme 20). Later on, this method was extended

for the synthesis of all rare-earth and yttrium complexes 111 [241-243], as well as lutetium 
system 112 with crown-ether substituents [85]. Despite the early findings, the structure of the rare-earth triple-decker compound was confirmed crystallographically only in 1999 for complex 112 (Figure 11) [244].

The preparation of triple-decker systems using the template condensation reaction is also reported for indium and bismuth complexes. For instance, the reaction between PN and indium/tin alloy at $210{ }^{\circ} \mathrm{C}$ results in the formation of triple-decker $\mathrm{Pc}_{3} \operatorname{In}_{2}$ complex [245], while heating of $\mathrm{PN}$ with bismuth selenide produces triple-decker $\mathrm{Pc}_{3} \mathrm{Bi}_{2}$ complex [246]. Although in both cases yields of the target compounds were not reported, structures of the final products were confirmed by X-ray crystallography. $\mathrm{Pc}_{3} \mathrm{Bi}_{2}$ complex was also prepared by the reaction between PN and bismuth acetate at the increased temperature of $310{ }^{\circ} \mathrm{C}$ [247]. In this case, the yield of $\mathrm{Pc}_{3} \mathrm{Bi}_{2}$ complex was reported as $63 \%$.

\subsection{Metallation of free-base ligand}

Crown-ether substituted triple-decker Pcs $112(\mathrm{Ln}=\mathrm{Gd}, \mathrm{Yb})$ were prepared using the reaction between metal-free macrocycles and the corresponding rare-earth acetates in the presence of DBU (1.5:1:2 molar ratio) in 1-ClN as a solvent in 10-15\% yield (Scheme 21, conditions 1) [209,212]. Replacement of rare-earth acetates by the corresponding acetylacetonates and exclusion of DBU from the reaction mixture (with a 1:3 Pc to rare-earth precursor molar ratio), allows the preparation of triple-decker compounds $112(\mathrm{Ln}=\mathrm{Nd}, \mathrm{Tb})$ in mild conditions and much better (62 and 68\%) yields (Scheme 21, conditions 2a) [248]. This synthetic modification was later used for the preparation of unstable triple-decker lanthanum complexes 112 [249]. 
The preparation of butoxy-substituted triple-decker $\mathbf{1 1 3}$ can be achieved by the reaction between metal-free macrocycle and rare-earth acetates (1:2.6 molar ratio) in boiling $n$-octanol in $76-83 \%$ yield (Scheme 21, conditions $2 b$ ) [250,251]. The target compounds can be purified using column chromatography on silica gel [250] or basic alumina [248,251]. In addition, size exclusion chromatography can also be used for the purification of triple-decker complexes $[250,251]$. A similar synthetic strategy was used for the preparation of alkylsubstituted tripledecker systems 114 and 115 (Scheme 21) [102]. For instance, the reaction between the corresponding metal-free Pc and europium acetate (1:1 molar ratio) in boiling $n$-octanol results in the formation of $\mathbf{1 1 4}$ and $\mathbf{1 1 5}$ in 92 and 94\% yields, respectively. Yields of the lutetium and erbium triple-decker systems are lower, which was attributed to the insufficient reaction temperature (ca. $190{ }^{\circ} \mathrm{C}$ ) [102]. Indeed, a similar reaction in $n$-hexadecanol at $280{ }^{\circ} \mathrm{C}$ results in the formation of lutetium and erbium triple-decker complexes $\mathbf{1 1 4}$ and $\mathbf{1 1 5}$ in 88-93\% yields (Scheme 21, conditions 2c). Triple-decker systems 115 were studied using X-ray crystallography [252] and NMR spectroscopy with ${ }^{13}$ C-labeled samples [253]. Aryl-substituted triple-decker complexes 116 [103] and 117 [254] were prepared in 67-80\% yields using a $n-\mathrm{C}_{16} \mathrm{H}_{33} \mathrm{OH} / \mathrm{TCB}$ $(1: 1 \mathrm{v} / \mathrm{v})$ mixture or in pure TCB (Scheme 21, conditions $2 a)$. Hexaphthalocyanines 118 were prepared as by-products in 7-14\% yields during preparation of the double-decker complexes $\mathbf{9 8}$ (Scheme 17) [222].

A triple-decker complex 119 was prepared by the reaction between dilithium 1,2-Nc and lutetium acetate in 1-ClN in 55-60\% yield (Scheme 22) [116,255]. It represents the only known example of a homoleptic triple-decker rare-earth system with the 1,2-Nc macrocycle. Similar to double-decker complex 104 (Figure 10), this compound was isolated as a mixture of all possible positional isomers, while only one of those is shown in Scheme 22. 
In addition to the systems mentioned above, rare-earth triple-decker Pors and TAPs were also reported in the literature (Figure 12). For instance, the reaction between metal-free $(\mathrm{OEP}) \mathrm{H}_{2}$ and cerium(III) acetylacetonate in boiling TCB produces cerium triple-decker $(\mathrm{OEP})_{3} \mathrm{Ce}_{2}$ complex 120 in $12 \%$ yield [233]. Similar reaction with a metal-free diazaporphyrin platform leads to the formation of $(\mathrm{DAP})_{3} \mathrm{Ln}_{2}$ complexes 121 [256]. TAP-containing $\left({ }^{\mathrm{Pr}} \mathrm{TAP}\right)_{3} \mathrm{Eu}_{2}$ compound 122 was prepared in $9 \%$ yield using the reaction between europium(II) iodide and metal-free $\left({ }^{\mathrm{Pr}} \mathrm{TAP}\right) \mathrm{H}_{2}$ in boiling $n$-hexanol [235]. Interesting lutetium triple-decker tetrathienotetraazaporphyrin complex 123 (Figure 12) was recently prepared in $36 \%$ yield as a mixture of possible positional isomers using $n-\mathrm{C}_{16} \mathrm{H}_{33} \mathrm{OH} / \mathrm{TCB}(1: 1 \mathrm{v} / \mathrm{v})$ mixture as a reaction solvent [257].

\subsection{Monophthalocyanine based techniques}

Simple heating of single-decker lutetium $\mathrm{PcLu}(\mathrm{OAc}) \cdot 2 \mathrm{H}_{2} \mathrm{O}$ complex to $400{ }^{\circ} \mathrm{C}$ in vacuum (1 torr) produced triple-decker complex 111 in 40\% yield (Scheme 23) [258]. A similar formation of the triple-decker systems under high vacuum $\left(10^{-6}\right.$ torr $)$ sublimation at $300-420{ }^{\circ} \mathrm{C}$ of the reaction products obtained from template condensation between PN and a series of rareearth acetates $(\mathrm{Ln}=\mathrm{La}, \mathrm{Nd}, \mathrm{Eu}, \mathrm{Gd}, \mathrm{Dy}, \mathrm{Er}, \mathrm{Yb}, \mathrm{Lu})$ was suggested earlier [242], although ultimate structural assignment of new compounds was not provided.

A very similar approach was utilized by Cook and co-workers for the preparation of cadmium triple-decker Pc complex 124 (Figure 13) [259]. In this case, a triple-decker compound was obtained upon slow crystallization of a simple cadmium Pc in $\mathrm{THF} / \mathrm{MeOH}$ mixture. Although the structure of triple-decker cadmium complex 124 was confirmed by X-ray crystallography, it has relatively low stability in solution as well as in the solid state. Later on, 
the same research group extended the preparation of triple-decker cadmium complexes to soluble 2,3,9,10,16,17,23,24-octasubstituted Pcs [260] and proven their radical nature by EPR spectroscopy [261]. Both EPR and electrochemical data were suggestive of a reversible dissociation of these triple-decker systems in solution [261,262]. Work done by Cook and coworkers stimulated an additional interest toward the preparation of heteronuclear rareearth/cadmium complexes with four or more tetrapyrrolic ligands [34-42].

\section{Synthetic approaches to heteroleptic and mixed-ligand double-decker complexes}

So far, three classes of heteroleptic (Pc "A" - Pc "B", Por "A" -Por "B", and Pc - Nc) and two classes of the mixed-ligand (Pc-Por and Nc-Por) double-decker rare-earth complexes were reported in the literature. All existing synthetic strategies for the preparation of these complexes can be classified into four following groups according to the type of reactants involved in the reactions: (i) reaction between two different PNs in the presence of rare-earth salt; (ii) reaction of the single-decker rare-earth complexes with PN or its analogues; (iii) reaction between two different metal-free or dilithium (disodium) Pc ligands with rare-earth salt; and (iv) reaction between single-decker rare-earth complexes and metal-free or alkali metal macrocycles. The first two methods could be associated with template synthesis, while two later methods belong to the direct synthetic methodology.

\subsection{Phthalocyanine-metal-phthalocyanine complexes}

The most simple, but the less selective method for the preparation of rare-earth heteroleptic complexes is a direct template condensation of rare-earth salt and two different PNs under appropriate reaction conditions. Indeed, if the reactivity and steric properties of equimolar 
quantities of two different PNs in the reaction are similar, one might expect the formation of 21 rare-earth double-decker reaction products. Taking into account a possible formation of singledecker, triple-decker, and open-chain oligomeric products, separation of such reaction mixture seems to be very challenging.

Nevertheless, the reaction between lutetium acetate and an equimolar mixture of 4propyloxyphthalonitrile and 4-tert-butylphthalonitrile at $270-280{ }^{\circ} \mathrm{C}$ for $4 \mathrm{~h}$ resulted in the formation of a lutetium double-decker tetra-tert-butyl-tetrapropyloxyphthalocyanine in $4.6 \%$ yield. FAB mass spectrum of the chromatographically isolated mixture of positional isomers was indicative of presence of four $t$-Bu and four propyloxy substituents in the target complex.

The steric hindrance strategy can also be used in the preparation of rare-earth doubledecker complexes from two different PNs. This approach was used initially for preparation of asymmetric transition-metal Pcs and their analogues and consists of the template condensation between two different precursors (usually PNs), one of which is sterically crowded (i.e. 3,6diphenylphthalonitrile or 3,4,5,6-tetraphenylphthalonitrile) [264-267]. When unsubstituted and 3,4,5,6-tetraphenyl-substituted PNs were condenced using lutetium acetate as a template, three homoleptic (46, 125, and 126) and three heteroleptic (127-129) double-decker complexes were isolated using preparative TLC approach and identified by UV-vis spectroscopy and elemental analysis (Scheme 24) [268].

A template condensation between unsubstituted and crown-ether containing PNs with lutetium acetate in boiling $n$-hexanol in the presence of DBU was studied by Ishikawa and coworkers (Scheme 25) [269,270]. Although the reaction mixture consisted of rare-earth singleand double-decker complexes along with the starting materials and oligomeric open-chain byproducts, the authors were able to separate a target lutetium double-decker complex $\mathbf{1 3 0}$ in $3 \%$ 
yield. A presence of crown-ether substituents in this compound is suitable for accommodation of different alkali metal ions [270].

Dinuclear, double-decker "sandwich-planar" complexes $\mathbf{1 3 1}$ were prepared in 4.3\% (131a) and 2\% (131b) yields using a template cross-condensation between a substituted Pn and bis(diiminoisoindoline) in boiling $n$-amyl alcohol in the presence of DBU (Scheme 26) [271]. Complexes 131a and 131b are biradical in nature and their NIR spectra resemble those observed in classic radical double-decker systems (Figure 14).

A reaction between rare-earth single-decker Pc and PN represents a more selective approach for the preparation of heteroleptic double-decker complexes. For instance, the reaction between single-decker europium Pc with a mixture of unsubstituted and crown-ether substituted PNs results in the formation of double-decker complex 130 in 13\% yield (Scheme 27) [272]. Besides of the target complex 130, new heteroleptic double-decker Pcs 132-135 were also isolated in 5-12\% yields from the reaction mixture using conventional chromatography.

The reaction between single-decker rare-earth Pc and the corresponding PN was used for the preparation of heteroleptic complexes 135-150 (Scheme 28, Table 5). In the case of heteroleptic double-decker Pcs 135-142, a large excess of the PN was applied as it was employed as a reactant and a solvent (Scheme 28, conditions 1) [86,87,89,98,273,274]. 
Table 5. Yields of the double-decker heteroleptic rare-earth Pcs prepared using conditions shown in Scheme 28.

\begin{tabular}{|c|c|c|c|c|c|c|c|c|c|c|}
\hline $\begin{array}{l}\mathrm{Cm} \\
\mathrm{pd}\end{array}$ & $\mathrm{R}$ & $\mathrm{R}^{\prime}$ & $\mathrm{R}^{1}$ & $\mathrm{R}^{2}$ & $\mathrm{R}^{3}$ & $\mathrm{Ln}$ & $X$ & $\begin{array}{l}\text { Condit } \\
\text { ions }\end{array}$ & Yield,\% & Ref. \\
\hline \multirow{2}{*}{135} & $\mathrm{H}$ & $\mathrm{H}$ & \multicolumn{2}{|c|}{ 15-crown-5 } & $\mathrm{H}$ & $\mathrm{Lu}$ & OAc & 1 & 14 & {$[273]$} \\
\hline & \multicolumn{2}{|c|}{ 15-crown-5 } & $\mathrm{H}$ & $\mathrm{H}$ & $\mathrm{H}$ & $\mathrm{Sm}, \mathrm{Dy}, \mathrm{Tm}$ & OAc & $2 c$ & $31-43$ & {$[101]$} \\
\hline 136 & $\mathrm{H}$ & $t-\mathrm{Bu}$ & $\mathrm{H}$ & $\mathrm{H}$ & $\mathrm{H}$ & $\mathrm{Lu}$ & $\mathrm{Cl}$ & 1 & - & {$[98,274]$} \\
\hline \multirow{2}{*}{137} & \multirow{2}{*}{$\mathrm{H}$} & \multirow{2}{*}{$\mathrm{Cl}$} & $\mathrm{H}$ & $\mathrm{H}$ & $\mathrm{H}$ & Sm, Ho, Er, Lu, Y & \multirow{2}{*}{$\mathrm{Cl}$} & \multirow{2}{*}{1} & \multirow{2}{*}{$28-61$} & \multirow{2}{*}[86,87]{} \\
\hline & & & $\mathrm{H}$ & $\mathrm{Bu}$ & $\mathrm{H}$ & $\mathrm{Er}$ & & & & \\
\hline \multirow{2}{*}{138} & \multirow{2}{*}{$\mathrm{H}$} & \multirow{2}{*}{$\mathrm{Br}$} & $\mathrm{H}$ & $\mathrm{H}$ & $\mathrm{H}$ & Er, Y & \multirow{2}{*}{$\mathrm{Cl}$} & \multirow{2}{*}{1} & \multirow{2}{*}{$43-55$} & \multirow{2}{*}[87]{} \\
\hline & & & $\mathrm{H}$ & $\mathrm{Bu}$ & $\mathrm{H}$ & $\mathrm{Er}$ & & & & \\
\hline 139 & $\mathrm{H}$ & $\mathrm{NO}_{2}$ & $\mathrm{H}$ & $\mathrm{H}$ & $\mathrm{H}$ & Nd, Sm, Ho, Er, Lu, Y & $\mathrm{Cl}$ & 1 & $31-57$ & {$[86,87]$} \\
\hline 140 & $\mathrm{H}$ & $\begin{array}{l}\mathrm{HO} \\
\mathrm{Me}\end{array}$ & $\mathrm{H}$ & $\mathrm{H}$ & $\mathrm{H}$ & $\mathrm{Nd}, \mathrm{Eu}, \mathrm{Lu}$ & $\begin{array}{l}\text { OAc, } \\
\text { HCOO }\end{array}$ & 1 & $62-75$ & [89] \\
\hline 141 & $\mathrm{H}$ & $\mathrm{MO}_{3} \mathrm{C}$ & $\mathrm{H}$ & $\mathrm{H}$ & $\mathrm{H}$ & $\mathrm{Nd}, \mathrm{Eu}, \mathrm{Lu}$ & $\begin{array}{l}\text { OAc, } \\
\text { HCOO }\end{array}$ & 1 & $52-67$ & [89] \\
\hline 142 & $\mathrm{H}$ & $\mathrm{Ph}_{2} \mathrm{CHCONH}$ & $\mathrm{H}$ & $\mathrm{H}$ & $\mathrm{H}$ & $\mathrm{Nd}, \mathrm{Eu}, \mathrm{Lu}$ & $\begin{array}{l}\text { OAc, } \\
\text { HCOO }\end{array}$ & 1 & $56-71$ & [89] \\
\hline 143 & $\mathrm{H}$ & $\mathrm{H}$ & $\mathrm{C}_{7} \mathrm{H}_{15}$ & $\mathrm{C}_{7} \mathrm{H}_{15}$ & $\mathrm{H}$ & $\mathrm{Eu}, \mathrm{Y}$ & acac & $2 b$ & 32,28 & {$[172,275]$} \\
\hline 144 & $\mathrm{H}$ & $\mathrm{H}$ & $\mathrm{C}_{5} \mathrm{H}_{11} \mathrm{O}$ & $\mathrm{C}_{5} \mathrm{H}_{11} \mathrm{O}$ & $\mathrm{H}$ & $\mathrm{Eu}, \mathrm{Y}$ & acac & $2 b$ & 27,25 & {$[172,275]$} \\
\hline
\end{tabular}




\begin{tabular}{|c|c|c|c|c|c|c|c|c|c|}
\hline 145 & $\mathrm{H} \quad \mathrm{H}$ & $\mathrm{PhO}$ & $\mathrm{PhO}$ & $\mathrm{H}$ & $\mathrm{Eu}, \mathrm{Ho}, \mathrm{Lu}$ & acac & $2 b$ & $26-29$ & [190] \\
\hline 146 & $\mathrm{H} \quad \mathrm{H}$ & $\mathrm{PhS}$ & $\mathrm{PhS}$ & $\mathrm{H}$ & $\mathrm{Eu}$ & acac & $2 b$ & 30 & {$[190]$} \\
\hline 147 & 15-crown-5 & $\mathrm{AlkO}^{*}$ & $\mathrm{AlkO}^{*}$ & $\mathrm{H}$ & $\mathrm{Lu}$ & OAc & $2 a$ & 7.5 & {$[181]$} \\
\hline 148 & $\mathrm{H} \quad \mathrm{H}$ & $\mathrm{H}$ & $\mathrm{H}$ & Alk'O* & $\mathrm{Sm}-\mathrm{Lu}, \mathrm{Y}$ & acac & $2 c$ & $15-31$ & {$[276,277]$} \\
\hline 149 & $\mathrm{H} \quad \mathrm{H}$ & & & $\mathrm{H}$ & $\mathrm{Y}$ & acac & $2 c, 6 \mathrm{~h}$ & 19 & [194] \\
\hline 150 & $\mathrm{H} \quad \mathrm{C}_{3} \mathrm{H}_{7} \mathrm{O}$ & $\mathrm{H}$ & $t-\mathrm{Bu}$ & $\mathrm{H}$ & $\mathrm{Lu}$ & OAc & 3 & 31.6 & [263] \\
\hline
\end{tabular}


This synthetic approach can be used for the preparation of double-decker heteroleptic complexes with electron-acceptor (137-139) as well as bulky (140-142) substituents in quite good yields (28 - 75\%, Table 5) [86,87,89]. Note, however, that structures of the target compounds were decided on the basis of only UV-vis and IR spectra as well as elemental analysis, while NMR and mass spectra of these complexes were not reported. Moreover, since the typical $Q$-band shift for rare-earth double-decker complexes as a function of the rare-earth ion radius was not observed, the purity of target complexes remains unclear.

The combination of alcohol and DBU can also be used in the preparation of rare-earth heteroleptic double-decker complexes (Scheme 28, conditions 2). In particular, well characterized complexes 135, 143-149 with alkyl- and alkoxy-substituents can be prepared using such reaction conditions [101,172,181,190,194,275-277]. Yields of the target compounds depend on the steric bulkiness of substituents and vary between 7.5 and $43 \%$ (Table 5). Doubledecker Pcs 148 and 149 are examples of chiral systems [190,276,277]. Chirality of the complexes 148 arises from the nature of their substituents, which directed the formation of only the $C_{4 h}$ symmetry macrocycle, existing as an enantiomeric pair. Use of four biphenyl substituents in complex 149 dictates (by definition) its chirality [190]. Note that the CD spectra of enantiomers of $\mathbf{1 4 9}$ are fairly close to the CD spectra of the enantiomeric pair of symmetric system 75 with eight binaphthyl groups (Figure 15).

Lithium amylate generated in situ was used as a strong base in the preparation of lutetium double-decker complex $\mathbf{1 5 0}$ in $32 \%$ yield as a mixture of positional isomers (Scheme 28, conditions 3) [263]. An interesting synthetic route for preparation of the heteroleptic lanthanum double-decker complex 135 was developed by Gorbunova and co-workers [213]. First, because 
of the low stability of single-decker Pc lanthanum complexes, preparation of $\mathbf{1 3 5}$ cannot be achieved at any standard conditions listed in Scheme 28. In addition, attempt to prepare this complex from $\mathrm{La}(\mathrm{acac})_{3} \cdot \mathrm{H}_{2} \mathrm{O}$ in the presence of lithium $\mathrm{Pc}$ and lithium crown-ether containing Pc also failed. In order to overcome these problems, Gorbunova and co-workers first prepared lanthanum triple-decker complex $\left[\left(\mathrm{R}_{4} \mathrm{Pc}^{2-}\right) \mathrm{La}^{3+}\left(\mathrm{Pc}^{2-}\right) \mathrm{La}^{3+}\left(\mathrm{Pc}^{2-}\right)\right](\mathrm{R}=15$-crown-5), which upon $\mathrm{z}$ prolonged stay in a chloroform solution dissociates to form double-decker $\mathbf{1 3 5}$ in $31 \%$ yield.

Rare-earth heteroleptic double-decker Pcs 151 (Figure 16) were prepared from $A_{3} B$ type asymmetric single-decker Pcs in 10-20\% yield using conditions $2 a$ in Scheme 28 [278]. As the starting $\mathrm{A}_{3} \mathrm{~B}$ single-decker compounds were synthesized in $\sim 20 \%$ yield, the overall yield of the target $\mathbf{1 5 1}$ is quite low $(2-4 \%)$.

In a series of publications, Bekaroğlu and co-workers discussed preparation and characterization of several interesting dinuclear double-decker complexes with conformationally flexible crown-thioether type bridging ligands (Scheme 29) [279,280]. Statistical condensation between diiminoisoindoline derivatives $\mathbf{1 5 2}$ and $\mathbf{1 5 3}$ in 1:6 molar ratio resulted in the formation of single-decker dinuclear complex 154, which after chromatographic purification was introduced into reaction with two equivalents of the substituted lithium Pc to form target dinuclear double-decker system 155. In spite of the presence of $A_{3} B$ type macrocycle in singledecker complexes 154, their UV-vis spectra resemble spectra of the regular single-decker rareearth Pcs with symmetric macrocycles and effective $C_{4 v}$ symmetry (Figure 17). In particular, a single $Q$-band in complexes $\mathbf{1 5 4}$ is suggestive of close energies of the LUMO and LUMO+1 and nearly equivalent electronic properties of crown-thioether and thioalkyl substituents. Reported UV-vis spectra of double-decker complexes 155 resemble those observed in free-radical $\mathrm{Pc}_{2} \operatorname{Ln}$ compounds except for a prominent low-energy shoulder observed next to the $Q$-band (Figure 17) 
$[279,280]$. Later on, the same research group reported synthesis of dinuclear tetraphthalocyanine 158, which was prepared using a similar strategy, i.e. reaction of dinuclear calix[4]arene precursor 156 with diiminoisoindoline 153 (Scheme 30) [281]. The reported MALDI-TOF spectrum of complex 158, however, shows a very low intensity molecular ion and no peaks associated with double-decker fragments (Figure 18). The most intense peak in the MALDI-TOF spectrum belongs to the metal-free derivative of $\mathbf{1 5 7}$, which can be formed by demetallation of dilutetium derivative 157 under reaction conditions. Such a hypothesis agrees well with the reported UV-vis spectrum of $\mathbf{1 5 8}$ (Figure 19), which has a split $Q$-band characteristic for the metal-free Pcs.

Further development of the above mentioned synthetic strategy for the preparation of double-decker multinuclear complexes resulted in reports on trinuclear single-decker complexes 159 and 160 as well as double-decker complexes 161 and 162 (Scheme 31) [282,283]. Reported UV-vis spectra of the target compounds 161 and 162 (Figures 20 and 21) could have an admixture of the metal-free derivatives of single-decker 159 and 160, which (by analogy with complexes 157 [281]) could be formed during demetalation reaction of these single-decker complexes.

An interesting set of Por-substituted rare-earth double-decker complexes 163-165 was prepared using the synthetic approaches outlined in Scheme 32 [284]. In this case, 4hydroxyphenyl-substituted Pors were introduced in the reaction with nitro-substituted PNs or 4,5-dichlorophthalonitrile to form PN-containing Pors. Further reaction of such PN-containing Pors with unsubstituted PN and europium PcEu(acac) precursor leads to the formation of Porsubstituted europium double-decker complexes $\mathbf{1 6 3 - 1 6 5}$ in $31-40 \%$ yields [284]. In a separate study, the rare-earth double-decker Pcs were linked to a fullerene using an esterification reaction 
between a double-decker hydroxymethyl Pc and a fullerene derivatized with a carboxylic acid functional group to form dyads 166 (Scheme 33) [285]. The compounds have interesting photophysical properties associated with intramolecular electron-transfer, which results in the formation of photoinduced charge-separation states.

Two different metal-free Pcs can react with the corresponding rare-earth salt in the presence of an organic base to form heteroleptic double-decker systems (Scheme 34). For instance, heteroleptic double-decker Pcs 136 and 167 were prepared using microwave radiation and DBU as a base [286-288]. The UV-vis spectrum of $\mathbf{1 3 6}$ prepared using this approach [286], however, is identical to the spectra of rare-earth single-decker Pcs and differ significantly from a previously reported spectrum of $\mathbf{1 3 6}$, which was prepared using dilithium salts of unsubstituted and tetra- $t$-Bu-substituted Pcs and 1-ClN as a solvent in $20 \%$ yield (Scheme 34, conditions $2 a$ ) [287]. Change of 1-ClN to basic QN and use of prolonged reaction time allowed the formation of amphiphilic double-decker Pc 167 in 47\% yield (Scheme 34, conditions 2b) [288].

Several heteroleptic rare-earth double-decker complexes 168-170 were prepared by the reaction between dilithium salts of two different Pcs and lutetium acetate (Scheme 34, conditions 2a) [289]. The yields of the target double-decker complexes (24-31\%) are significantly compromised by the formation of the homoleptic double-decker derivatives.

Use of the dilithium salts of two different Pc ligands was also explored in the preparation of terbium complex 171, which has a pyrene substituent capable of forming non-covalent $\pi-\pi$ conjugates with single wall nanotubes and possesses interesting magnetic properties [81]. A synthetic approach for the preparation of this complex requires synthesis of $A_{3} B$ type macrocycle 171a using a statistical template condensation of two different PNs and another statistical 
reaction between dilithium salts of two different Pc ligands (Scheme 35). Not surprisingly, overall yield of the target complex $\mathbf{1 7 1}$ is quite low.

The last method for preparation of rare-earth heteroleptic double-decker complexes belongs to the interaction between a rare-earth single-decker Pc complex and a metal-free Pc macrocycle in a protic or an aprotic solvent (Scheme 36, conditions $1 a$ and $1 b$ ). This approach was used for the first time in 1993 by Japanese researchers [290] and is now known as the "raiseby-one-story" method because it includes a single-step reaction for the preparation of doubledecker systems. Double-decker heteroleptic compounds 135 [270,290,291], 148 [277], 172 [292,293] and 173 [205] were prepared using this methodology, but the yields did not exceed $32 \%$. Again, similar to synthetic methodologies mentioned in Schemes 24-35, the formation of homoleptic double-decker Pcs is predominantly responsible for relatively low yields.

Use of a TCB/alcohol mixture with or without an organic base (Scheme 36, conditions $1 c$ and 2) allows for increased (71-85\%) yields of the heteroleptic complexes 174 and 175 substituted with $n$-Bu groups and chlorine atoms [294]. Interestingly, optimal conditions for the formation of europium complexes 174 and 175 are conditions 2 (Scheme 36), while those for the formation of lutetium analogs are conditions $1 c$ (Scheme 36). Similar to the earlier mentioned $(R)$ - and $(S)$-enantiomers of double-decker complexes 75 and 149 (Figure 15), chiral heteroleptic derivatives 173 with peripheral $(D)$ - and $(L)$-mentol groups have close CD spectra with those observed in homoleptic double-decker compounds 82 [205].

Another interesting set of heteroleptic double-decker complexes $\mathbf{1 7 2}$ has eight butoxy groups at the $\alpha$-positions of one Pc ligand. Oxygen atom of these substituents can be involved in secondary coordination with sodium cations to form a dimeric structure $\left\{\left[{ }^{\mathrm{R} 8} \mathrm{PcLnPc}\right] \mathrm{Na}\right\}_{2} \mathbf{1 7 6}$ in a solid state (Figure 22) [292]. This structure can be viewed as a pseudo quadruple-decker 
complex in which two sodium cations are held by coordination bonds with oxygen atoms of butoxy-groups between the two double-decker Pc anions.

By analogy with the synthesis of heteroleptic double-decker complexes presented in Scheme 36, complex 177, which has one Pc and one tetrabenzotriazoporphyrin ligand, was recently characterized in the literature (Scheme 37) [227].

\subsection{Phthalocyanine-metal-naphthalocyanine complexes}

Representatives of this class of compounds are relatively rare to date. This is largely due to the insufficient development of synthetic methods. Thus, the reaction between equimolar amounts of PN and 2,3-NPN in the presence of lutetium acetate and DBU in boiling $n$-hexanol produced [295] the following set of complexes by ratio of isoindole and benzoisoindole fragments with the yields (\%) given in parenthesess: 8:0 (1), 7:1 (5.5), 6:2 mixture of positional isomers (20), 5:3 mixture of positional isomers (37), 4:4 mixture of positional isomers (28), 3:5 mixture of positional isomers (7), 2:6 mixture of positional isomers (1.5). Note that the isolation procedure for the target heteroleptic complex NcLuPc (178) out of the mixture has not been described by the authors [295]. This compound was later obtained by the direct interaction of an alkali metal Nc with lutetium single-decker Pc [296] or with lithium Pc in the presence of lutetium acetate [231] (Scheme 38). However, in the first case, the authors do not provide the yield of the title compound. In the second case, the formation of significant amounts of the corresponding homoleptic product was observed; yield of the desired complex $\mathbf{1 7 8}$ in this case was 17\%.

By analogy with the heteroleptic double-decker Pcs (Section 5.1, Scheme 28) substituted complexes 178-182 were prepared by the template condensation starting from single-decker rare-earth Pcs in a melt [274], or in $n$-hexanol [297] or $n$-octanol [298] solutions of NPNs 
(Scheme 39, conditions 1-3). Selectivity of this approach is low as well and yields of compounds

178, 180-182 are in the range of $25-59 \%$, which is caused not only by the formation of the homoleptic products, but also by oligomerization and/or oxidative destruction of the initial NPNs. Note chirality of compounds 182, which, by analogy with some double-decker Pcs (for example, 148, Section 5.1), exists as a mixture of enantiomers [298].

\subsection{Phthalocyanine-metal-porphyrin complexes}

The main feature in the synthesis of the Por containing sandwich-type rare-earth complexes, including mixed-ligand derivatives, consists in the introduction of a Por moiety exclusively as a preformed free-base ligand. Both template and direct formation synthetic strategies are employed for the Pc-Por complexes (Schemes 40 and 41) as in the case of the heteroleptic double-decker Pcs (Section 5.1).

Thus, metallation of the free-base Pors with rare-earth salts in TCB or $n$-octanol as a solvent results in the formation of corresponding single-decker complexes, which further react with PNs in alcohol media in the presence of DBU [172,299-303] to form compounds 183-195 (Scheme 40). Yields of the products depend both on the nature of rare-earth ion and substituents in the ligands, varying within the wide range from 2 to $69 \%$. For example, maximum yields (up to $36 \%$ ) were observed in the case of complexes 190 [301] for the mid-row elements, ionic radii of which, according to the authors, set optimal distance between the ligands, thereby causing the most effective stabilizing overlap of their $\pi$-orbitals. At the same time, an introduction of bulky substituents in the peripheral positions of macrocycles leads to an expected decrease in the yields of the target compounds [299]. 
Direct interaction of the single-decker rare-earth Pors with a free-base Pc or its lithium salt generally proceeds more efficiently in comparison with the template method and results in the formation of mixed-ligand complexes 183 [304], 188 [305], 196-203 [306-310] (Scheme 41) with yields varying in a wide range. Thus, compounds $\mathbf{1 8 3}$ and $\mathbf{1 8 8}$ were synthesized [304,305] in TCB in 60-85\% yields, while complexes 196-199 were prepared in boiling $n$-octanol [74,306,307] with 24-61\% yields (Scheme 41, conditions $1 a, b$ ). Using nanoporous anodized alumina as a template, authors [308] were able to use double-decker europium complex 196 for the preparation of nanotubes. Synthesis of compound $\mathbf{2 0 0}$ was carried out using microwave radiation (Scheme 41, conditions 2); the yield was 66\% [309]. For obtaining compounds 201203, europium and cerium halogenides were initially treated with two equivalents of $\mathrm{LiN}\left(\mathrm{SiMe}_{3}\right)_{2}$ in diglyme to form salts of general formula of $\operatorname{LnX}\left[\mathrm{N}\left(\mathrm{SiMe}_{3}\right)_{2}\right]_{2}(\mathrm{Ln}=\mathrm{Ce}, \mathrm{Eu} ; \mathrm{X}=$ $\mathrm{Cl}, \mathrm{I})$, which reacted in situ with the free-base Pors to form the corresponding single-decker complexes [310]. Further interaction of the single-decker rare-earth Pors with unsubstituted or tetra-t-Bu-substituted lithium Pc in boiling diglyme allowed isolation of mixed-ligand products 201-203 in yields from moderate to high (38-94\%) (Scheme 41, conditions 3).

An alternative way of the direct synthesis (Scheme 42) involves a reverse sequence of the complexation reactions. Thus, the reaction of lithium Pc with $\operatorname{Ln}(\mathrm{acac})_{3}$ leads to formation of the corresponding single-decker complexes, which further react in situ with free-base Pors forming the mixed-ligand derivatives. This method allowed obtaining compounds $\mathbf{1 8 3}$ [304,311] and 188 [179] for the elements of a first half of the $\mathrm{Ln}$ series $(\mathrm{Ln}=\mathrm{La}-\mathrm{Nd}, \mathrm{Eu}, \mathrm{Gd})$ with yields of 3669\%. The described methodology (Scheme 41) also provided a basis for the synthesis of a series of low-symmetry complexes 204-208 (Figure 23, Scheme 43) [75,312-314], including 205, which contain $N$-confused Por ligands [313], optically active complex 206 [314], and complex 
208, which possesses interesting photophysical properties [75] due to the presence of a perylenediimide fragment.

Particularly noteworthy is the fact that during direct synthesis, double-decker complexes of trivalent metals are formed as the anionic species, which are gradually transformed into the neutral paramagnetic species oxidation with a variety of oxidizing agents, such as atmospheric oxygen. In addition, the stability of the anionic forms among the similar type of rare-earth complexes decreases with decreasing ionic radii of these elements [304]. In contrast, tetravalent metals exclusively form neutral diamagnetic double-decker compounds with Pcs and their analogues. Thus, a direct interaction of single-decker $\operatorname{PorMCl}_{2}(\mathrm{M}=\mathrm{U}, \mathrm{Th}, \mathrm{Zr}, \mathrm{Hf})$ with sodium Pc in a boiling 1-ClN [229,315] produced complexes 183, 201, and 209 with tetravalent metals (Figure 24). In the case of uranium and thorium ions, the synthesis was carried out for 40 hours with the mixed-ligand products isolated in $20-45 \%$ yields [229], while zirconium and hafnium provided the desired compounds within only 3 hours with 25-69\% yields [315].

\subsection{Naphthalocyanine-metal-porphyrin complexes}

The first double-decker complexes of this type, namely, compounds 210 and 211 were prepared by Jiang and co-workers in 1999 [316] by a template tetramerization of unsubstituted and 6,7-bis(dodecylthio)-substituted NPNs in the presence of single-decker europium Pors (Scheme 44) in 52 and 69\% yields, respectively. Single-decker rare-earth Por complexes studied in the work [316] were prepared by metallation of the corresponding ligands with europium acetylacetonate in boiling TCB, which was then evaporated. After that, further reaction with the corresponding NPNs was carried out under conditions of Scheme 44. Later, these researchers have shown [179,317-319] that a direct reaction between the metal-free Por, NPN and rare-earth 
salt (Scheme 44) leads to mixed-ligand complexes 212-214 in comparable yields ( $\mathrm{Ln}=\mathrm{Eu})$. For compounds 212 [317] and 214 [319] the authors note a downward trend for yields along the rareearth series with decreasing ionic radii from 73 to $29 \%$ and from 45 to $21 \%$, respectively, and explained this fact by the increased influence of steric effects. Notably, all the studies of the rareearth Nc-Por sandwich complexes hitherto belong to the same group of researchers, which can explain the use of only one synthetic approach for complexes of this type.

\subsection{Porphyrin-metal-porphyrin complexes}

Synthesis of the heteroleptic double-decker rare-earth Pors is based on the direct interaction of single-decker metal complexes with dianions of the respective ligands (Scheme 45). Thus, interaction between single-decker (TPP) $\operatorname{Ln}(\mathrm{acac})$ and (OEP) $\mathrm{Li}_{2}$ obtained in situ by the reaction of butyllithium and $(\mathrm{OEP}) \mathrm{H}_{2}$ [320] results in formation of compounds $\mathbf{2 1 5}$ in 5-35\% yields $[320,321]$ as well as the corresponding homoleptic derivatives $(\mathrm{TPP})_{2} \operatorname{Ln},(\mathrm{OEP})_{2} \mathrm{Ln}$, and $(\mathrm{OEP})_{2} \mathrm{Ln}_{3}$. Separation of this mixture, also containing residues of the starting compounds, was carried out by a four-step chromatography on basic alumina using several types of eluents. The complexes of tetravalent metals (OEP)M(TPP) $(\mathrm{M}=\mathrm{U}$, Th) [229] were obtained under similar conditions, and the yields of uranium and double-decker thorium Pors after chromatographic purification were 30 and 16\%, respectively. A more complex sequence of the reactions (Scheme 46) allowed synthesizing low-symmetry heteronuclear compounds 216 [322], one of which contains a ferrocene moiety, that war further explored as molecular motor on the surface of HOPG by STM method.

The authors of [237] showed that Por-centered complexation proceeds more efficiently in the presence of silver triflate. Thus, ligand exchange reaction with (OEP) $\mathrm{ZrCl}_{2}$ afforded 
zirconium single-decker $(\mathrm{OEP}) \mathrm{Zr}(\mathrm{OTf})_{2}$, which reacted in mild conditions with lithium octaethyl-substituted TAP forming compound 217 in 74\% yield (Scheme 47).

\section{Synthetic approaches to heteroleptic and mixed-ligand triple-decker complexes}

Triple-decker rare-earth complexes containing different tetrapyrrolic ligands have been known for nearly twenty years, while a sharp rise in the number of papers on this topic was observed in the period from 2000 to 2007. Studies conducted in these years have shown that synthesis of the heteroligand and heteronuclear derivatives allows for the efficient managing of interlignad $\pi-\pi$ interactions and $f-f$ interactions of metal ions in the triple-decker complexes, giving the last ones pronounced magnetic [323] and nonlinear optical $[23,71]$ properties, as well as opening up the possibility of their application in high-capacity information storage devices $[310,324]$.

Currently known systems of this type can be divided into three groups depending on the nature of their constituent ligands: (i) heteroleptic Pcs; (ii) mixed-ligand complexes of Pcs with Pors; and (iii) mixed-ligand complexes of Ncs with Pors. Synthetic approaches, with a rare exception, represent various modifications of the direct complexation method and are often characterized by a low selectivity. By analogy with Section 5, this part of the review is also classified by type of the target compounds.

\subsection{Heteroleptic phthalocyanine complexes}

The first triple-decker rare-earth complex containing different ligands, namely, heteroleptic lutetium system 218 was prepared (Scheme 48) by Ishikawa and Kaizu in 1994 [325]. The reaction was carried out using a three-fold molar excess of single-decker lutetium relative to the 
tetra-crown substituted ligand, while the corresponding double-decker system 135 (Scheme 36) was prepared from an equimolar mixture of these reactants [290]. Complex $\mathbf{2 1 8}$ was isolated in an individual state as a result of repeated chromatography and characterized by elemental analysis, mass- (FAB method) and ${ }^{1} \mathrm{H}$ NMR spectra. Unfortunately, the yield of this compound was not specified by the authors [325].

The first series of heteroleptic triple-decker compounds for almost all rare-earth range (except La, Pm, and Lu) was obtained by Jiang and co-workers in 2000 [326]. They carried out reaction between the rare-earth acetylacetonates, lithium Pc and the corresponding double-decker Pcs in boiling TCB, which afforded compounds 219 (Scheme 49) in 26-79\% yield. Along with the main products, the authors also isolated and characterized complexes 220 (except $\mathrm{Ln}=\mathrm{Pr}$ ) in 3-17\% yield. They explain the formation of $\mathbf{2 2 0}$ by possible thermolysis of $\mathbf{2 1 9}$ to form heteroleptic complexes ${ }^{\mathrm{R}} \mathrm{PcLnPc}\left(\mathrm{R}=\mathrm{C}_{8} \mathrm{H}_{17} \mathrm{O}\right)$, which further react with an excess of the initially formed single-decker PcLn(acac) systems. This assumption is supported by the fact that the final yield of $\mathbf{2 2 0}$ increases proportionally with the duration of the synthesis. Furthermore, a control experiment, comprising interaction of $\mathrm{PcLn}(\mathrm{acac})(\mathrm{Ln}=\mathrm{Tb})$ and ${ }^{\mathrm{R}} \mathrm{PcH}_{2}\left(\mathrm{R}=\mathrm{C}_{8} \mathrm{H}_{17} \mathrm{O}\right)$ in boiling TCB medium, resulted in complex $\mathbf{2 2 0}$ with $51 \%$ yield, while the yield of $\mathbf{2 1 9}$ was found to be $37 \%$. Using the corresponding free-base ligand instead of lithium Pc, Ishikawa and co-workers carried out synthesis of heteroleptic homo- and heteronuclear complexes 221-223 under the similar conditions (Scheme 49) with yields of $\sim 60 \%$ [323,327]. In this case, the formation of byproducts, analogous to $\mathbf{2 2 0}$, was not mentioned by the authors. Compounds $\mathbf{2 2 1}-\mathbf{2 2 3}$ were characterized by elemental analysis and ${ }^{1} \mathrm{H}$ NMR spectral data [328]. By analogy with the method of Ishikawa, amphiphilic complexes 224-227 [183,329-331] as well as triple-decker 
system 228 [332] composed of two unsubstituted and one external 15-crown-5-substituted Pc ligands were obtained in $20-48 \%$ and $39-70 \%$ yields, respectively.

The formation of the heteroleptic triple-decker compounds is also facilitated by protic solvents. Thus, a set of isomeric samarium, gadolinium, and lutetium complexes $\mathbf{2 2 9}$ (Scheme 49) was prepared [333] in boiling $n$-octanol with 40,42 , and $24 \%$ yields, respectively. The authors explain the lower yield of the lutetium complex by increased steric hindrance due to the smallest ionic radius of this ion. Synthesis of triple-decker system $\mathbf{2 2 0}$ and its heteronuclear analogues 230 was also carried out by Jiang and co-workers according to Scheme 50 by the reaction between the corresponding single-decker Pcs and heteroleptic double-decker complexes in boiling TCB [334]. Target compounds $\mathbf{2 2 0}$ and $\mathbf{2 3 0}$ were isolated in $8-15 \%$ yield, while the formation of even trace amounts of the alternative complexation products was not observed, which is quite unusual, taking into consideration the earlier studies of these authors [326].

An original approach to the synthesis of triple-decker Pcs 218 and 231 was proposed by Gorbunova and co-authors [335,336] (Scheme 51). Unstable double-decker lanthanum Pc utilized as the donor of the unsubstituted ligand reacted with the rare-earth acetylacetonates in the presence of tetra(15-crown-5)-substituted Pc leading to compounds $\mathbf{2 1 8}$ in 10-31\% yield, while triple-deckers $\mathbf{2 3 1}$ were the major products and their yields varied between 31 and 53\%.

One of the most spectacular examples of heteroleptic Pcs obtained to date is quintupledecker tetranuclear complex 232 synthesized by Katoh and co-authors [337], which belongs to the "sandwich-planar" type (Scheme 52). This complex shows an absorption spectrum similar to the classic triple-decker Pcs (Figure 25), while considerable bathochromic shift of the $Q_{2}$ band to the $800-900 \mathrm{~nm}$ region should be noted, which is apparently reflects the presence of the "planar" 
type ligand in the molecule of $\mathbf{2 3 2}$. Unfortunately, the synthetic procedure selected by the authors allowed obtaining of the desired product in only a $2.3 \%$ yield.

The authors of [294] found conditions for the selective preparation of heteronuclear europium-lutetium complexes 233 and 234 starting from the corresponding mono- and doubledecker Pcs in 70-89\% yield (Scheme 53). Compounds $\mathbf{2 3 3 b}$ and $\mathbf{2 3 4 b}$ are the first triple-decker Pcs, which molecules contain ligands with both donor and acceptor substituents.

\subsection{Mixed-ligand phthalocyanine and porphyrin complexes}

This type of triple-decker complexes includes a much larger number of members as compared to the sandwich-type heteroleptic Pcs. The main reason for this is a generally better development of the Por chemistry, which expands opportunities to produce compounds with the desired properties. Nevertheless, the available synthetic approaches to the Por-containing heteroligand complexes, in most cases, are characterized by low selectivity and often lead to a mixture of compounds.

There are three types of triple-decker Pc-Por systems known to date, which differ in composition and internal arrangement of the ligands. Synthetic methods used for their preparation can also be divided into three major groups depending on the nature of the reacting substrates (Scheme 54). Table 6 summarizes data on the synthesis and yields of triple-decker complexes 235-265, for which the symbols "a", "b" and "c" denote the type of product according to the Scheme 54. 
Table 6. Yields of the triple-decker Ln complexes synthesized by Scheme 54.

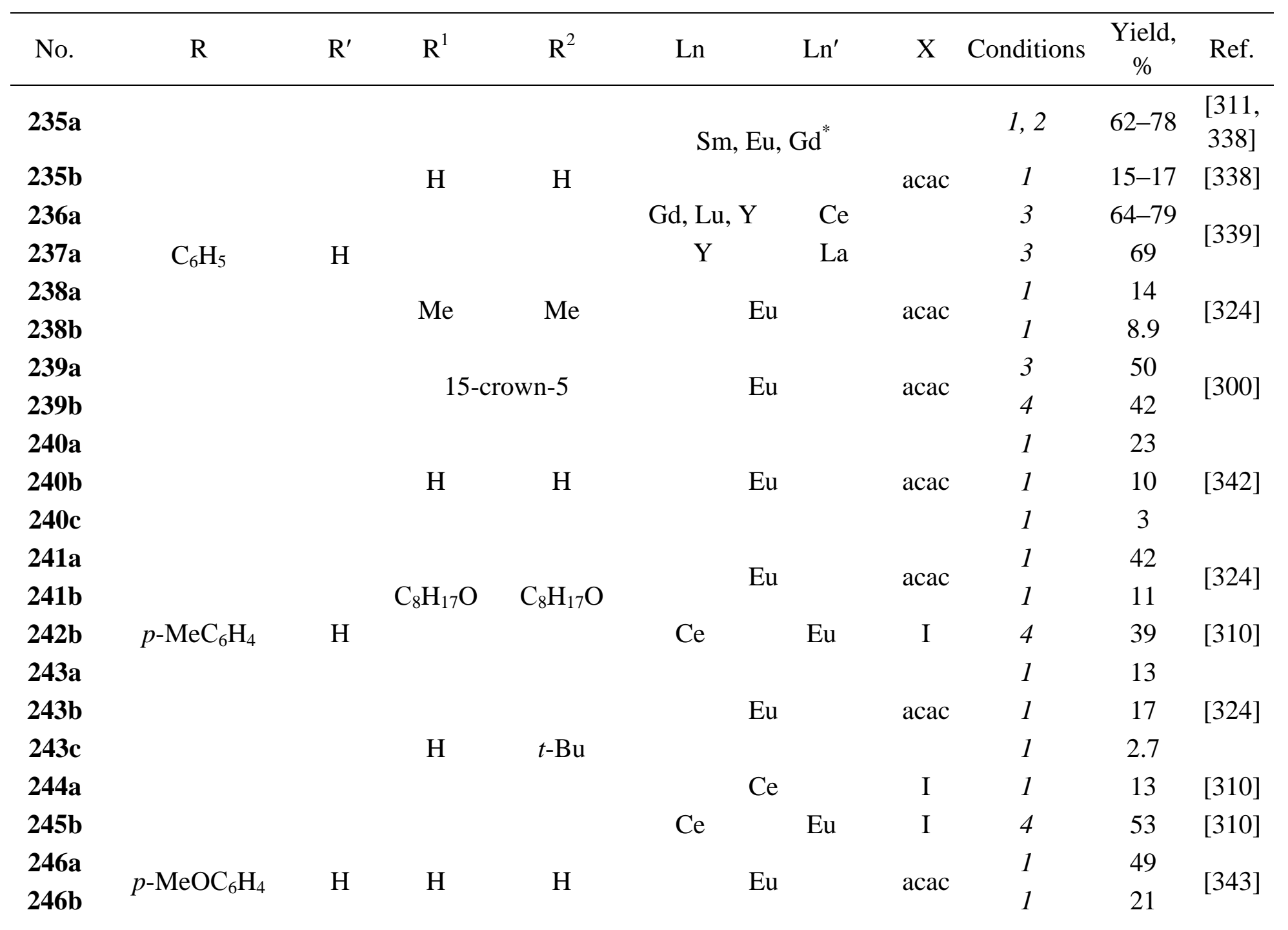




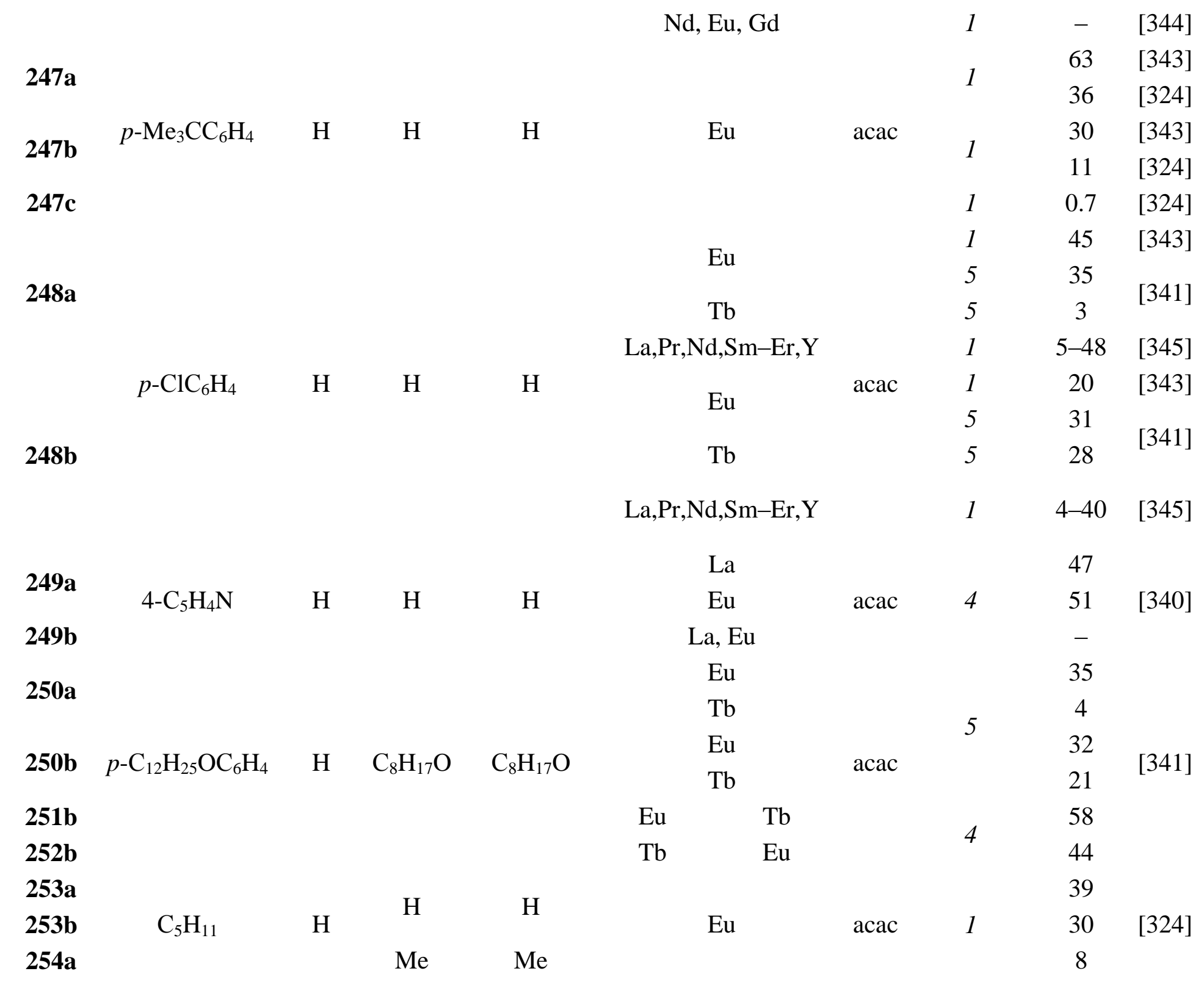




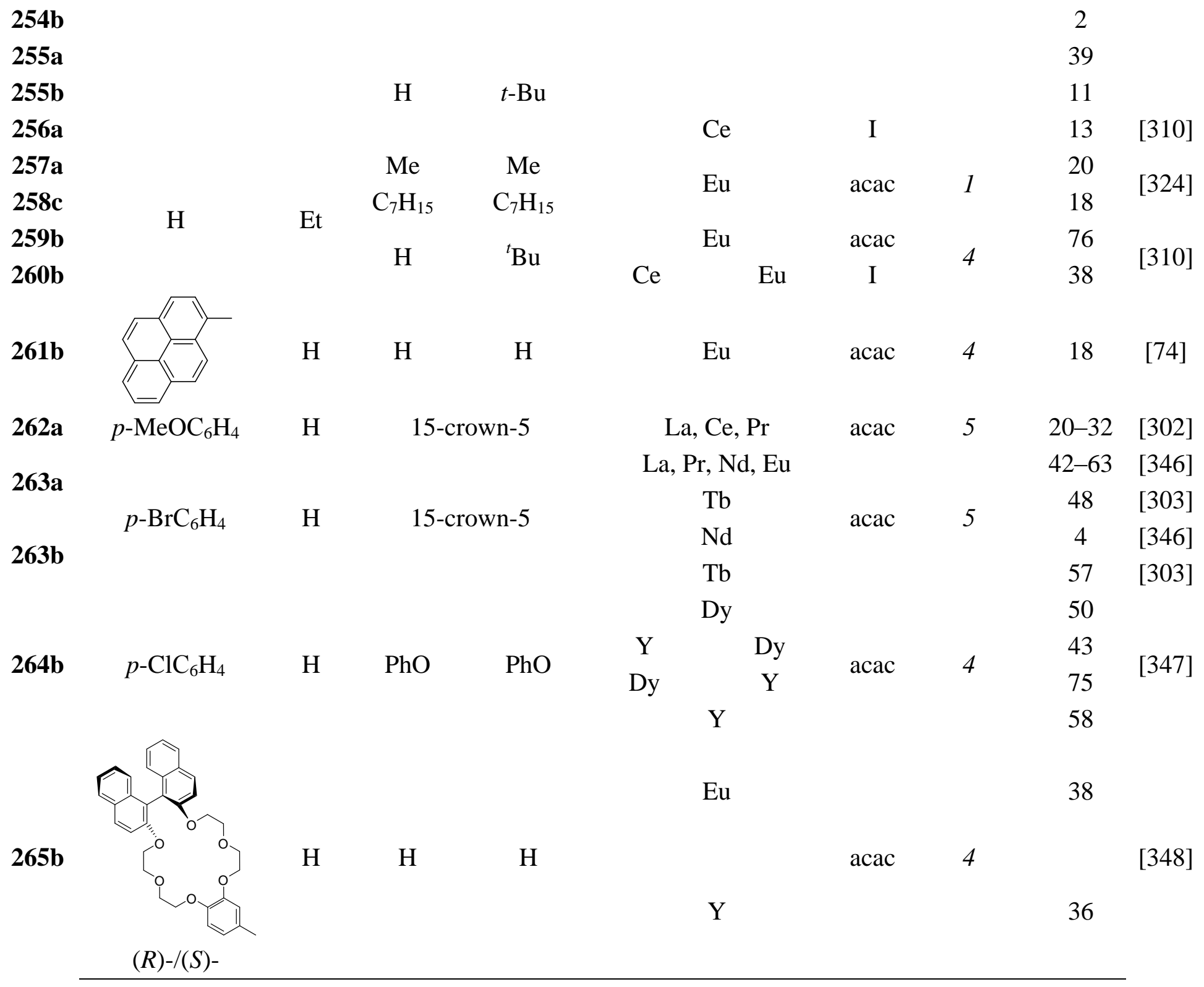


here and further merging of columns corresponds to $\mathrm{Ln}=\mathrm{Ln}$ '. 
The first method (Scheme 54, conditions 1) consists of a consecutive reaction of the rareearth salts with Por and Pc ligands. At the initial step, a Ln(acac $)_{3}$ interacts with a free-base Por in TCB forming a single-decker complex, which further reacts with an excess of dilithium Pc resulting in the formation of a mixture of sandwich-type products of both double-decker and triple-decker nature. Triple-decker complexes synthesized by this method are presented in Table 6 , and the yields of the target complexes tend to gradually decrease from the type "a" to the type "c" compounds. The formation of the latter was mentioned in only one work [324] with a maximum yield of $18 \%(\mathbf{2 5 8 c})$, which is evidence of their relatively low stability. Varying the ratio of initial reagents allows to shift the equilibrium towards a particular product; however, substantial increase in the process selectivity can hardly be achieved following conditions 1 [324]. Reverse order of the reaction (Scheme 54, conditions 2) also has virtually no effect on the yields of the target compounds (235a, Table 6) [311,338].

The second method (Scheme 54) involves interaction of the in situ obtained single-decker rare-earth Por with the double-decker $\left(\mathrm{R}^{1} \mathrm{R}^{2}\right) \mathrm{PcLnPor}$ (conditions 3) or $\left(\mathrm{R}^{1} \mathrm{R}^{2}\right) \mathrm{Pc}_{2} \mathrm{Ln}$ (conditions 4), complexes which leads to the type "a" and type "b" products, respectively, formed in good yields (Table 6). Scheme 54 (conditions 3) has also been used for the synthesis of heteronuclear triple-decker systems composed of different Por ligands, namely (TPP)CePcGd(OEP) (266) and $(\mathrm{PnP}) \mathrm{Ce}\left(t-\mathrm{Bu}_{4} \mathrm{Pc}\right) \mathrm{Eu}(\mathrm{TTP})(\mathbf{2 6 7})$ [310]. Nevertheless, selectivity of this approach, as in the case of that discussed above (Scheme 54, conditions 1), strongly depends on the reaction conditions. Thus, compounds 249a were obtained as the main products following Scheme 54 (Conditions 4) by refluxing the reagents in TCB, while expected triple-deckers $249 \mathrm{~b}$ were isolated only in trace amounts [340]. 
The third method, unlike the first two, is the template one and comprises the reaction between the single-decker rare-earth Por with PNs in the presence of DBU (Scheme 54, conditions 5). This approach was tested [341] for obtaining complexes 248a,b and 250a,b; the authors mentioned its low selectivity comparable to the synthesis by the conditions 1 (Table 6). Conditions 5 (Scheme 54) were also used [302,303,346] for the synthesis of crown-substituted complexes 262 and 263.

The synthesis of a number of the triple-deckers containing asymmetrically substituted Por ligands was performed according to Scheme 54 as well. Thus, using conditions 1 , complexes 268 and 269 [349], which include two $\mathrm{A}_{3} \mathrm{~B}$-type Por moieties linked through the butadiyne bridge (Figure 26), were obtained in 33 and 17\% yield, respectively. Likewise, a series of compounds 270-272 [63] containing triallyl fragments was synthesized (Figure 27). The introduction of these functional groups allowed the formation of the ordered triple-decker monolayers by adsorption onto $\mathrm{Si}(100)$ surface. Efficient binding of the Pc-Por complexes to the electrodes provides high concentration of the redox-active species on their surface, which increases density of the generated charge. High charge density is crucial for the development of molecular materials for large-volume information carriers [63].

The synthesis of the functionally substituted multi-decker systems, as well as a number of bridged structures, was carried out $[62,324,342,350,351]$ using $\operatorname{Pd}(0)$ catalyzed cross-coupling reactions. Some examples are shown in Schemes 55 and 56. Thus, initial complexes 273-275 were prepared following Scheme 54 (conditions 4) and further reacted with terminal alkynes at Sonogashira coupling conditions (Scheme 55, conditions 1) forming thioacetyl derivatives 276279 in $10-50 \%$ yield $[62,324,342]$. The authors observed the formation of considerable amounts of side products, mainly, as a result of homo-coupling of the initial alkynes that significantly 
complicated isolation of the target complexes. Further optimization of the reaction conditions (Scheme 55, conditions 2) allowed minimization of the undesirable side processes [324,342]. However, yields of target products 276-279 were not improved.

Coupling of the terminal ethynyl groups by the modified Eglinton-Glaser reaction [342] led to the triple-decker complexes, linked through the butadiyne bridge. As an example, Scheme 56 shows a homo-coupling of compound $\mathbf{2 8 0}$ to form dimeric product $\mathbf{2 8 1}$ in $89 \%$ yield. Using a large variety of methods described above, synthesis of the more complex derivatives was performed [350,351] with some examples (282-287) shown in Figure 28.

\subsection{Mixed-ligand naphthalocyanine and porphyrin complexes}

Among the possible combinations of Ncs and Pors in the triple-decker complexes there are representatives of only one structural type synthesized to date (Scheme 57). Moreover, these compounds are still the only example of the sandwich-type tetrapyrrole triple-decker systems containing 2,3-Nc ligand. Their synthesis was carried out exclusively by the direct method (Scheme 57). first metallating the free-base Por by the rare-earth acetylacetonate to form the single-decker complex, which is then reacted with lithium Nc (conditions 1) or with the Nc-Por rare-earth double-decker (conditions 2). The first route afforded europium triple-decker complex 288 [324] by refluxing a mixture of the reagents in TCB in 3\% yield. Yields of products $\mathbf{2 8 9}$ synthesized by the second route in boiling TCB amount to $46 \%$ and $63 \%$ for europium and neodymium, respectively [319].

\section{Conclusions}


Without reservations, there is a wide range of the rare-earth complexes with tetrapyrrole ligands of single-, double- and triple-decker nature known to date, including their heteroleptic, mixed-ligand and heteronuclear derivatives. Bisphthalocyanines are the most extensively studied representatives among the homoleptic complexes, and porphyrin-phthalocyanine double-deckers are the most explored among the heteroleptic and mixed-ligand compounds. Recent advances in the synthetic studies, including those made by the authors of this review, provide increased yields and selectivity, thus, contributing to the development of chemistry of the tetrapyrrole rareearth compounds and enhancing their availability for practical use.

\section{Acknowledgements}

Generous support from the NSF CHE-1110455 and CHE-14010375, the Minnesota Supercomputing Institute to VNN is greatly appreciated. We also thank Presidium of the Russian Academy of Sciences, Ministry of Science and Education (Project No. 14.576.21.0029), Council under the President of the Russian Federation for State Support of Young Scientists and Leading Scientific Schools (Grant MD-3738.2015.3) and Russian Foundation for Basic Research (Grant Nos. 15-03-05890, 15-33-21012, 16-33-00097, 16-33-60031) for financial support. 


\section{References}

[1] F.H. Thomas, A.L. Moser, The Phthalocyanines: Manufacture and Application, Vol. 2, CRC Press, Boca Raton, 1983.

[2] D. Wöhrle, in: C.C. Leznoff, A.B.P. Lever (Eds.), Phthalocyanines: Properties and Applications, Vol. 1, VCH Publisher, Inc. New York, 1989, pp. 55-132.

[3] G. Ferraudi, in: C.C. Leznoff, A.B.P. Lever (Eds.), Phthalocyanines: Properties and Applications, Vol. 1, VCH Publisher, Inc. New York, 1989, pp. 291-340.

[4] M.R. Wasielewski, Chem. Rev. 92 (1992) 435-461.

[5] D. Gust, T.A. Moore, A.L. Moore, Acc. Chem. Res. 26 (1993) 198-205.

[6] J. Cheek, J.H. Dawson, in: K.M. Kadish, K.M. Smith, R. Guillard (Eds.), Porphyrin Handbook, Vol. 7, Academic Press, New York, 2000, pp. 339-369.

[7] I. Rosenthal, E. Ben-Hur, in: C.C. Leznoff, A.B.P. Lever (Eds.), Phthalocyanines: Properties and Applications, Vol. 1, VCH Publisher, Inc. New York, 1989, pp. 393-425.

[8] R. Bonnett, Chemical Aspects of Photodynamic Therapy, Gordon and Breach, Amsterdam, 2000.

[9] B. Grimm, A. Hausmann, A. Kahnt, W. Seitz, F. Spanig, D.M. Guldi, in: K.M. Kadish, K.M. Smith, R. Guilard (Eds.), Handbook of Poprhyrin Science Vol. 1, World Scientific, Singapore, 2010, pp. 133 - 219.

[10] E.A. Lukyanets, V.N. Nemykin, J. Porphyrins Phthalocyanines 14 (2010) 1-40.

[11] A.W. Snow, W.R. Barger, in: C.C. Leznoff, A.B.P. Lever (Eds.), Phthalocyanines: Properties and Applications, Vol. 1, VCH Publisher, Inc. New York, 1989, pp. 341-392. 
[12] M. Jurow, A.E. Schuckman, J.D. Batteas, C.M. Drain, Coord. Chem. Rev. 254 (2010) 22972310.

[13] N.B. McKeown, Phthalocyanine Materials: Synthesis, Structure and Function, Cambridge University Press, Cambridge, 1998.

[14] D. Dini, M. Hanack, in: K.M. Kadish, K.M. Smith, R. Guillard (Eds.), Porphyrin Handbook, Vol. 17, Academic Press, San Diego, 2003, pp. 1-36.

[15] M. Wark, in: K.M. Kadish, K.M. Smith, R. Guillard (Eds.), Porphyrin Handbook, Vol. 17, Academic Press, San Diego, 2003, pp. 247-284.

[16] E. Ben-Hur, W.-H. Chan, in: K.M. Kadish, K.M. Smith, R. Guillard (Eds.), Porphyrin Handbook, Vol. 19, Academic Press, San Diego, 2003, pp. 1-36.

[17] M. Bouvet, in: K.M. Kadish, K.M. Smith, R. Guillard (Eds.), Porphyrin Handbook, Vol. 19, Academic Press, San Diego, 2003, pp. 37-104.

[18] S.R. Flom, in: K.M. Kadish, K.M. Smith, R. Guillard (Eds.), Porphyrin Handbook, Vol. 19, Academic Press, San Diego, 2003, pp. 179-190.

[19] M.G. Walter, A.R. Rudine, C.C. Wamser, J. Porphyrins Phthalocyanines 14 (2010) 759792.

[20] I.S. Kirin, P.N. Moskalev, Yu.A. Makashev, Russ. J. Inorg. Chem. 10 (1965) 1065-1066.

[21] I.S. Kirin, P.N. Moskalev, Yu.A. Makashev, Russ. J. Inorg. Chem. 10 (1965) 369-372.

[22] P.N. Moskalev, Sov. J. Coord. Chem. 16 (1990) 77-89.

[23] D.K.P. Ng, J.Jiang, Chem. Soc. Rev. 26 (1997) 433-442.

[24] B.I. Kharisov, M.A. Mendes-Rokhas, E.A. Ganich, Russ. J. Coord. Chem. 26 (2000) 301310.

[25] V.N. Nemykin, S.V. Volkov, Russ. J. Coord. Chem. 26 (2000) 436-450. 
[26] J.W. Buchler, D.K.P. Ng, in: K.M. Kadish, K.M. Smith, R. Guilard (Eds.), The Porphyrin Handbook, Academic Press, San Diego, 2000, p. 245-294 (Volume 3, Chapter 20).

[27] R. Weiss, J. Fischer, in: K.M. Kadish, K.M. Smith, R. Guilard (Eds.), The Porphyrin Handbook, Academic Press, San Diego, 2003, p. 171-246 (Volume 16, Chapter 105).

[28] N. Kobayashi, Coord. Chem. Rev. 227 (2002) 129-152.

[29] J. Jiang, W. Liu, D.P. Arnold, J. Porphyrins Phthalocyanines 7 (2003) 459-473.

[30] J. Jiang, K. Kasuga, D.P. Arnold, in: H.S. Nalwa (Ed.), Supramolecular Photosensitive and Electroactive Materials, Academic Press, New York, 2001, p. 113-210 (Chapter 2).

[31] V.E. Pushkarev, L.G. Tomilova, Yu.V. Tomilov, Russ. Chem. Rev. 77 (2008) 875-907.

[32] J.Jiang, D.K.P. Ng, Acc. Chem. Res. 42 (2009) 79-88.

[33] Y. Bian, Y. Zhang, Z. Ou, J. Jiang, in: K.M. Kadish, K.M. Smith, R. Guilard (Eds.), Handbook of Porphyrin Science: With Applications to Chemistry, Physics, Materials Science, Engineering, Biology and Medicine, World Scientific, Singapore, 2011, p. 249-460 (Volume 14, Chapter 64).

[34] T. Fukuda, T. Biyajima, N. Kobayashi, J. Am. Chem. Soc. 132 (2010) 6278-6279.

[35] H. Wang, K. Wang, Y. Bian, J. Jiang, N. Kobayashi, Chem. Commun. 47 (2011) 68796881.

[36] H. Wang, K. Qian, K. Wang, Y. Bian, J. Jiang, S. Gao, Chem. Commun. 47 (2011) 96249626.

[37] T. Fukuda, W. Kuroda, N. Ishikawa, Chem. Commun. 47 (2011) 11686-11688.

[38] H. Wang, N. Kobayashi, J. Jiang, Chem. Eur. J. 18 (2012) 1047-1049.

[39] H. Wang, T. Liu, K. Wang, C. Duan, J. Jiang, Chem. Eur. J. 18 (2012) 7691-7694.

[40] T. Fukuda, K. Matsumura, N. Ishikawa, J. Phys. Chem. A, 117 (2013) 10447-10454. 
[41] H. Shang, H. Wang, K. Wang, J. Kan, W. Cao, J. Jiang, Dalton Trans. 42 (2013) 1109_1115.

[42] H. Wang, D. Qi, Z. Xie, W. Cao, K. Wang, H. Shang, J. Jiang, Chem. Commun. 49 (2013) 889-891.

[43] T. Basova, I. Jushina, A.G. Gürek, V. Ahsen, A.K. Ray, J. R. Soc. Interface, 5 (2008) 801806.

[44] G. Gümrükçü, M. Üstün Özgür, A. Altındal, A.R. Özkaya, B. Salih, Ö. Bekaroğlu, Synth. Met. 161 (2011) 112-123.

[45] M.L. Rodríguez-Méndez, J. Souto, J. de Saja-González, J.A. de Saja, Sens. Actuators B 31 (1996) 51-55.

[46] Y. Chen, H.-G. Liu, N. Pan, J. Jiang, Thin Solid Films 460 (2004) 279-285.

[47] N. Kılınç, D. Atilla, A.G. Gürek, Z.Z. Öztürk, V. Ahsen, Talanta 80 (2009) 263-268.

[48] Y. Açıkbaş, M. Evyapan, T. Ceyhan, R. Çapan, Ö. Bekaroğlu, Sens. Actuators B 135 (2009) $426-429$.

[49] Y. Chen, M. Bouvet, T. Sizun, Y. Gao, C. Plassard, E. Lesniewska, J. Jiang, Phys. Chem. Chem. Phys. 12 (2010) 12851-12861.

[50] Y. Chen, M. Bouvet, T. Sizun, G. Barochi, J. Rossignol, E. Lesniewska, Sens. Actuators B 155 (2011) 165-173.

[51] M. Kandaz, A.T. Bilgiçli, A. Altındal, Synth. Met. 160 (2010) 52-60.

[52] N. Gutierrez, M.L. Rodríguez-Méndez, J.A. de Saja, Sens. Actuators B 77 (2001) 437-442.

[53] A. Arrieta, M.L. Rodriguez-Mendez, J.A. de Saja, Sens. Actuators B 95 (2003) 357-365.

[54] V. Parra, Á.A. Arrieta, J.A. Fernández-Escudero, H. García, C. Apetrei, M.L. RodríguezMéndez, J.A. de Saja, Sens. Actuators B 115 (2006) 54-61. 
[55] C. Pal, A.N. Cammidge, M.J. Cook, J.L. Sosa-Sanchez, A.K. Sharma, A.K. Ray, J. R. Soc. Interface 9 (2012) 183-189.

[56] C. Pal, A.K Sharma, A.N. Cammidge, M.J. Cook, A.K. Ray, J. Phys. Chem. B 117 (2013) $15033-15040$.

[57] K. Katoh, T. Komeda, M. Yamashita, Dalton Trans. 39 (2010) 4708-4723.

[58] M. Urdampilleta, N.-V. Nguyen, J.-P. Cleuziou, S. Klyatskaya, M. Ruben, W. Wernsdorfer, Int. J. Mol. Sci. 12 (2011) 6656-6667.

[59] M. Gonidec, R. Biagi, V. Corradini, F. Moro, V. De Renzi, U. del Pennino, D. Summa, L. Muccioli, C. Zannoni, D.B. Amabilino, J. Veciana, J. Am. Chem. Soc. 133 (2011) 6603-6612.

[60] Y.-S. Fu, J. Schwöbel, S.-W. Hla, A. Dilullo, G. Hoffmann, S. Klyatskaya, M. Ruben, R. Wiesendanger, Nano Lett. 12 (2012) 3931-3935.

[61] Z. Liu, A.A. Yasseri, J.S. Lindsey, D.F. Bocian, Science 302 (2003) 1543-1545.

[62] L. Wei, K. Padmaja, W.J. Youngblood, A.B. Lysenko, J.S. Lindsey, D.F. Bocian, J. Org. Chem. 69 (2004) 1461-1469.

[63] K. Padmaja, W.J. Youngblood, L. Wei, D.F. Bocian, J.S. Lindsey, Inorg. Chem. 45 (2006) $5479-5492$.

[64] S.L. Selektor, A.V. Shokurov, V.V. Arslanov, Yu.G. Gorbunova, K.P. Birin, O.A. Raitman, F. Morote, T. Cohen-Bouhacina, C. Grauby-Heywang, A.Yu. Tsivadze, J. Phys. Chem. C 118 (2014) 4250-4258.

[65] B. Simic-Glavaski, in: C.C. Leznoff, A.B.P. Lever (Eds.), Phthalocyanines - Properties and Applications, VCH, New York, 1993, p. 119-165 (Volume 3, Chapter 3).

[66] T. Basova, A.G. Gürek, V. Ahsen, A.K. Ray, Org. Electronics 8 (2007) 784-790. 
[67] N.B. Chaure, J.L. Sosa-Sanchez, A.N. Cammidge, M.J. Cook, A.K. Ray, Org. Electronics $11(2010)$ 434-438.

[68] H.S. Nalwa, J.S. Shirk, in: C.C. Leznoff, A.B.P. Lever (Eds.), Phthalocyanines - Properties and Applications, VCH, New York, 1996, p. 79-181 (Volume 4, Chapter 3).

[69] H.G. Yağlıoğlu, M. Arslan, Ş. Abdurrahmanoğlu, H. Ünver, A. Elmali, Ö. Bekaroğlu, J. Phys. Chem. Solids 69 (2008) 161-167.

[70] T. Ceyhan, M.A. Özdağ, B. Salih, M.K. Erbil, A. Elmalı, A.R. Özkaya, Ö. Bekaroğlu, Eur. J. Inorg. Chem. (2008) 4943-4950.

[71] W. Huang, H. Xiang, Q. Gong, Y. Huang, C. Huang, J. Jiang, Chem. Phys. Lett. 374 (2003) 639-644.

[72] S. Casilli, M. De Luca, C. Apetrei, V. Parra, A.A. Arrieta, L. Valli, J. Jiang, M.L. Rodríguez-Méndez, J.A. De Saja, Appl. Surf. Sci. 246 (2005) 304-312.

[73] C. Apetrei, S. Casilli, M. De Luca, L. Valli, J. Jiang, M.L. Rodríguez-Méndez, J.A. De Saja, Coll. Surf. A 284-285 (2006) 574-582.

[74] N. Sheng, P. Zhu, C. Ma, J. Jiang, Dyes Pigm. 81 (2009) 91-96.

[75] S. Dong, X. Zhang, Y. Zhou, J. Jiang, Y. Bian, Dyes Pigm. 91 (2011) 99-104.

[76] Y. Li, Y. Bian, M. Yan, P.S. Thapaliya, D. Johns, X. Yan, D. Galipeau, J. Jiang, J. Mater. Chem. 21 (2011) 11131-11141.

[77] T. Fukuda, K. Hata, N. Ishikawa, J. Am. Chem. Soc. 134 (2012) 14698-14701.

[78] L. Chen, R. Hu, J. Xu, S. Wang, X. Li, S. Li, G. Yang, Spectrochim. Acta A 105 (2013) $577-581$.

[79] J. Lu, P. Ma, X. Zhang, J. Jiang, Dalton Trans. 40 (2011) 12895-12900. 
[80] X. Zhang, Q. Wang, L. Wu, W. Lv, J. Lu, Y. Bian, J. Jiang, J. Phys. Chem. B 114 (2010) 1233-1240.

[81] S. Klyatskaya, J.R.G. Mascarós, L. Bogani, F. Hennrich, M. Kappes, W. Wernsdorfer, M. Ruben, J. Am. Chem. Soc. 131 (2009) 15143-15151.

[82] K. Kasuga, S. Takahashi, K. Tsukahara, T. Ohno, Inorg. Chem. 29 (1990) 354-356.

[83] K. Kasuga, M. Ando, H. Morimoto, Inorg. Chim. Acta 112 (1986) 99-101.

[84] A.G. MacKay, J.F. Boas, G.J. Troup, Aust. J. Chem. 27 (1974) 955-964.

[85] E.O. Tolkacheva, A.Yu. Tsivadze, S.G. Bitiev, Yu.G. Gorbunova, V.I. Zhilov, V.V. Minin, Zh. Neorg. Khim. 40, (1995) 984-989 (in Russian).

[86] E.E. Kolesnikova, G.P. Shaposhnikov, V.P. Kulinich, R.P. Smirnov, Izv. Vyssh. Uchebn. Zaved., Khim. Khim. Tekhnol. 33 (1990) 22-26 (in Russian).

[87] V.P. Kulinich, G.P. Shaposhnikov, V.E. Maizlish, R.P. Smirnov, Russ. J. Coord. Chem. 20 (1994) 721-724.

[88] S.D. Kolnin, A.V. Postnikov, S.V. Koroleva, E.N. Lebedeva, E.R. Milaeva, Izv. Akad. Nauk. Ser. Khim. (1994) 2249-2250 (in Russian).

[89] E.R. Milaeva, S.D. Kolnin, V.S. Petrosyan, Vestn. Mosk. Univ. Ser. 2 Khim. 38 (1997) $350-353$.

[90] A. De Cian, M. Moussavi, J. Fischer, R. Weiss, Inorg. Chem. 24 (1985) 3162-3167.

[91] L.G. Tomilova, A.V. Ivanov, I.V. Kostyuchenko, E.V. Shulishov, O.M. Nefedov, Mendeleev Commun. 12 (2002) 149-151.

[92] A.V. Ivanov, P.A. Svinareva, I.V. Zhukov, L.G. Tomilova, N.S. Zefirov, Russ. Chem. Bull. Int. Ed. 55 (2006) 281-286.

[93] N. Jiazan, S. Feng, L. Zhenxiang, Y. Shaoming, Inorg. Chim. Acta 139 (1987) 165-168. 
[94] Y. Liu, K. Shigehara, A. Yamada, Bull. Chem. Soc. Jpn. 65 (1992) 250-257.

[95] V.N. Nemykin, N.B. Subbotin, N.A. Kostromina, S.V. Volkov, Ukr. Khim. Zh. 61 (1995) 3-7 (in Russian).

[96] V.P. Kulinich, S.I. Vasilev, G.P. Shaposhnikov, V.E. Maizlish, O.A. Doroshina, R.P. Smirnov, Russ. J. Coord. Chem. 23 (1997) 737-740.

[97] N.B. Subbotin, L.G. Tomilova, N.A. Kostromina, E.A. Luk'yanets, Zh. Obshch. Khim. 56 (1986) 397-400.

[98] L.G. Tomilova, Doctoral Thesis in Chemical Sciences, Institute of Organic Intermediates and Dyes, Moscow, 1995 (350 pages).

[99] V.N. Nemykin, A.Yu. Tsivadze, N.B. Subbotin, N.A. Kostromina, S.V. Volkov, Coord. Khim. 22 (1996) 315-320 (in Russian).

[100] L.A. Lapkina, V.E. Larchenko, E.O. Tolkacheva, K.I. Popov, N.Yu. Konstantinov, V.M. Nosova, A.Yu. Tsivadze, Zh. Neorg. Khim. 43 (1998) 987-995 (in Russian).

[101] A.G. Martynov, Yu.G. Gorbunova, Inorg. Chim. Acta 360 (2007) 122-130.

[102] V.E. Pushkarev, M.O. Breusova, E.V. Shulishov, Yu.V Tomilov, Russ. Chem. Bull. Int. Ed. 54 (2005) 2087-2093.

[103] T.V. Dubinina, K.V. Paramonova, S.A. Trashin, N.E. Borisova, L.G. Tomilova, N.S. Zefirov, Dalton Trans. 43 (2014) 2799-2809.

[104] V.N. Nemykin, V.Y. Chernii, S.V. Volkov, J. Chem. Soc., Dalton Trans. (1998) 29952999.

[105] S. Bo, D. Tang, X. Liu, Z. Zhen, Dyes Pigm. 76 (2008) 35-40.

[106] H. Sugimoto, T. Higashi, M. Mori, Chem. Lett. 11 (1982) 801-804. 
[107] H. Sugimoto, T. Higashi, A. Maeda, Y. Hirai, J. Teraoka, M. Mori, H. Masuda, T. Taga, J. Less Common Met. 112 (1985) 387-392.

[108] A. Iwasse, K. Tanaka, Electrochim. Acta 35 (1990) 1707-1712.

[109] H. Sugimoto, T. Higashi, M. Mori, Chem. Lett. 12 (1983) 1167-1170.

[110] V.N. Nemykin, T.I. Mironyuk, V.Ya. Zub, S.V. Volkov, Ukr. Khim. Zh. 64 (1998) 75-79 (in Russian).

[111] R. Guilard, A. Dormond, M. Belkalem, J.E. Anderson, Y.H. Liu, K.M. Kadish, Inorg. Chem. 26 (1987) 1410-1414.

[112] H. Sugimoto, T. Higashi, M. Mori, J. Chem. Soc., Chem. Commun. (1983) 622-623.

[113] H. Sugimoto, T. Higashi, A. Maeda, M. Mori, H. Masuda, T. Taga, J. Chem. Soc., Chem. Commun. (1983) 1234-1235.

[114] N. Kobayashi, J. Rizhen, S. Nakajima, T. Osa, H. Hino, Chem. Lett. 22 (1993) 185-188.

[115] V.N. Nemykin, N.A. Kostromina, S.V. Volkov, Ukr. Khim. Zh. 63 (1997) 3-6 (in Russian).

[116] F. Guyon, A. Pondaven, J.-M. Kerbaol, M. L’Her, Inorg. Chem. 37 (1998) 569-576.

[117] V.M. Negrimovskii, M. Bouvet, E.A. Luk’yanets, J. Simon, J. Porphyrins Phthalocyanines 4 (2000) 248-255.

[118] V.N. Nemykin, N.A. Kostromina, N.B. Subbotin, S.V. Volkov, Izv. Akad. Nauk, Ser. Khim. (1996) 99-102 (in Russian).

[119] T.V. Dubinina, R.A. Piskovoi, A.Yu. Tolbin, V.E. Pushkarev, M.Yu. Vagin, L.G. Tomilova, N.S. Zefirov, Russ. Chem. Bull., Int. Ed. 57 (2008) 1912-1919.

[120] V.N. Nemykin, N.B. Subbotin, N.A. Kostromina, S.V. Volkov, E.A. Luk'yanets, Zh. Neorg. Khim. 40 (1995) 1183-1188 (in Russian). 
[121] W.-K. Wong, L. Zhang, W.-T. Wong, F. Xue, T.C.W. Mak, J. Chem. Soc., Dalton Trans. (1999) 615-622.

[122] W.-K. Wong, L. Zhang, F. Xue, T.C.W. Mak, J. Chem. Soc., Dalton Trans. (1999) 30533062.

[123] J. Jiang, L. Wei, P. Gao, Z. Gu, K. Machida, G. Adachi, J. Alloys Compounds 225 (1995) $363-366$.

[124] J. Jiang, K. Machida, E. Yamamoto, G. Adachi, Chem. Lett. 20 (1991) 2035-2038.

[125] J. Jiang, W. Liu, K.-W. Poon, D. Du, D.P. Arnold, D.K.P. Ng, Eur. J. Inorg. Chem. (2000) 205-209.

[126] W.-K. Wong, A. Hou, J. Guo, H. He, L. Zhang, W.-Y. Wong, K.-F. Li, K.-W. Cheah, F. Xue, T.C.W. Mak, J. Chem. Soc., Dalton Trans. (2001) 3092-3098.

[127] T.J. Foley, B.S. Harrison, A.S. Knefely, K.A. Abboud, J.R. Reynolds, K.S. Schanze, J.M. Boncella, Inorg. Chem. 42 (2003) 5023-5032.

[128] F.-L. Jiang, W.-K. Wong, X.-J. Zhu, G.-J. Zhou, W.-Y. Wong, P.-L. Wu, H.-L. Tam, K.W. Cheah, C. Ye, Y. Liu, Eur. J. Inorg. Chem. (2007) 3365-3374.

[129] X.-J. Zhu, P. Wang, H.W.C. Leung, W.-K. Wong, W.-Y. Wong, D.W.J. Kwong, Chem. Eur. J. 17 (2011) 7041-7052.

[130] X.-J. Zhu, F.-L. Jiang, C.-T. Poon, W.-K. Wong, W.-Y. Wong, Eur. J. Inorg. Chem. (2008) $3151-3162$.

[131] H. Ke, W.-K. Wong, W.-Y. Wong, H.-L. Tam, C.-T. Poon, F. Jiang, Eur. J. Inorg. Chem. (2009) 1243-1247.

[132] F. Gao, M.-X. Yao, Y.-Y. Li, Y.-Z. Li, Y. Song, J.-L. Zuo, Inorg. Chem. 52 (2013) 64076416. 
[133] H. Wang, W. Cao, T. Liu, C. Duan, J. Jiang, Chem. Eur. J. 19 (2013) 2266-2270.

[134] Q. Ma, X. Feng, W. Cao, H. Wang, J. Jiang, Cryst. Eng. Commun. 15 (2013) 1038310388.

[135] F. Gao, Y.-Y. Li, C.-M. Liu, Y.-Z. Li, J.-L. Zuo, Dalton Trans. 42 (2013) 11043-11046.

[136] H. Wang, C. Liu, T. Liu, S. Zeng, W. Cao, Q. Ma, C. Duan, J. Dou, J. Jiang, Dalton Trans. 42 (2013) 15355-15360.

[137] Ya.Z. Voloshin, O.A. Varzatskii, L.G. Tomilova, M.O. Breusova, T.V. Magdesieva, Yu.N. Bubnov, R. Krämer, Polyhedron 26 (2007) 2733-2740.

[138] Ya.Z. Voloshin, O.A. Varzatskii, S.V. Korobko, V.Y. Chernii, S.V. Volkov, L.A. Tomachynski, V.I. Pehn'o, M.Yu. Antipin, Z.A. Starikova, Inorg. Chem. 44 (2005) 822-824.

[139] L.A. Tomachynski, V.Ya. Chernii, S.V. Volkov, J. Porphyrins Phthalocyanines 6 (2002) $114-121$.

[140] K. Schweiger, H. Hückstädt, H. Homborg, Z. Anorg. Allg. Chem. 624 (1998) 44-50.

[141] M. Hanack, H. Heckmann, Eur. J. Inorg. Chem. (1998) 367-373.

[142] M. Plater, A. Jeremiah, G. Bourhill, J. Chem. Soc., Perkin Trans. 1 (2002) 91-96.

[143] J.R. Sabin, O.A. Varzatskii, Y.Z. Voloshin, Z.A. Starikova, V.V. Novikov, V.N. Nemykin, Inorg. Chem., 51 (2012) 8362-8372.

[144] S.J. Dammer, P.V. Solntsev, J.R. Sabin, V.N. Nemykin, Inorg. Chem. 52 (2013) 94969510.

[145] S. Misumi, K. Kasuga, Nippon Kagaku Zasshi 92 (1971) 335-338.

[146] C. Clarisse, M.T. Riou, Inorg. Chim. Acta 130 (1987) 139-144.

[147] K.L. Trojan, J.L. Kendall, K.D. Kepler, W.E. Hatfield, Inorg. Chim. Acta 198-200 (1992) 795-804. 
[148] L.G. Tomilova, E.V. Chernykh, N.T. Ioffe, E.A. Luk'yanets, Zh. Obshch. Khim. 53 (1983) 2594-2601 (in Russian).

[149] D. Battisti, L. Tomilova, R. Aroca, Chem. Mater. 4 (1992) 1323-1328.

[150] L.G. Tomilova, E.V. Chernykh, V.I. Gavrilov, I.V. Shelepin, V.M. Derkacheva, E.A. Luk'yanets, Zh. Obshch. Khim. 52 (1982) 2606-2611 (in Russian).

[151] L.G. Tomilova, E.V. Chernykh, T.B. Nikolaeva, V.V. Zelentsov, E.A. Luk'yanets, Zh. Obshch. Khim. 54 (1984) 1678-1679 (in Russian).

[152] L.G. Tomilova, K.M. Dyumaev, O.P. Tkachenko, Izv. Akad. Nauk, Ser. Khim. (1995) 425-430 (in Russian).

[153] M.A. Ovseevich, L.G. Tomilova, E.G. Kogan, N.S. Zefirov, Mendeleev Commun. 8 (1998) 186-187.

[154] V.E. Pushkarev, A.V. Ivanov, I.V. Zhukov, E.V. Shulishov, Yu.V. Tomilov, Russ. Chem. Bull., Int. Ed. 53 (2004) 554-560.

[155] R. Słota, G. Dyrda, M. Hofer, G. Mele, E. Bloise, R. del Sole, Molecules 17 (2012) $10738-10753$.

[156] L.A. Lapkina, E. Niskanen, H. Rönkkömäki, V.E. Larchenko, E.O. Tolkacheva, K.I. Popov, A.Yu. Tsivadze, Koord. Khim. 24 (1998) 639-640 (in Russian).

[157] C. Ercolani, A.M. Paoletti, G. Pennesi, G. Rossi, A. Chiesi-Villa, C. Rizzoli, J. Chem. Soc., Dalton Trans. (1990) 1971-1977.

[158] M. Pia Donzello, C. Ercolani, A. Chiesi-Villa, C. Rizzoli, Inorg. Chem. 37 (1998) 13471351.

[159] L.G. Tomilova, E.V. Chernykh, E.A. Luk'yanets, Zh. Obshch. Khim. 55 (1985) 2631 (in Russian). 
[160] L.G. Tomilova, E.V. Chernykh, E.A. Luk'yanets, Zh. Obshch. Khim. 57 (1987) 2368-2375 (in Russian).

[161] H. Konami, M. Hatano, A. Tajiri, Chem. Phys. Lett. 160 (1989) 163-167.

[162] N. Koike, H. Uekusa, Y. Ohashi, C. Harnoode, F. Kitamura, T. Ohsaka, K. Tokuda, Inorg. Chem. 35 (1996) 5798-5804.

[163] M. Safarpour Haghighi, H. Homborg, Z. Naturforsch. 46b (1991) 1641-1649.

[164] M. Safarpour Haghighi, H. Homborg, Z. Anorg. Allg. Chem. 620 (1994) 1278-1284.

[165] K. Kasuga, H. Morimoto, M. Ando, Inorg. Chem. 25 (1986) 2478-2479.

[166] J. Janczak, R. Kubiak, A. Jezierski, Inorg. Chem. 38 (1999) 2043-2049.

[167] J. Janczak, Y.M. Idemori, Inorg. Chim. Acta 325 (2001) 85-93.

[168] L.G. Tomilova, N.A. Ovchinnikova, E.A. Luk'yanets, Zh. Obshch. Khim. 57 (1987) 21002104 (in Russian).

[169] N.A. Ovchinnikova, L.G. Tomilova, N.B. Seregina, V.V. Minin, G.M. Larin, E.A. Luk'yanets, Zh. Obshch. Khim. 62 (1992) 1631-1639 (in Russian).

[170] E.G. Kogan, A.V. Ivanov, L.G. Tomilova, N.S. Zefirov, Mendeleev Commun. 12 (2002) 54-55.

[171] J. Jiang, R.C.W. Liu, T.C.W. Mak, T.W.D. Chan, D.K.P. Ng, Polyhedron 16 (1997) 515520.

[172] J. Jiang, J. Xie, M.T.M. Choi, Y. Yan, S. Sun, D.K.P. Ng, J. Porphyrins Phthalocyanines 3 (1999) 322-328.

[173] I.P. Kalashnikova, I.V. Zhukov, L.G. Tomilova, N.S. Zefirov, Izv. Akad. Nauk, Ser. Khim. (2003) 1621-1626 (in Russian). 
[174] K. Binnemans, J. Sleven, S. De Feyter, F.C. De Schryver, B. Donnio, D. Guillon, Chem. Mater. 15 (2003) 3930-3938.

[175] W. Liu, J. Jiang, D. Du, D.P. Arnold, Aust. J. Chem. 53 (2000) 131-135.

[176] J. Sleven, C. Görller-Walrand, K. Binnemans, Mater. Sci. Eng. C 18 (2001) 229-238.

[177] F. Maeda, K. Hatsusaka, K. Ohta, M. Kimura, J. Mater. Chem. 13 (2003) 243-251.

[178] Z. Belarbi, C. Sirlin, J. Simon, J.-J. Andre, J. Phys. Chem. 93 (1989) 8105-8110.

[179] Y. Bian, J. Jiang, Y. Tao, M.T.M. Choi, R. Li, A.C.H. Ng, P. Zhu, N. Pan, X. Sun, D.P. Arnold, Z.-Y. Zhou, H.-W. Li, T.C.W. Mak, D.K.P. Ng, J. Am. Chem. Soc. 125 (2003) 1225712267.

[180] Ö. Bekaroğlu, J. Porphyrins Phthalocyanines 4 (2000) 465-473.

[181] T. Toupance, V. Ahsen, J. Simon, J. Am. Chem. Soc. 116 (1994) 5352-5361.

[182] T. Toupance, P. Bassoul, L. Mineau, J. Simon, J. Phys. Chem. 100 (1996) 11704-11710.

[183] R. Li, P. Ma, S. Dong, X. Zhang, Y. Chen, X. Li, J. Jiang, Inorg. Chem. 46 (2007) 1139711404.

[184] K. Hatsusaka, M. Kimura, K. Ohta, Bull. Chem. Soc. Jpn. 76 (2003) 781-787.

[185] I.P. Kalashnikova, I.V. Zhukov, L.G. Tomilova, N.S. Zefirov, Izv. Akad. Nauk, Ser. Khim. (2005) 2031-2035 (in Russian).

[186] K. Ban, K. Nishizawa, K. Ohta, A.M. Van de Craats, J.M. Warman, I. Yamamoto, H. Shirai, J. Mater. Chem. 11 (2001) 321-331.

[187] A.G. Gürek, T. Basova, D. Lineau, C. Lebrun, E. Kol’tsov, A.K. Hassan, V. Ahsen, Inorg. Chem. 45 (2006) 1667-1676.

[188] D. Atilla, N. Kilinç, F. Yuksel, A.G. Gürek, Z.Z. Öztürk, V. Ahsen, Synth. Met. 159 (2009) 13-21. 
[189] K.M. Kadish, T. Nakanishi, A. Gürek, V. Ahsen, I. Yilmaz, J. Phys. Chem. B 105 (2001) 9817-9821.

[190] G. Lu, M. Bai, R. Li, X. Zhang, C. Ma, P.-C. Lo, D.K.P. Ng, J. Jiang, Eur. J. Inorg. Chem. (2006) 3703-3709.

[191] I.P. Kalashnikova, I.V. Zhukov, T.V. Magdesieva, K.P. Butin, L.G. Tomilova, N.S. Zefirov, Izv. Akad. Nauk, Ser. Khim. (2001) 1238-1241 (in Russian).

[192] T. Yonekura, T. Ohsaka, F. Kitamura, K. Tokuda, J. Porphyrins Phthalocyanines 9 (2005) $54-58$.

[193] A. Yazıcı, N. Ünüş, A. Altındal, B. Salih, Ö. Bekaroğlu, Dalton Trans. 41 (2012) 37733779.

[194] H. Zhou, K. Wang, D. Qi, J. Jiang, Dalton Trans. 43 (2014) 1699-1705.

[195] M.G. Gal'pern, T.D. Talismanova, L.G. Tomilova, E.A. Luk'yanets, Zh. Obshch. Khim. 55 (1985) 1099-1106 (in Russian).

[196] T.V. Dubinina, V.E. Pushkarev, S.A. Trashin, K.V. Paramonova, L.G. Tomilova, Macroheterocycles 5 (2012) 366-370.

[197] T.V. Dubinina, L.G. Tomilova, N.S. Zefirov, Russ. Chem. Rev. 82 (2013) 865-895.

[198] T. Nyokong, F. Furuya, N. Kobayashi, D. Du, W. Liu, J. Jiang, Inorg. Chem. 39 (2000) $128-135$.

[199] E.I. Kovshev, E.A. Luk'yanets, Zh. Organ. Khim. 7 (1971) 696-699 (in Russian).

[200] R. Aroca, R.E. Clavijo, C.A. Jennings, G.J. Kovacs, J.M. Duff, R.O. Loutfy, Spectrochim. Acta 45A (1989) 957-962.

[201] A. Iwase, C. Harnoode, Y. Kameda, J. Alloys Compounds 192 (1993) 280-283. 
[202] K. Takahashi, Y. Tomita, Y. Hada, K. Tsubota, M. Handa, K. Kasuga, K. Sogabe, T. Tokii, Chem. Lett. 21 (1992) 759-762.

[203] R. Wang, R. Li, Y. Bian, C.-F. Choi, D.K.P. Ng, J. Dou, D. Wang, P. Zhu, C. Ma, R.D. Hartnell, D.P. Arnold, J. Jiang, Chem. Eur. J. 11 (2005) 7351-7357.

[204] Y. Gao, R. Li, S. Dong, Y. Bian, J. Jiang, Dalton Trans. 39 (2010) 1321-1327.

[205] W. Lv, P. Zhu, Y. Bian, C. Ma, X. Zhang, J. Jiang, Inorg. Chem. 49 (2010) 6628-6635.

[206] M. Gonidec, I. Krivokapic, J. Vidal-Gancedo, E.S. Davies, J. McMaster, S.M. Gorun, J. Veciana, Inorg. Chem. 52 (2013) 4464-4471.

[207] L.-C. Liu, C.-C. Lee, A.T. Hu, J. Porphyrins Phthalocyanines 5 (2001) 806-807.

[208] L.-C. Liu, A.T. Hu, J. Porphyrins Phthalocyanines 7 (2003) 565-571.

[209] L.A. Lapkina, E. Niskanen, H. Rönkkömäki, V.E. Larchenko, K.I. Popov, A.Yu. Tsivadze, J. Porphyrins Phthalocyanines 4 (2000) 587-589.

[210] Yu.G. Gorbunova, L.A. Lapkina, S.V. Golubeva, V.E. Larchenko, A.Yu. Tsivadze, Mendeleev Commun. 11 (2001) 214-215.

[211] L.A. Lapkina, Yu.G. Gorbunova, S.E. Nefedov, A.Yu. Tsivadze, Zefirov, Izv. Akad. Nauk, Ser. Khim. (2003) 1548-1551 (in Russian).

[212] Yu.G. Gorbunova, L.A. Lapkina, A.G. Martynov, I.V. Biryukova, A.Yu. Tsivadze, Koord. Khim. 30 (2004) 263-270 (in Russian).

[213] A.G. Martynov, Yu.G. Gorbunova, I.V. Khrapova, S.G. Sakharov, A.Yu. Tsivadze, Zh. Neorg. Khim. 47 (2002) 1616-1622 (in Russian).

[214] F. Castaneda, C. Piechocki, V. Plichon, J. Simon, J. Vaxiviere, Electrochim. Acta 31 (1986) 131-133.

[215] T. Komatsu, K. Ohta, T. Fujimoto, I. Yamamoto, J. Mater. Chem. 4 (1994) 533-536. 
[216] T. Komatsu, K. Ohta, T. Watanabe, H. Ikemoto, T. Fujimoto, I. Yamamoto, J. Mater. Chem. 4 (1994) 537-540.

[217] C. Piechocki, J. Simon, J.-J. André, D. Guillon, P. Petit, A. Skoulios, P. Weber, Chem. Phys. Lett. 122 (1985) 124-128.

[218] S. Besbes, V. Plichon, J. Simon, J. Vaxiviere, J. Electroanal. Chem. 237 (1987) 61-68.

[219] V.E. Pushkarev, A.Yu. Tolbin, N.E. Borisova, S.A. Trashin, L.G. Tomilova, Eur. J. Inorg. Chem. (2010) 5254-5262.

[220] V.E. Pushkarev, A.Yu. Tolbin, A.V. Ryabova, L.G. Tomilova, Mendeleev Commun. 19 (2009) 24-26.

[221] A.Yu. Tolbin, V.E. Pushkarev, G.F. Nikitin, L.G. Tomilova, Tetrahedron Lett. 50 (2009) $4848-4850$.

[222] V.E. Pushkarev, A.Yu. Tolbin, F.E. Zhurkin, N.E. Borisova, S.A. Trashin, L.G. Tomilova, N.S. Zefirov, Chem. Eur. J. 18 (2012) 9046-9055.

[223] V.V. Kalashnikov, V.E. Pushkarev, L.G. Tomilova, Mendeleev Commun. 21 (2011) 9293.

[224] V.V. Kalashnikov, L.G. Tomilova, Macroheterocycles 4 (2011) 209-210.

[225] V.V. Kalashnikov, V.E. Pushkarev, Z.A. Starikova, L.G. Tomilova, Dyes Pigm. 105 (2014) 216-222.

[226] V.V. Kalashnikov, V.E. Pushkarev, L.G. Tomilova, Russ. Chem. Rev. 83 (2014) 657-675.

[227] V.E. Pushkarev, V.V. Kalashnikov, S.A. Trashin, N.E. Borisova, L.G. Tomilova, N.S. Zefirov, Dalton Trans. 42 (2013) 12083-12086.

[228] E.N. Tarakanova, P.A. Tarakanov, V.E. Pushkarev, L.G. Tomilova, J. Porphyrins Phthalocyanines 18 (2014) 149-154. 
[229] K.M. Kadish, G. Moninot, Y. Hu, D. Dubois, A. Ibnlfassi, J.-M. Barbe, R. Guilard, J. Am. Chem. Soc. 115 (1993) 8153-8166.

[230] L.G. Tomilova, K.M. Dyumaev, Mendeleev Commun. 5 (1995) 109-110.

[231] F. Guyon, A. Pondaven, P. Guenot, M. L’Her, Inorg. Chem. 33 (1994) 4787-4793.

[232] M. Ikeda, M. Takeuchi, S. Shinkai, F. Tani, Y. Naruta, Bull. Chem. Soc. Jpn. 74 (2001) 739-746.

[233] J.W. Buchler, A. De Cian, J. Fischer, M. Kihn-Botulinski, H. Paulus, R. Weiss, J. Am. Chem. Soc. 108 (1986) 3652-3659.

[234] J.W. Buchler, B. Scharbert, J. Am. Chem. Soc. 110 (1988) 4272-4276.

[235] A.G. Montalban, S.L.J. Michel, S.M. Baum, B.J. Vesper, A.J.P. White, D.J. Williams, A.G.M. Barrett, B.M. Hoffman, J. Chem. Soc., Dalton Trans. (2001) 3269-3272.

[236] K. Kim, W.S. Lee, H.-J. Kim, S.-H. Cho, G.S. Girolami, P.A. Gorlin, K.S. Suslick, Inorg. Chem. 30 (1991) 2652-2656.

[237] J.P. Collman, J.L. Kendall, J.L. Chen, T.A. Eberspacher, C.R. Moylan, Inorg. Chem. 36 (1997) 5603-5608.

[238] O. Ohno, N. Ishikawa, H. Matsuzawa, Y. Kaizu, H. Kobayashi, J. Phys. Chem. 93 (1989) $1713-1718$.

[239] G.A. Spyroulias, D. De Montauzon, A. Maisonat, R. Poilblanc, A.G. Coutsolesos, Inorg. Chim. Acta 275-276 (1998) 182-191.

[240] I.S. Kirin, P.N. Moskalev, N.V. Ivannikova, Russ. J. Inorg. Chem. 12 (1967) 497-498.

[241] K. Kasuga, M. Ando, H. Morimoto, K. Isa, Chem. Lett. 15 (1986) 1095-1098.

[242] M. M’Sadak, J. Roncali, F. Garnier, J. Chim. Phys. 83 (1986) 211-216. 
[243] T.N. Sokolova, T.N. Lomova, V.V. Morozov, B.D. Berezin, Koord. Khim. 20 (1994) 637640 (in Russian).

[244] S.I. Troyanov, L.A. Lapkina, V.E. Larchenko, A.Yu. Tsivadze, Dokl. Akad. Nauki 367 (1999) 644-648.

[245] J. Janczak, R. Kubiak, J. Chem. Soc., Dalton Trans. (1993) 3809-3812.

[246] J. Janczak, R. Kubiak, J. Richter, H. Fuess, Polyhedron 18 (1999) 2775-2780.

[247] K. Benihya, M. Mossoyan-Déneux, H. Friedemann, N. Boucharat, G. Terzian, Eur. J. Inorg. Chem. (2000) 1771-1779.

[248] I.V. Nefedova, Yu.G. Gorbunova, S.G. Sakharov, A.Yu. Tsivadze, Zh. Neorg. Khim. 50 (2005) 204-212 (in Russian).

[249] A.G. Martynov, I.V. Nefedova, Yu.G. Gorbunova, A.Yu. Tsivadze, Mendeleev Commun. 17 (2007) 66-67.

[250] K. Takahashi, M. Itoh, Y. Tomita, K. Nojima, K. Kasuga, K. Isa, Chem. Lett. 22 (1993) 1915-1918.

[251] K. Takahashi, J. Shimoda, M. Itoh, Y. Fuchita, H. Ōkawa, Chem. Lett. 27 (1998) 173-174. [252] V.E. Pushkarev, M.O. Breusova, S.E. Nefedov, L.G. Tomilova, Mendeleev Commun. 17 (2007) 220-221.

[253] V.E. Pushkarev, E.V. Shulishov, Yu.V. Tomilov, L.G. Tomilova, Mendeleev Commun. 17 (2007) 218-219.

[254] J. Kan, Y. Chen, D. Qi, Y. Liu, J. Jiang, Adv. Mater. 24 (2012) 1755-1758.

[255] F. Guyon, A. Pondaven, M. L’Her, J. Chem. Soc., Chem. Commun. (1994) 1125-1126.

[256] N. Pan, Y. Bian, T. Fukuda, M. Yokoyama, R. Li, S. Neya, J. Jiang, N. Kobayashi, Inorg. Chem. 43 (2004) 8242-8244. 
[257] T.V. Dubinina, D.V. Dyumaeva, S.A. Trashin, M.V. Sedova, A.S. Dudnik, N.E. Borisova, L.G. Tomilova, N.S. Zefirov, Dyes Pigm. 96 (2013) 699-704.

[258] N. Ishikawa, T. Okubo, Y. Kaizu, Inorg. Chem., 38 (1999) 3173-3181.

[259] I. Chambrier, D.L. Hughes, J.C. Swarts, B. Isare, M.J. Cook, Chem. Commun. (2006) $3504-3506$.

[260] I. Chambrier, G.F. White, M.J. Cook, Chem. Eur. J. 13 (2007) 7608-7618.

[261] M.J. Cook, I. Chambrier, G.F. White, E. Fourie, J.C. Swarts, Dalton Trans. (2009) P. 1136-1144.

[262] E. Fourie, J.C. Swarts, I. Chambrier, M.J. Cook, Dalton Trans. (2009) 1145-1154.

[263] Y. Liu, K. Shigehara, M. Hara, A. Yamada, J. Am. Chem. Soc. 113 (1991) 440-443.

[264] N.B. Subbotin, V.N. Nemykin, Y.Z. Voloshin, Mendeleev Commun. (1993) 121-122.

[265] V.N. Nemykin, N.B. Subbotin, N.A. Kostromina, S.V. Volkov, Mendeleev Commun. (1995) 71-72.

[266] V.N. Nemykin, N. Kobayashi, T. Nonomura, E.A. Luk'yanets, Chem. Lett. (2000) 184185.

[267] N. Kobayashi, T. Ashida, T. Osa, Chem. Lett. (1992) 2031-2032.

[268] L.G. Tomilova, Yu.G. Gorbunova, M.L. Rodríguez-Méndez, J.A. De Saja, Mendeleev Commun. 4 (1994) 127-128.

[269] N. Ishikawa, Y. Kaizu, Chem. Lett., 27 (1998) 183-184.

[270] N. Ishikawa, Y. Kaizu, J. Phys. Chem. A 104 (2000) 10009-10016.

[271] K. Wang, D. Qi, H. Wang, W. Cao, W. Li, T. Liu, C. Duan, J. Jiang, Chem. Eur. J. 19 (2013) 11162-11166. 
[272] N. Sheng, R. Li, C.-F. Choi, W. Su, D.K.P. Ng, X. Cui, K. Yoshida, N. Kobayashi, J. Jiang, Inorg. Chem. 45 (2006) 3794-3802.

[273] Yu.G. Gorbunova, E.O. Tolkacheva, A.Yu. Tsivadze, Koord. Khim. 22 (1996) 944-946 (in Russian).

[274] N.B. Subbotin, L.G. Tomilova, E.V. Chernykh, N.A. Kostromina, E.A. Luk'yanets, Zh. Obshch. Khim. 56 (1986) 232-233 (in Russian).

[275] J. Jiang, W. Liu, W.-F. Law, J. Lin, D.K.P. Ng, Inorg. Chim. Acta 268 (1998) 141-144.

[276] Y. Bian, R. Wang, J. Jiang, C.-H. Lee, J. Wang, D.K.P. Ng, Chem. Commun. (2003) 1194-1195.

[277] Y. Bian, R. Wang, D. Wang, P. Zhu, R. Li, J. Dou, W. Liu, C.-F. Choi, H.-S. Chan, C. Ma, D.K.P. Ng, J. Jiang, Helv. Chim. Acta 87 (2004) 2581-2596.

[278] D. Pernin, K. Haberroth, J. Simon, J. Chem. Soc., Perkin Trans. 1 (1997) 1265-1266.

[279] S. Abdurrahmanoglu, A. Altindal, A.R. Özkaya, M. Bulut, Ö. Bekaroglu, Chem. Commun. (2004) 2096-2097.

[280] S. Abdurrahmanoglu, A.R. Özkaya, M. Bulut, Ö. Bekaroglu, J. Chem. Soc., Dalton Trans. (2004) 4022-4029.

[281] T. Ceyhan, A. Altindal, A.R. Özkaya, M.K. Erbil, Ö. Bekaroğlu, Polyhedron 26 (2007) 73-84.

[282] T. Ceyhan, M. Korkmaz, M.K. Erbil, Ö. Bekaroğlu, J. Porphyrins Phthalocyanines 9 (2005) 423-429.

[283] P. Şen, F. Dumludağ, B. Salih, A.R. Özkaya, Ö. Bekaroğlu, Synth. Met. 161 (2011) 12451254. 
[284] Y. Bian, X. Chen, D. Wang, C.-F. Choi, Y. Zhou, P. Zhu, D.K.P. Ng, J. Jiang, Y. Weng, X. Li, Chem. Eur. J. 13 (2007) 4169-4177.

[285] B. Ballesteros, G. de la Torre, A. Shearer, A. Hausmann, M. Ángeles Herranz, D.M. Guldi, T. Torres, Chem. Eur. J. 16 (2010) 114-125.

[286] L.-C. Liu, C.-H. Tai, A. T. Hu, T.-H. Wei, J. Porphyrins Phthalocyanines 8 (2004) 984988.

[287] A. Pondaven, Y. Cozien, M. L'Her, New J. Chem. 15 (1991) 515-516.

[288] C. Cadiou, A. Pondaven, M. L’Her, P. Jéhan, P. Guenot, J. Org. Chem. 64 (1999) 90469050.

[289] A. Mentec, A. Pondaven, J.-M. Kerbaol, M. L’Her, Inorg. Chem. Commun. 9 (2006) 810813.

[290] N. Ishikawa, Y. Kaizu, Chem. Phys. Lett. 203 (1993) 472-476.

[291] N. Ishikawa, Y. Kaizu, Coord. Chem. Rev. 226 (2002) 93-101.

[292] H. Zhang, R. Wang, P. Zhu, Z. Lai, J. Han, C.-F. Choi, D. K. P. Ng, X. Cui, C. Ma, J. Jiang, Inorg. Chem. 43 (2004) 4740-4742.

[293] H. Zhang, Z. Lai, X. Cui, J. Jiang, K. Machida, J. Alloys Compounds 408-412 (2006) $1041-1045$.

[294] V.E. Pushkarev, E.V. Shulishov, Yu.V. Tomilov, L.G. Tomilova, Tetrahedron Lett. 48 (2007) 5269-5273.

[295] M. Bouvet, J. Simon, Chem. Phys. Lett. 172 (1990) 299-302.

[296] N. Ishikawa, O. Ohno, Y. Kaizu, Chem. Phys. Lett. 180 (1991) 51-56.

[297] T. Komeda, H. Isshiki, J. Liu, K. Katoh, M. Shirakata, B.K. Breedlove, M. Yamashita, ACS Nano 7 (2013) 1092-1099. 
[298] R. Wang, Y. Li, R. Li, D.Y.Y. Cheng, P. Zhu, D.K.P. Ng, M. Bao, X. Cui, N. Kobayashi, J. Jiang, Inorg. Chem. 44 (2005) 2114-2120.

[299] J. Jiang, M. T. M. Choi, W.-F. Law, J. Chen, D.K.P. Ng, Polyhedron 17 (1998) 39033908.

[300] M. Bai, M. Bao, C. Ma, D.P. Arnold, M.T.M. Choi, D.K.P. Ng, J. Jiang, J. Mater. Chem. 13 (2003) 1333-1339.

[301] F. Lu, X. Sun, R. Li, D. Liang, P. Zhu, C.-F. Choi, D.K.P. Ng, T. Fukuda, N. Kobayashi, M. Bai, C. Ma, J. Jiang, New J. Chem. 28 (2004) 1116-1122.

[302] K.P. Birin, Yu.G. Gorbunova, A.Yu. Tsivadze, J. Porphyrins Phthalocyanines 13 (2009) 283-290.

[303] K.P. Birin, Yu.G. Gorbunova, A.Yu. Tsivadze, Dalton Trans. 41 (2012) 9672-9681.

[304] D. Chabach, M. Tahiri, A. De Cian, J. Fischer, R. Weiss, M. El Malouli Bibout, J. Am. Chem. Soc. 117 (1995) 8548-8556.

[305] J. Jiang, T.C.W. Mak, D.K.P. Ng, Chem. Ber. 129 (1996) 933-936.

[306] R. Wang, R. Li, Y. Li, X. Zhang, P. Zhu, P.-C. Lo, D.K.P. Ng, N. Pan, C. Ma, N. Kobayashi, J. Jiang, Chem. Eur. J. 12 (2006) 1475-1485.

[307] Y. Zhou, Y. Zhang, H. Wang, J. Jiang, Y. Bian, A. Muranaka, N. Kobayashi, Inorg. Chem. 48 (2009) 8925-8933.

[308] Q. Liu, Y. Li, H. Liu, Y. Chen, X. Wang, Y. Zhang, X. Li, J. Jiang, J. Phys. Chem. C 111 (2007) 7298-7301.

[309] M.O. Liu, A.T. Hu, J. Organomet. Chem. 689 (2004) 2450-2455.

[310] T. Gross, F. Chevalier, J.S. Lindsey, Inorg. Chem. 40 (2001) 4762-4774. 
[311] T.-H. Tran-Thi, T.A. Mattioli, D. Chabach, A. De Cian, R. Weiss, J. Phys. Chem. 98 (1994) 8279-8288.

[312] X. Wu, W. Lv, Q. Wang, H. Wang, X. Zhang, J. Jiang, Dalton Trans. 40 (2011) 107-113.

[313] W. Cao, H. Wang, X. Wang, H.K. Lee, D.K.P. Ng, J. Jiang, Inorg. Chem. 51 (2012) 92659272.

[314] X. Zhang, A. Muranaka, W. Lv, Y. Zhang, Y. Bian, J. Jiang, N. Kobayashi, Chem. Eur. J. 14 (2008) 4667-4674.

[315] R. Guilard, J.-M. Barbe, A. Ibnlfassi, A. Zrineh, V.A. Adamian, K.M. Kadish, Inorg. Chem. 34 (1995) 1472-1481.

[316] J. Jiang, D. Du, M.T.M. Choi, J. Xie, D.K.P. Ng, Chem. Lett. 28 (1999) 261-262.

[317] J. Jiang, W. Liu, K.-L. Cheng, K.-W. Poon, D.K.P. Ng, Eur. J. Inorg. Chem. (2001) 413417.

[318] F. Furuya, N. Kobayashi, Y. Bian, J. Jiang, Chem. Lett. 30 (2001) 944-945.

[319] J. Jiang, Y. Bian, F. Furuya, W. Liu, M.T.M. Choi, N. Kobayashi, H.-W. Li, Q. Yang, T.C.W. Mak, D.K.P. Ng, Chem. Eur. J. 7 (2001) 5059-5069.

[320] G.A. Spyroulias, A.G. Coutsolesos, C.P. Raptopoulou, A. Terzis, Inorg. Chem. 34 (1995) $2476-2479$.

[321] G.A. Spyroulias, C.P. Raptopoulou, D. De Montauzon, A. Mari, R. Poilblanc, A. Terzis, A.G. Coutsolesos, Inorg. Chem. 38 (1999) 1683-1696.

[322] J. Otsuki, Yu. Komatsu, D. Kobayashi, M. Asakawa, K. Miyake, J. Am. Chem. Soc. 132 (2010) 6870-6871.

[323] N. Ishikawa, T. Iino, Y. Kaizu, J. Am. Chem. Soc. 124 (2002) 11440-11447. 
[324] D. Gryko, J. Li, J.R. Diers, K.M. Roth, D.F. Bocian, W.G. Kuhr, J.S. Lindsey, J. Mater. Chem. 11 (2001) 1162-1180.

[325] N. Ishikawa, Y. Kaizu, Chem. Phys. Lett. 228 (1994) 625-632.

[326] W. Liu, J. Jiang, N. Pan, D.P. Arnold, Inorg. Chim. Acta 310 (2000) 140-146.

[327] N. Ishikawa, T. Iino, Y. Kaizu, J. Phys. Chem. A 106 (2002) 9543-9550.

[328] N. Ishikawa, T. Iino, Y. Kaizu, J. Phys. Chem. A 107 (2003) 7879-7884.

[329] Y. Chen, W. Su, M. Bai, J. Jiang, X. Li, Y. Liu, L. Wang, S. Wang, J. Am. Chem. Soc. 127 (2005) 15700-15701.

[330] Y. Chen, R. Li, R. Wang, P. Ma, S. Dong, Y. Gao, X. Li, J. Jiang, Langmuir 23 (2007) $12549-12554$.

[331] Y. Gao, P. Ma, Y. Chen, Y. Zhang, Y. Bian, X. Li, J. Jiang, C. Ma, Inorg. Chem. 48 (2009) 45-54.

[332] A.G. Martynov, O.V. Zubareva, Yu.G. Gorbunova, S.G. Sakharov, A.Yu. Tsivadze, Inorg. Chim. Acta 362 (2009) 11-18.

[333] Y. Bian, L. Li, D. Wang, C.-F. Choi, D.Y.Y. Cheng, P. Zhu, R. Li, J. Dou, R. Wang, N. Pan, D.K.P. Ng, N. Kobayashi, J. Jiang, Eur. J. Inorg. Chem. (2005) 2612-2618.

[334] P. Zhu, N. Pan, R. Li, J. Dou, Y. Zhang, D.Y.Y. Cheng, D. Wang, D.K.P. Ng, J. Jiang, Chem. Eur. J. 11 (2005) 1425-1432.

[335] A.G. Martynov, O.V. Zubareva, Yu.G. Gorbunova, S.G. Sakharov, S.E. Nefedov, F.M. Dolgushin, A.Yu. Tsivadze, Eur. J. Inorg. Chem. (2007) 4800-4807.

[336] A.G. Martynov, E.A. Safonova, Yu.G. Gorbunova, A.Yu. Tsivadze, Russ. J. Inorg. Chem. 55 (2010) 347-354. 
[337] T. Morita, K. Katoh, B.K. Breedlove, M. Yamashita, Inorg. Chem. 52 (2013) 1355513561.

[338] J. Jiang, R.L.C. Lau, T.W.D. Chan, T.C.W. Mak, D.K.P. Ng, Inorg. Chim. Acta 255 (1997) 59-64.

[339] D. Chabach, A. De Cian, J. Fischer, R. Weiss, M. El Malouli-Bibout, Angew. Chem., Int. Ed. Engl. 35 (1996) 898-899.

[340] X. Sun, X. Cui, D.P. Arnold, M.T.M. Choi, D.K.P. Ng, J. Jiang, Eur. J. Inorg. Chem. (2003) 1555-1561.

[341] N. Pan, J. Jiang, X. Cui, D.P. Arnold, J. Porphyrins Phthalocyanines 6 (2002) 347-358.

[342] J. Li, D. Gryko, R.B. Dabke, J.R. Diers, D.F. Bocian, W.G. Kuhr, J.S. Lindsey, J. Org. Chem. 65 (2000) 7379-7390.

[343] J. Jiang, W. Liu, W.-F. Law, D.K.P. Ng, Inorg. Chim. Acta 268 (1998) 49-53.

[344] M. Moussavi, A. De Cian, J. Fischer, R. Weiss, Inorg. Chem. 25 (1986) 2107-2108.

[345] X. Sun, R. Li, D. Wang, J. Dou, P. Zhu, F. Lu, C. Ma, C.-F. Choi, D.Y.Y. Cheng, D.K.P. Ng, N. Kobayashi, J. Jiang, Eur. J. Inorg. Chem. (2004) 3806-3813.

[346] K.P. Birin, Yu.G. Gorbunova, A.Yu. Tsivadze, Dalton Trans. 40 (2011) 11539-11549.

[347] J. Kan, H. Wang, W. Sun, W. Cao, J. Tao, J. Jiang, Inorg. Chem. 52 (2013) 8505-8510.

[348] J. Lu, Y. Deng, X. Zhang, N. Kobayashi, J. Jiang, Inorg. Chem. 50 (2011) 2562-2567.

[349] D.P. Arnold, J. Jiang, Chem. Lett. 28 (1999) 483-484.

[350] K.-H. Schweikart, V.L. Malinovskii, J.R. Diers, A.A. Yasseri, D.F. Bocian, W.G. Kuhr, J.S. Lindsey, J. Mater. Chem. 12 (2002) 808-828.

[351] K.-H. Schweikart, V.L. Malinovskii, A.A. Yasseri, J. Li, A.B. Lysenko, D.F. Bocian, J.S. Lindsey, Inorg. Chem. 42 (2003) 7431-7446. 


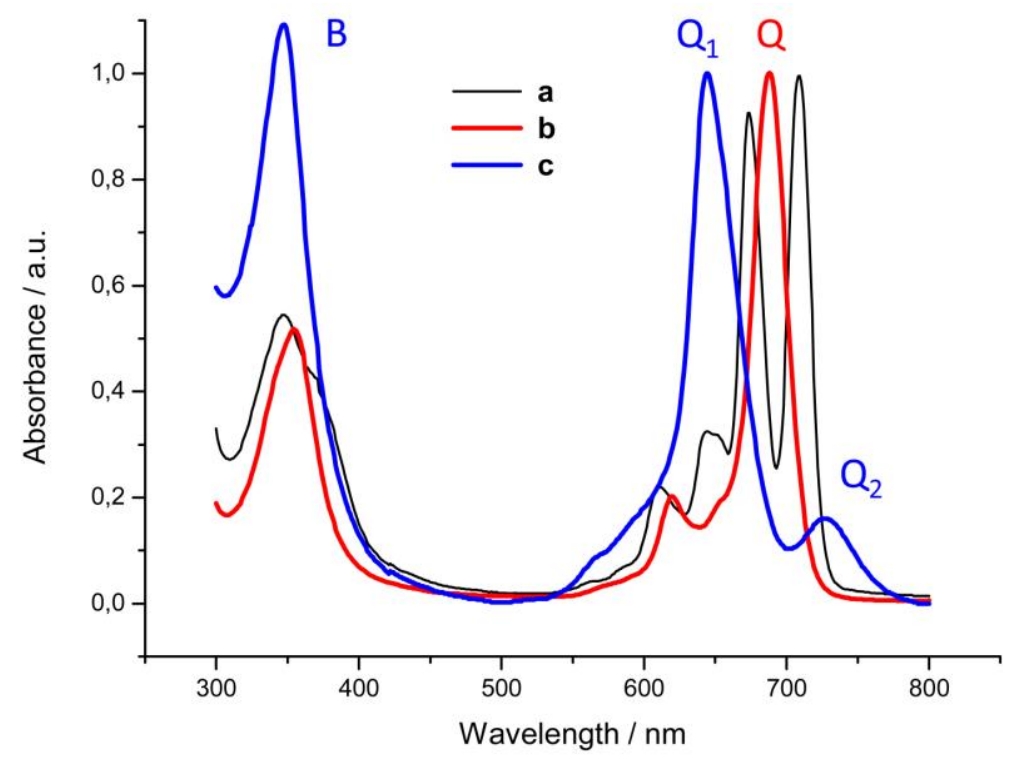

Fig. 1. UV-vis spectra of generalized free-base ligand $\mathrm{PcH}_{2}$ (a), single-decker PcLnOAc (b) and triple-decker $\mathrm{Pc}_{3} \operatorname{Ln}_{2}$ (c) compounds in solution (for $\mathrm{Ln}=\mathrm{Lu}$ ). 

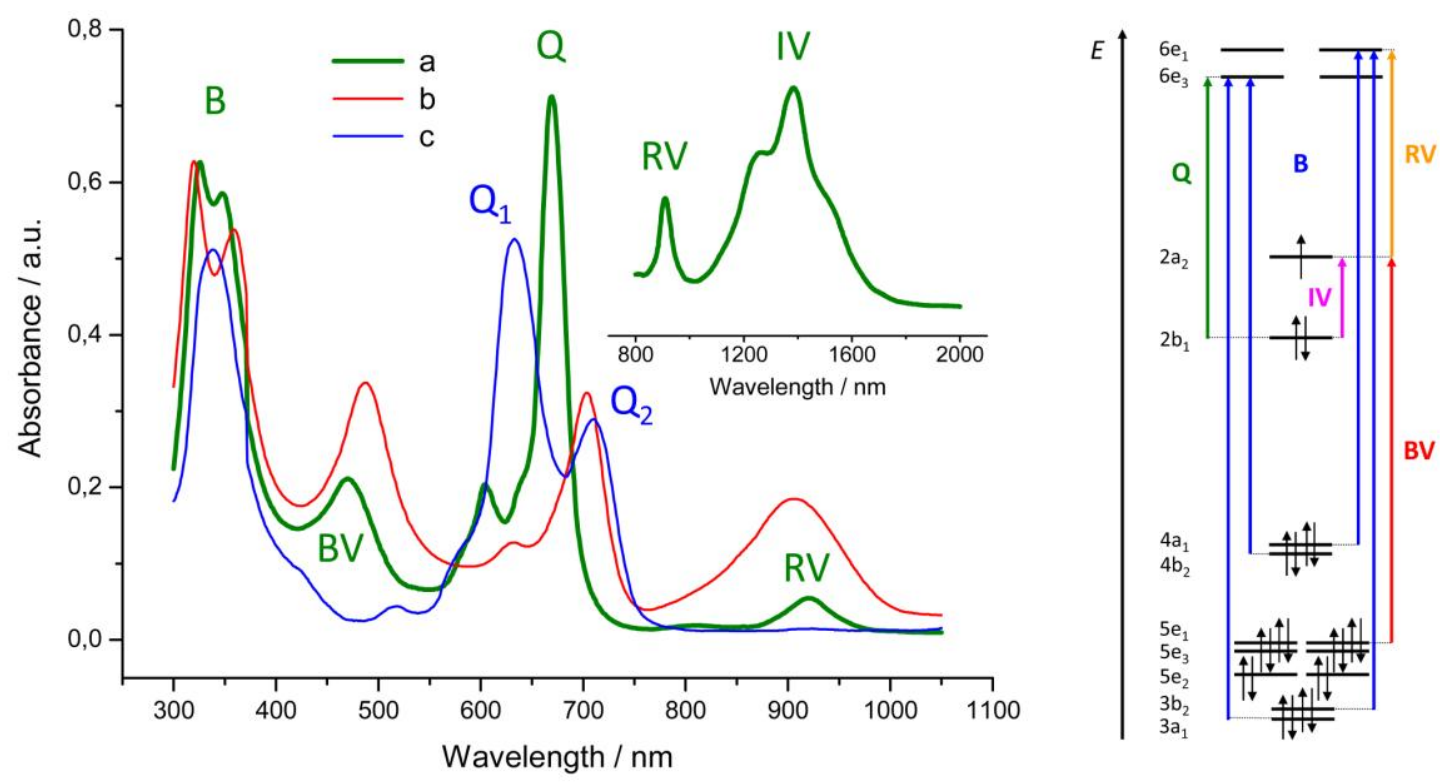

Fig. 2. Left part: UV-vis spectra of generalized double-decker $\mathrm{Pc}_{2} \mathrm{Ln}$ (for $\mathrm{Ln}=\mathrm{Lu}$ ) in neutral (a), one-electron oxidized (b) and reduced (c) states; inset shows the NIR part of the spectrum of the neutral form. Right part: schematic representation of the energetic levels and transitions with the main contributions to the correspondidng absorption bands for the general $\mathrm{Pc}_{2} \mathrm{Ln}$ neutral form in $D_{4 \mathrm{~d}}$ symmetry according to [26,27 and references therein]. 


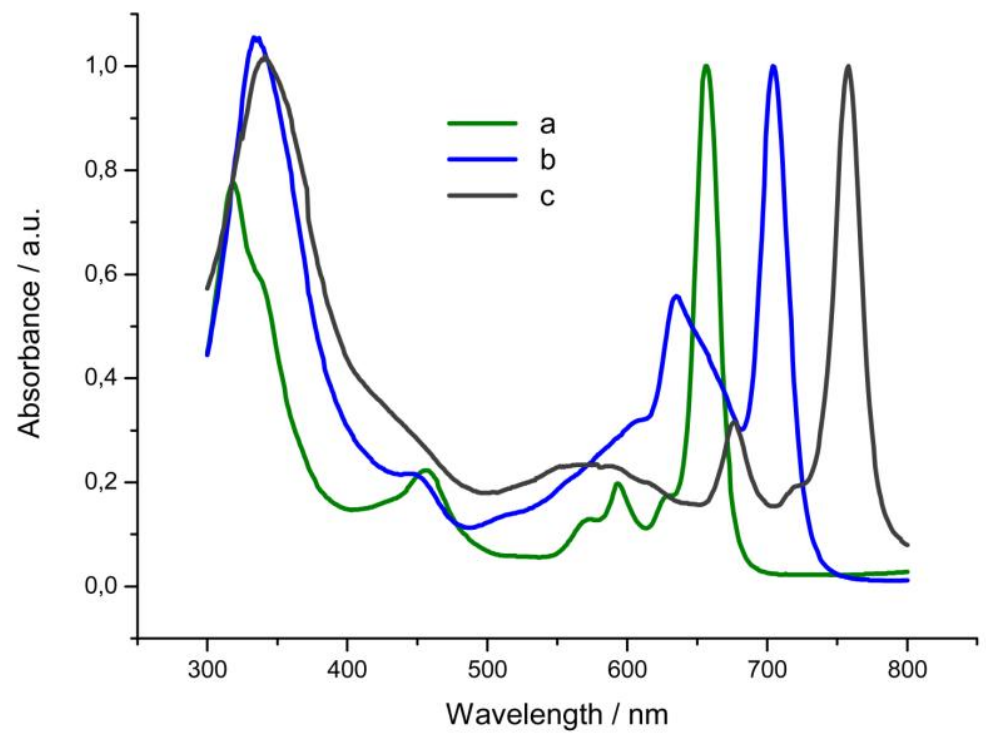

Fig. 3. UV-vis spectra of generalized double-deckers $\mathrm{Pc}_{2} \mathrm{Ln}$ (a), $P c L n N c$ (b) and $\mathrm{Nc}_{2} \mathrm{Ln}$ (c) in solution (for $\mathrm{Ln}=\mathrm{Lu}$ ). 


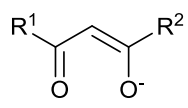

$\mathrm{R}^{1}=\mathrm{R}^{2}=\mathrm{Me}(\mathrm{acac})$, tert-Bu (dpm), Ph (dbm)

$\mathrm{R}^{1}=$ tert-Bu, $\mathrm{R}^{2}=\mathrm{C}_{3} \mathrm{~F}_{7}$ (fod)

$\mathrm{R}^{1}=\mathrm{Ph}, \mathrm{R}^{2}=\mathrm{CF}_{3}(\mathrm{btfa})$

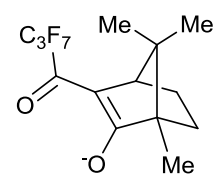

(hfbc)

Fig. 4. Structures and abbreviations of selected $\beta$-diketone anions. 


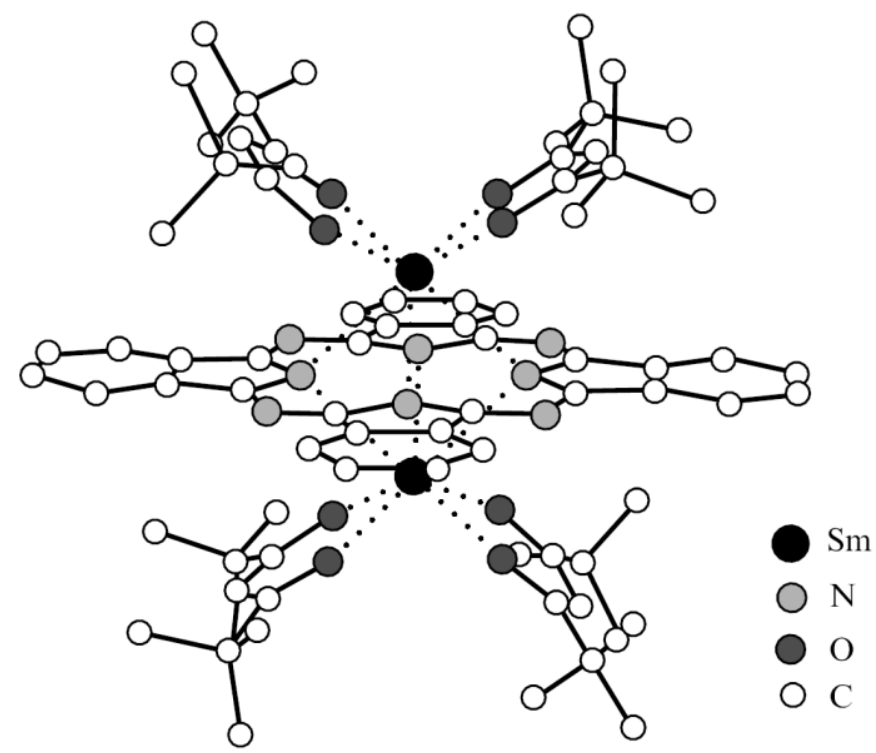

Fig. 5. X-ray structure of binuclear samarium Pc 21 [113]. 


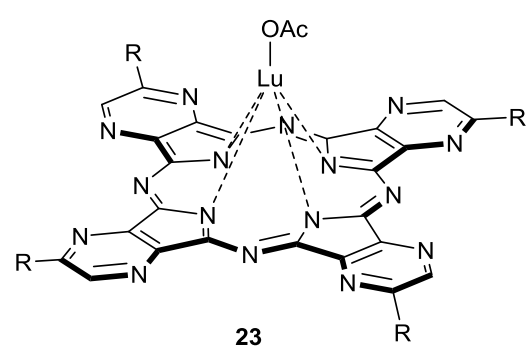

$\mathrm{R}=$ tert $-\mathrm{Bu}$

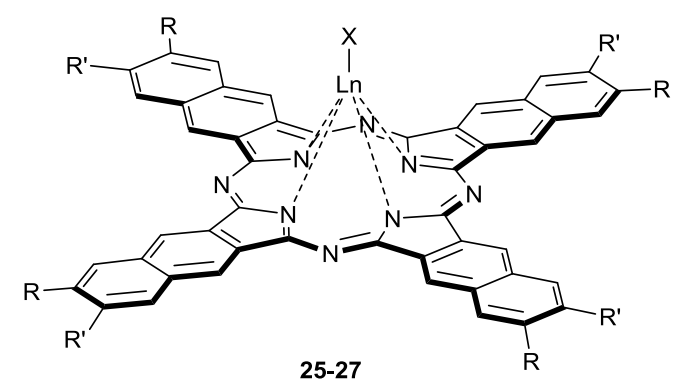

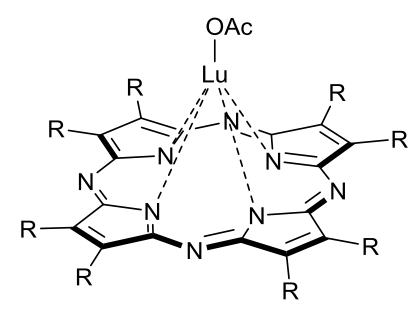

24

$\mathrm{R}=\mathrm{Ph}, \mathrm{EtS}, \mathrm{C}_{10} \mathrm{H}_{21} \mathrm{~S}$

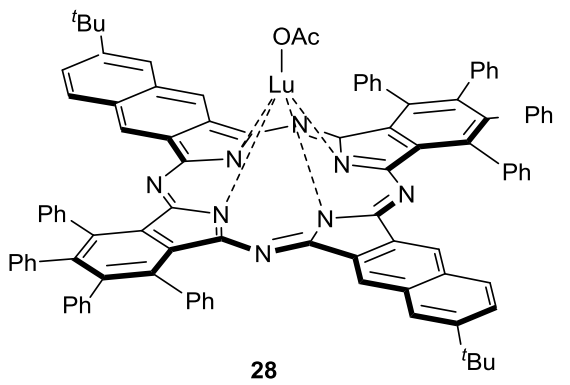

$\mathrm{R}=$ tert-Bu, R' = H; Ln = Pr, Nd, Sm, Eu, Gd, Tb, Ho, Er, Tm, Lu; X = Cl, OAc, acac, dpm (25)

$\mathrm{R}=\mathrm{R}^{\prime}=\mathrm{PhO} ; \mathrm{Ln}=\mathrm{Eu}, \mathrm{Er}, \mathrm{Lu} ; \mathrm{X}=\mathrm{OAc}(\mathbf{2 6})$

$\mathrm{R}=\mathrm{R}^{\prime}=\mathrm{Ph} ; \mathrm{Ln}=\mathrm{Eu}, \mathrm{Er}, \mathrm{Lu} ; \mathrm{X}=\mathrm{OAc}(\mathbf{2 7})$

Fig. 6. Representative examples of the single-decker rare-earth $P c$ analogues. 


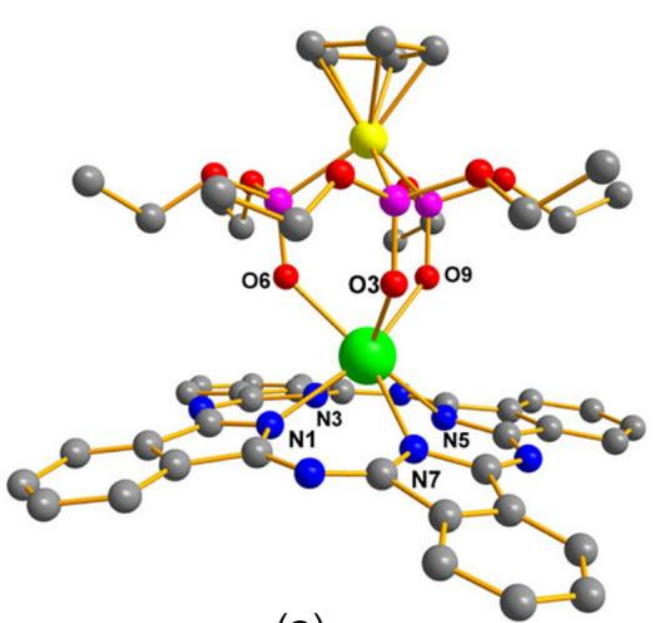

(a)

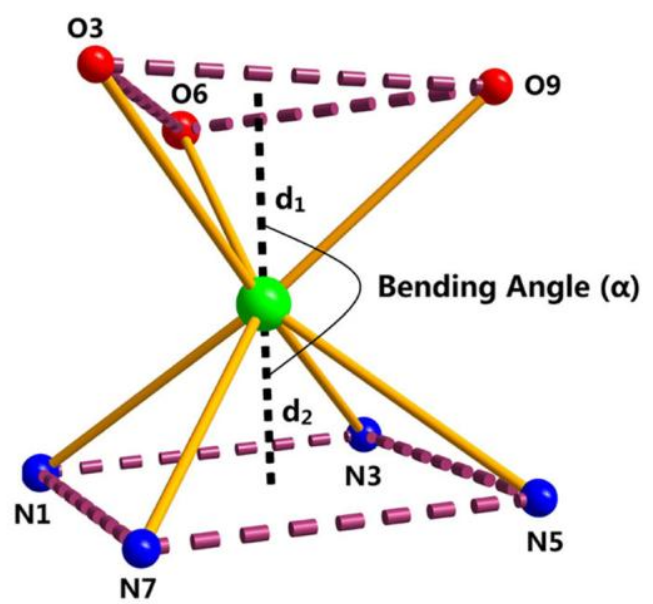

(b)

Fig. 7. (a) X-ray crystal structure of binuclear complex $\mathbf{4 0}$ and (b) schematic representation of the first coordination sphere of the rare-earth ions $\mathrm{Ln}^{3+}(\mathrm{Ln}=\mathrm{Dy}, \mathrm{Tb}, \mathrm{Ho}$, and Gd) [132]. 


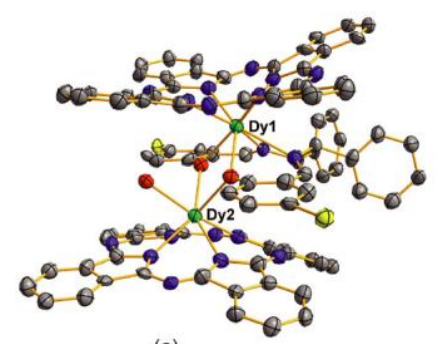

(a)

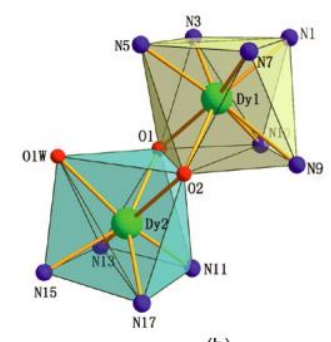

(b)

Fig. 8. (a) X-ray crystal structure of complex 45 and (b) schematic representation of the first coordination sphere of $\mathrm{Dy}^{3+}$ ions [135]. 


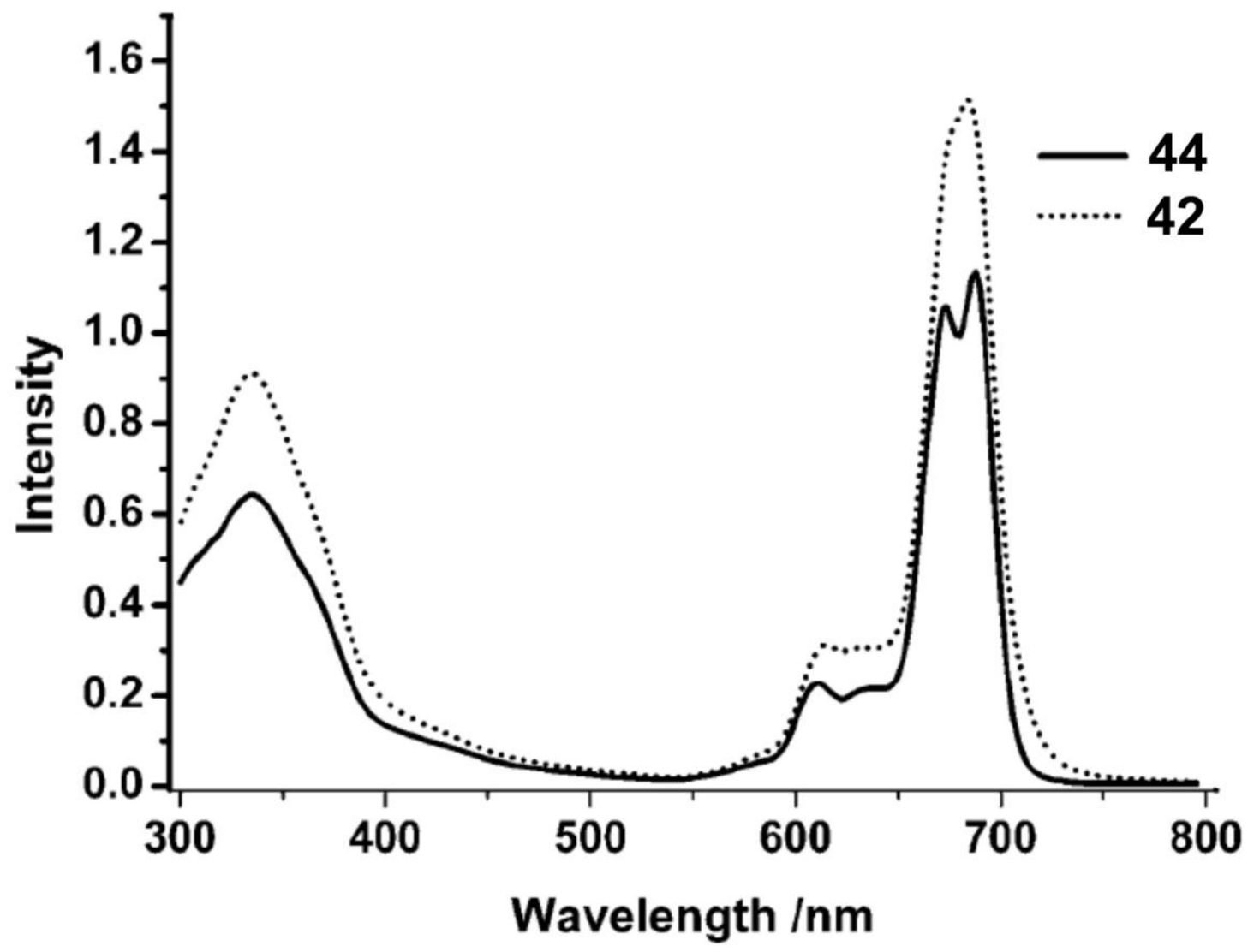

Fig. 9. UV-vis spectra of mononuclear (42) and binuclear (44) dysprosium complexes in $\mathrm{CHCl}_{3} / \mathrm{DMSO}(9: 1 \mathrm{v} / \mathrm{v})$ system [133]. 

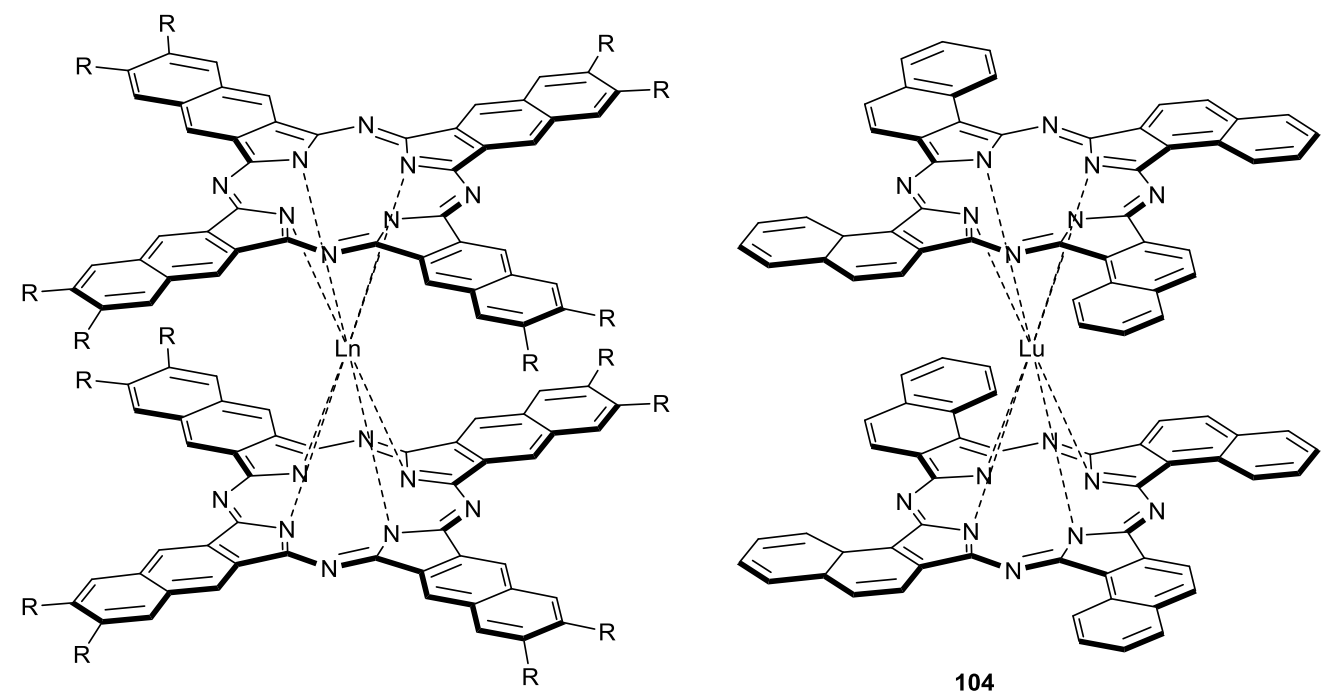

$\mathrm{R}=\mathrm{H} ; \mathrm{Ln}=\mathrm{Lu}(\mathbf{1 0 3})$

$\mathrm{R}=\mathrm{Ph} ; \mathrm{Ln}=\mathrm{Eu}, \mathrm{Er}, \mathrm{Lu}(\mathbf{1 0 5})$
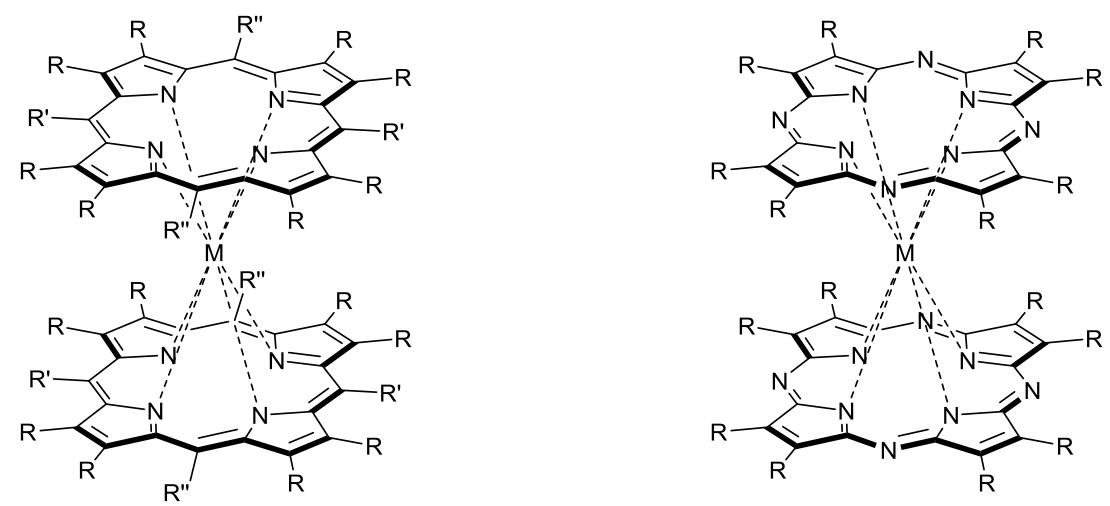

109,110

$\mathrm{R}=\mathrm{H} ; \mathrm{R}^{\prime}=p-\mathrm{MeOPh} ; \mathrm{R}^{\prime \prime}=4-\mathrm{Py} ; \mathrm{M}=\mathrm{La}(\mathbf{1 0 6})$

$\mathrm{R}=n-\mathrm{C}_{3} \mathrm{H}_{7} ; \mathrm{M}=\mathrm{Ce}, \mathrm{Eu}, \mathrm{Lu}(109)$

$\mathrm{R}=\mathrm{Et} ; \mathrm{R}^{\prime}=\mathrm{R}^{\prime \prime}=\mathrm{H} ; \mathrm{M}=\mathrm{La}-\mathrm{Nd}, \mathrm{Sm}-\mathrm{Lu}, \mathrm{Y}$ (107)

$\mathrm{R}=\mathrm{Et} ; \mathrm{M}=\operatorname{Zr}(\mathbf{1 1 0})$

$\mathrm{R}=\mathrm{H}, \mathrm{Et} ; \mathrm{R}^{\prime}=\mathrm{R}^{\prime \prime}=\mathrm{Ph}, \mathrm{H} ; \mathrm{M}=\mathrm{Zr}$, Hf (108)

Fig. 10. Representative examples of double-decker rare-earth Pc analogues. 


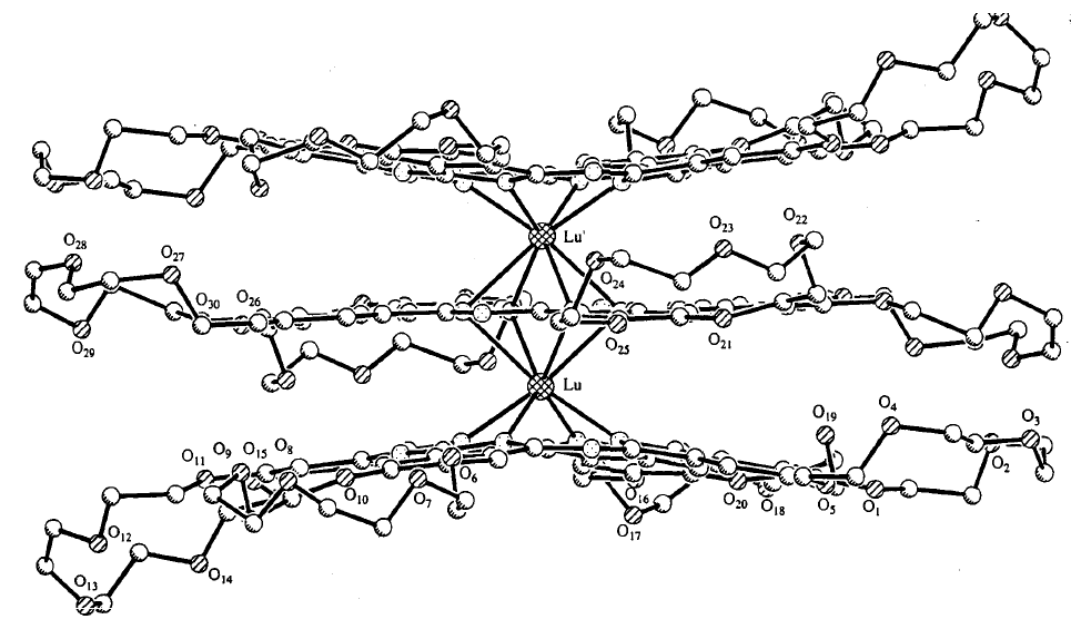

Fig. 11. X-ray crystal structure of triple-decker dilutetium Pc 112 [244]. 


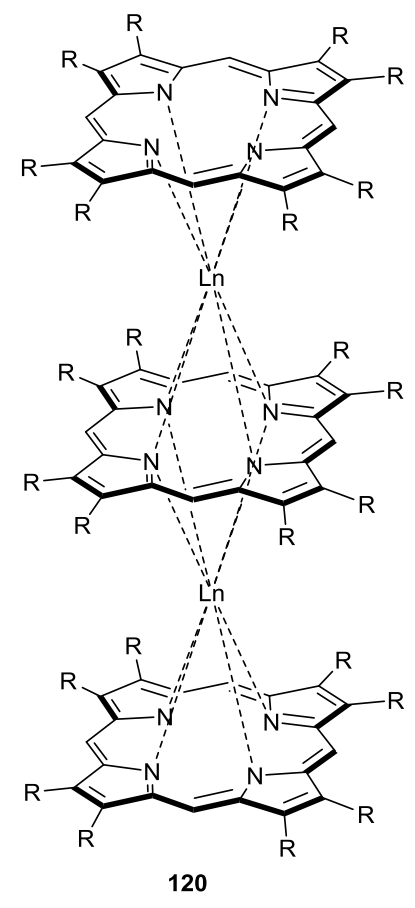

$\mathrm{R}=\mathrm{Et} ; \mathrm{Ln}=\mathrm{Ce}(\mathbf{1 2 0})$

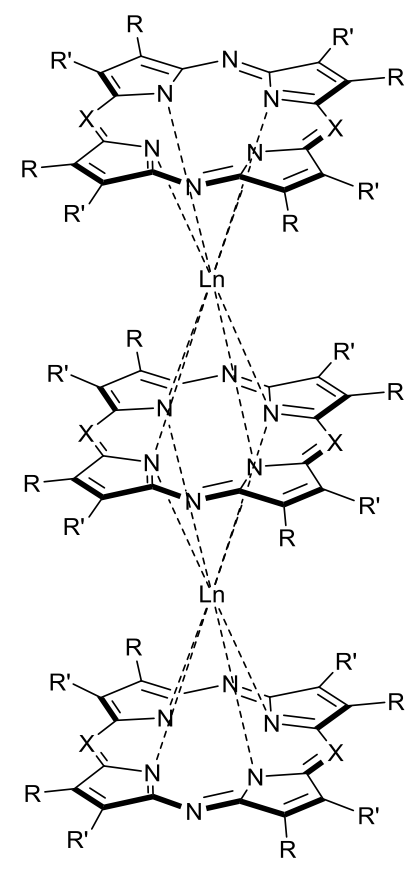

121,122

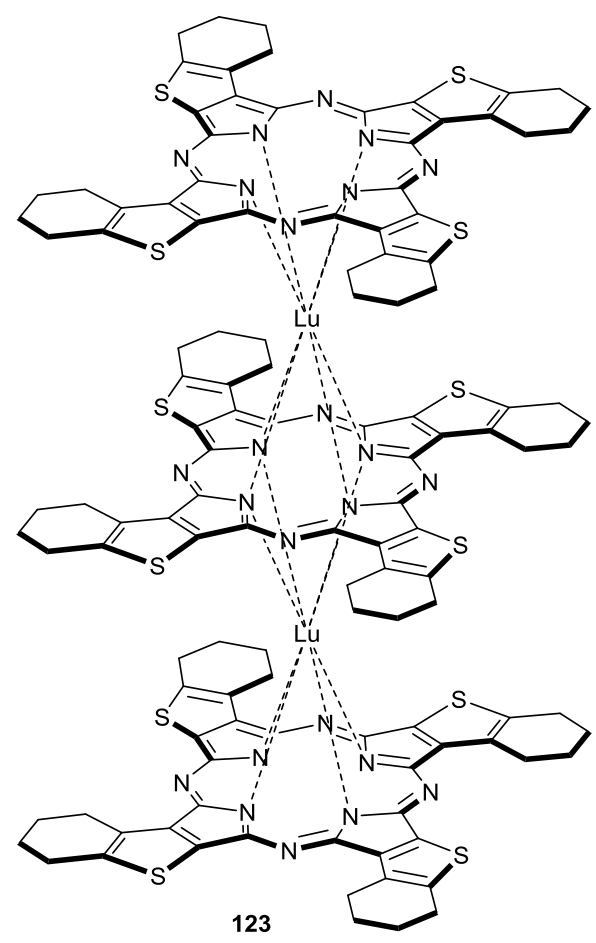

$\mathrm{X}=\mathrm{CH} ; \mathrm{R}=\mathrm{Me} ; \mathrm{R}^{\prime}=\mathrm{Et} ; \mathrm{Ln}=\mathrm{Ce}, \mathrm{Eu}(\mathbf{1 2 1})$

$\mathrm{X}=\mathrm{N} ; \mathrm{R}=\mathrm{R}^{\prime}=n-\mathrm{C}_{3} \mathrm{H}_{7} ; \mathrm{Ln}=\mathrm{Eu}(\mathbf{1 2 2})$

Fig. 12. Representative examples of the rare-earth triple-decker Pors, DAPs, and TAPs. 


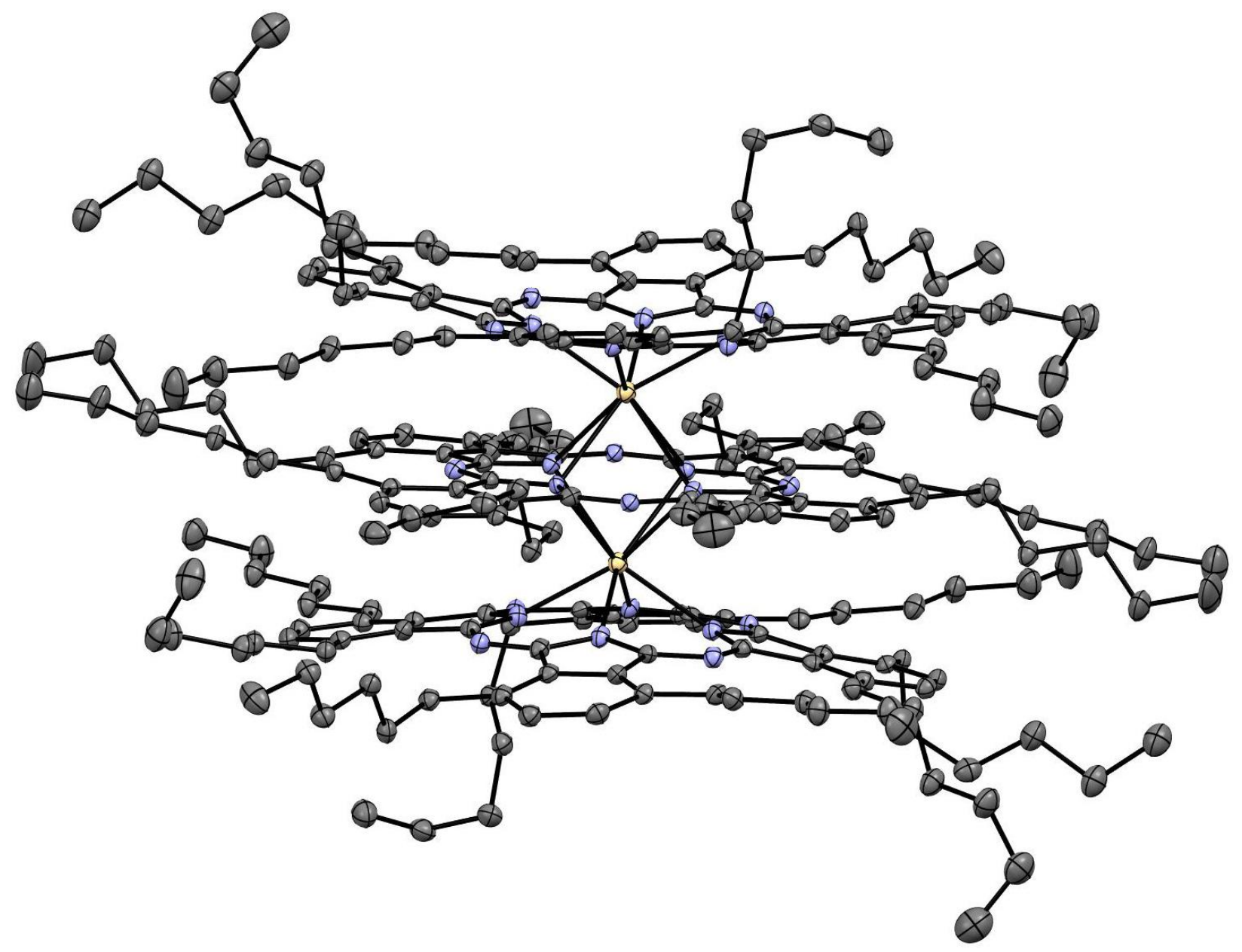

Fig. 13. X-ray crystal structure of $n$-hexyl substituted triple-decker cadmium Pc 124 [259]. 

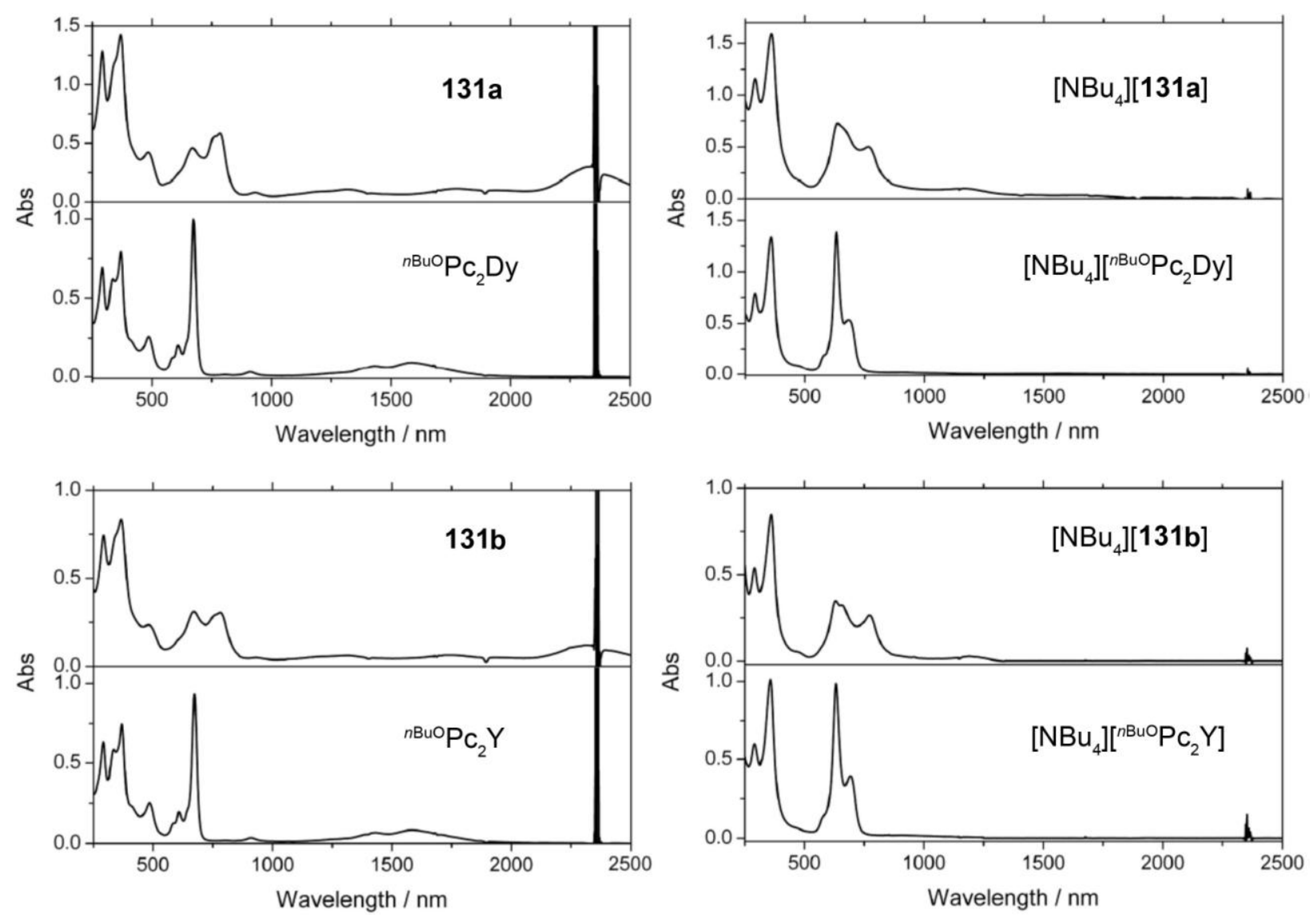

Fig. 14. UV-vis spectra of binuclear complexes 131, their respective mononuclear analogues $\mathbf{5 5}$ ( $\mathrm{Ln}=\mathrm{Dy}, \mathrm{Y}$ ), and their reduced forms obtained by the reduction with $\mathrm{N}_{2} \mathrm{H}_{4} \cdot \mathrm{H}_{2} \mathrm{O}$ in the presence of $\mathrm{NBu}_{4} \mathrm{Br}$ in $\mathrm{CHCl}_{3}$. Narrow bands at $\sim 2350 \mathrm{~nm}$ are solvent overtones [271]. 

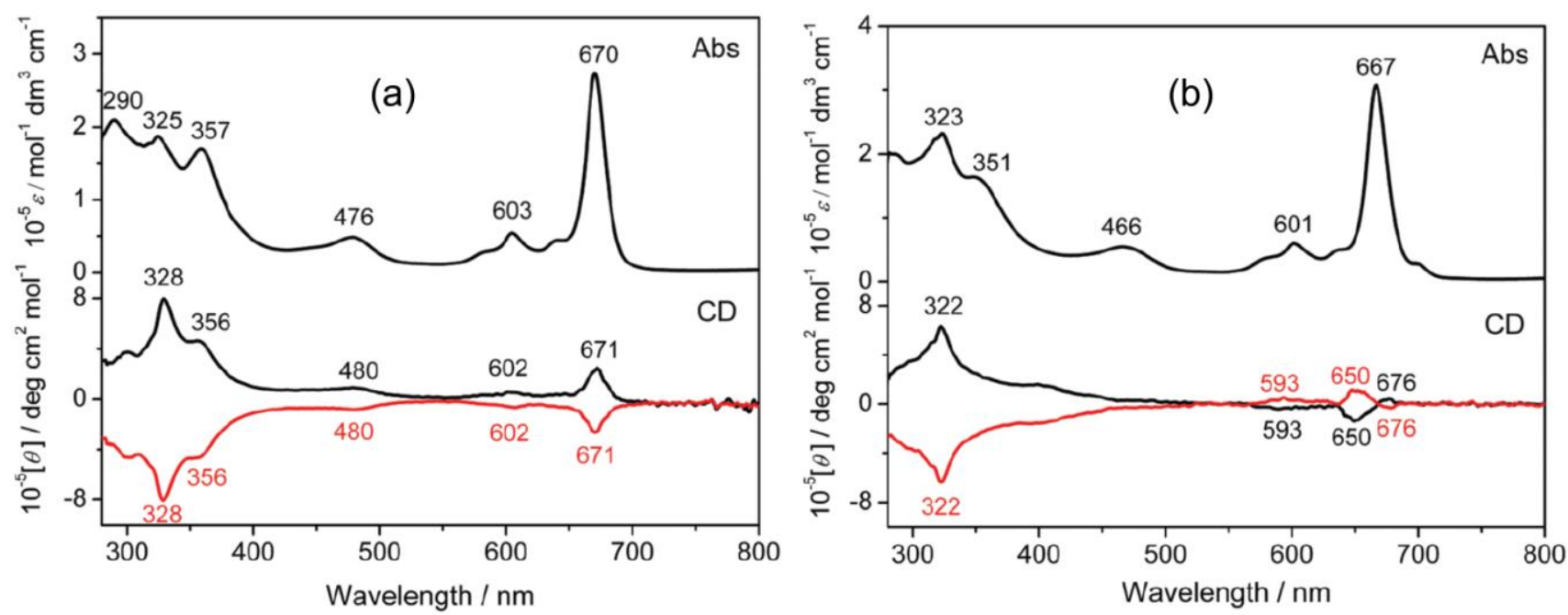

Fig. 15. UV-vis and CD spectra of homoleptic complexes 75 (a) and their heteroleptic analogues 149 (b). Black and red lines represent CD spectra of $(R)$ - and $(S)$-enantiomers, respectively [194]. 


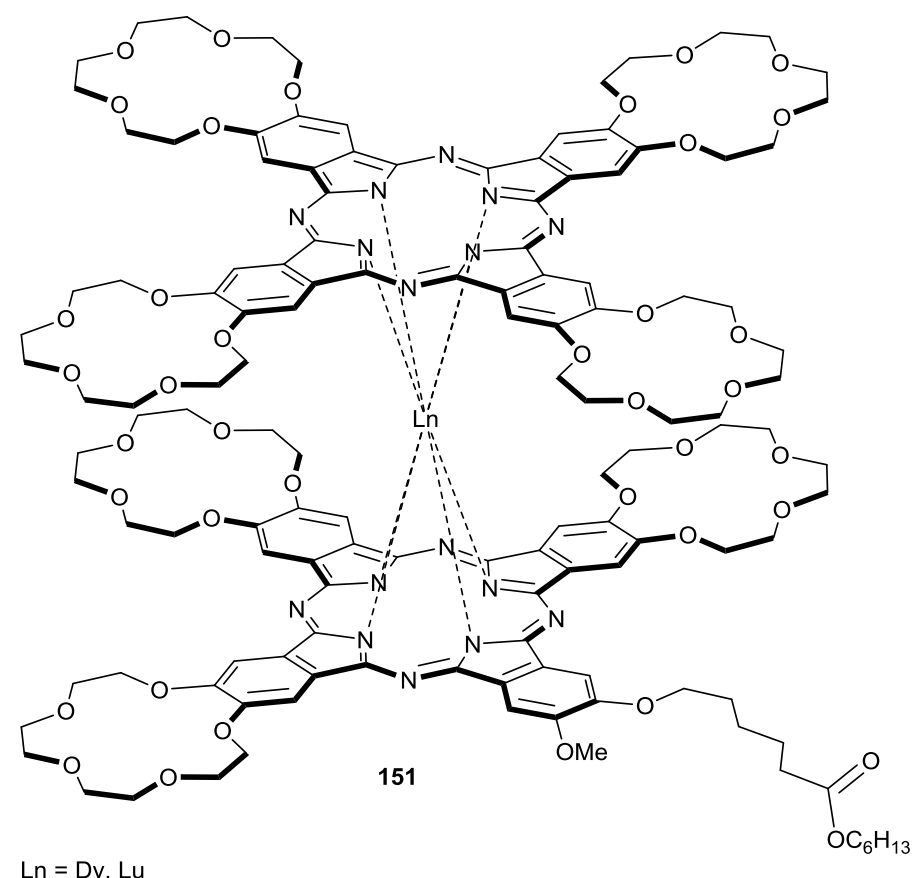

Fig. 16. Rare-earth heteroleptic double-decker complexes with $\mathrm{A}_{3} \mathrm{~B}$ type of asymmetric macrocyclic ligand [278]. 


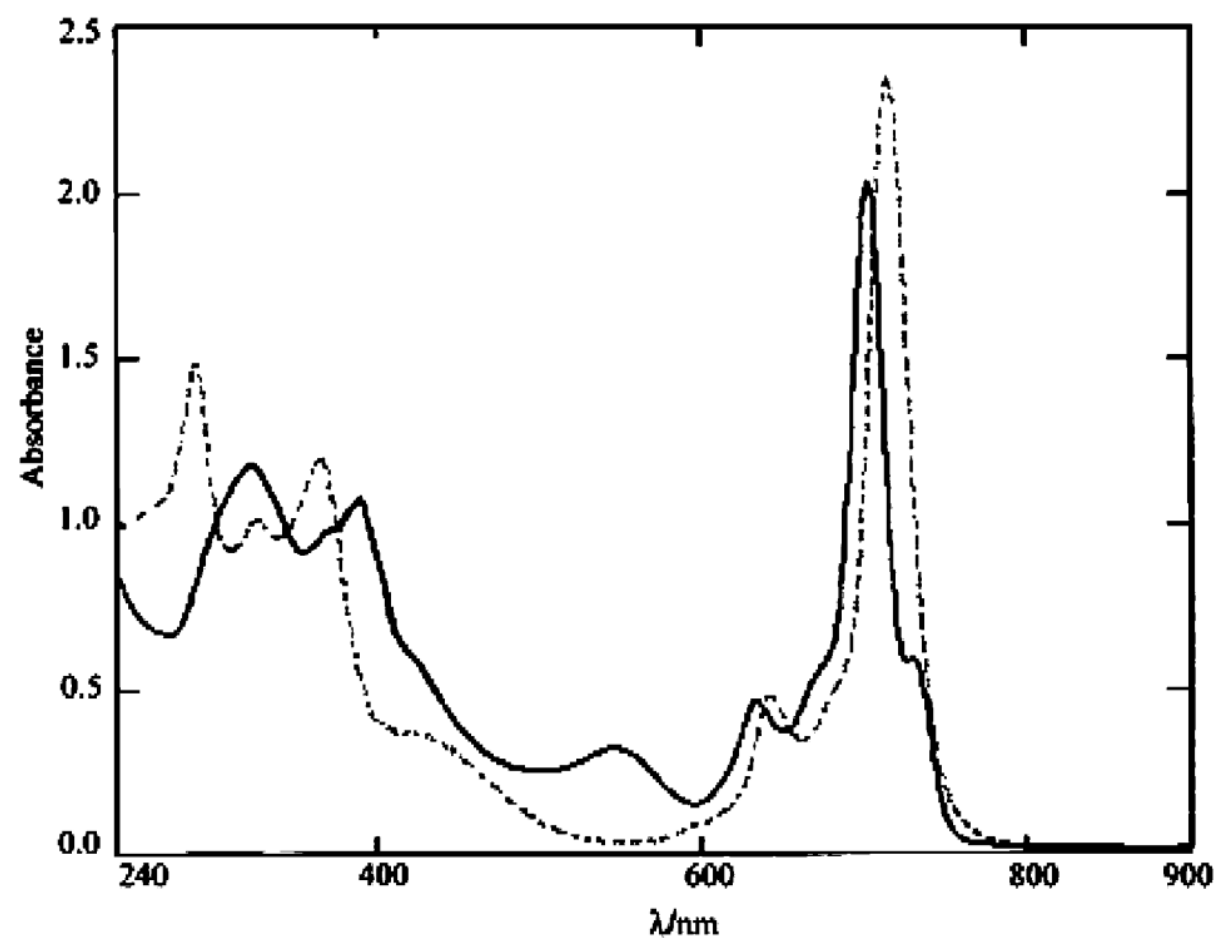

Fig. 17. UV-vis spectra of $\mathbf{1 5 4}(\cdots)$ and $\mathbf{1 5 5}(-)$ in $\mathrm{CHCl}_{3}[279,280]$. 


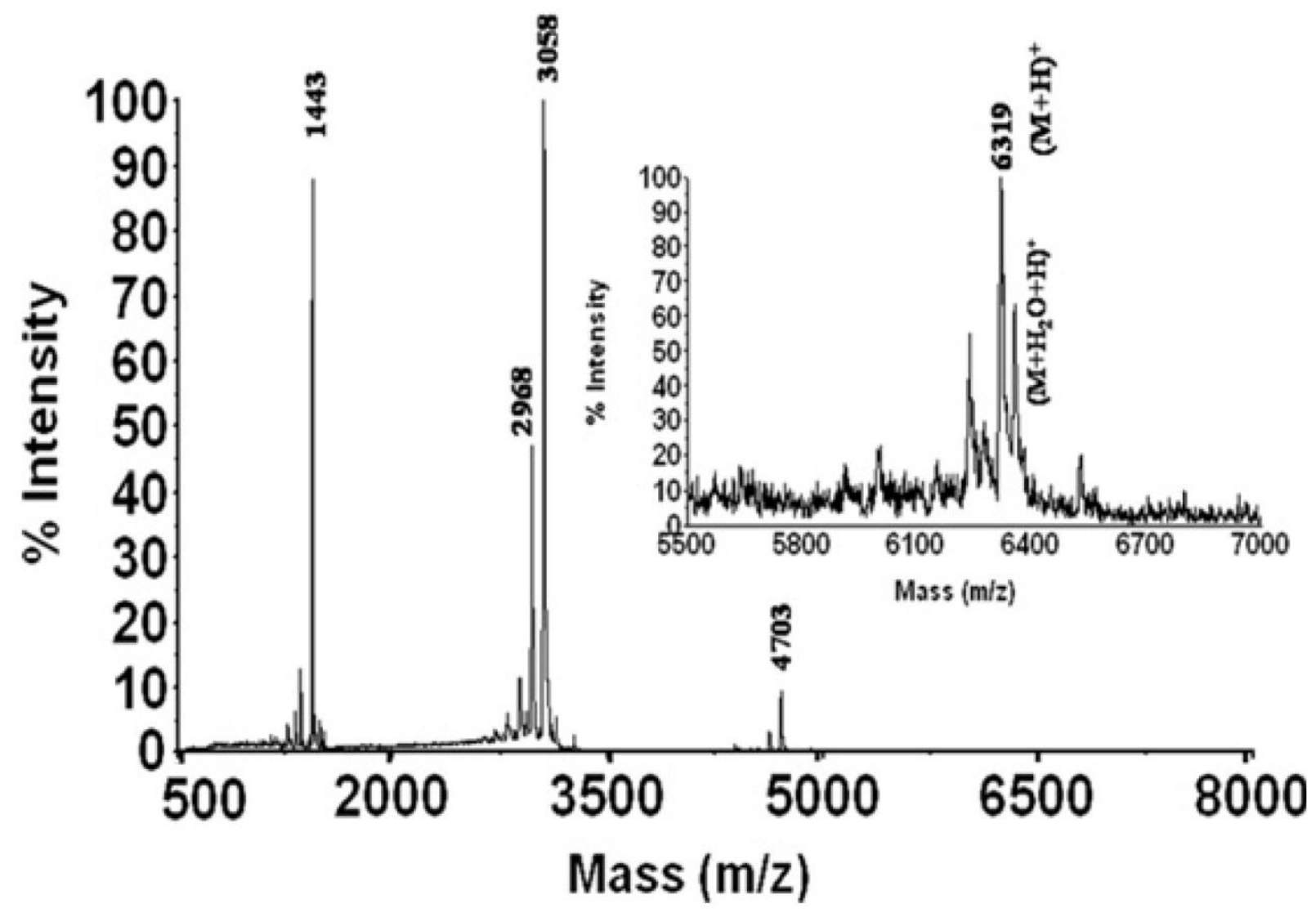

Fig. 18. MALDI-TOF spectrum of $\mathbf{1 5 8}$ in 3,5-dinitrobenzene matrix [281]. 


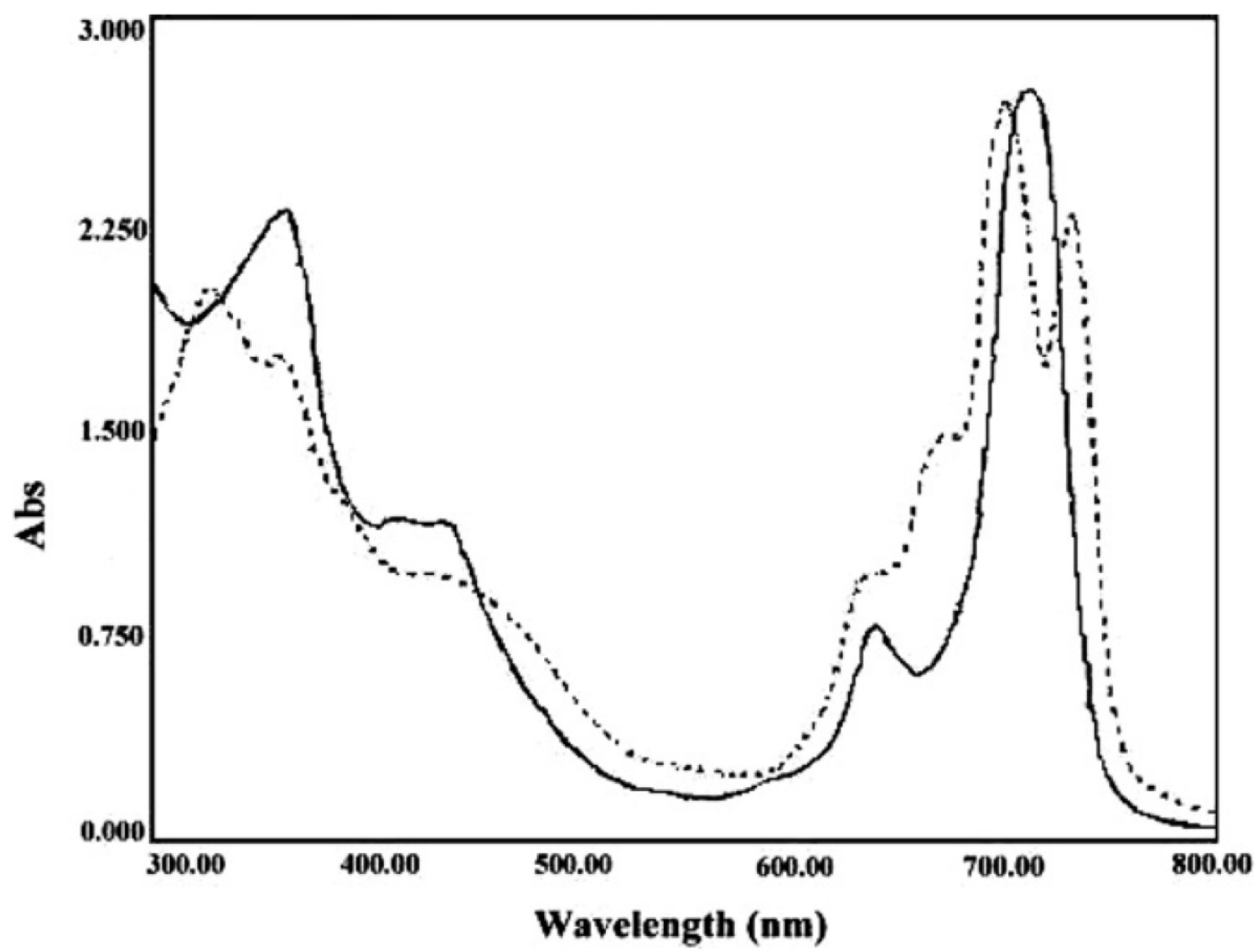

Fig. 19. UV-vis spectra of $\mathbf{1 5 7}(-)$ and $\mathbf{1 5 8}(\cdots)$ in $\mathrm{CHCl}_{3}$ [281]. 


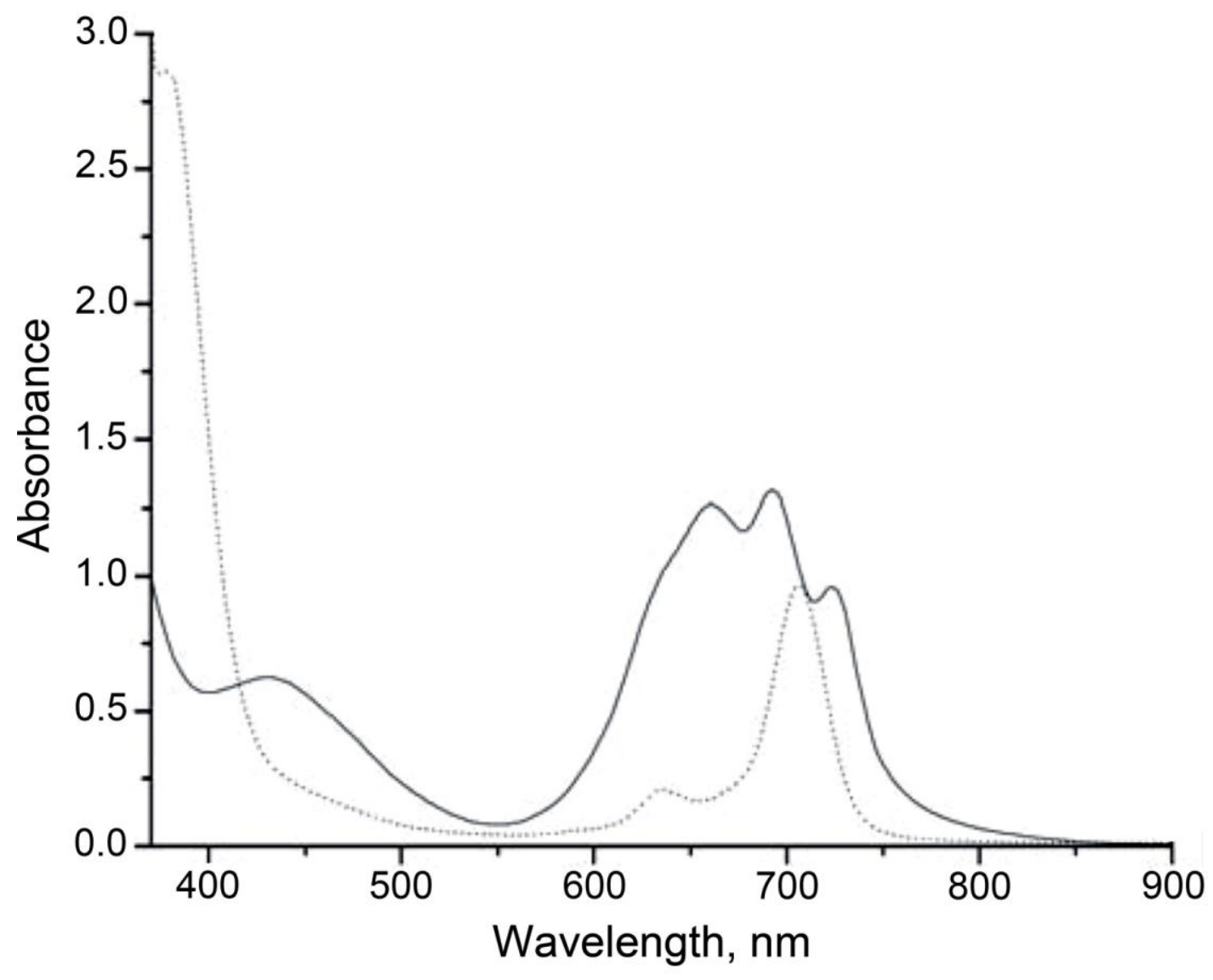

Fig. 20. UV-vis spectra of $159(\cdots)$ and 161 ( - ) in $\mathrm{CHCl}_{3}$ [282]. 


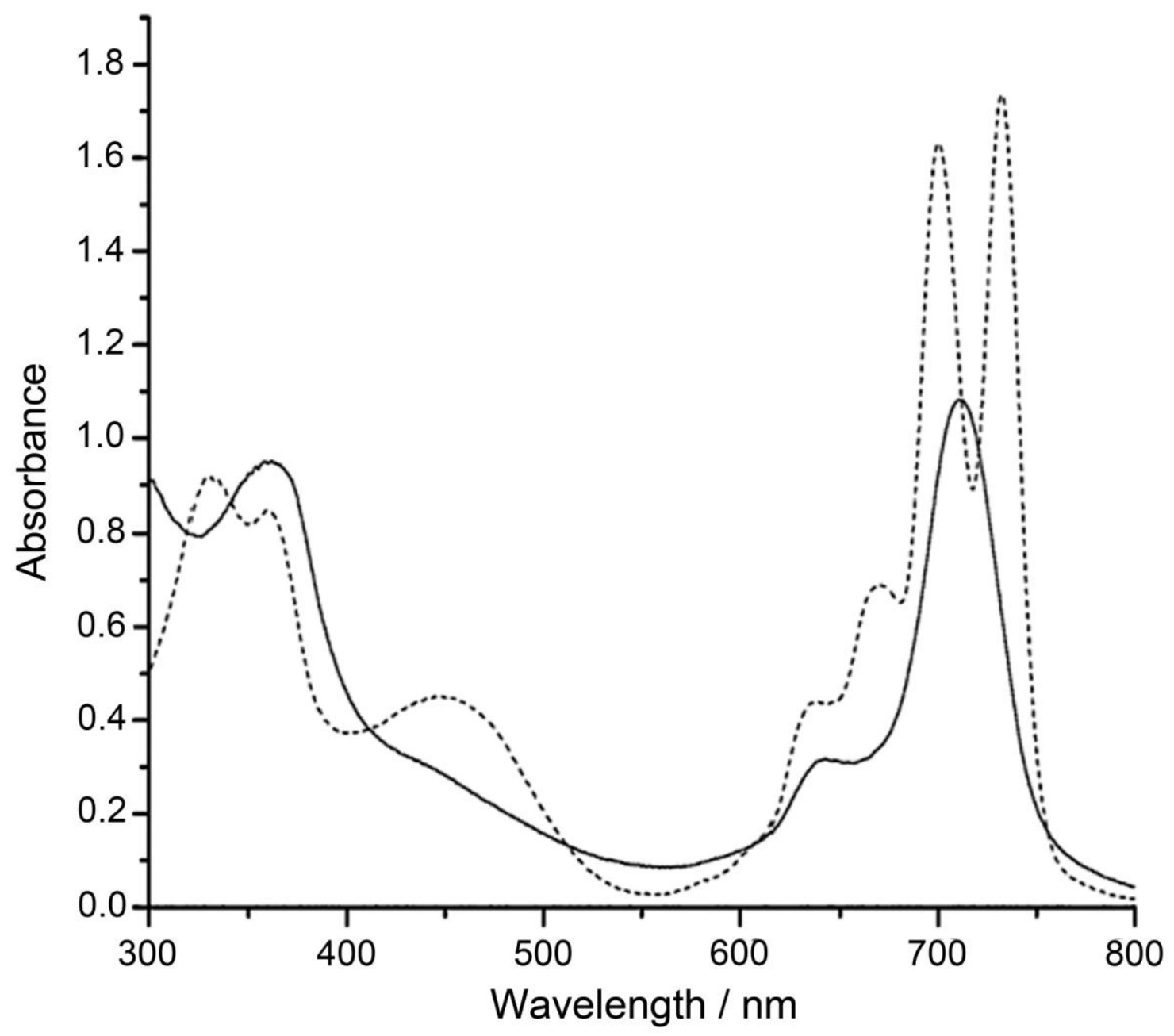

Fig. 21. UV-vis spectra of $\mathbf{1 6 0}(-)$ and $\mathbf{1 6 2}(\cdots)$ in $\mathrm{CHCl}_{3}$ [283]. 


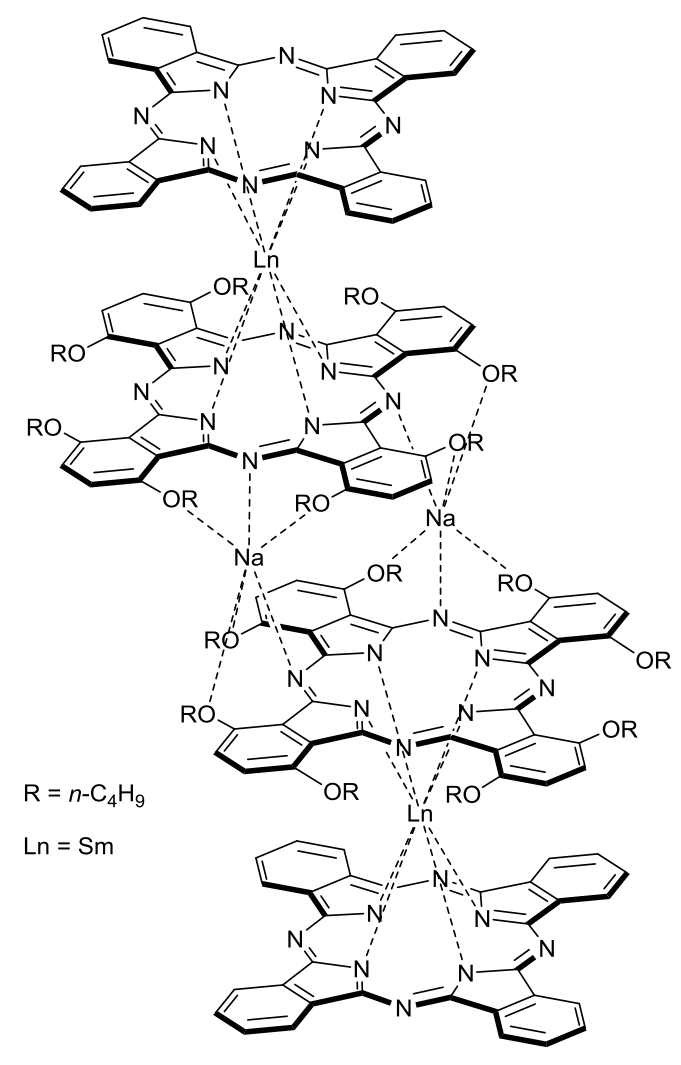

Fig. 22. Structure of the pseudo tetra-decker heteroleptic samarium complex 176 [292]. 


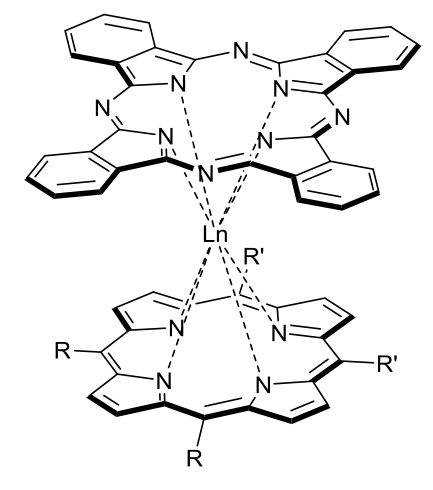

204

$\mathrm{R}=\mathrm{C}_{6} \mathrm{H}_{5} ; \mathrm{R}^{\prime}=4-\left(n-\mathrm{C}_{8} \mathrm{H}_{17} \mathrm{NH}\right) \mathrm{C}_{6} \mathrm{H}_{4} ; \mathrm{Ln}=\mathrm{Eu}, \mathrm{Lu}$
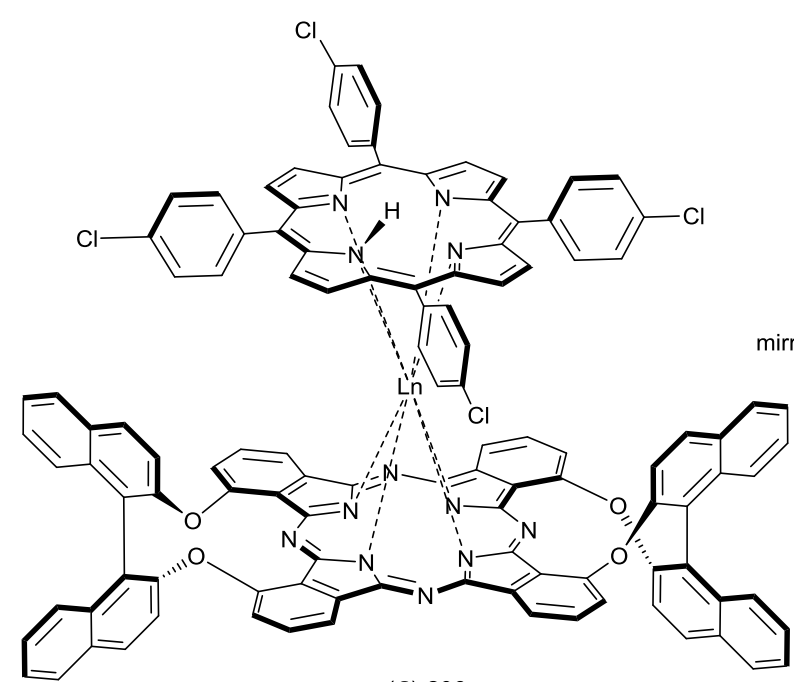

(S)-206

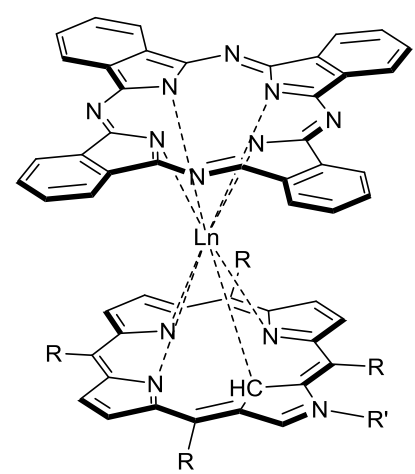

205

$\mathrm{R}=4-\left(\right.$ tert-Bu) $\mathrm{C}_{6} \mathrm{H}_{4} ; \mathrm{R}^{\prime}=\mathrm{H}, \mathrm{CH}_{3} ; \mathrm{Ln}=\mathrm{La}, \mathrm{Eu}, \mathrm{Lu}, \mathrm{Y}$

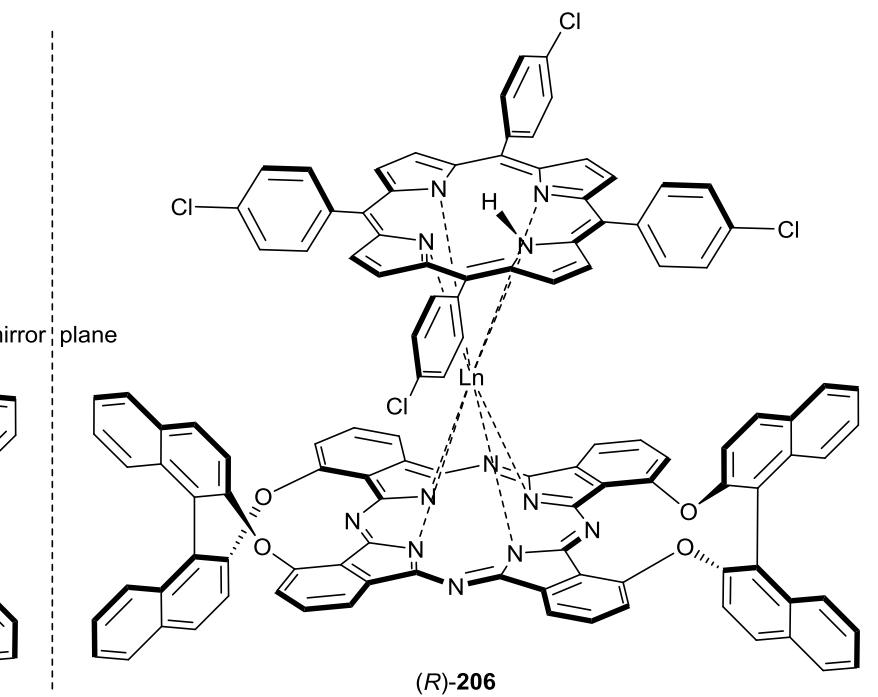

$\mathrm{Ln}=\mathrm{Eu}, \mathrm{Y}$

Fig. 23. Representative examples of Pc-Por mixed-ligand complexes [312-314]. 


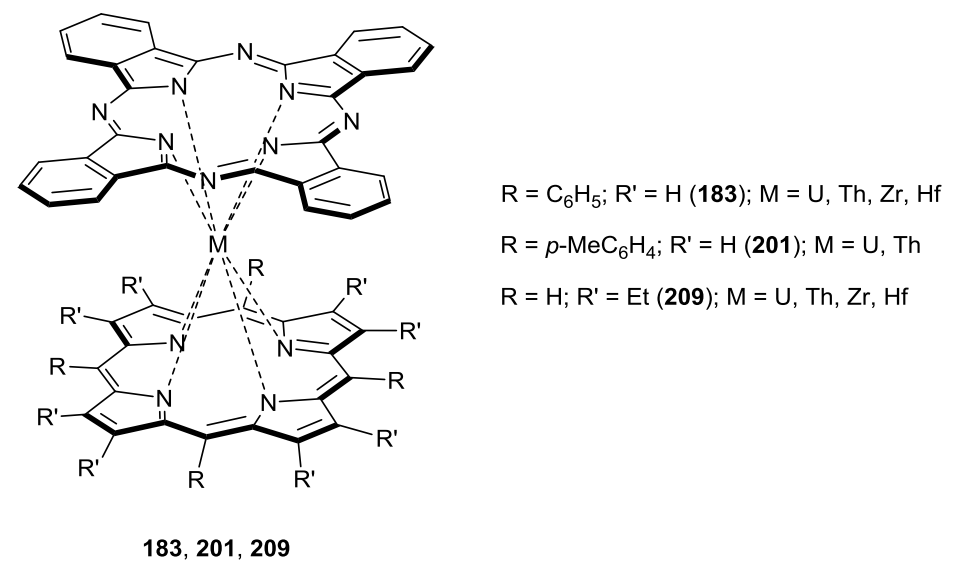

Fig. 24. Representative examples of double-decker Pc-Por mixed-ligand complexes of tetravalent ions 183, 201, and 209 [229,315]. 


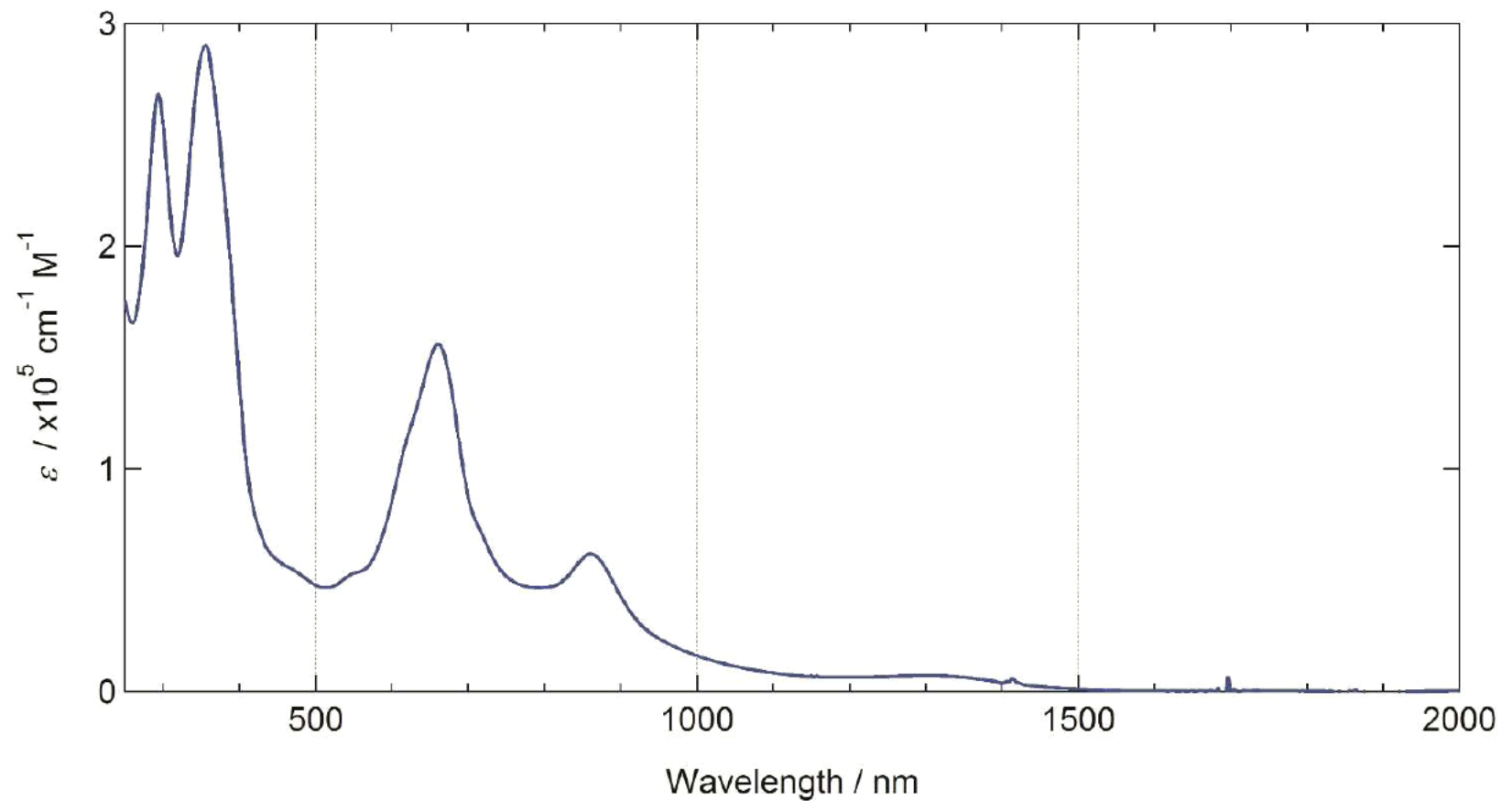

Fig. 25. UV-vis spectrum of 232 in $\mathrm{CHCl}_{3}\left(8.2 \times 10^{-6} \mathrm{M}, 298 \mathrm{~K}\right)$ [337]. 


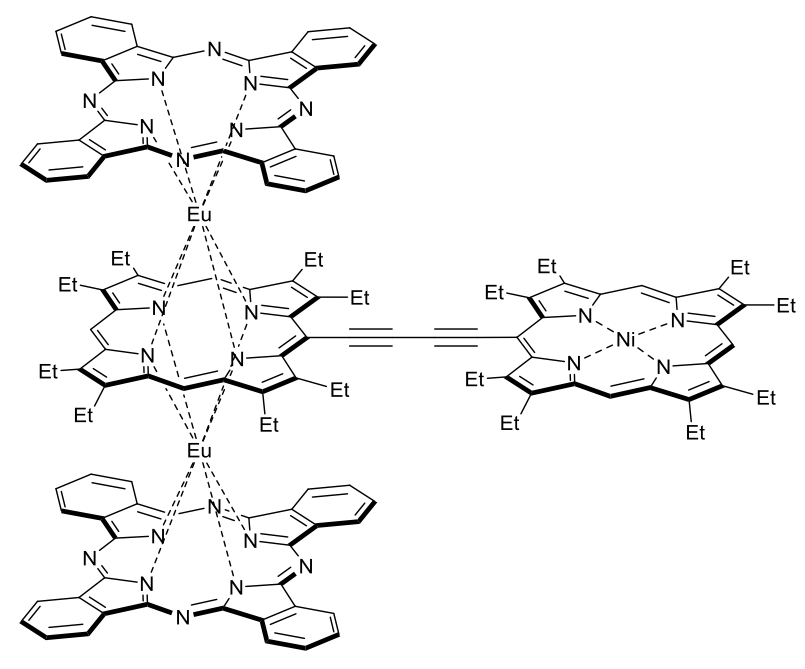

268

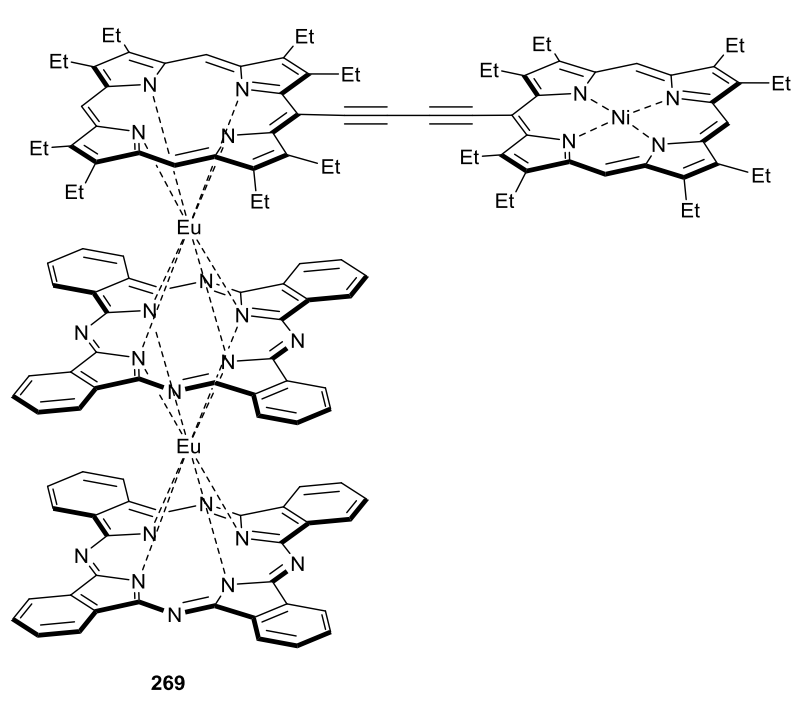

Fig. 26. Representative examples of mixed-ligand triple-decker Pc-Por complexes with covalently linked Por substituents [349]. 


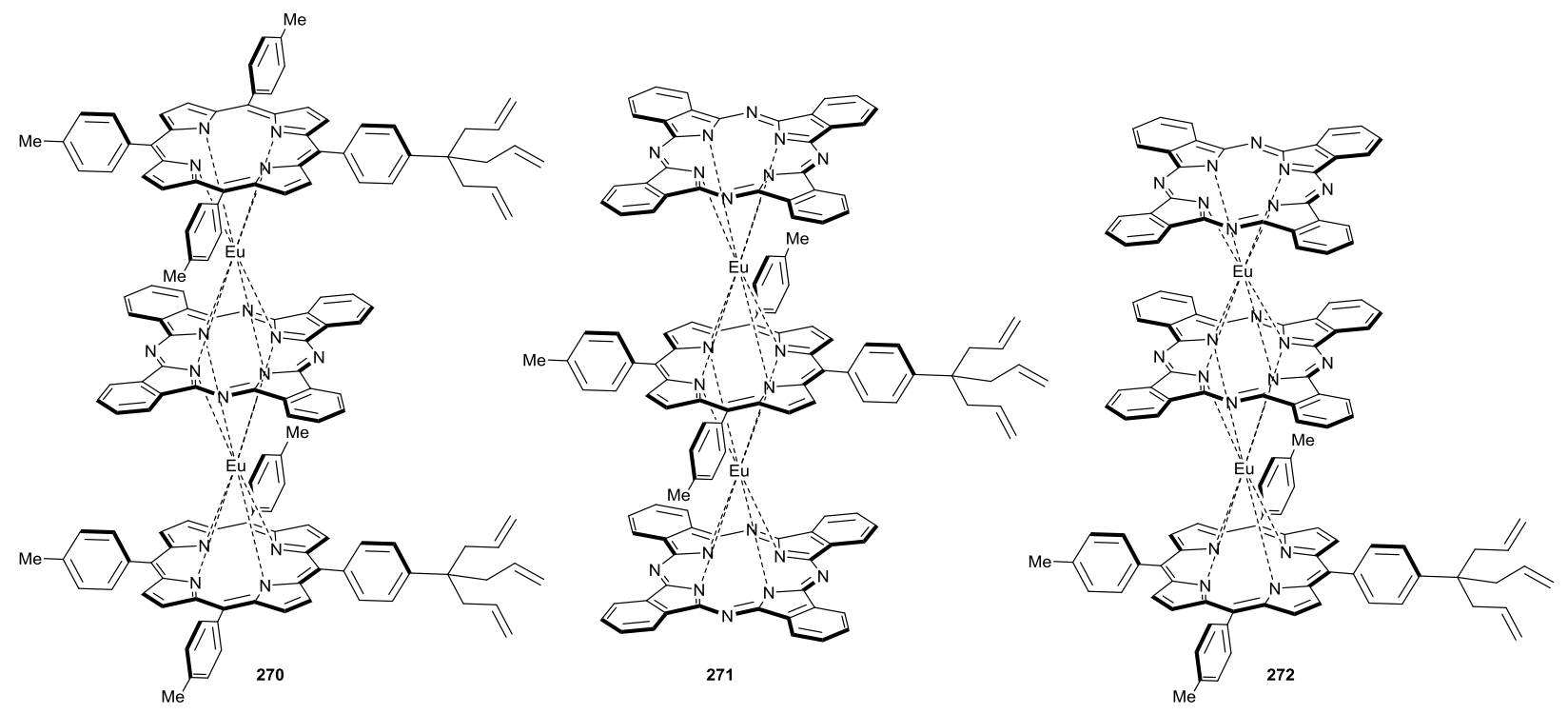

Fig. 27. Representative examples of mixed-ligand triple-decker Pc-Por complexes with terminal tri-allyl groups [63]. 


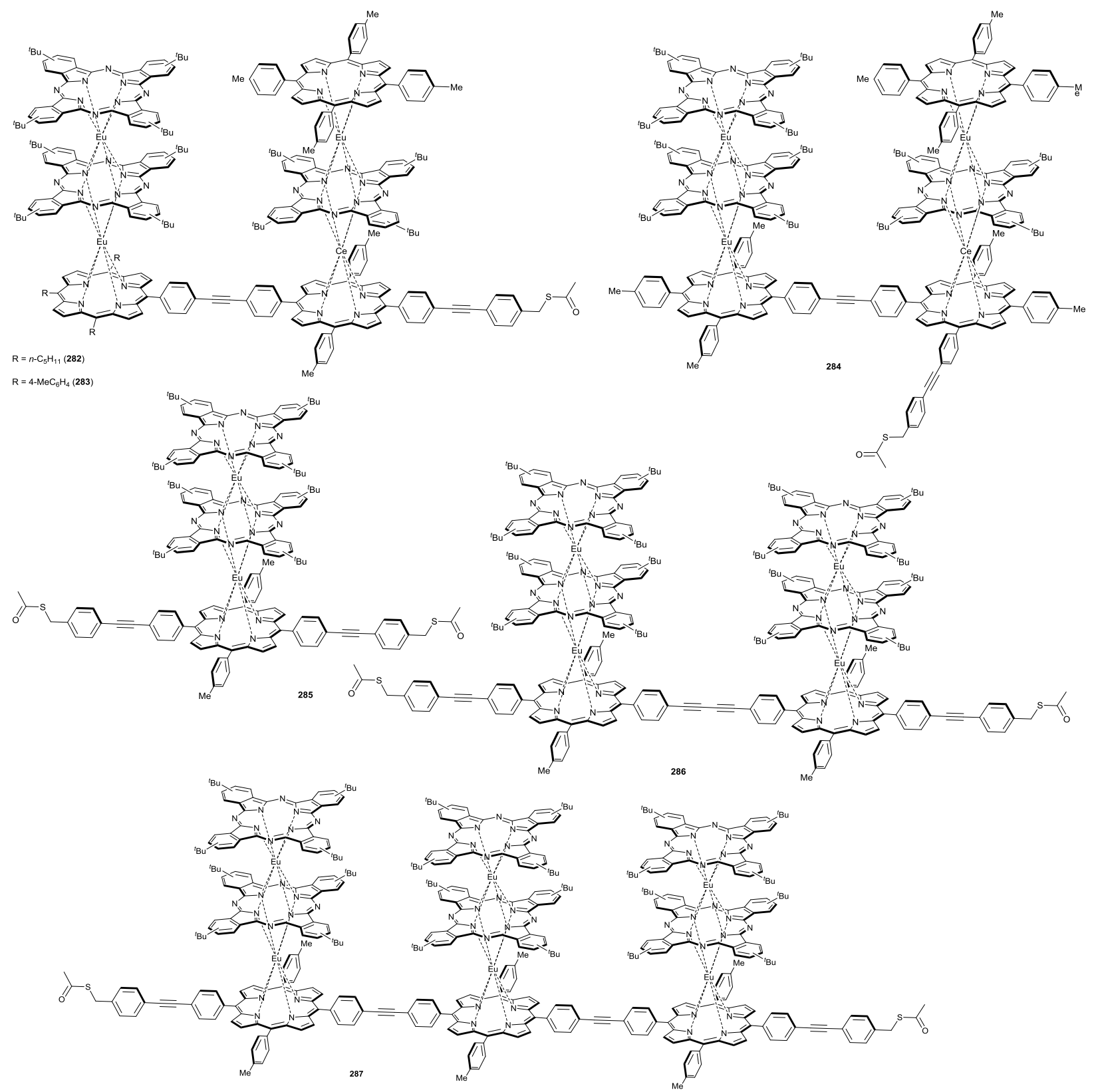

Fig. 28. Representative examples of triple-decker and expanded triple-decker Pc-Por complexes prepared by the cross-coupling reactions $[350,351]$. 


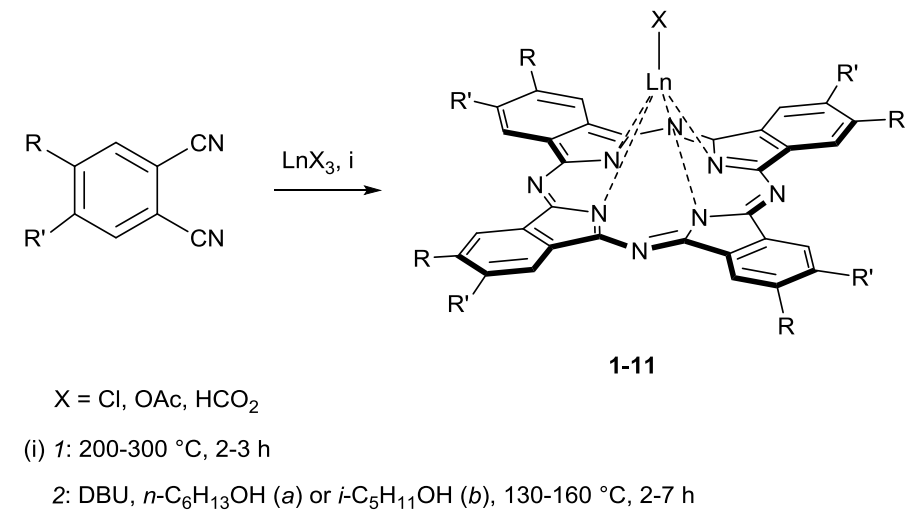

Scheme 1. 

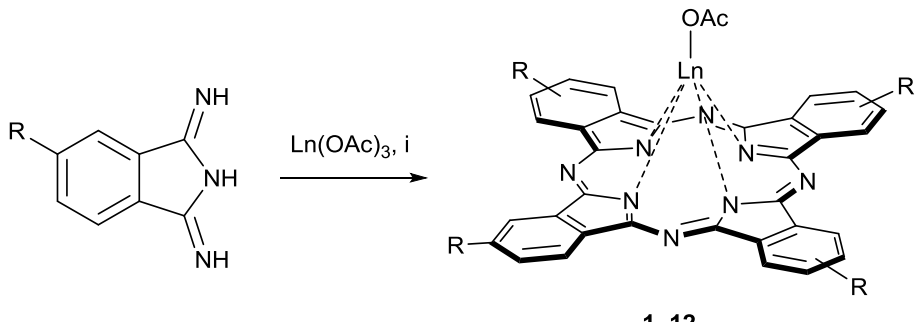

$\mathrm{R}=\mathrm{H} ; \mathrm{Ln}=\mathrm{Sm}, \mathrm{Eu}, \mathrm{Tb}-\mathrm{Lu}(\mathbf{1})$

$\mathrm{R}=\mathrm{OPr} ; \mathrm{Ln}=\mathrm{Lu}(\mathbf{1 2})$

(i) DMF or DMAE, $135-150^{\circ} \mathrm{C}, 5-7 \mathrm{~h}$

\section{Scheme 2.}




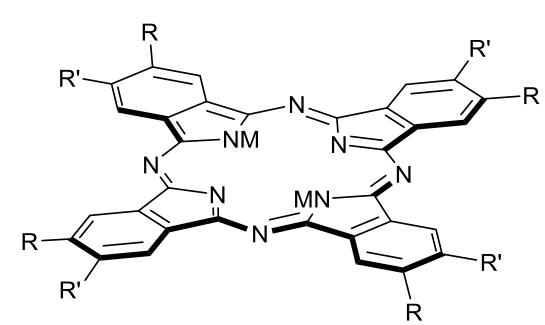

$\mathrm{M}=\mathrm{H}, \mathrm{Li} ; \mathrm{X}=\mathrm{Cl}$, OAc, $\beta$-diketonate

(i) 1: $\mathrm{BuLi}, \mathrm{Ca}(\mathrm{OAc})_{2}, \mathrm{DMSO}, 190^{\circ} \mathrm{C}$

2: $\mathrm{DBU}, \mathrm{DCB}, 180^{\circ} \mathrm{C}$

3: DMSO (a), DCB (b), $\mathrm{MeOH}(c), 65-190^{\circ} \mathrm{C}$

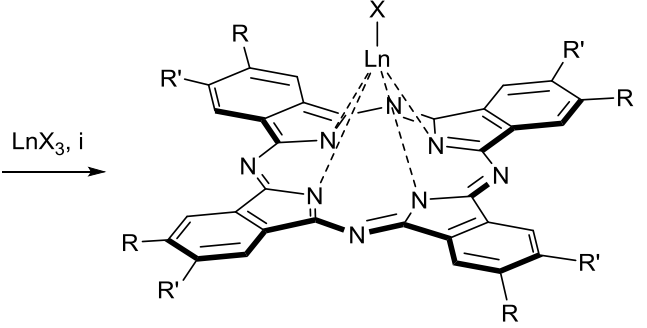

$1,2,15-20$

\section{Scheme 3.}




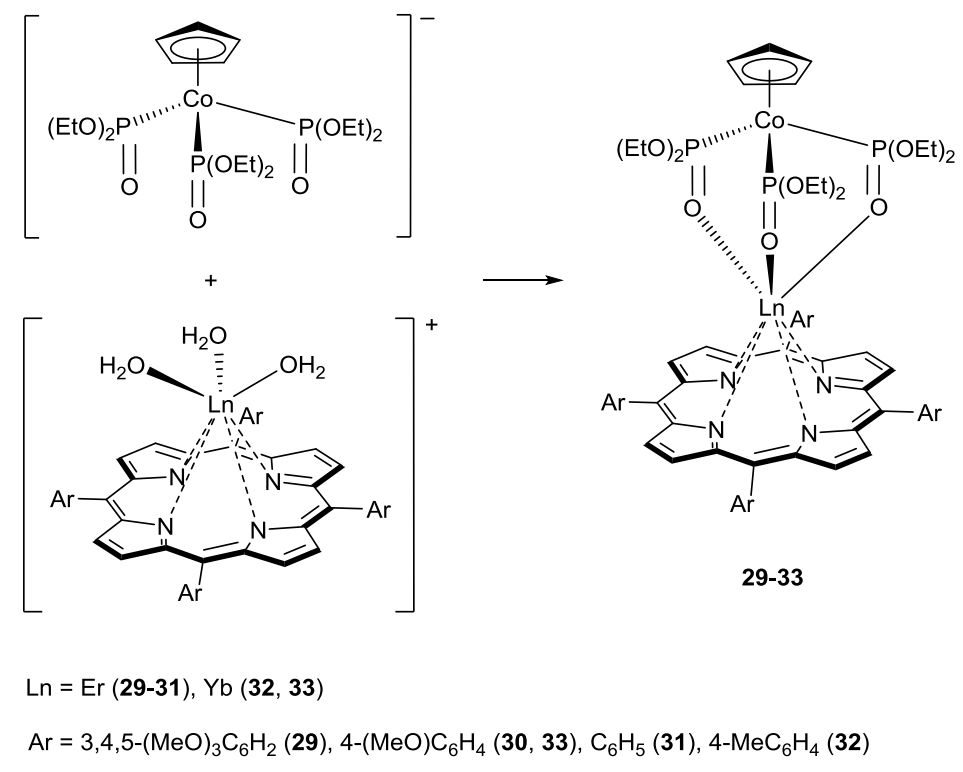

Scheme 4. 


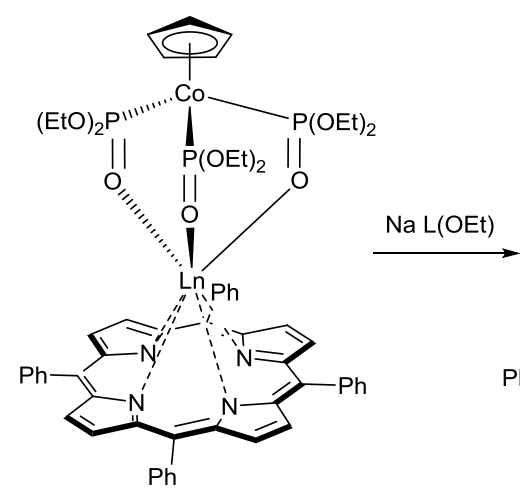

Ln(TPP)(L(OEt)), 31

$\mathrm{Ln}=\mathrm{Pr}, \mathrm{Nd}, \mathrm{Ho}, \mathrm{Er}, \mathrm{Tm}, \mathrm{Yb}$

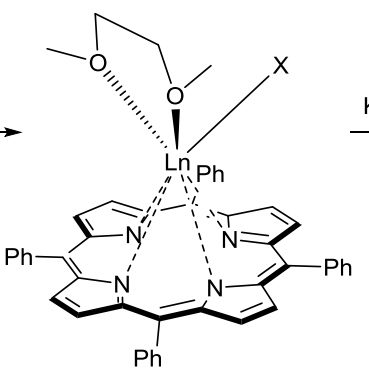

$\operatorname{Ln}(\mathrm{TPP})(\mathrm{X})(\mathrm{DME})$

$X=\mathrm{Cl}$ for $\mathrm{Ln}=\mathrm{Ho}, \mathrm{Er}, \mathrm{Tm}, \mathrm{Yb}$

$X=I$ for $\operatorname{Ln}=\mathrm{Nd}, \mathrm{Pr}$

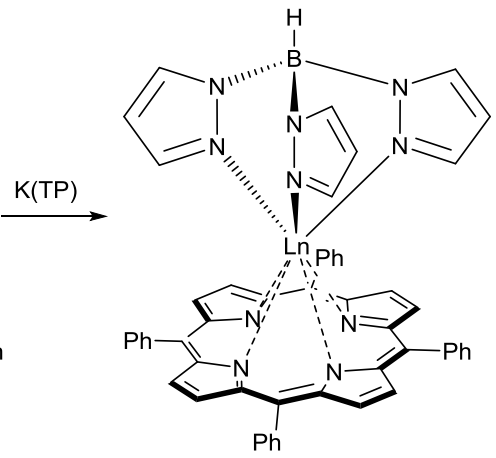

Ln(TPP)Tp, 34

$\mathrm{Ln}=\mathrm{Pr}, \mathrm{Nd}, \mathrm{Ho}, \mathrm{Er}, \mathrm{Tm}, \mathrm{Yb}$

\section{Scheme 5.}



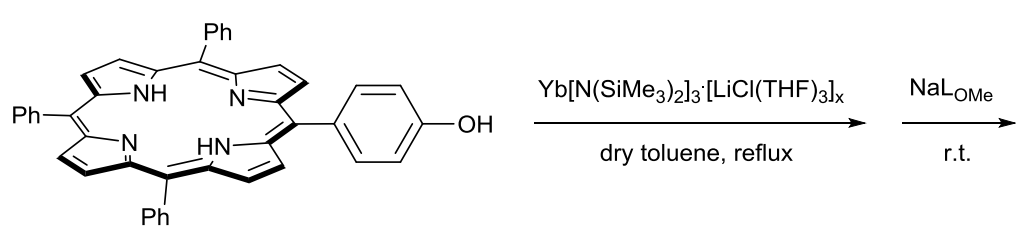

p-OH-TPPH ${ }_{2}$

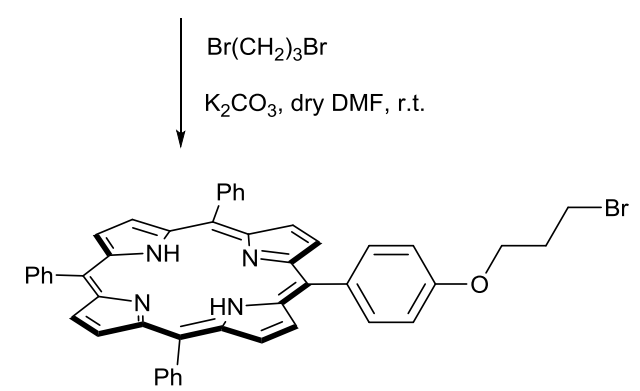

$p-\mathrm{BrC}_{3} \mathrm{O}-\mathrm{TPPH}_{2}$

[Yb(p-OH-TPP)(LOMe)] $\mathrm{K}_{2} \mathrm{CO}_{3}$, dry DMF $60^{\circ} \mathrm{C}$
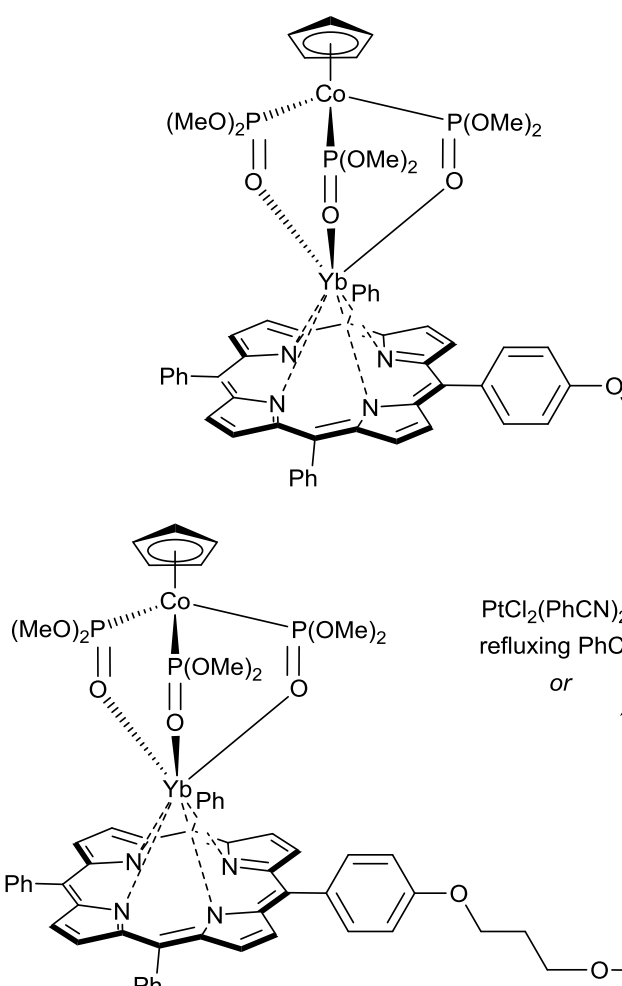

$\mathrm{Ph}$

p-OH-TPPH ${ }_{2}$

$\mathrm{PtCl}_{2}(\mathrm{PhCN})_{2}$ in refluxing $\mathrm{PhCN}$

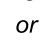

$\mathrm{Zn}(\mathrm{OAc})_{2}{ }^{2} \mathrm{H}_{2} \mathrm{O}$ or $\mathrm{Pd}(\mathrm{OAc})_{2} \cdot{ }^{2} \mathrm{H}_{2} \mathrm{O}$

in refluxing

$\mathrm{CHCl}_{3} / \mathrm{MeOH}(1: 1, \mathrm{v} / \mathrm{v})$

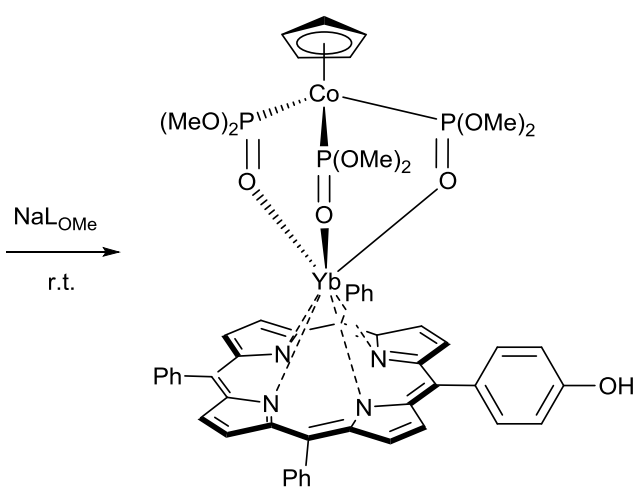

[Yb(p-OH-TPP) $\left.\left(\mathrm{L}_{\mathrm{OMe}}\right)\right]$

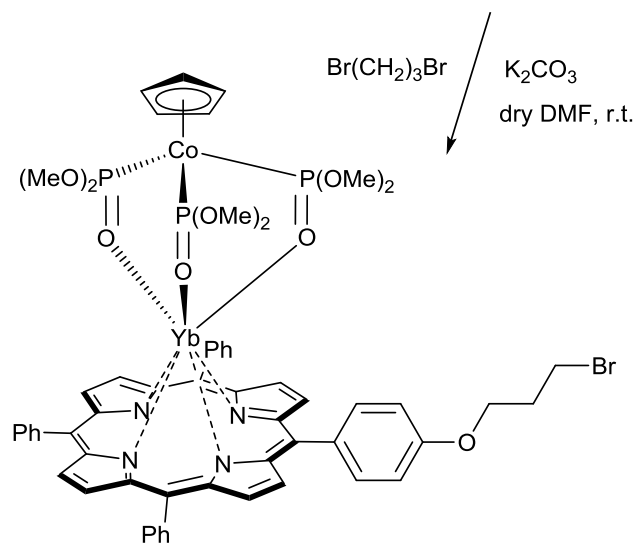

$\left[\mathrm{Yb}\left(p-\mathrm{BrC}_{3} \mathrm{O}-\mathrm{TPP}\right)\left(\mathrm{L}_{\mathrm{OMe}}\right)\right]$ $\mathrm{K}_{2} \mathrm{CO}_{3}$, dry DMF, $60^{\circ} \mathrm{C}$

35

$\mathrm{Ph}$

$M=Z n, P d, P t$

\section{Scheme 6.}




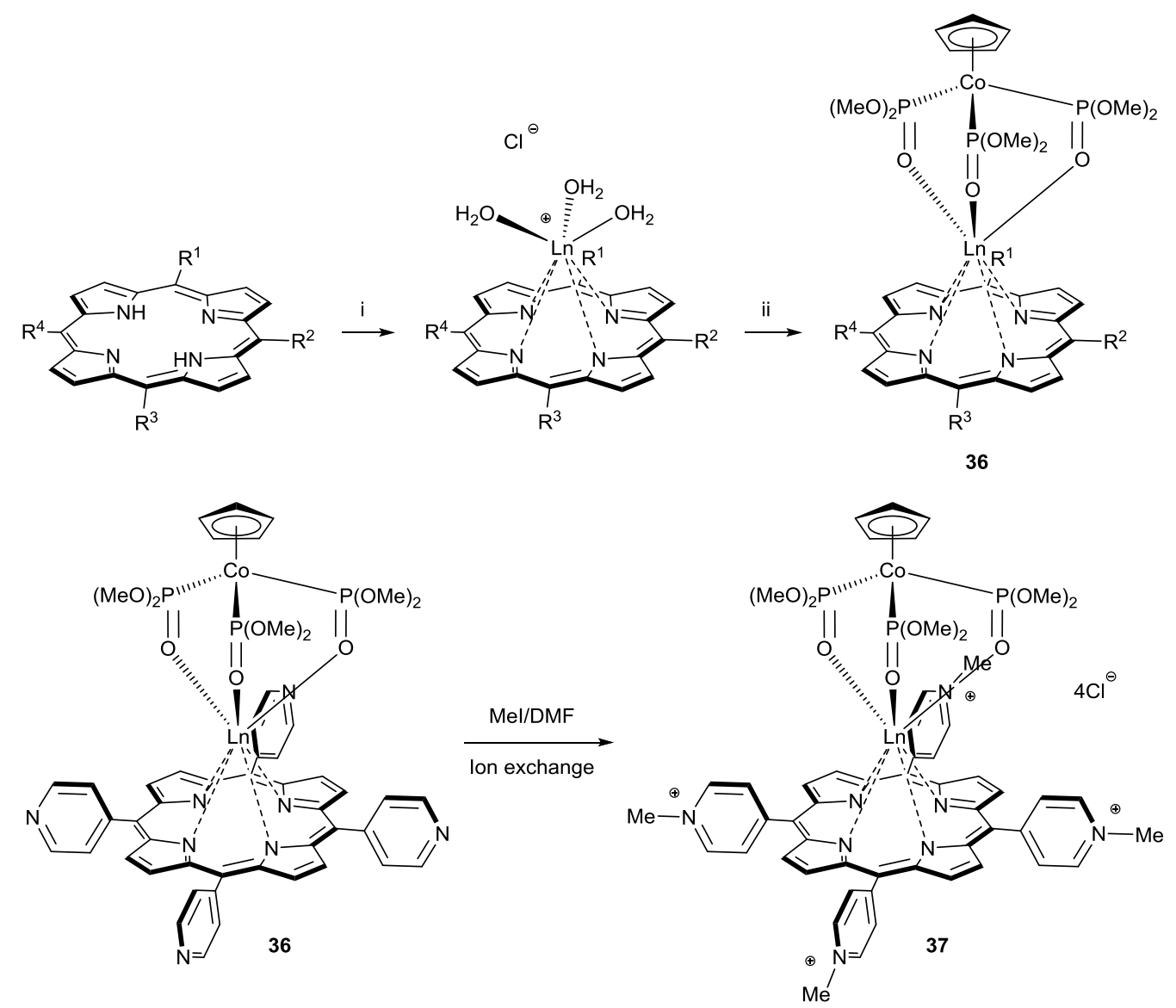

$\mathrm{Ln}=\mathrm{Er}, \mathrm{Yb} ; \mathrm{R}^{1-4}=\mathrm{Ph}, 4-\mathrm{Py}$

(i) $\left[\mathrm{Ln}\left\{\mathrm{N}\left(\mathrm{SiMe}_{3}\right)_{2}\right\}_{3}\right]$, toluene/ $\mathrm{CH}_{2} \mathrm{Cl}_{2}$, reflux, $12 \mathrm{~h}$

(ii) $\mathrm{NaL}, 20^{\circ} \mathrm{C}, 12 \mathrm{~h}$

Scheme 7. 


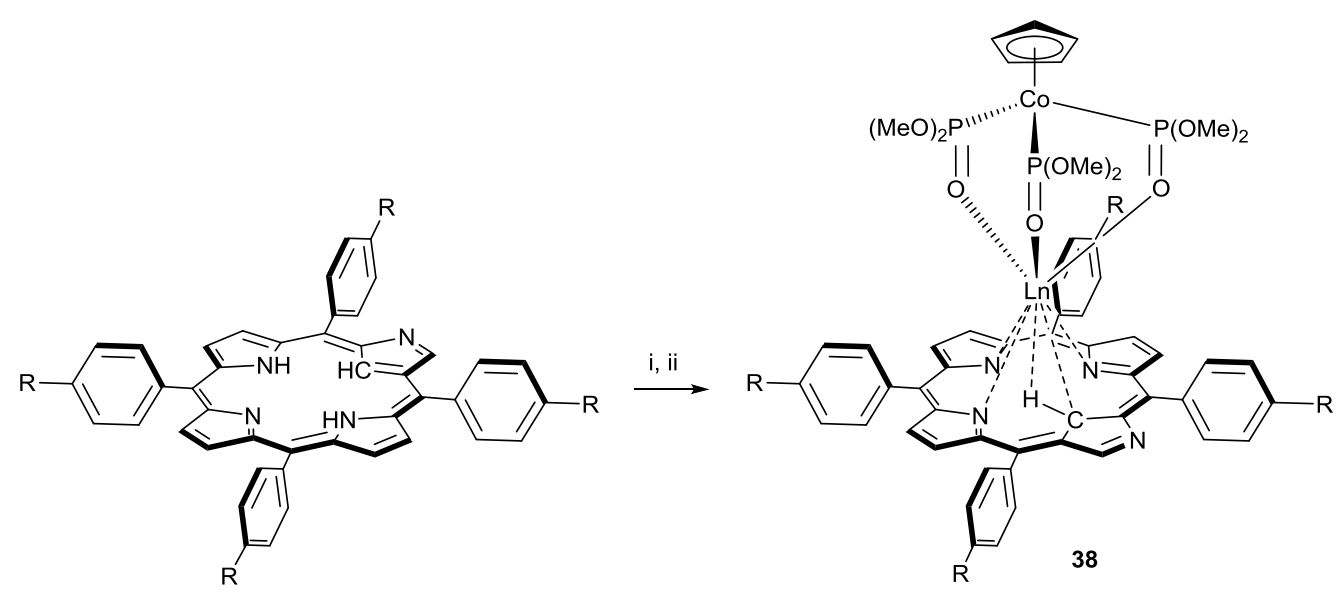

$\mathrm{Ln}=\mathrm{Er}, \mathrm{Yb} ; \mathrm{R}=\mathrm{H}, \mathrm{Me}, \mathrm{F}, \mathrm{CN}, \mathrm{C} \equiv \mathrm{CTMS}$

(i) $\left[\mathrm{Ln}\left\{\mathrm{N}\left(\mathrm{SiMe}_{3}\right)_{2}\right\}_{3}\right]$, toluene $/ \mathrm{CH}_{2} \mathrm{Cl}_{2}$, reflux, $12 \mathrm{~h}$; ii: $\mathrm{NaL}, 20^{\circ} \mathrm{C}, 12 \mathrm{~h}$
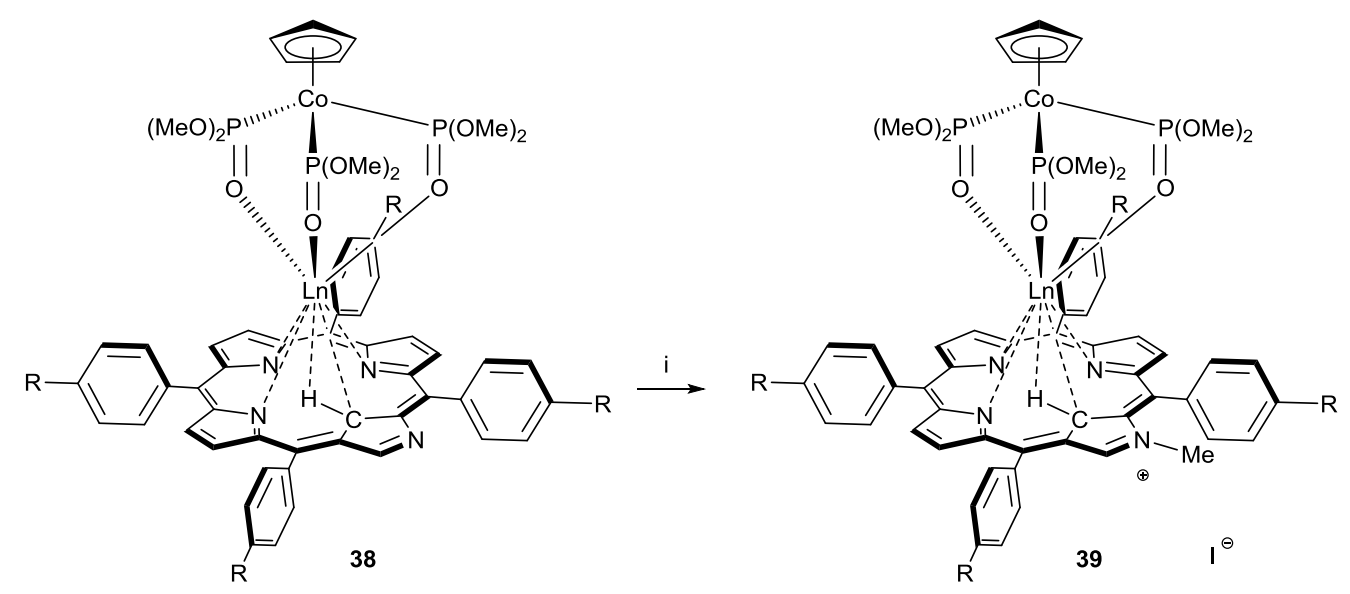

$\mathrm{Ln}=\mathrm{Er}, \mathrm{Yb} ; \mathrm{R}=\mathrm{H}, \mathrm{F}, \mathrm{CN}$

(i) $\mathrm{Mel} / \mathrm{Cs}_{2} \mathrm{CO}_{3} / \mathrm{CH}_{2} \mathrm{Cl}_{2} / \mathrm{N}_{2}$

Scheme 8. 

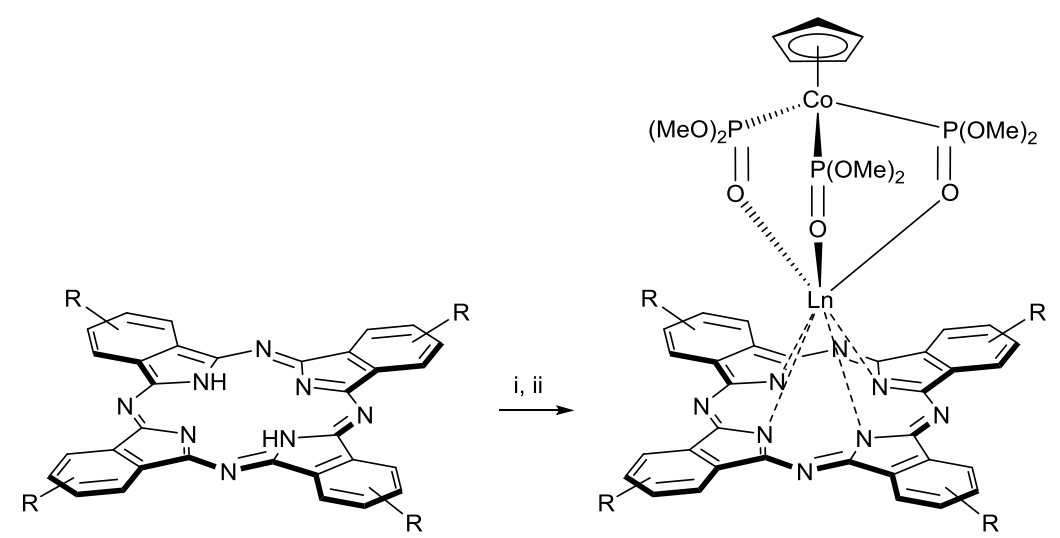

$\mathrm{Ln}=\mathrm{Dy}, \mathrm{Tb}, \mathrm{Ho}, \mathrm{Gd}, \mathrm{Er}, \mathrm{Yb} ; \mathrm{R}=\mathrm{H}(\mathbf{4 0})$, tert-Bu (41)

40, 41

(i) $\left[\mathrm{Ln}\left\{\mathrm{N}\left(\mathrm{SiMe}_{3}\right)_{2}\right\}_{3}\right] \cdot\left[\mathrm{LiCl}(\mathrm{THF})_{3}\right]_{\mathrm{x}}$, toluene, reflux, $12 \mathrm{~h}$

(ii) $\mathrm{NaL}, 20^{\circ} \mathrm{C}, 12 \mathrm{~h}$

\section{Scheme 9.}




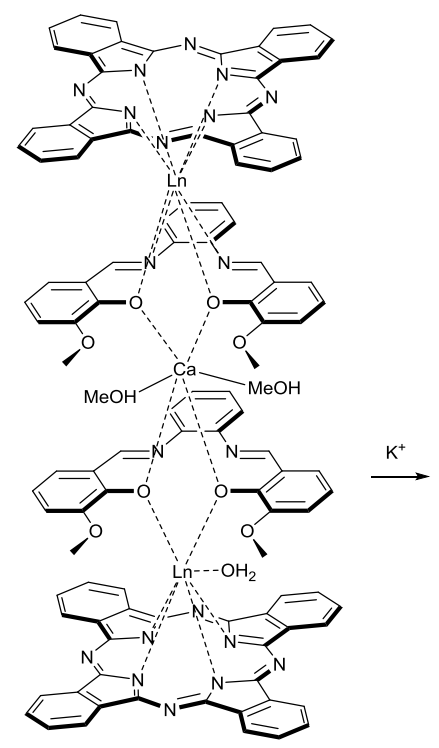

44

$\operatorname{Ln}=\mathrm{Dy}, \mathrm{Y}$

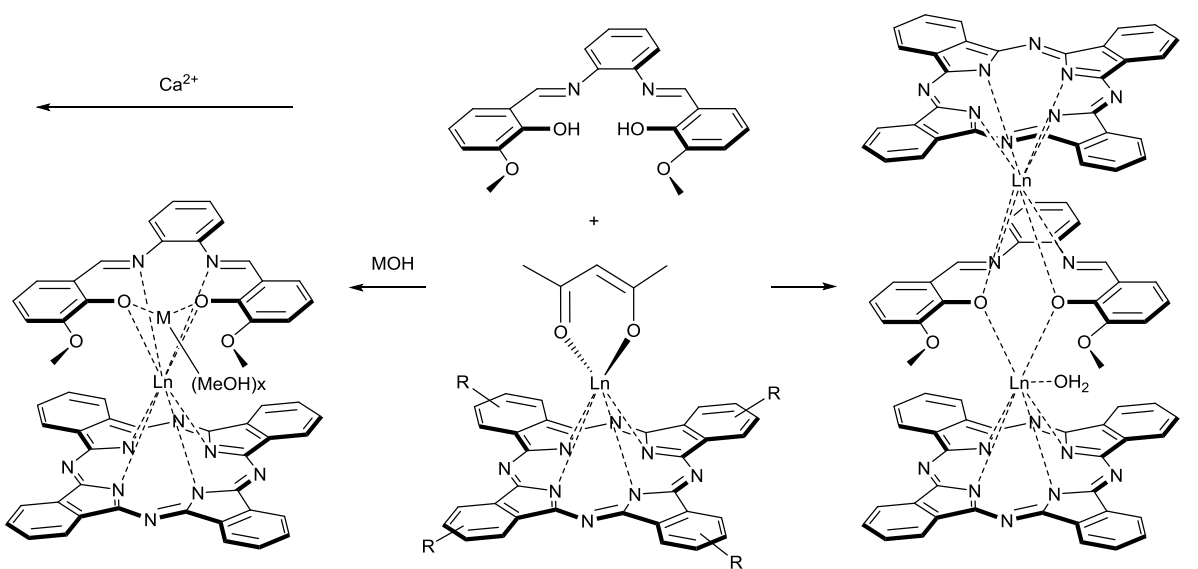

42

$\mathrm{Ln}=\mathrm{Tb}, \mathrm{Dy}, \mathrm{Y}$

$X=1$ for $M=N a, K, R b, C s$

$\mathrm{X}=2$ for $\mathrm{M}=\mathrm{Li}$
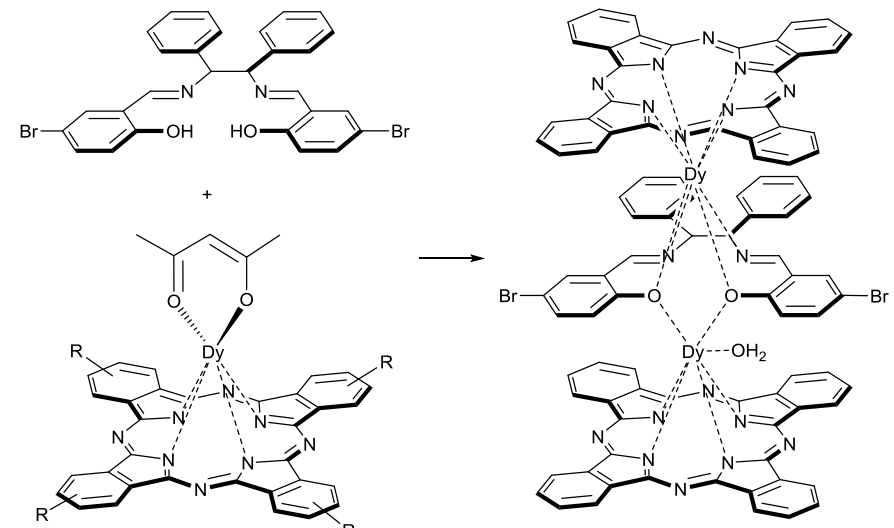

45

Scheme 10. 


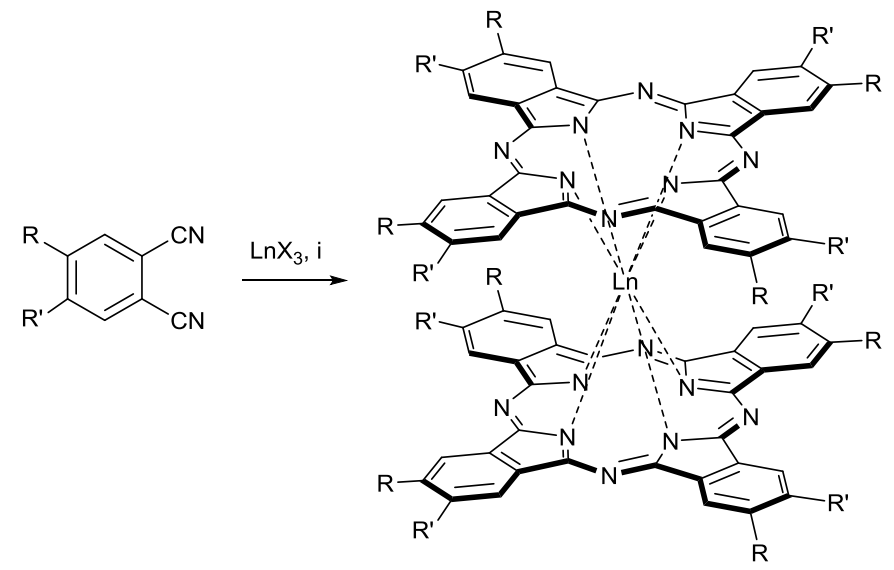

(i) $1: 250-350{ }^{\circ} \mathrm{C}, 0.5-4 \mathrm{~h}$

2: $\mathrm{MW}(300-700 \mathrm{~W}), 5-10 \mathrm{~min}$

3: $\mathrm{DBU}, \mathrm{YOH}\left(\mathrm{Y}=n-\mathrm{C}_{6} \mathrm{H}_{13}(a), i-\mathrm{C}_{5} \mathrm{H}_{11}(b), n-\mathrm{C}_{5} \mathrm{H}_{11}(c)\right)$ or sulfolane $(d), 130-160{ }^{\circ} \mathrm{C}, 5-48 \mathrm{~h}$

\section{Scheme 11.}



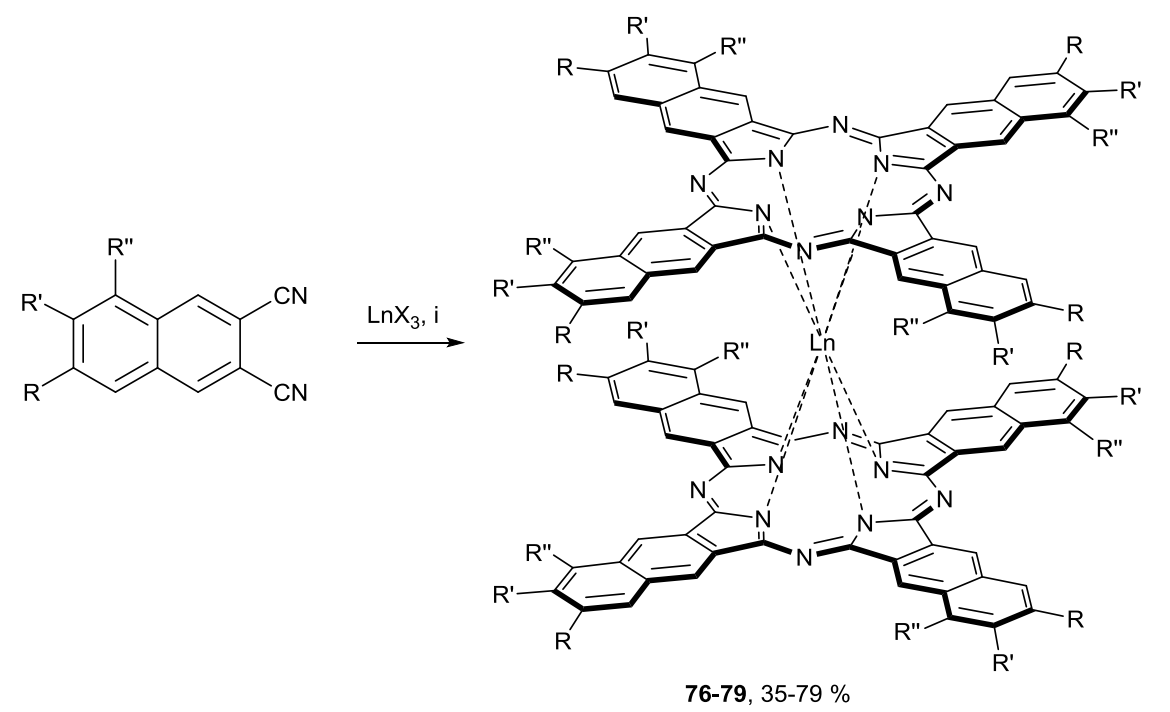

$\mathrm{R}=$ tert-Bu, $\mathrm{R}^{\prime}=\mathrm{H}, \mathrm{R}^{\prime \prime}=\mathrm{Br} ; \mathrm{Ln}=\mathrm{Lu} ; \mathrm{X}=\mathrm{OAc}(\mathbf{7 6})$

$\mathrm{R}=\mathrm{R}^{\prime}=\mathrm{PhO}, \mathrm{R}^{\prime \prime}=\mathrm{H} ; \mathrm{Ln}=\mathrm{Eu}, \mathrm{Er}, \mathrm{Lu} ; \mathrm{X}=\mathrm{OAc}(\mathbf{7 7})$

$\mathrm{R}=$ tert-Bu, R' = R" = H; Ln = La, Ce, Pr, Nd, Eu, Gd, Tb, Er, Y; X = acac (78)

$\mathrm{R}=\mathrm{R}^{\prime}=\mathrm{C}_{12} \mathrm{H}_{25} \mathrm{~S}, \mathrm{R}^{\prime \prime}=\mathrm{H} ; \mathrm{Ln}=\mathrm{Eu} ; \mathrm{X}=\operatorname{acac}(79)$

(i) $1: 280-310^{\circ} \mathrm{C}, 2-4 \mathrm{~h}$

2: $\mathrm{MW}(700 \mathrm{~W})$, 5-7 $\mathrm{min}$

3: $\mathrm{DBU}, n-\mathrm{C}_{8} \mathrm{H}_{17} \mathrm{OH}, 190^{\circ} \mathrm{C},>18 \mathrm{~h}$

\section{Scheme 12.}




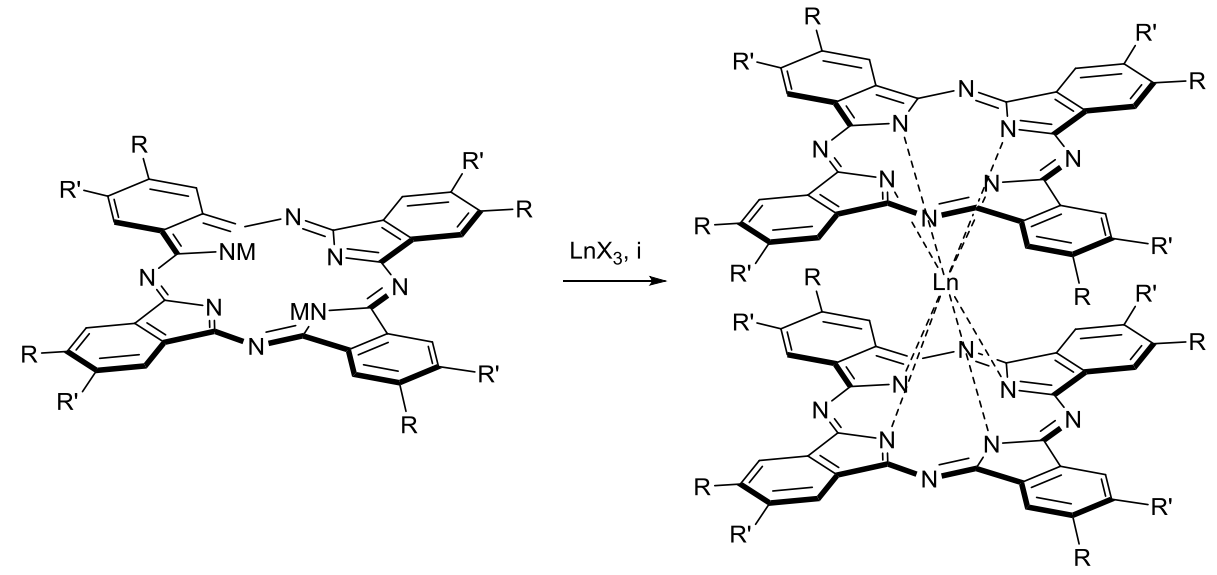

$46,47,54-56,80-86$

$M=H, L i ; X=O A c$, acac

(i) 1: quinoline, $240^{\circ} \mathrm{C}(a) ; \mathrm{TCB}, 220^{\circ} \mathrm{C}(b) ; n-\mathrm{C}_{8} \mathrm{H}_{17} \mathrm{OH}, 190^{\circ} \mathrm{C}(c) ; n-\mathrm{C}_{16} \mathrm{H}_{33} \mathrm{OH}, 230^{\circ} \mathrm{C}(d)$

2: DBU, $n-\mathrm{C}_{6} \mathrm{H}_{13} \mathrm{OH}(a), n-\mathrm{C}_{5} \mathrm{H}_{11} \mathrm{OH}(b), n-\mathrm{C}_{8} \mathrm{H}_{17} \mathrm{OH}(c), 130-190{ }^{\circ} \mathrm{C}, 2-3 \mathrm{~h} ; \mathrm{DBU}, 1-\mathrm{CIN}, 260{ }^{\circ} \mathrm{C}, 1-2 \mathrm{~h}(d)$

3: DBU, MW (240 W), $10 \mathrm{~min}$

4: $n-\mathrm{C}_{5} \mathrm{H}_{11} \mathrm{OK}, n-\mathrm{C}_{5} \mathrm{H}_{11} \mathrm{OH}, 135^{\circ} \mathrm{C}$

\section{Scheme 13.}




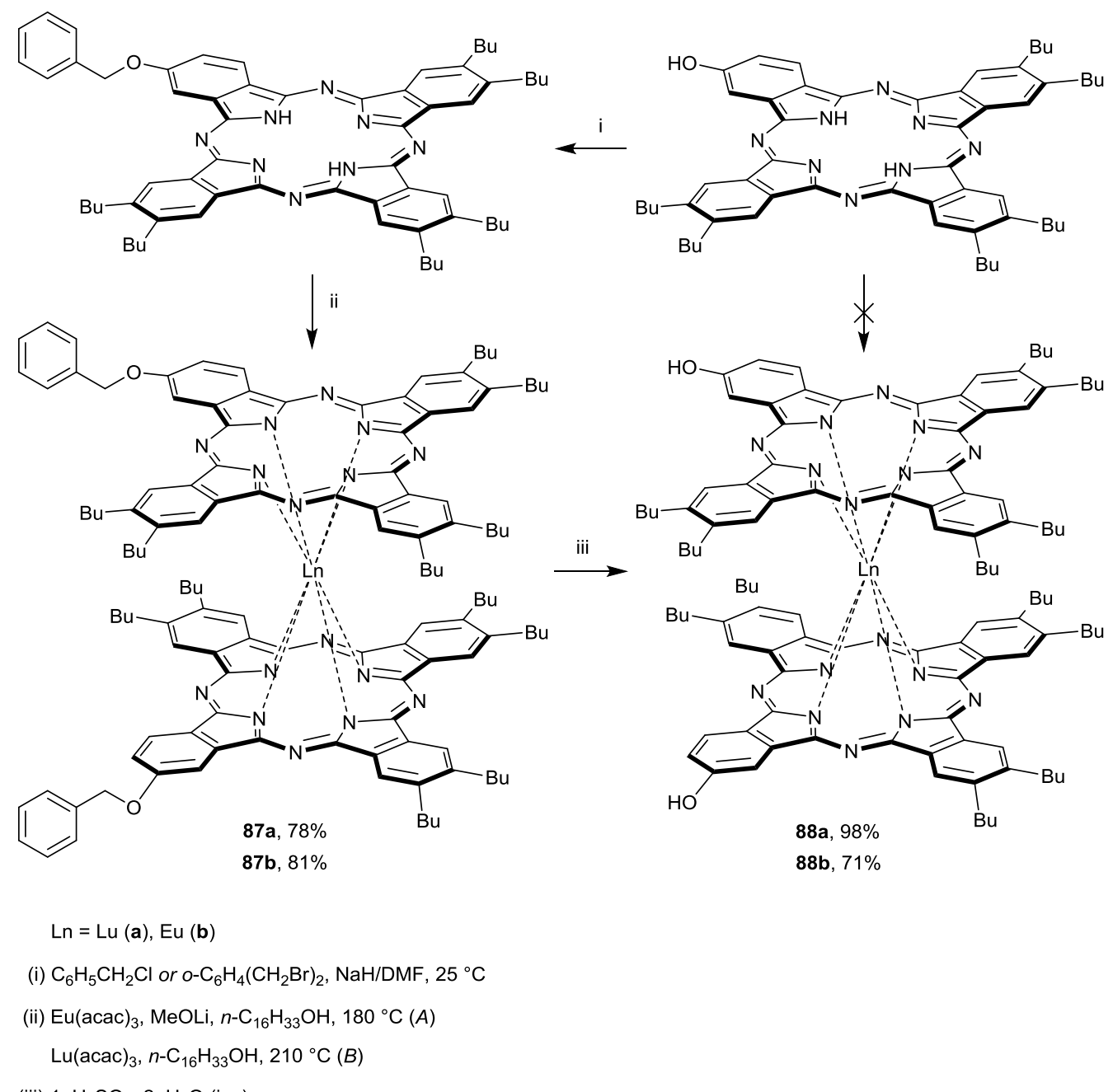

(iii) 1. $\mathrm{H}_{2} \mathrm{SO}_{4} ; 2 . \mathrm{H}_{2} \mathrm{O}$ (ice)

Scheme 14. 


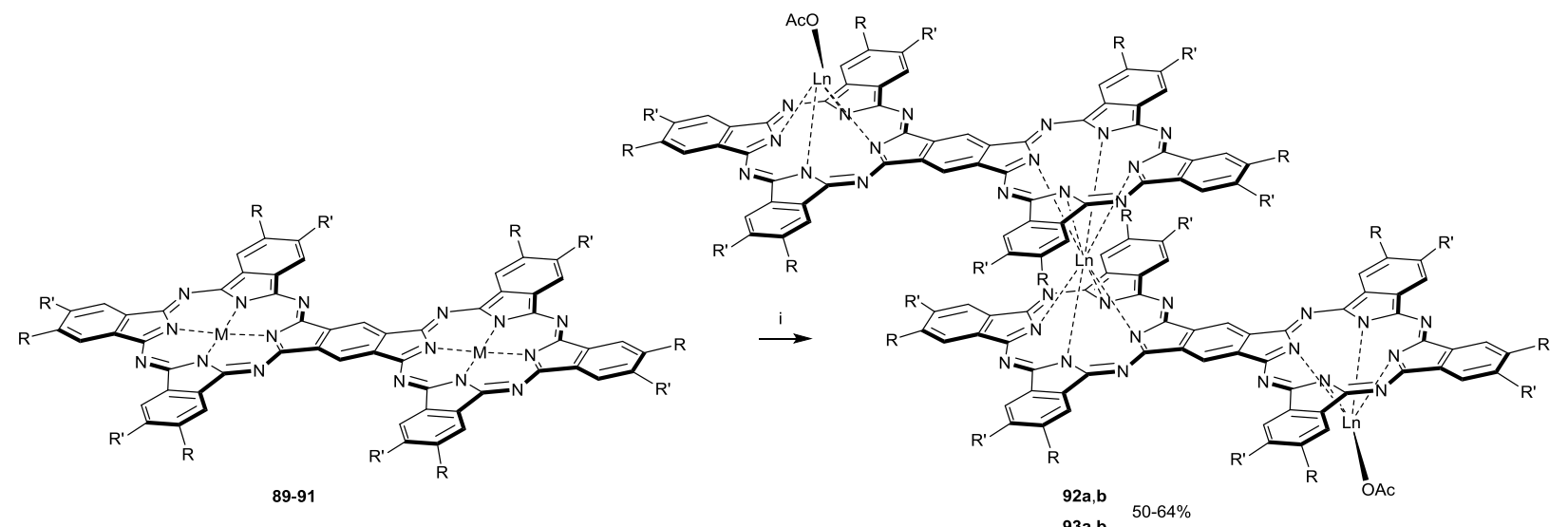

$\mathrm{R}=$ tert-Bu, $\mathrm{R}^{\prime}=\mathrm{H}(\mathbf{8 9}, \mathbf{9 1}, \mathbf{9 2}, \mathbf{9 4})$

$\mathrm{R}=\mathrm{R}^{\prime}=n-\mathrm{Bu}(90,93)$

$M=2 H(89,90)$, LuOAC (91)

$\operatorname{Ln}=\operatorname{Lu}(\mathbf{a}), \mathrm{Eu}(\mathbf{b})$

(i) $\mathrm{Ln}(\mathrm{OAc})_{3} \cdot n \mathrm{H}_{2} \mathrm{O}$ (for 89, 90), MeOLi, TCB- $n-\mathrm{C}_{16} \mathrm{H}_{33} \mathrm{OH}(50: 1), 215^{\circ} \mathrm{C}$

(ii) $1 . \mathrm{H}_{2} \mathrm{SO}_{4} ; 2 . \mathrm{H}_{2} \mathrm{O}$ (ice)

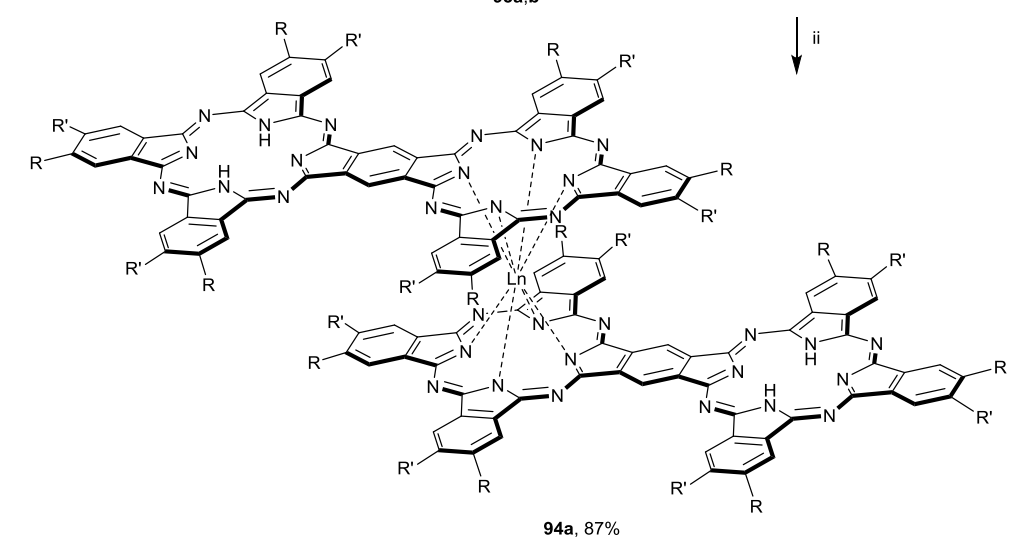

Scheme 15. 


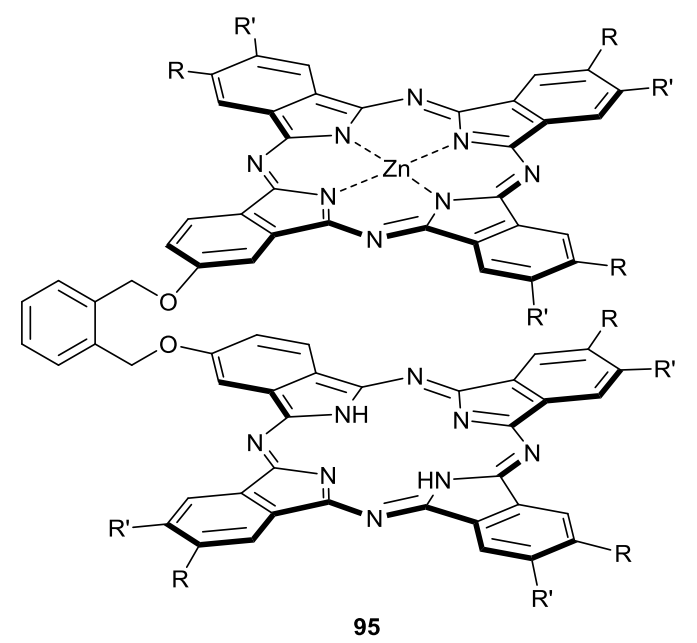

$\mathrm{R}=\mathrm{H}, \mathrm{R}^{\prime}=$ tert $-\mathrm{Bu}$

(i) $\mathrm{Lu}(\mathrm{acac})_{3}, \mathrm{MeOLi}, n-\mathrm{C}_{16} \mathrm{H}_{33} \mathrm{OH}, 220^{\circ} \mathrm{C}$

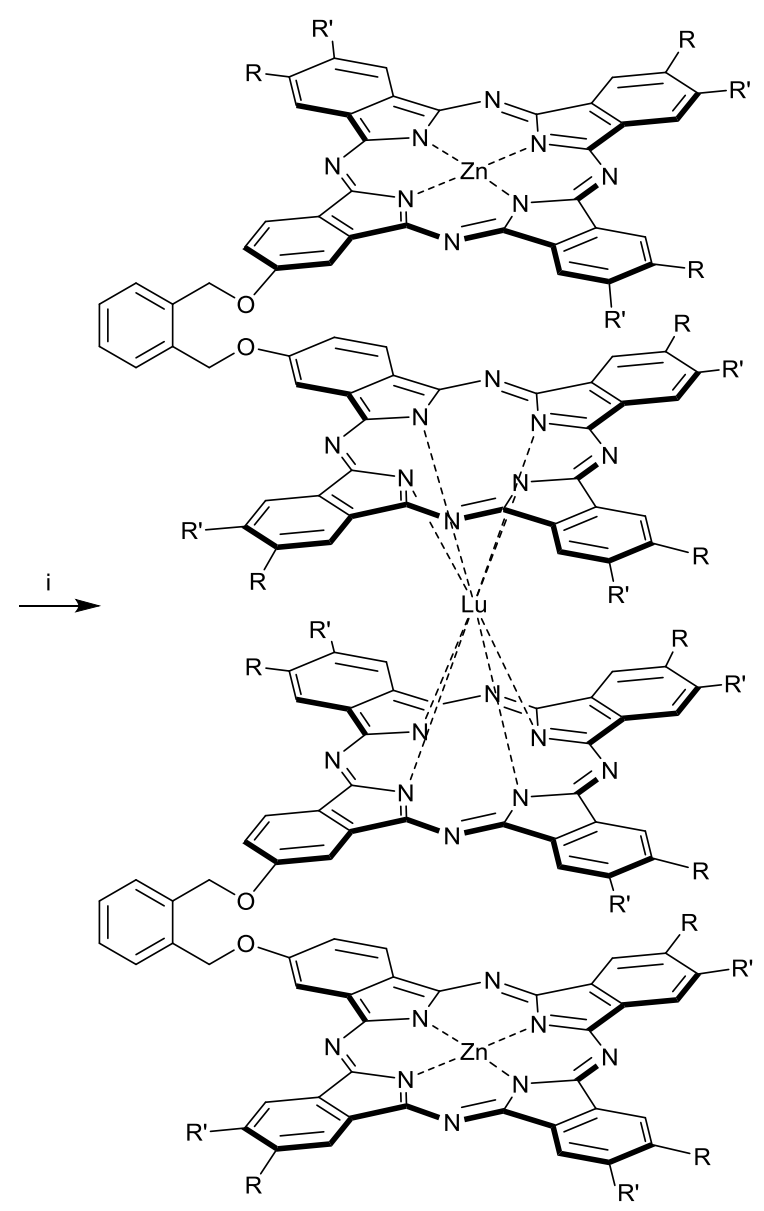

$96,45 \%$

\section{Scheme 16.}



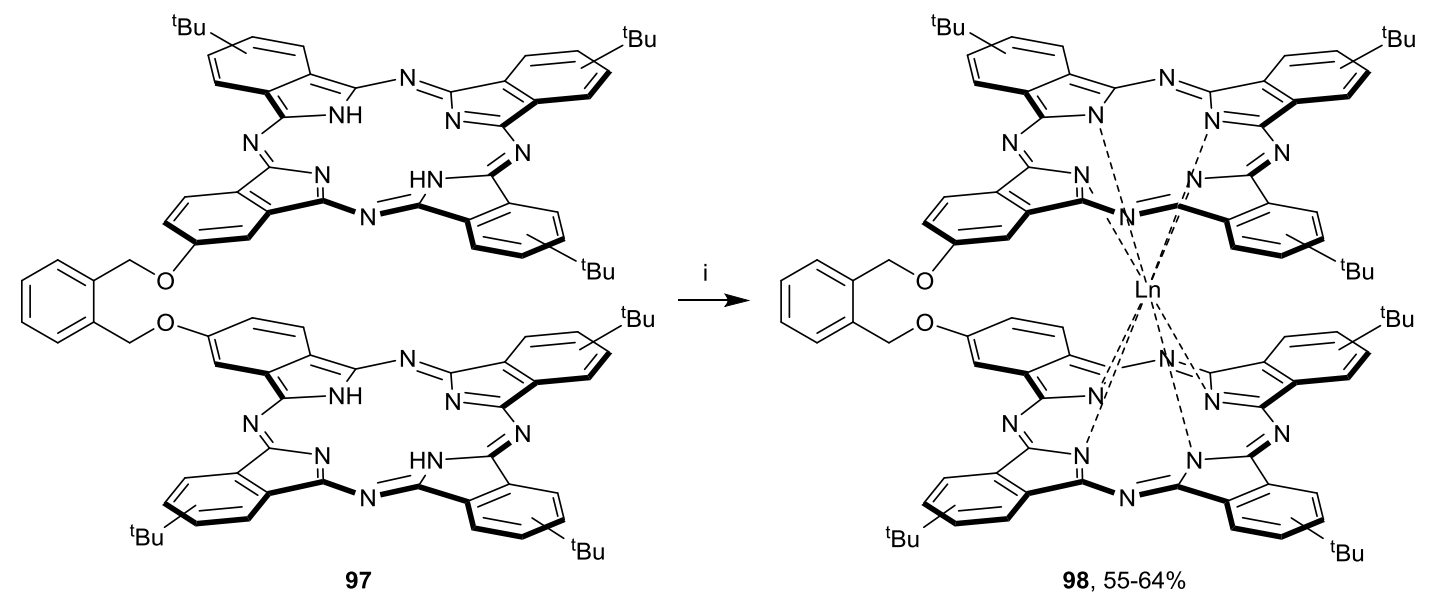

$\operatorname{Ln}=\operatorname{Lu}(\mathbf{a}), \operatorname{Dy}(\mathbf{b}), \mathrm{Eu}(\mathbf{c})$

(i) $\mathrm{Ln}(\mathrm{acac})_{3}, \mathrm{MeOLi}, n-\mathrm{C}_{16} \mathrm{H}_{33} \mathrm{OH}, 180-200{ }^{\circ} \mathrm{C}$

Scheme 17. 


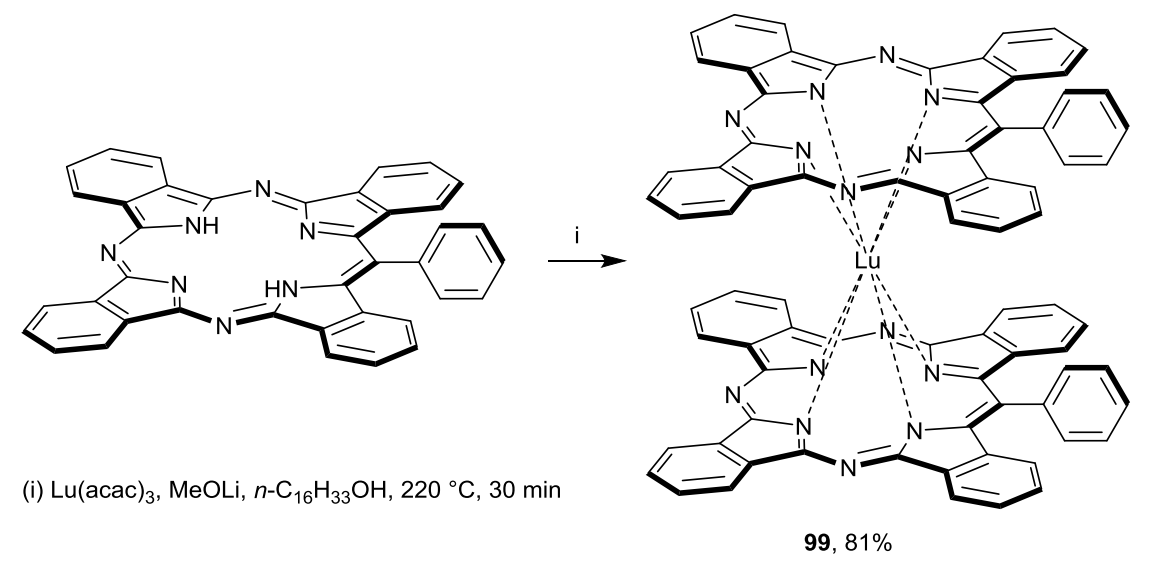

Scheme 18. 

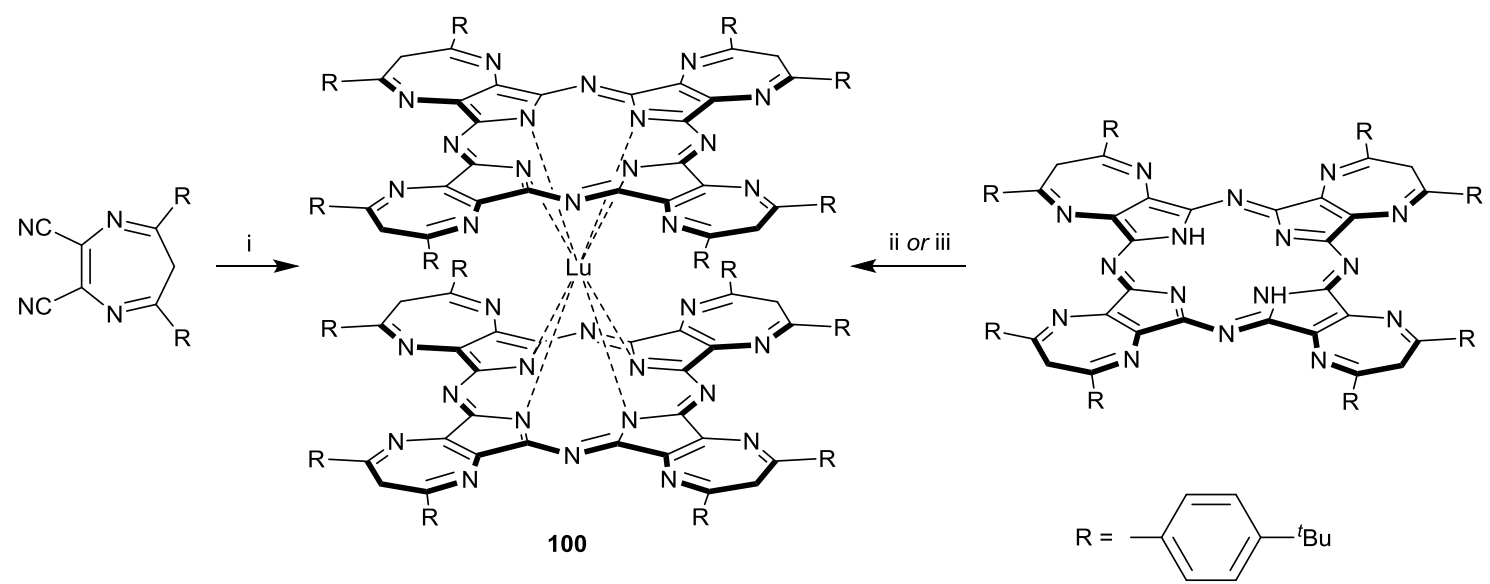
(i) $\mathrm{Lu}(\mathrm{CHOO})_{3}, \mathrm{DBU}, i-\mathrm{C}_{5} \mathrm{H}_{11} \mathrm{OH}$, reflux, $19 \mathrm{~h}$ (5\% yield)
(ii) $\mathrm{Lu}(\mathrm{CHOO})_{3}, \mathrm{DBU}, \mathrm{o}-\mathrm{DCB}$, reflux, $4.5 \mathrm{~h}$ (30\% yield)
(iii) $\mathrm{Lu}(\mathrm{acac})_{3}, \mathrm{DBU}, \mathrm{o}-\mathrm{DCB}$, reflux, $3 \mathrm{~h}$ ( $85 \%$ yield)

Scheme 19. 


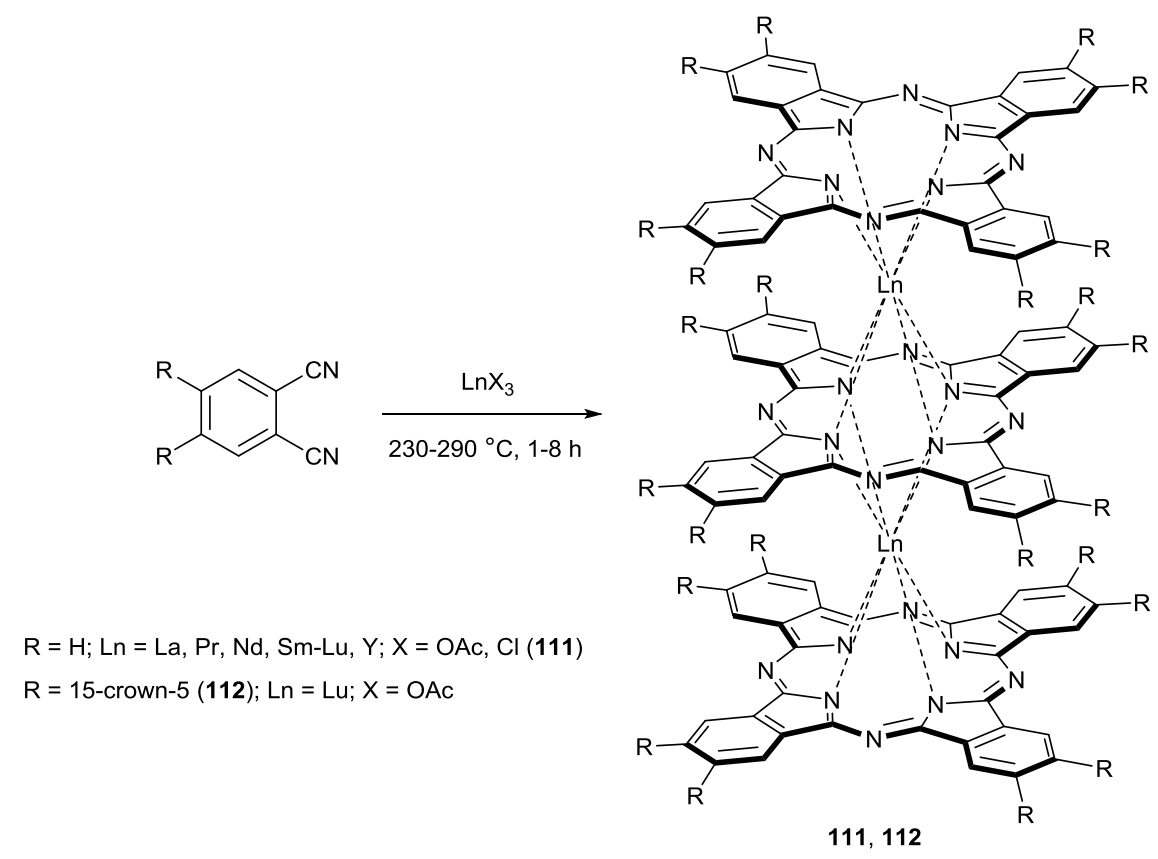

Scheme 20. 


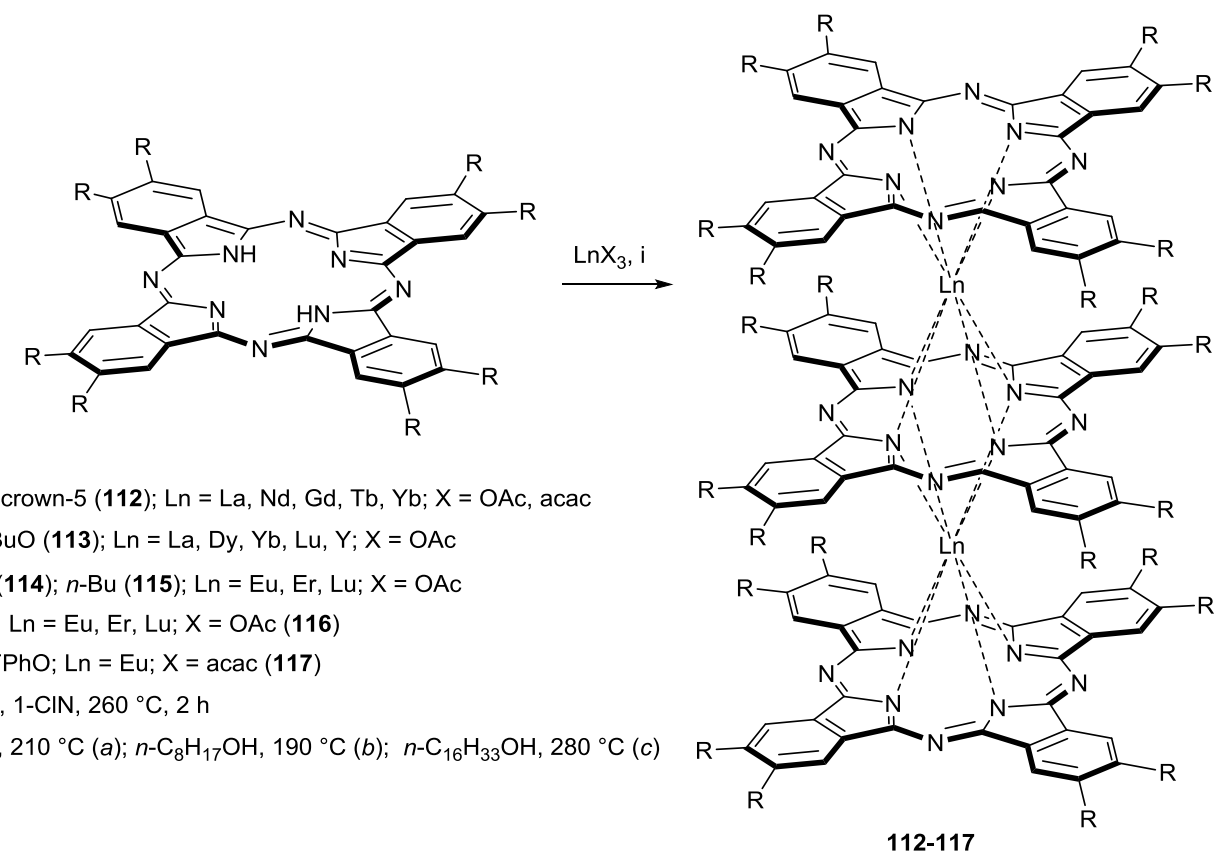

Scheme 21. 


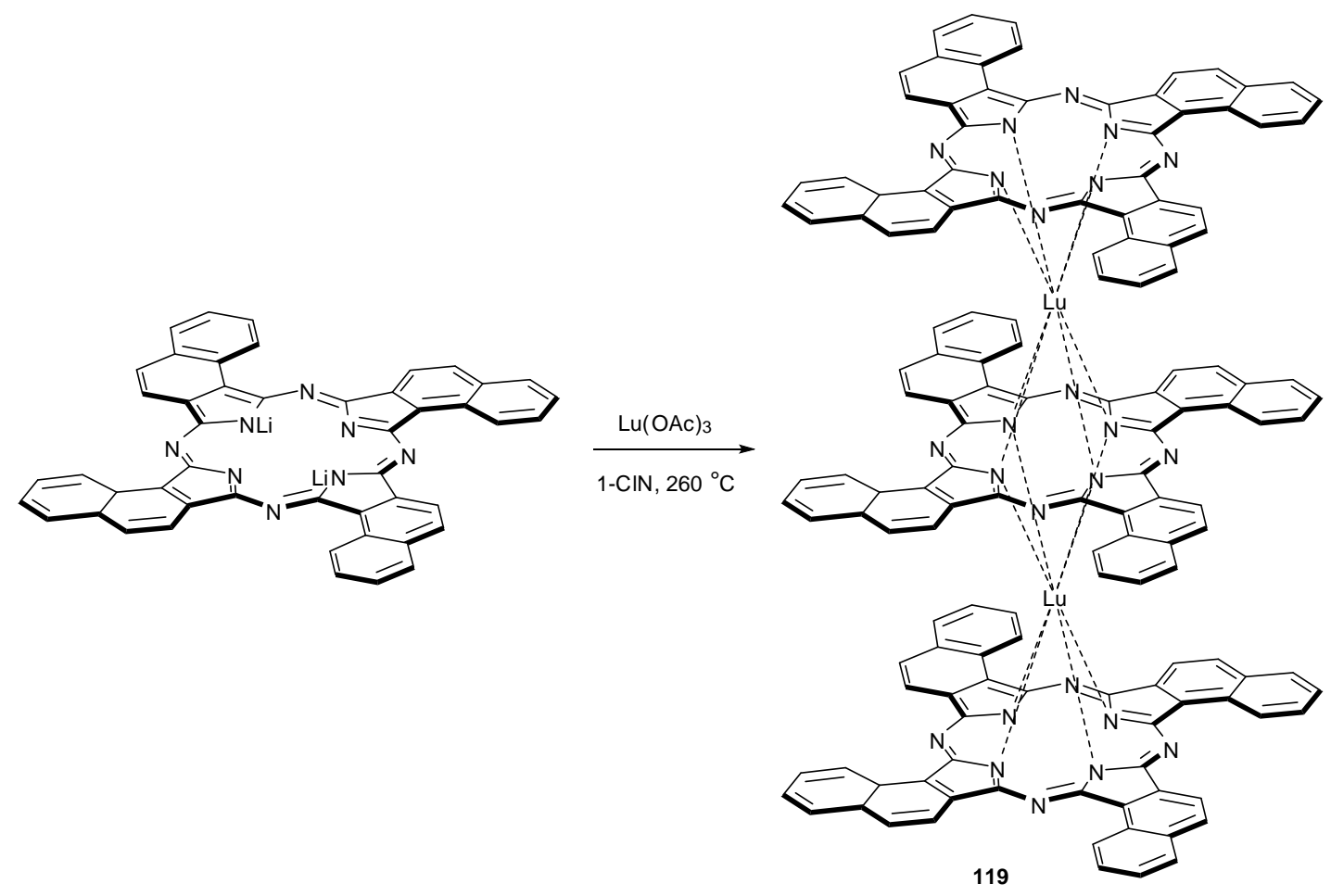

Scheme 22. 


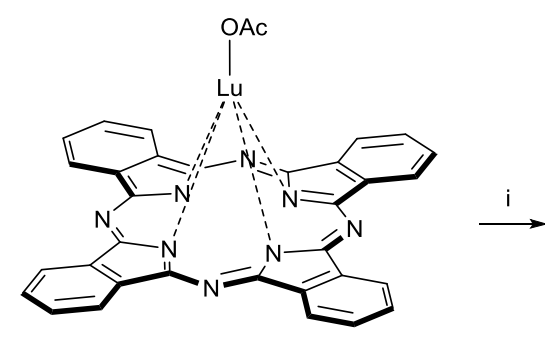

(i) 1 torr, $400^{\circ} \mathrm{C}, 4 \mathrm{~h}$

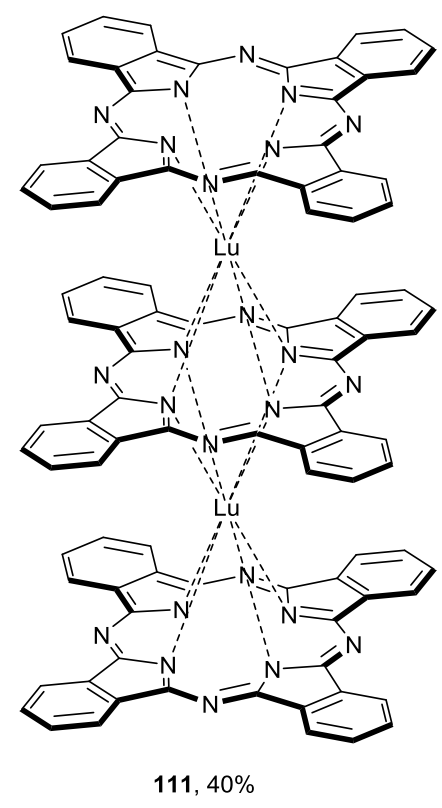

Scheme 23. 

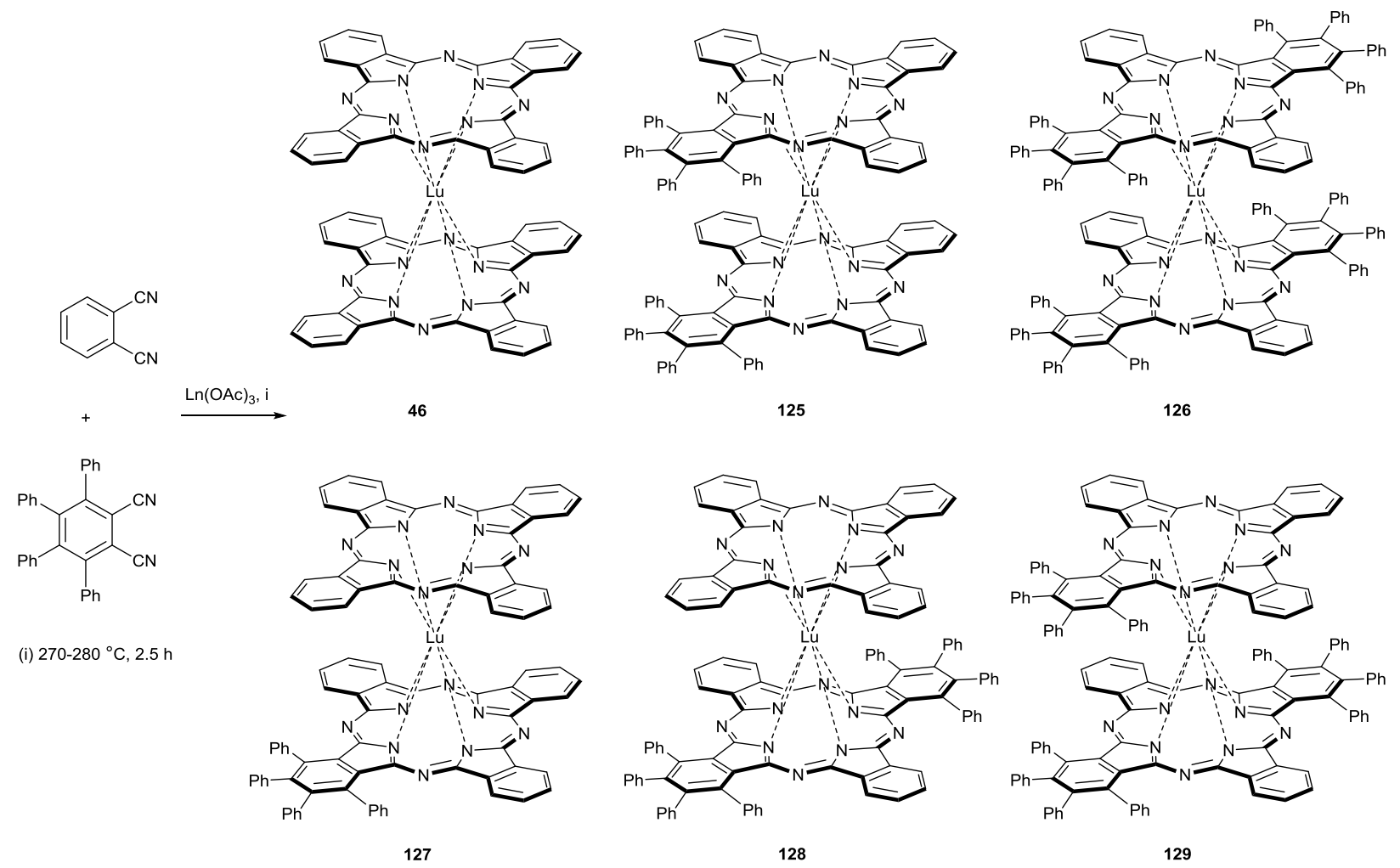

Scheme 24. 

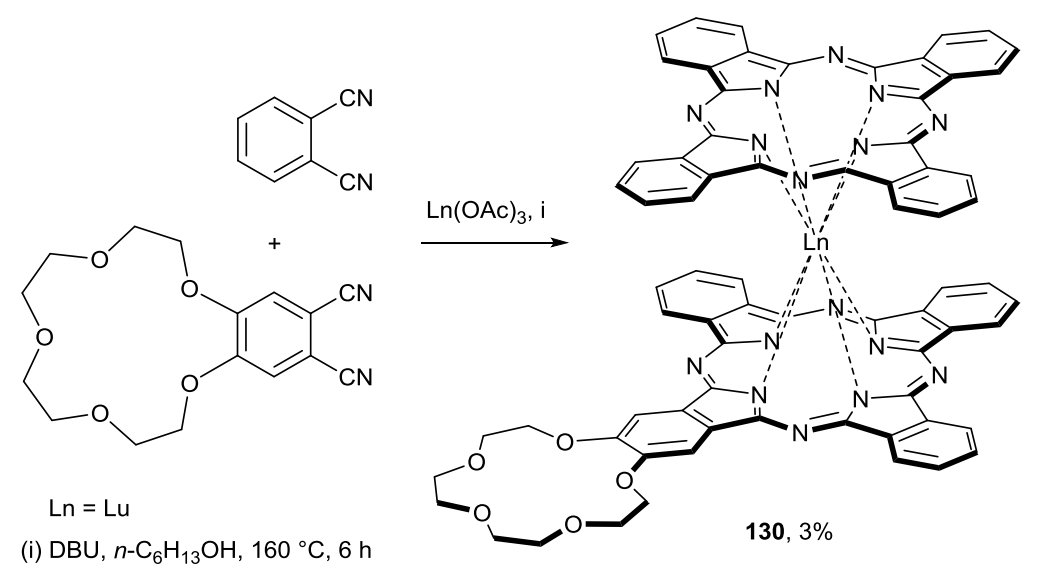

Scheme 25. 


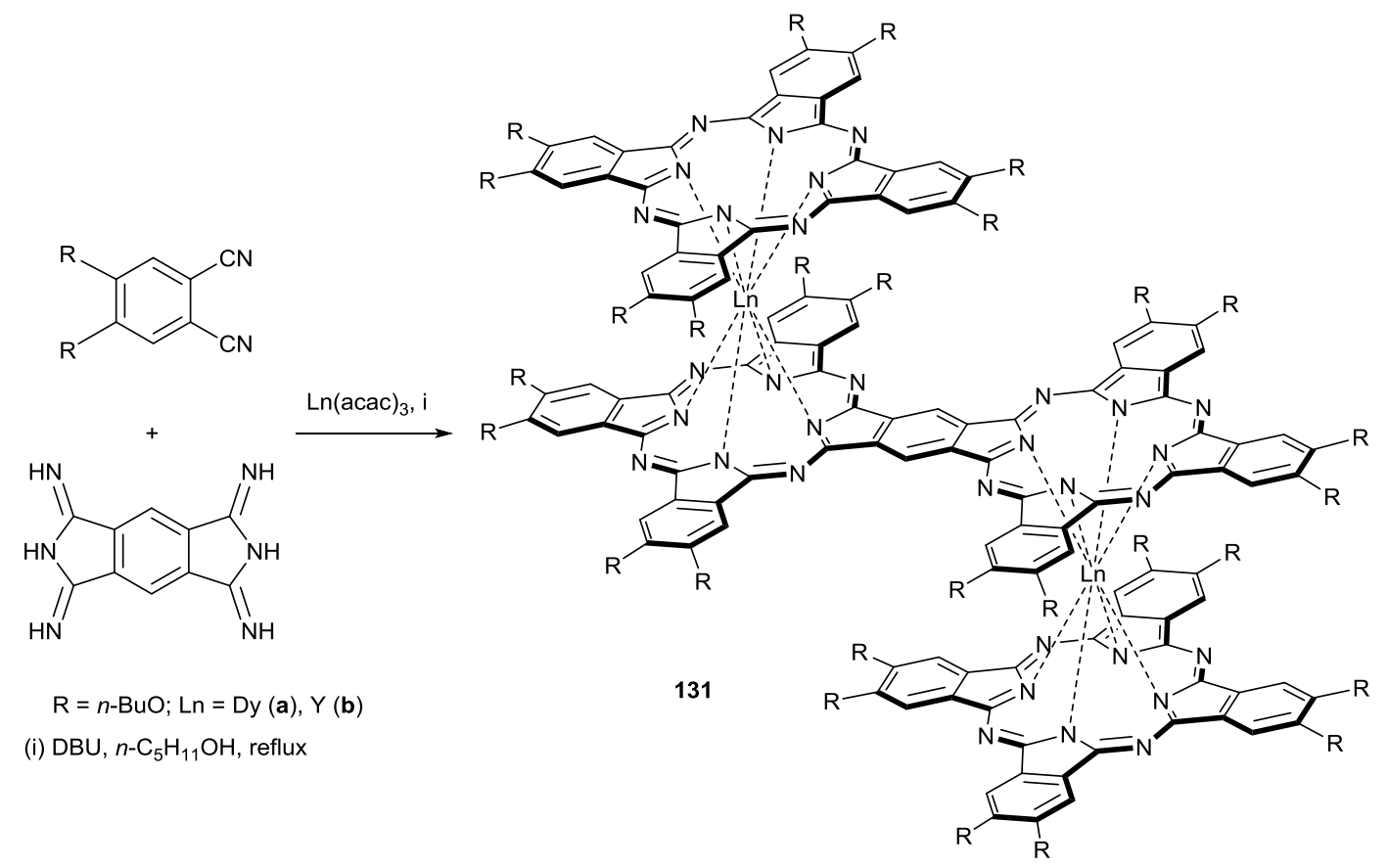

Scheme 26. 


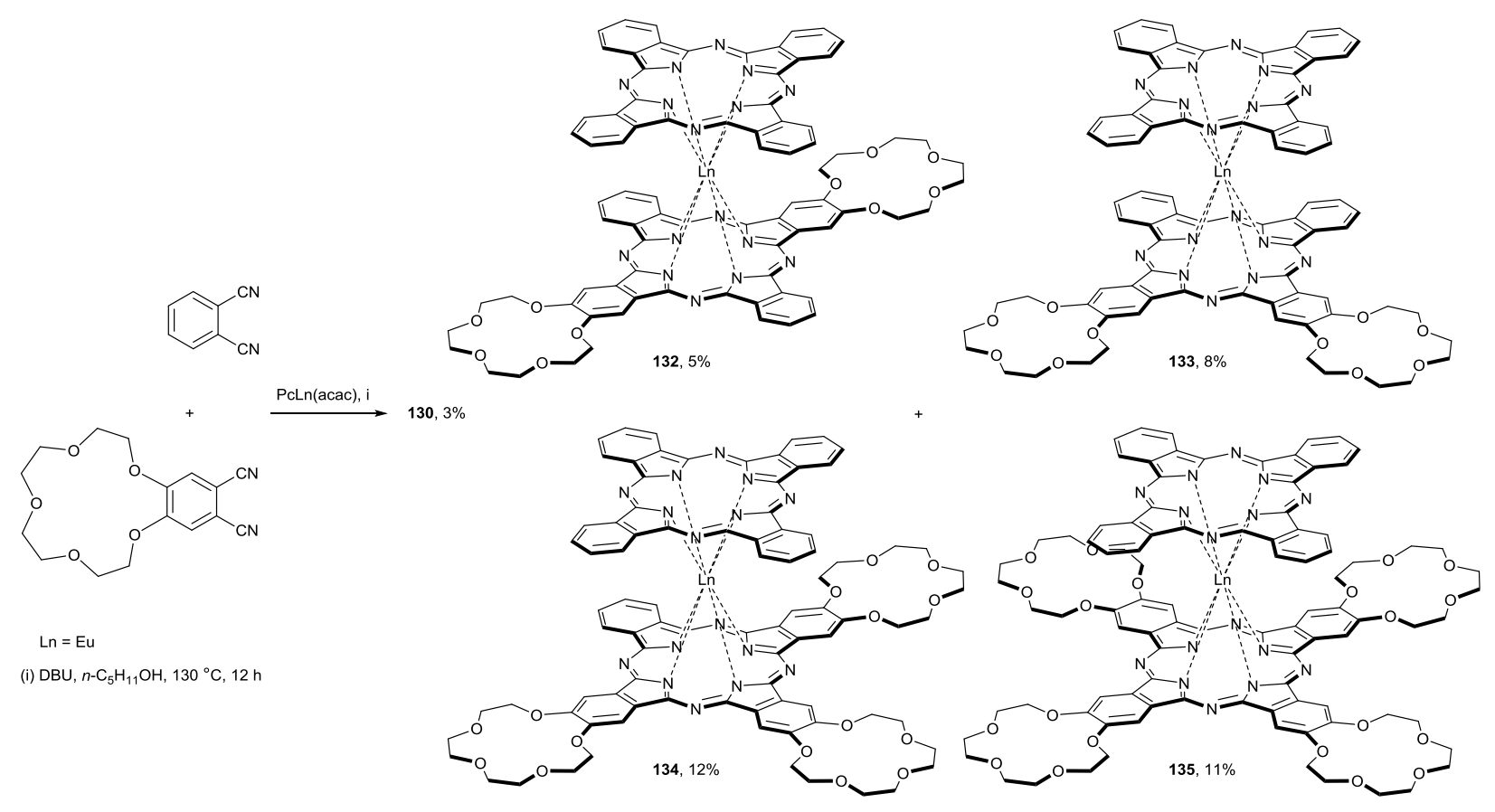

Scheme 27. 

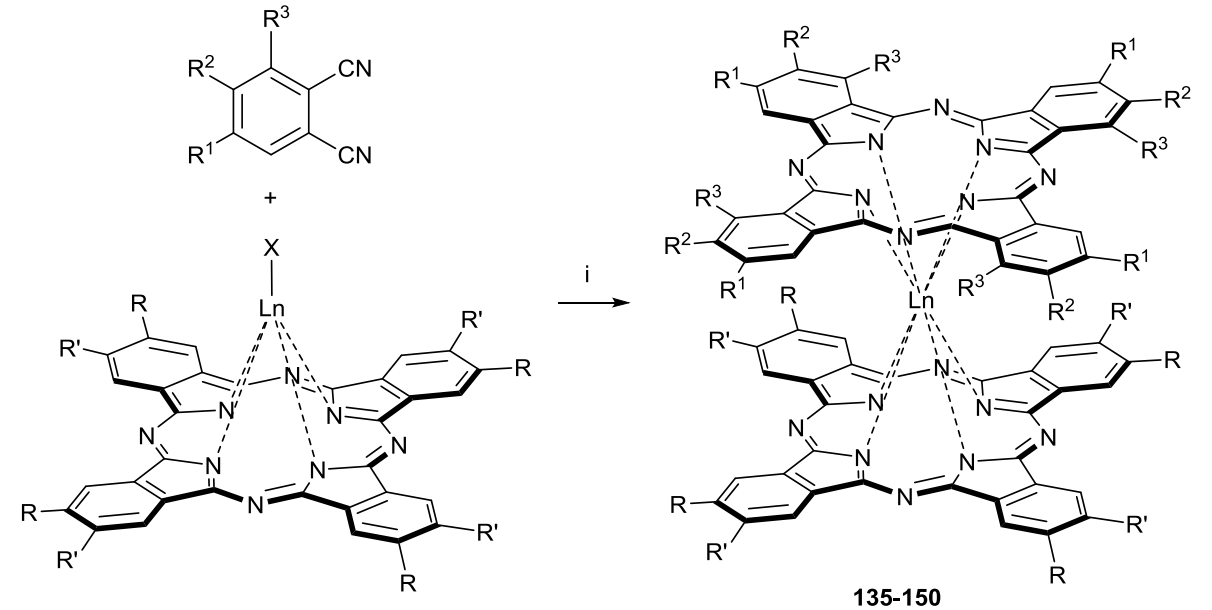

(i) $1: 240-310^{\circ} \mathrm{C}, 0.5-3 \mathrm{~h}$

2: $\mathrm{DBU}, \mathrm{YOH}\left(\mathrm{Y}=n-\mathrm{C}_{6} \mathrm{H}_{13}(a), n-\mathrm{C}_{5} \mathrm{H}_{11}(b)\right), 130-160{ }^{\circ} \mathrm{C}, 6-20 \mathrm{~h}$

2c: DBU, 1-CIN- $n-\mathrm{C}_{4} \mathrm{H}_{9} \mathrm{OH}$ (1:1, vol.), reflux, $2 \mathrm{~h}$

3: $\mathrm{Li}, n-\mathrm{C}_{5} \mathrm{H}_{11} \mathrm{OH}, 130{ }^{\circ} \mathrm{C}, 17 \mathrm{~h}$

\section{Scheme 28.}




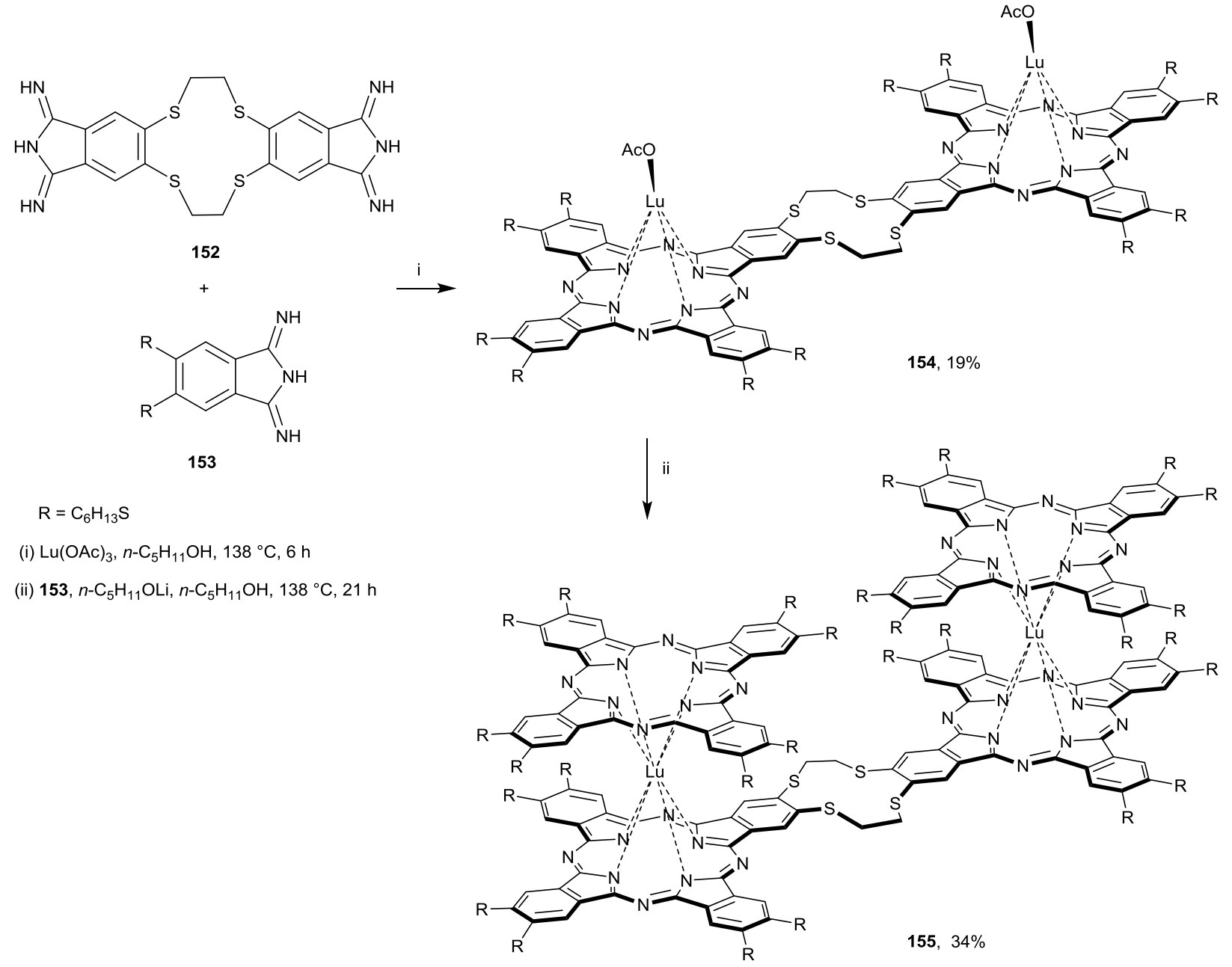

Scheme 29. 

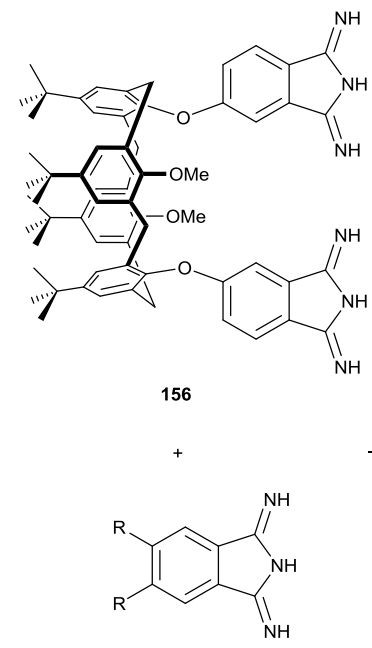

153

$\mathrm{R}=\mathrm{C}_{6} \mathrm{H}_{13} \mathrm{~S}$

(i) $\mathrm{Lu}(\mathrm{OAc})_{3}, \mathrm{DMF}, 153^{\circ} \mathrm{C}, 24 \mathrm{~h}$

(ii) $153, n-\mathrm{C}_{5} \mathrm{H}_{11} \mathrm{OLi}, n-\mathrm{C}_{5} \mathrm{H}_{11} \mathrm{OH}, 138^{\circ} \mathrm{C}, 29 \mathrm{~h}$

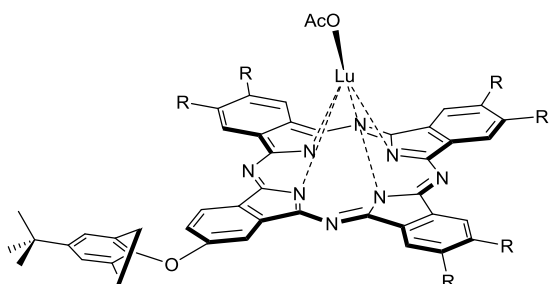

i.
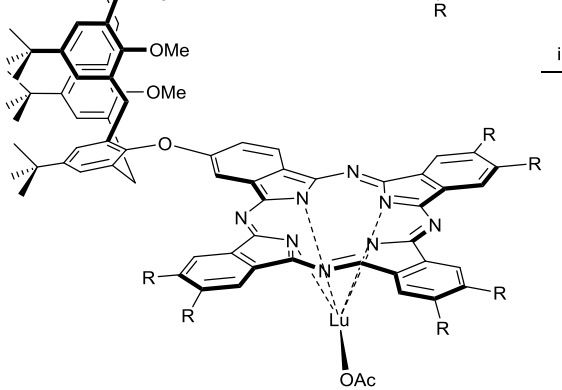

$157,18 \%$

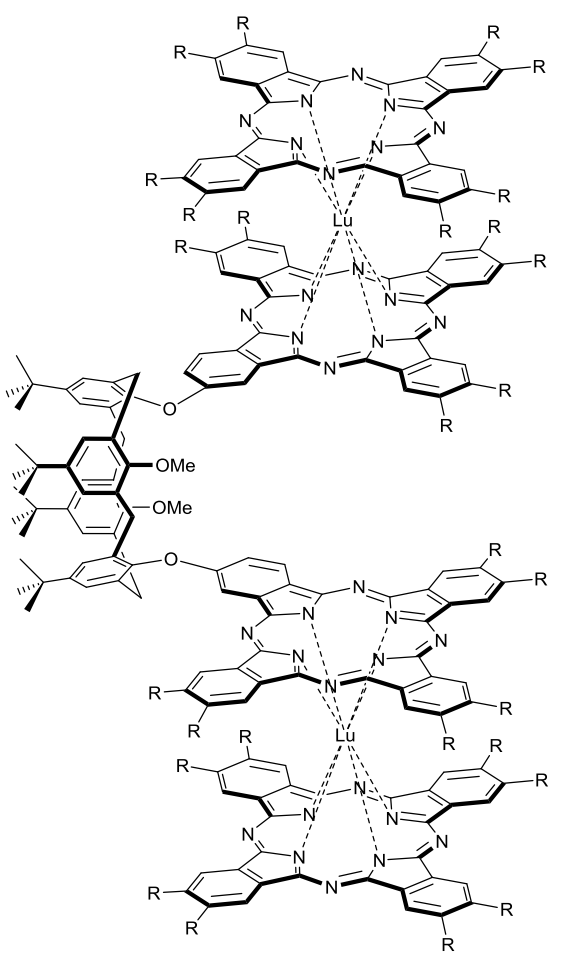

158, $46 \%$

Scheme 30. 

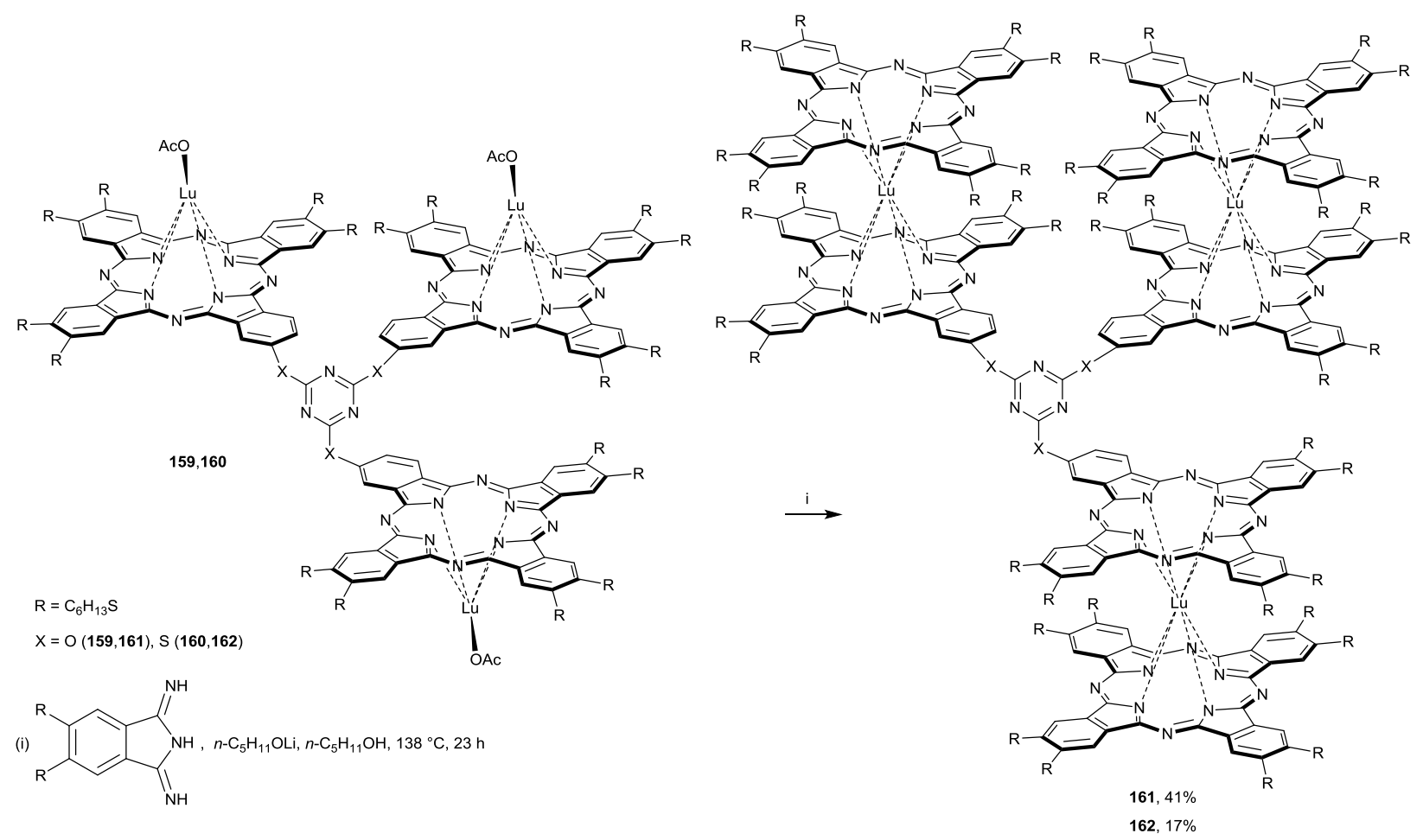

Scheme 31 . 

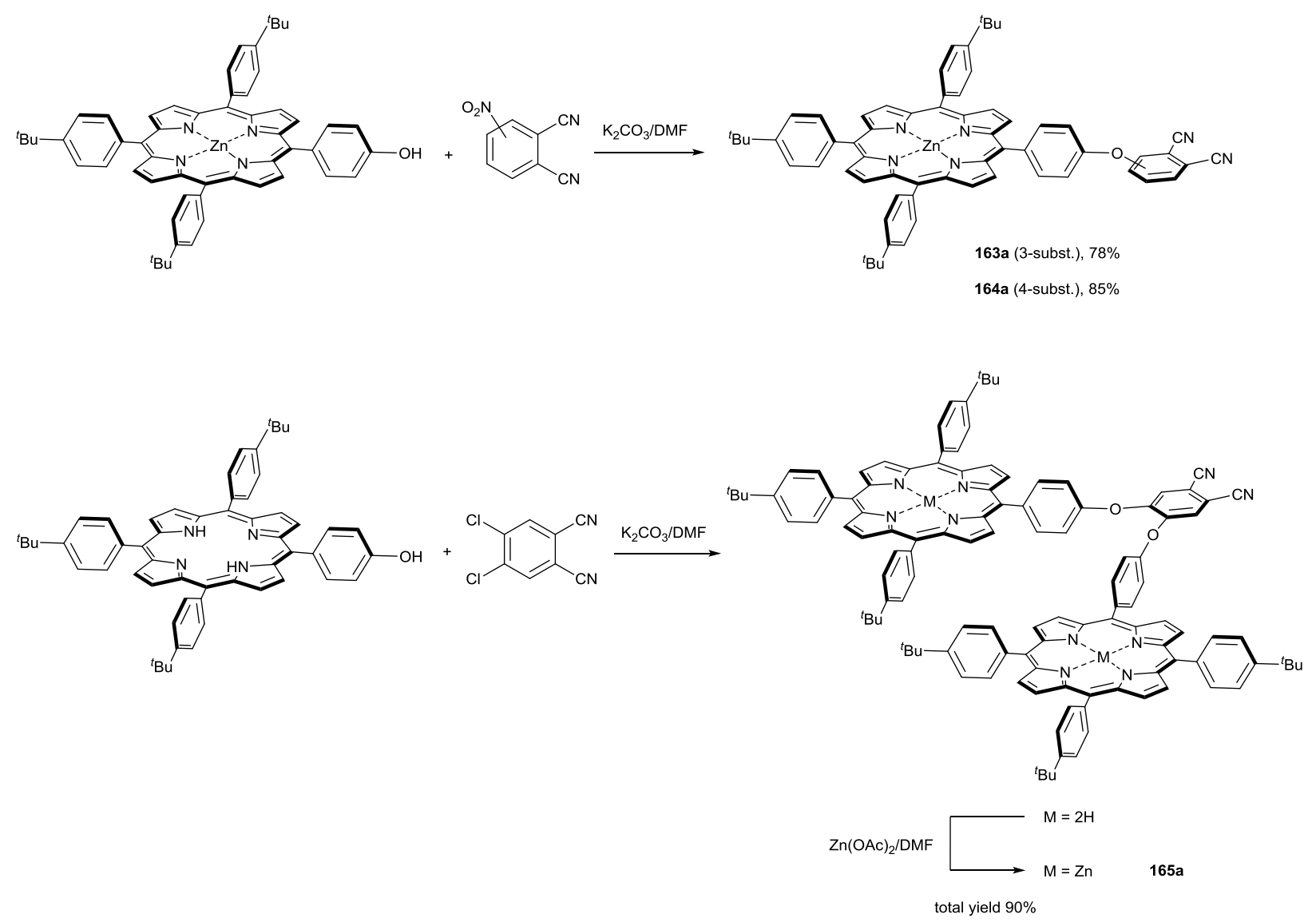


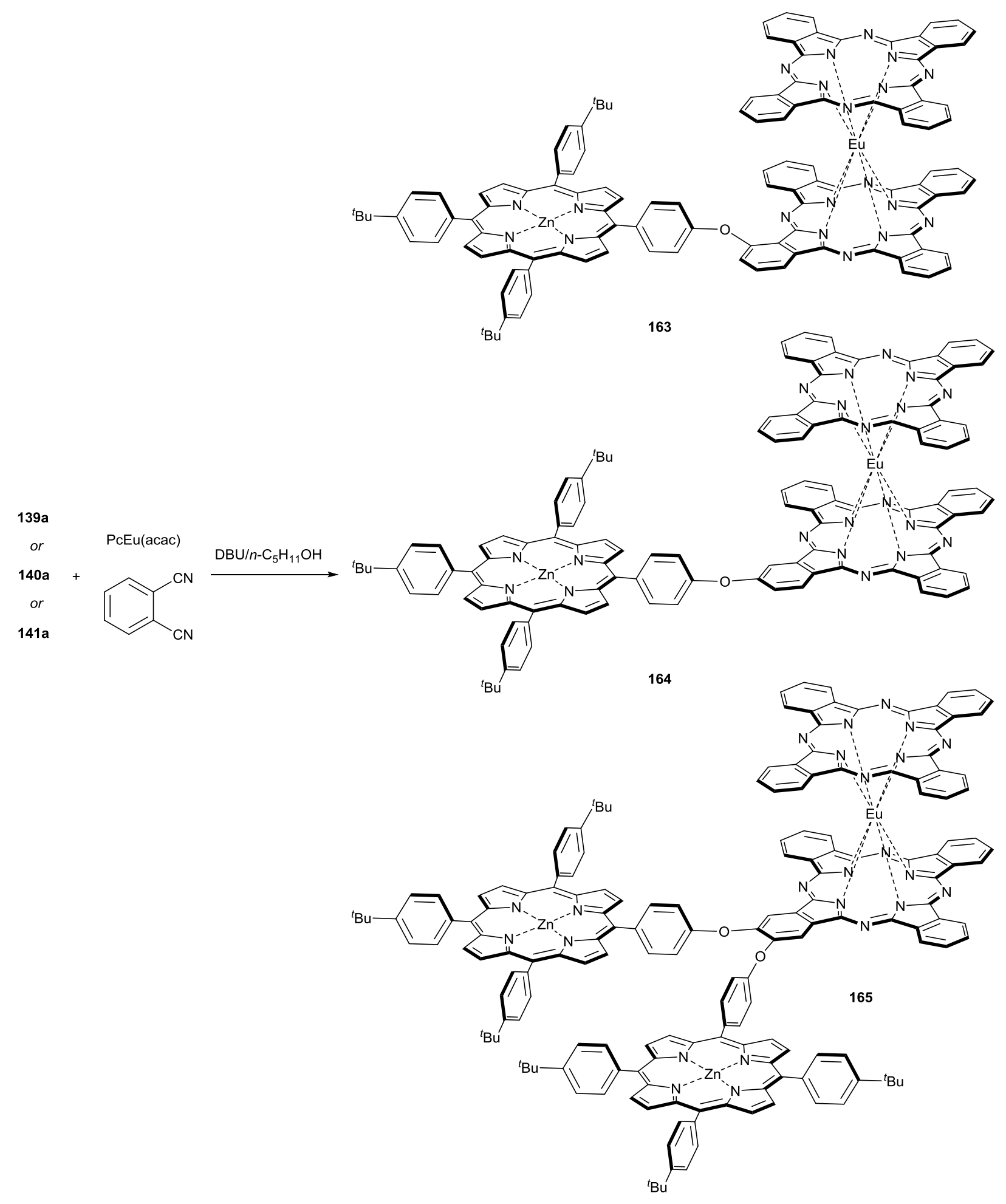

Scheme 32. 

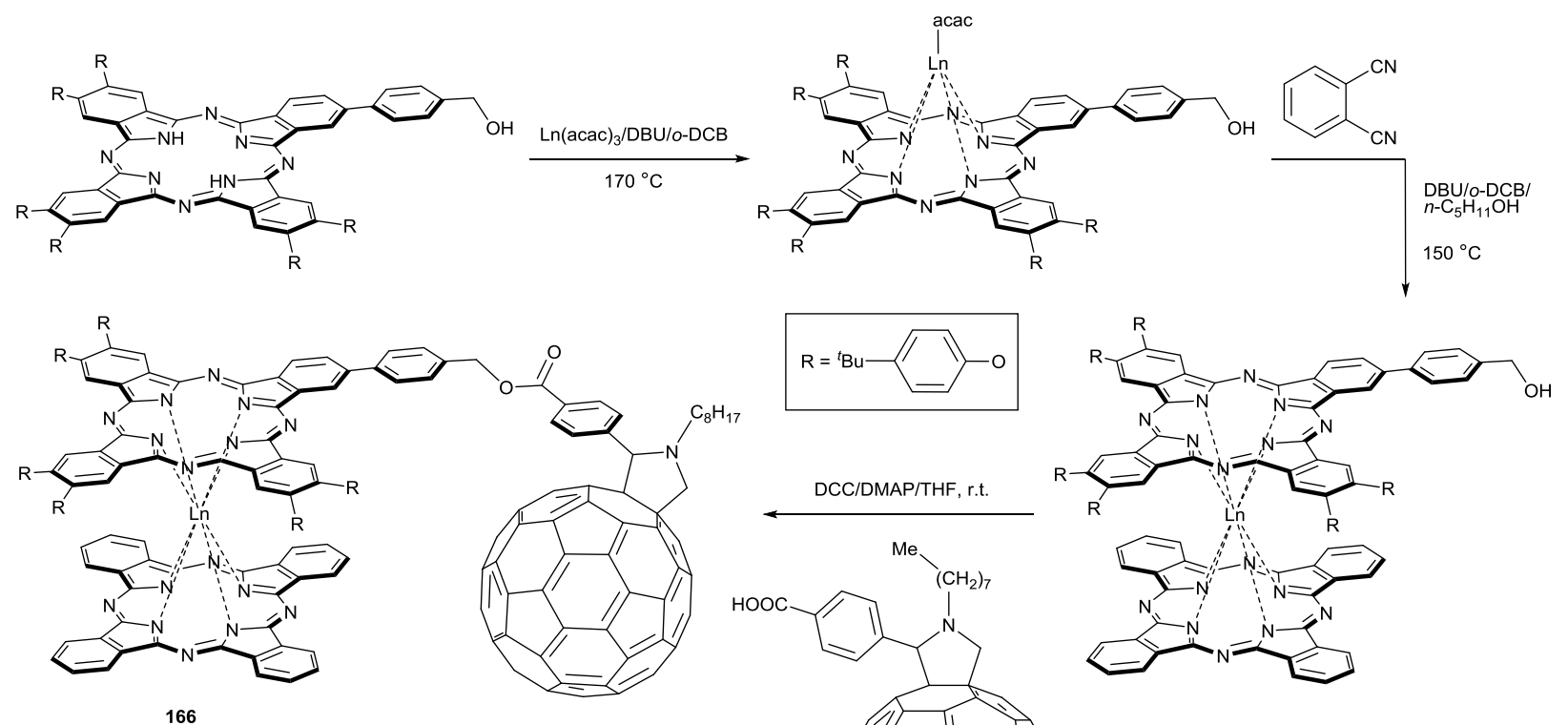

$\operatorname{Ln}=\operatorname{Sm}(\mathbf{a}), \mathrm{Eu}(\mathbf{b}), \mathrm{Lu}(\mathbf{c})$
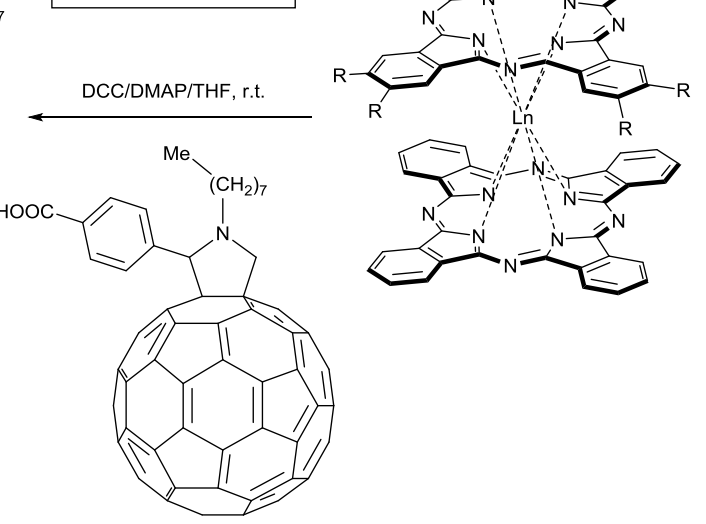

\section{Scheme 33.}



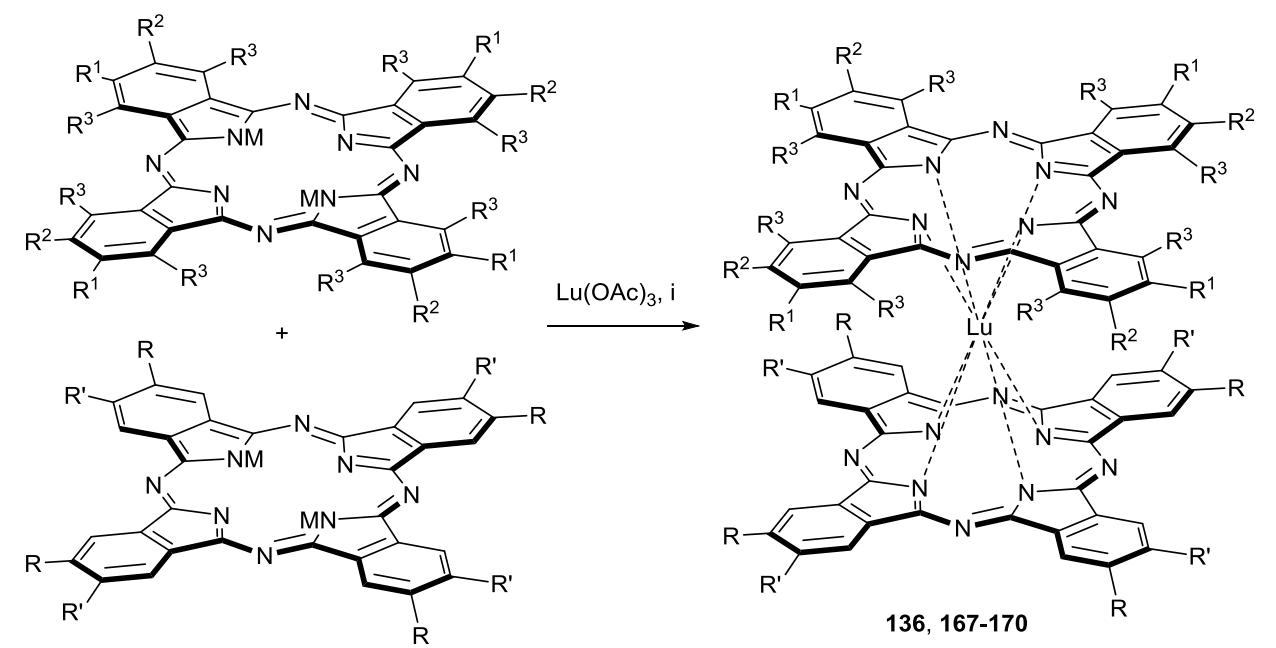

$M=\mathrm{H}, \mathrm{Li}$

$\mathrm{R}=\mathrm{R}^{\prime}=\mathrm{H}, \mathrm{R}^{1}=\mathrm{H}, \mathrm{R}^{2}=$ tert-Bu, $\mathrm{R}^{3}=\mathrm{H}$ (136)

$\mathrm{R}=\mathrm{H}, \mathrm{R}^{\prime}=\mathrm{CH}_{3}\left(\mathrm{OC}_{2} \mathrm{H}_{4}\right)_{8} \mathrm{O}, \mathrm{R}^{1}=\mathrm{H}, \mathrm{R}^{2}=\mathrm{C}_{12} \mathrm{H}_{25} \mathrm{O}, \mathrm{R}^{3}=\mathrm{H}$ (167)

$\mathrm{R}=\mathrm{H}, \mathrm{R}^{\prime}=$ tert-Bu, $\mathrm{R}^{1}=\mathrm{Cl}, \mathrm{R}^{2}=\mathrm{R}^{3}=\mathrm{H}(\mathbf{1 6 8})$

$\mathrm{R}=\mathrm{H}, \mathrm{R}^{\prime}=$ tert-Bu, $\mathrm{R}^{1}=\mathrm{R}^{2}=\mathrm{Cl}, \mathrm{R}^{3}=\mathrm{H}(\mathbf{1 6 9})$

$\mathrm{R}=\mathrm{H}, \mathrm{R}^{\prime}=$ tert-Bu, $\mathrm{R}^{1}=\mathrm{R}^{2}=\mathrm{R}^{3}=\mathrm{Cl}(\mathbf{1 7 0})$

(i) 1: DBU, MW (240 W), $10 \mathrm{~min}$

2: 1-CIN (a), quinoline $(b), 240-260^{\circ} \mathrm{C}, 1-24 \mathrm{~h}$

\section{Scheme 34.}




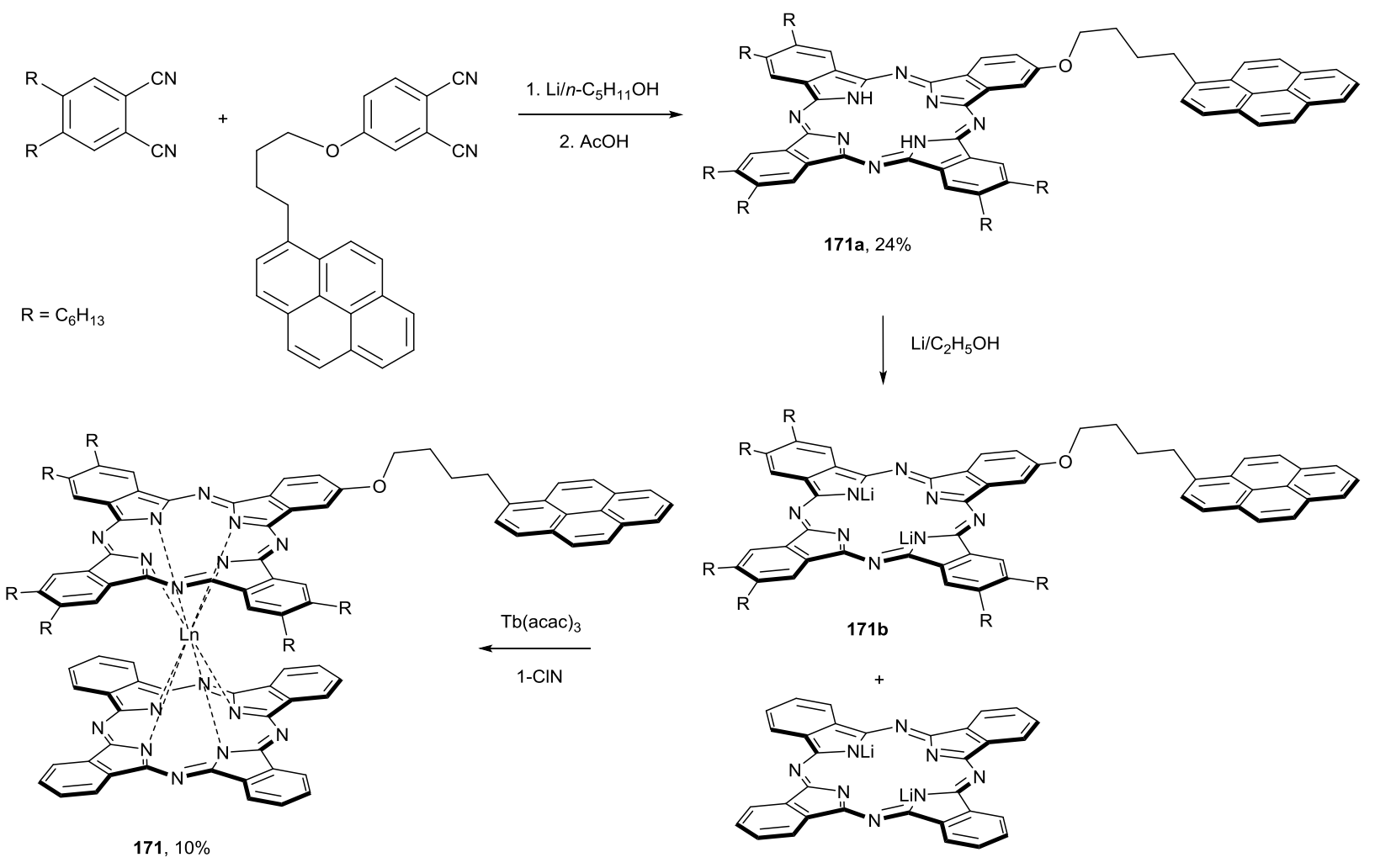

Scheme 35. 

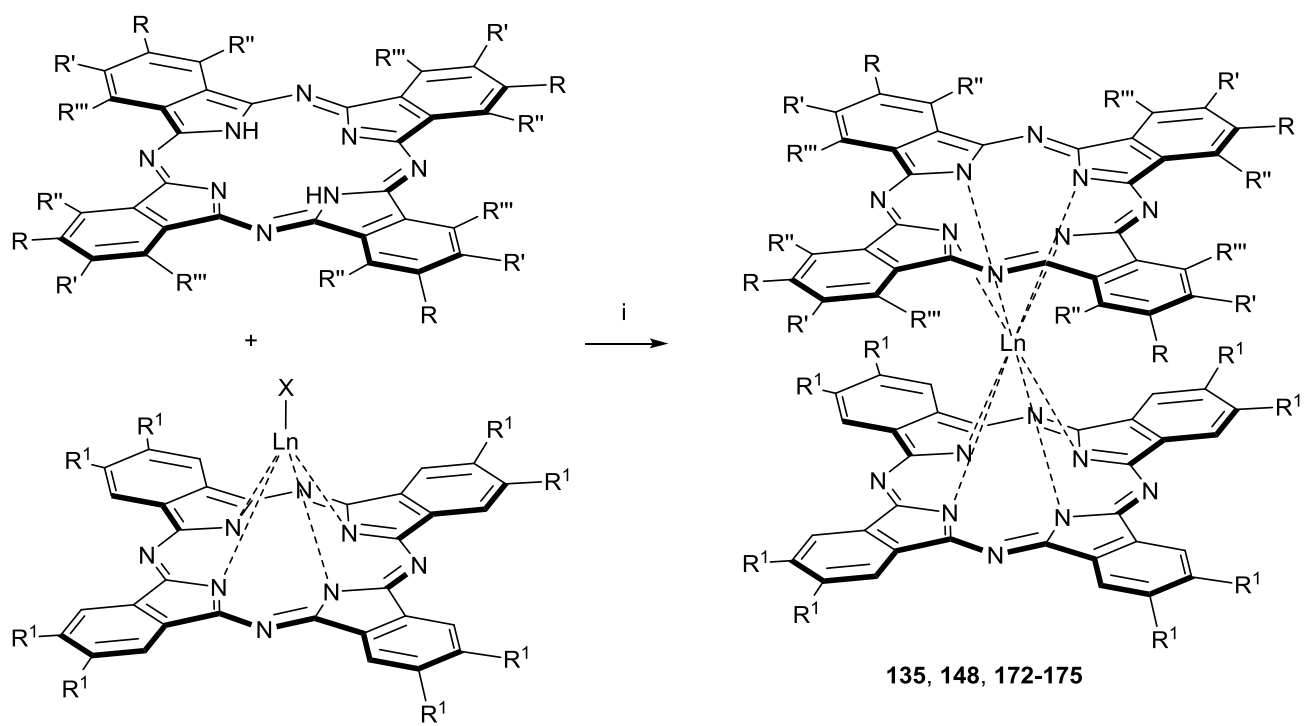

$135,148,172-175$

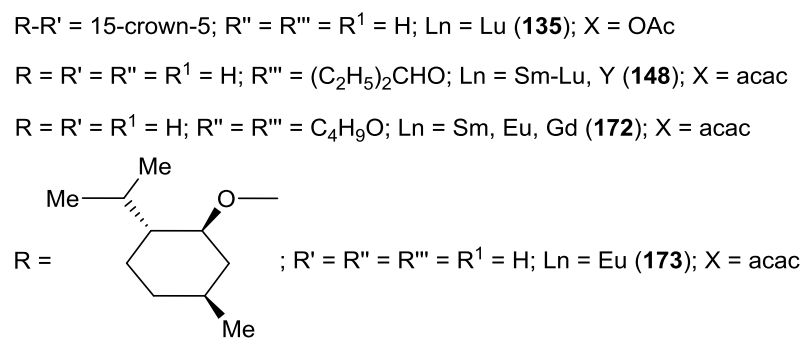

$\mathrm{R}=n-\mathrm{Bu} ; \mathrm{R}^{\prime}=\mathrm{R}^{\prime \prime}=\mathrm{H} ; \mathrm{R}^{1}=\mathrm{H}(\mathbf{1 7 4}), \mathrm{Cl}(\mathbf{1 7 5}) ; \mathrm{Ln}=\mathrm{Eu}, \mathrm{Lu} ; \mathrm{X}=\mathrm{OAc}$

(i) $1: n-\mathrm{C}_{8} \mathrm{H}_{17} \mathrm{OH}(a), 1-\mathrm{CIN}(b), 190-260{ }^{\circ} \mathrm{C}, 8 \mathrm{~h}$; TCB- $n-\mathrm{C}_{16} \mathrm{H}_{33} \mathrm{OH}(50: 1$, vol. $), 220^{\circ} \mathrm{C}, 1 \mathrm{~h}(c)$

2: DBU,TCB- $n-\mathrm{C}_{16} \mathrm{H}_{33} \mathrm{OH}\left(50: 1\right.$, vol.), $220^{\circ} \mathrm{C}, 2 \mathrm{~h}$

\section{Scheme 36.}




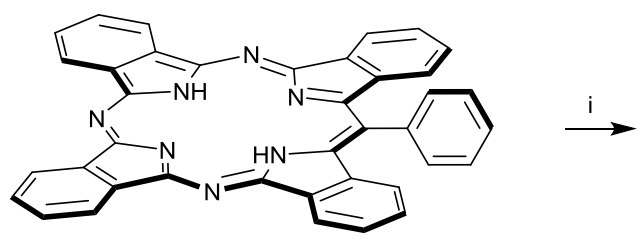

(i) $\mathrm{PcLu}(\mathrm{OAc})$, MeOLi, $n-\mathrm{C}_{16} \mathrm{H}_{33} \mathrm{OH}-\mathrm{TCB}, 220^{\circ} \mathrm{C}, 30 \mathrm{~min}$

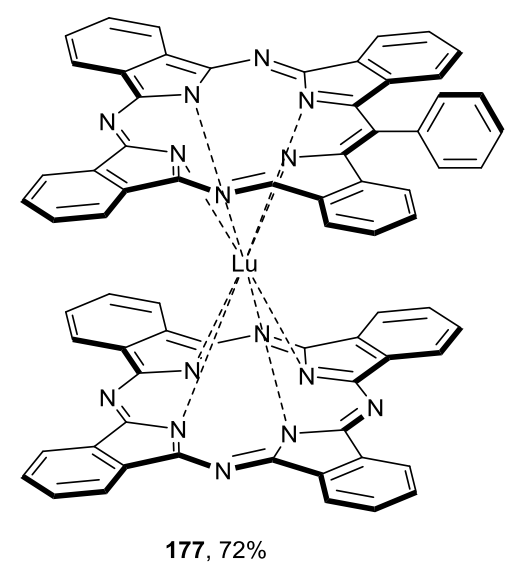

\section{Scheme 37.}




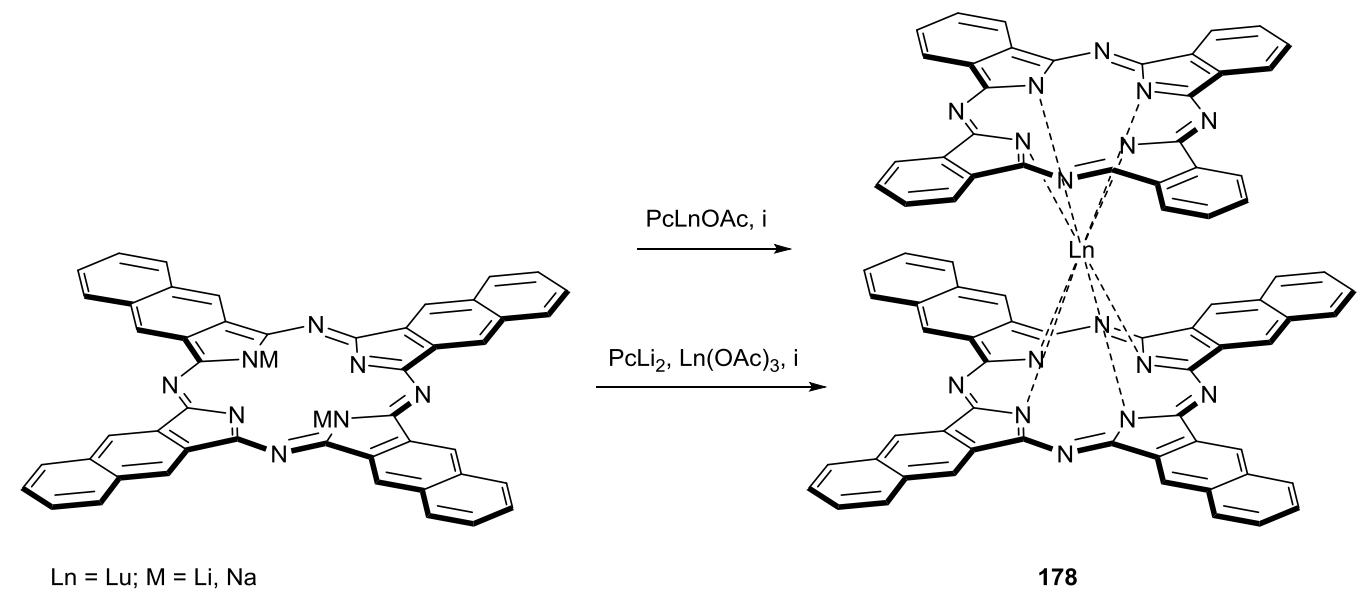

(i) $1-\mathrm{CIN}, 260^{\circ} \mathrm{C}, 4-6 \mathrm{~h}$

Scheme 38. 

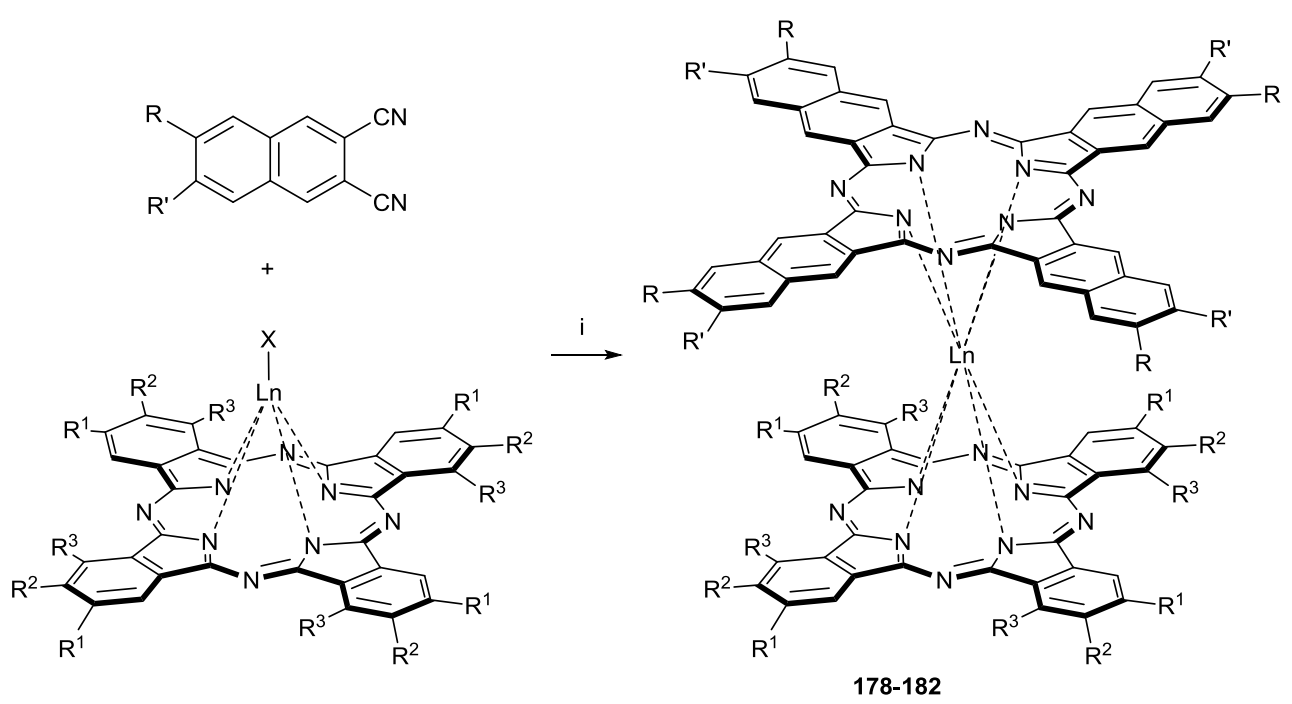

$$
\begin{aligned}
& R=R^{\prime}=R^{1}=R^{2}=R^{3}=H(178) ; L n=T b ; X=O A c \\
& R=H ; R^{\prime}=\text { tert-Bu; } R^{1}=R^{2}=R^{3}=H(179) ; L n=L u, S m ; X=O A c \\
& R=R^{\prime}=H ; R^{1}=\left(C_{2} H_{5}\right)_{2} C H O ; R^{2}=R^{3}=H(180) ; L n=S m ; X=a c a c \\
& R=R^{\prime}=H ; R^{1}=R^{2}=C_{8} H_{17} O ; R^{3}=H(181) ; L n=S m ; X=a c a c \\
& R=R^{\prime}=R^{1}=R^{2}=H ; R^{3}=\left(C_{2} H_{5}\right)_{2} \mathrm{CHO}(182) ; L n=S m, E u, Y ; X=a c a c \\
& \text { (i) 1: } 250-270{ }^{\circ} \mathrm{C}, 1.5-2 h \\
& \text { 2: } \mathrm{DBU},\left(\mathrm{NH}_{4}\right)_{6} \mathrm{Mo}_{7} \mathrm{O}_{24}, n-\mathrm{C}_{6} \mathrm{H}_{13} \mathrm{OH}, \text { reflux, } 20 \mathrm{~h} \\
& \text { 3: DBU, } n-\mathrm{C}_{8} \mathrm{H}_{17} \mathrm{OH}, 190^{\circ} \mathrm{C}, 7 \mathrm{~h}
\end{aligned}
$$

\section{Scheme 39.}




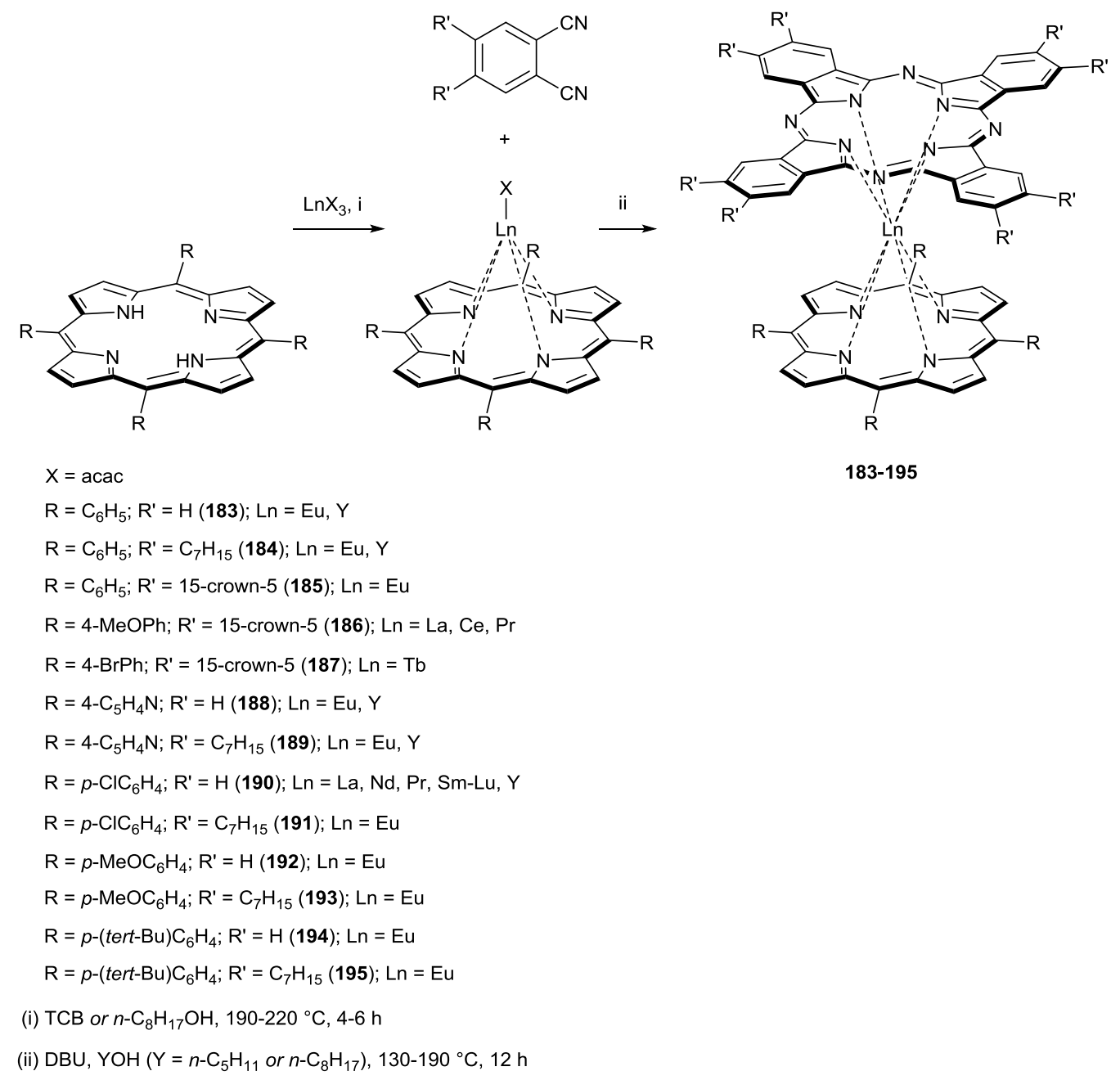

\section{Scheme 40.}




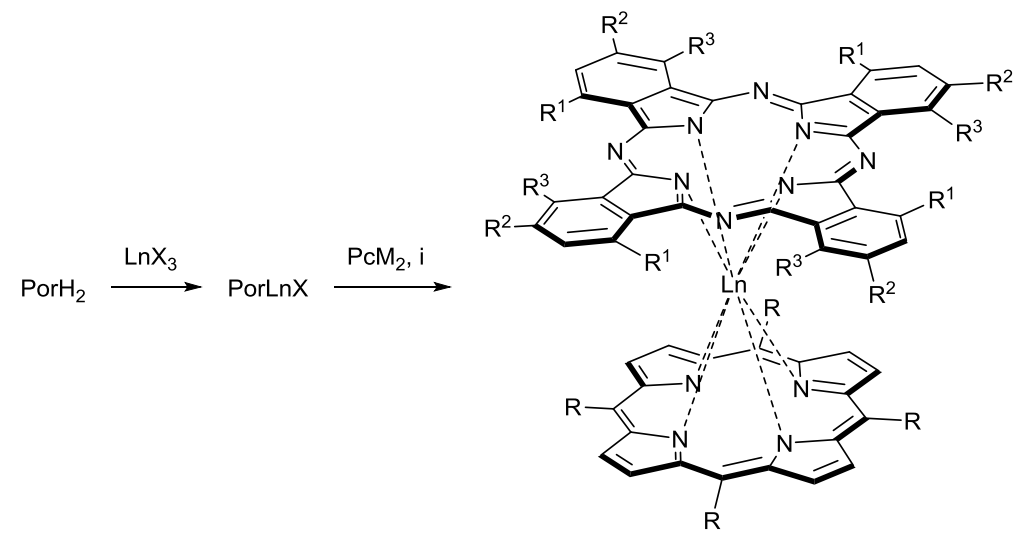

$183,188,196-203$

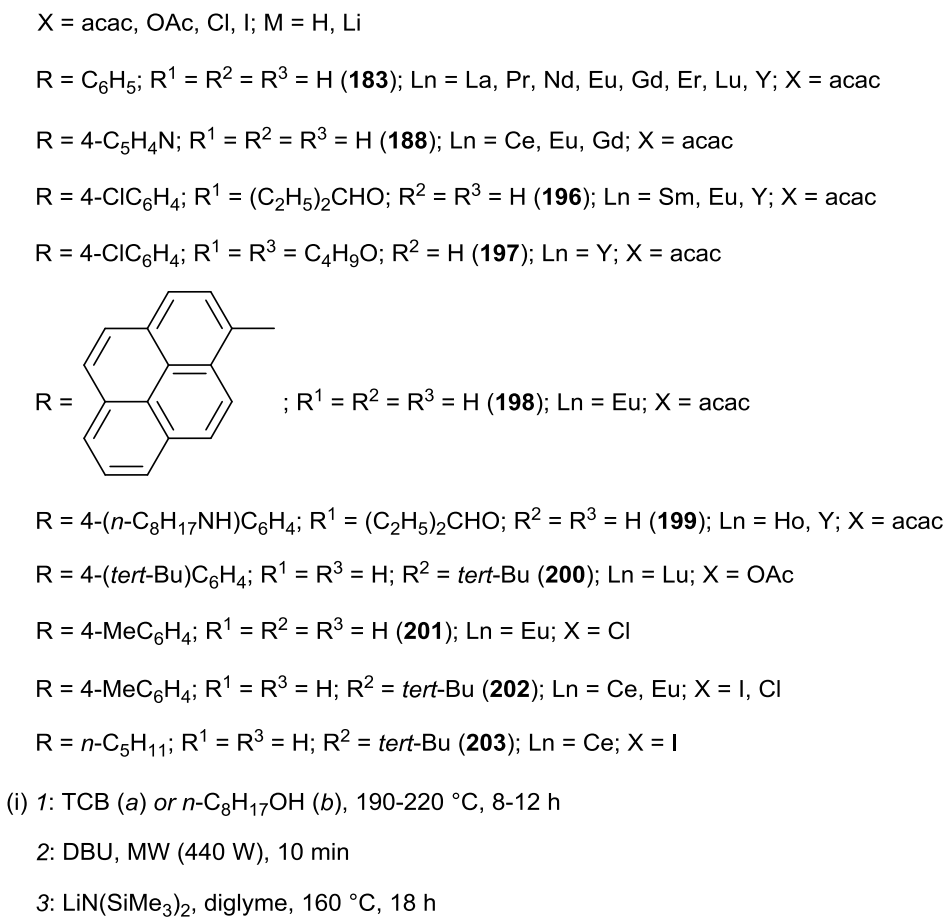

\section{Scheme 41.}




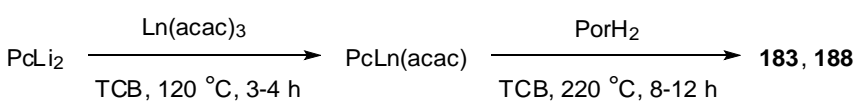

Scheme 42. 


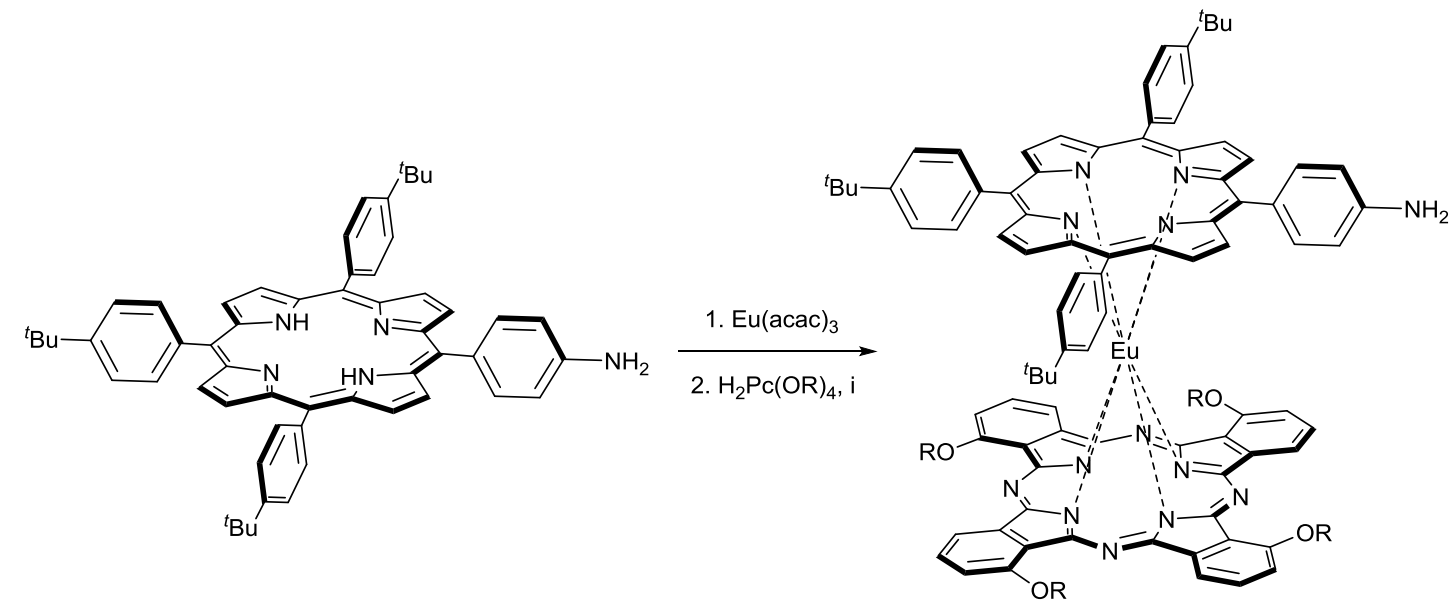

(i) $n-\mathrm{C}_{8} \mathrm{H}_{17} \mathrm{OH}$, reflux, $6 \mathrm{~h}$

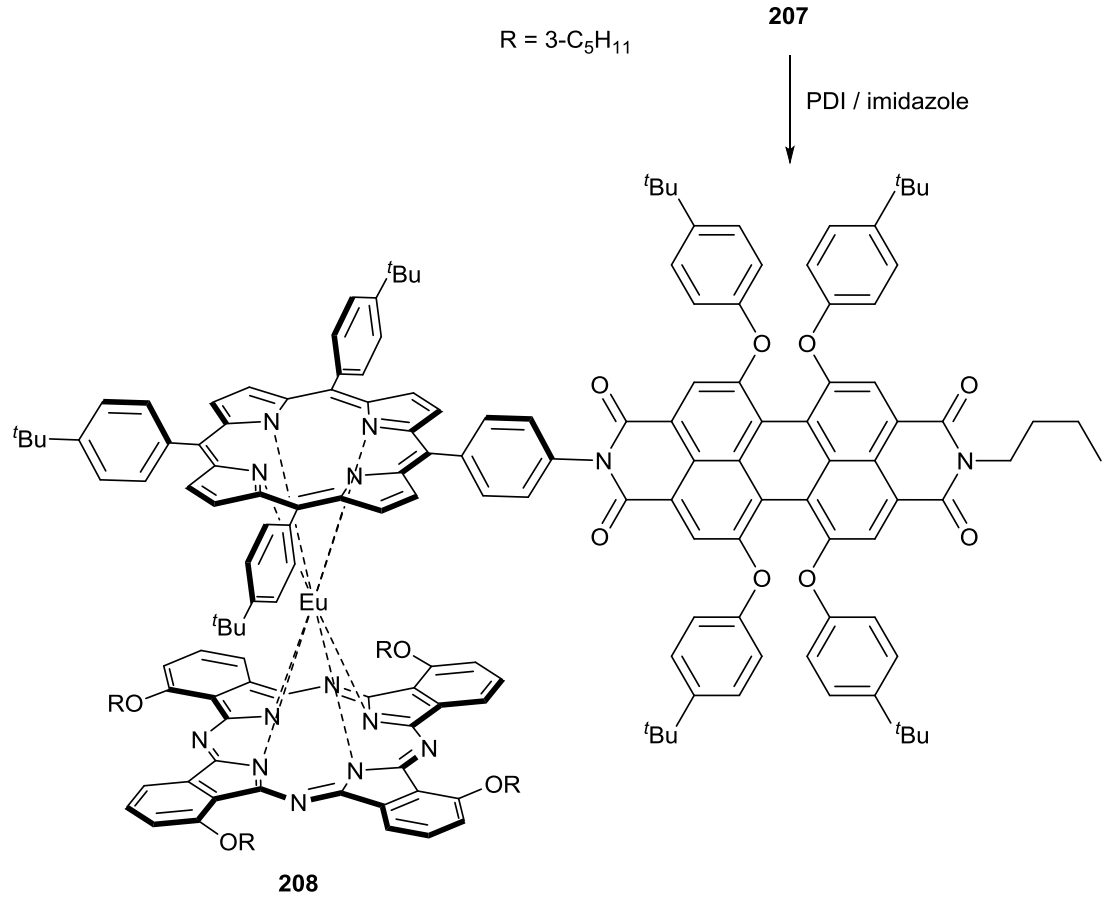

\section{Scheme 43.}




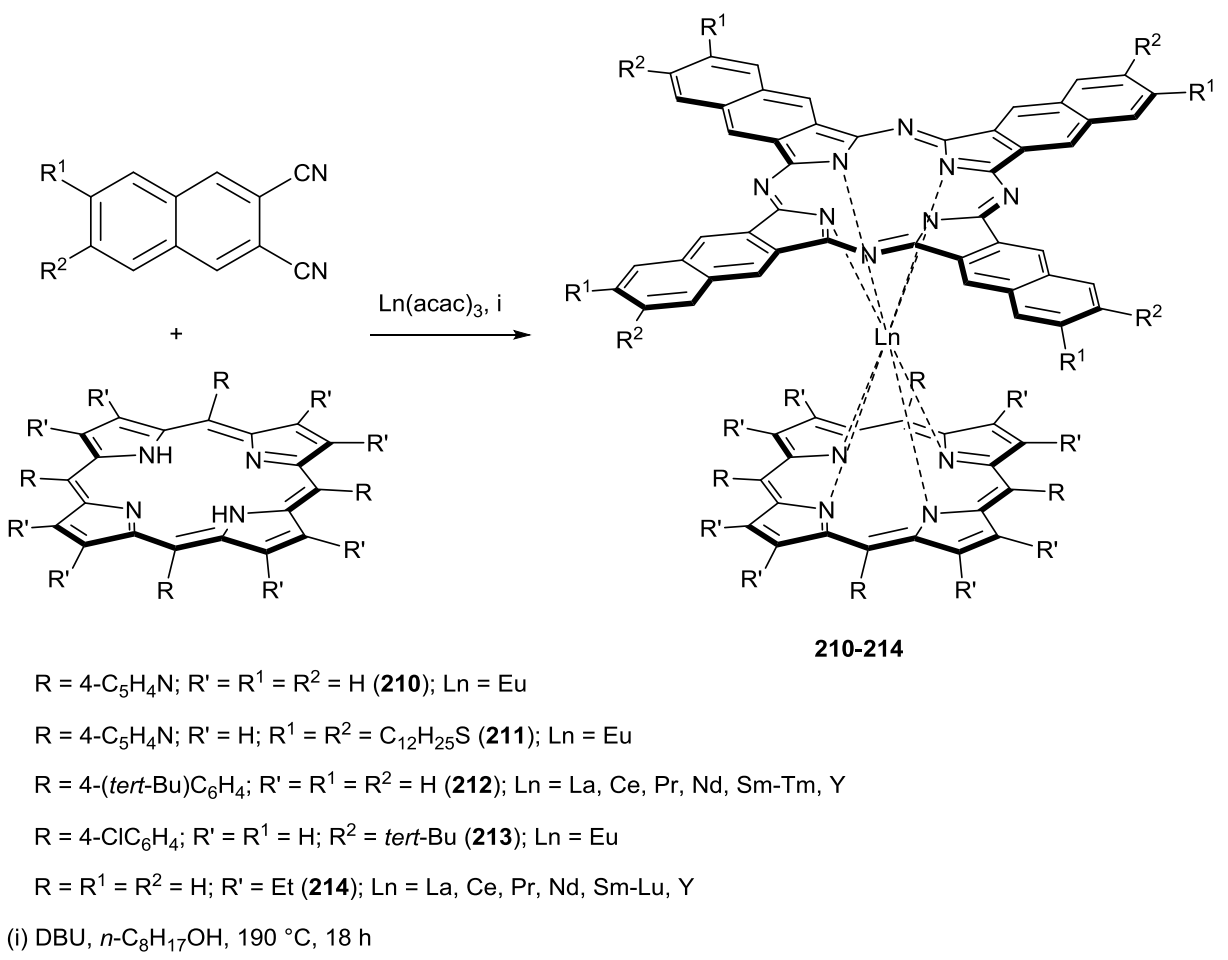

\section{Scheme 44.}



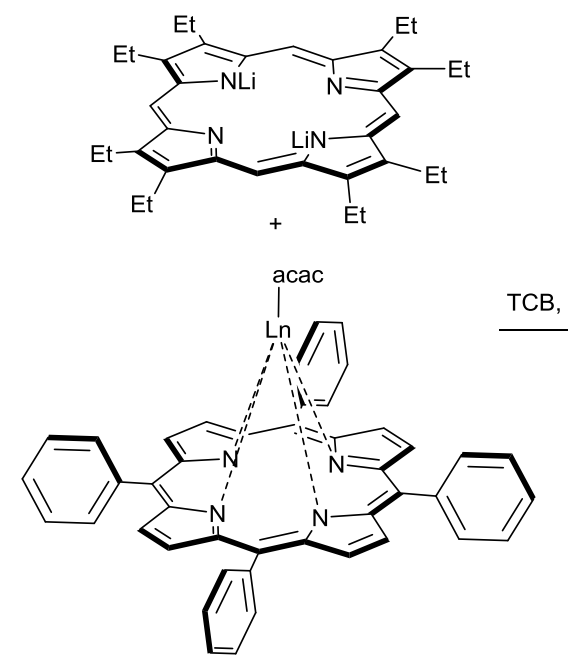

$\mathrm{Ln}=\mathrm{Nd}, \mathrm{Sm}-\mathrm{Lu}$

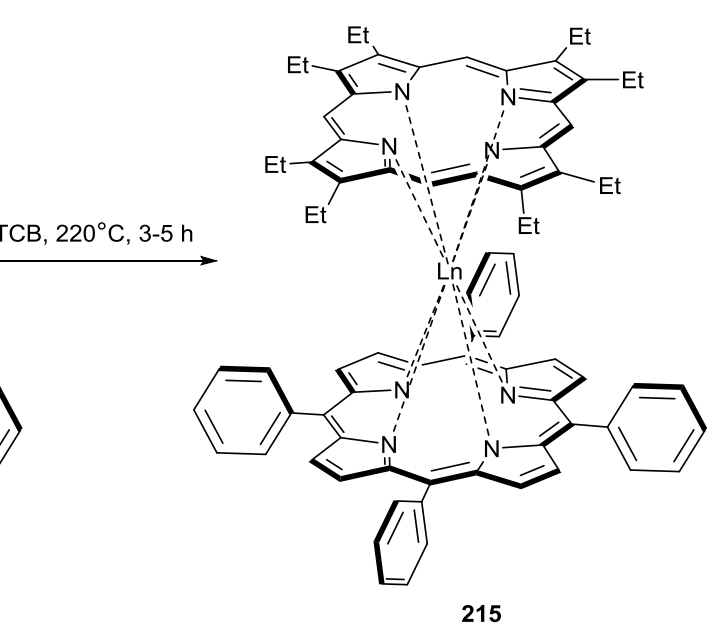

\section{Scheme 45.}



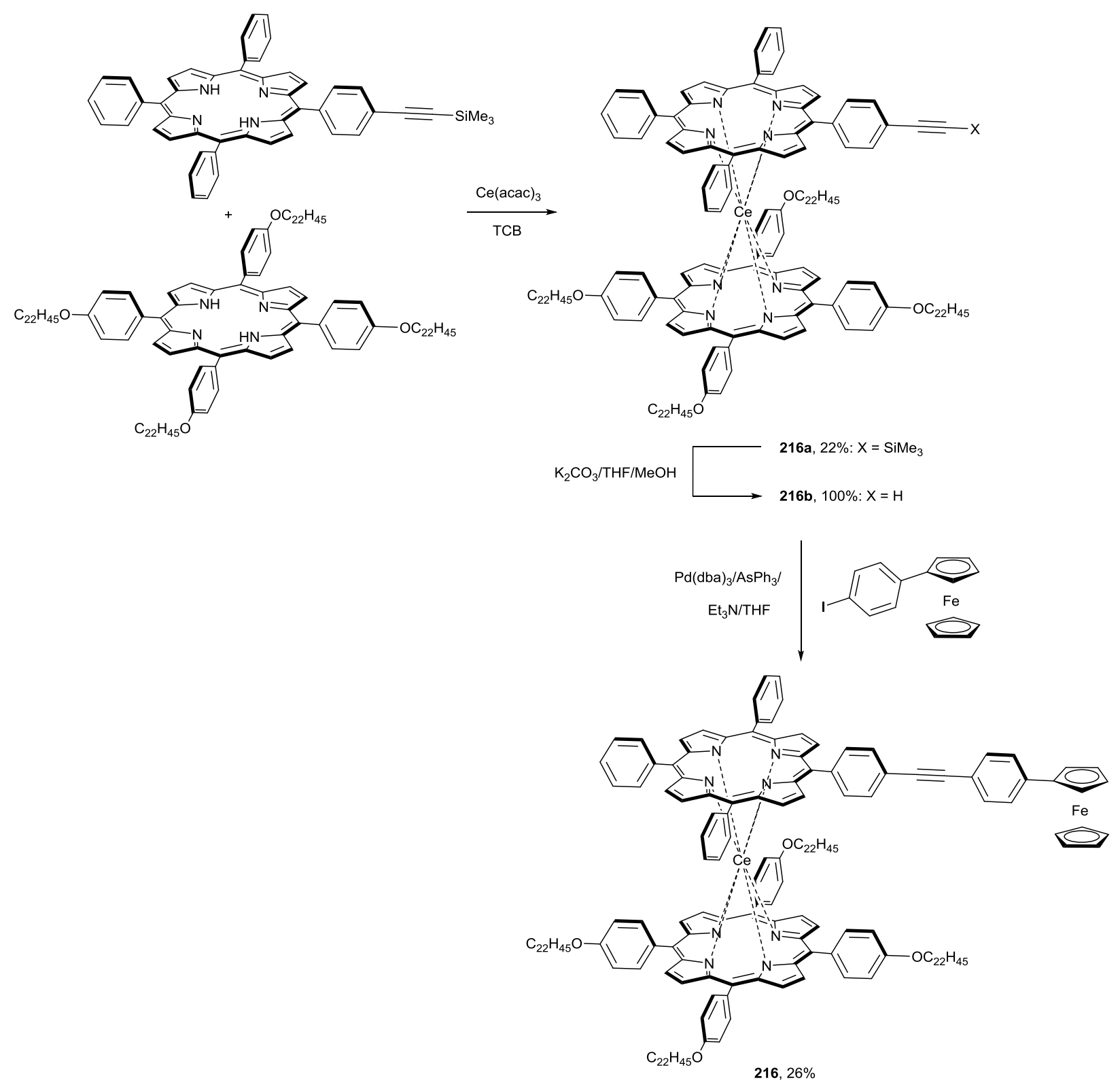

Scheme 46. 

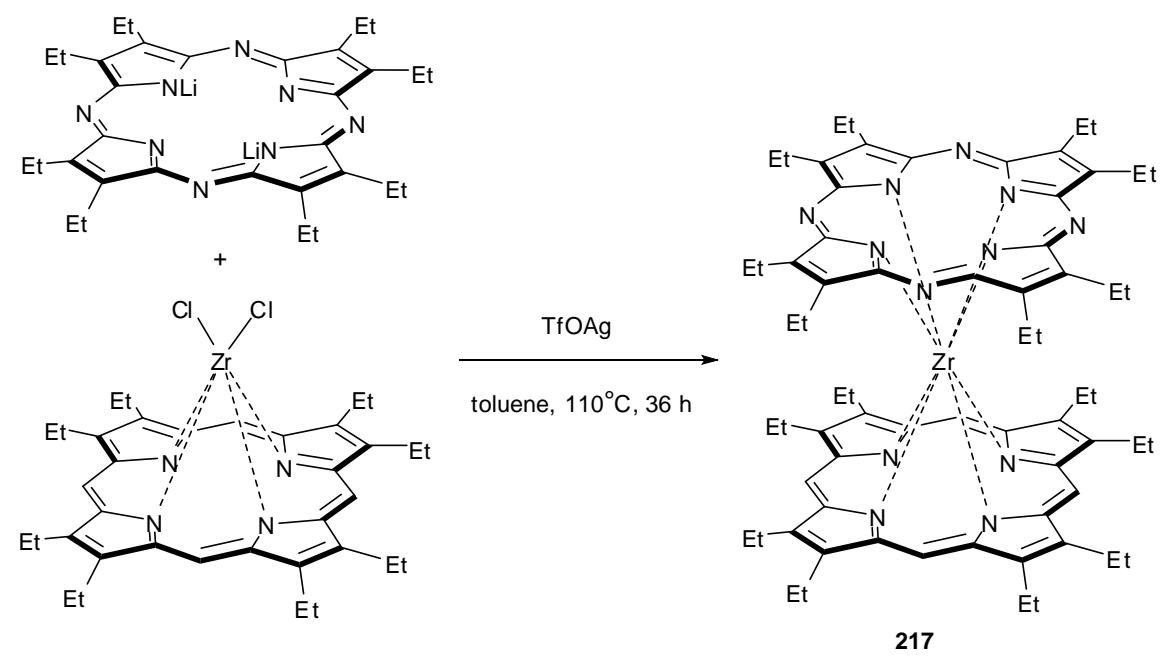

Scheme 47. 

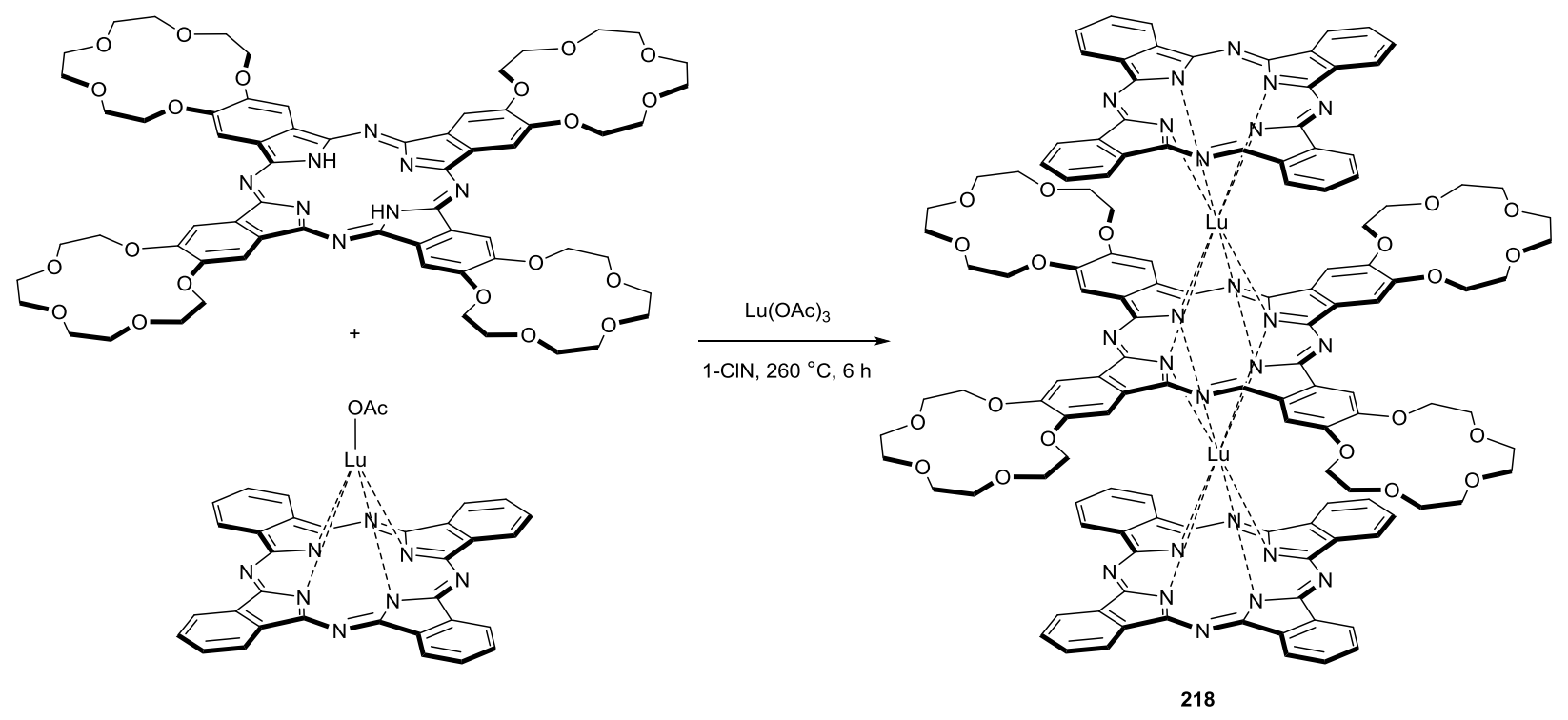

Scheme 48. 

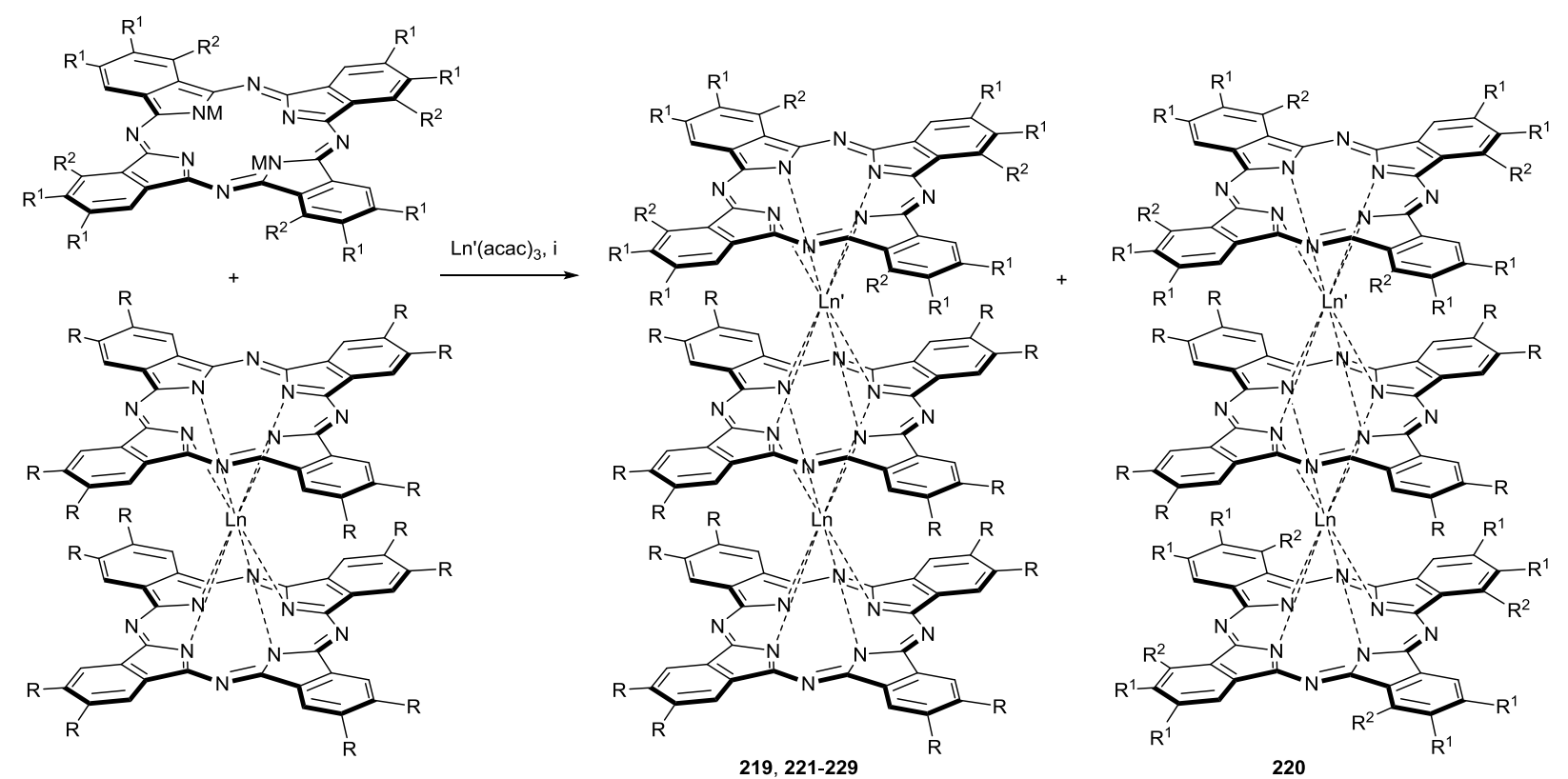

$\mathrm{M}=\mathrm{H}, \mathrm{Li}$

$\mathrm{R}=n-\mathrm{C}_{8} \mathrm{H}_{17} \mathrm{O} ; \mathrm{R}^{1}=\mathrm{R}^{2}=\mathrm{H}(\mathbf{2 1 9}, \mathbf{2 2 0}) ; \mathrm{Ln}=\mathrm{Ln}=\mathrm{Pr}, \mathrm{Nd}, \mathrm{Sm}-\mathrm{Tm} ; \mathrm{M}=\mathrm{Li}$

$\mathrm{R}=\mathrm{R}^{2}=\mathrm{H} ; \mathrm{R}^{1}=n-\mathrm{C}_{4} \mathrm{H}_{9} \mathrm{O}$ (221-223); $\mathrm{M}=\mathrm{H}$

$L n=L n^{\prime}=T b, D y, H o, E r, T m, Y b(221)$

$L n=T b, D y, H o, E r, T m, Y b ; L n^{\prime}=Y(222)$

$L n=Y ; L^{\prime}=T b, D y, H o, E r, T m, Y b(223)$

$\mathrm{R}=\mathrm{MeO}\left(\mathrm{C}_{2} \mathrm{H}_{4} \mathrm{O}\right)_{2} ; \mathrm{R}^{1}=\mathrm{C}_{n} \mathrm{H}_{2 n+1} \mathrm{O}(\mathrm{n}=6,8,10,12) ; \mathrm{R}^{2}=\mathrm{H} ; \mathrm{Ln}=\mathrm{Ln}^{\prime}=\mathrm{Eu} ; \mathrm{M}=\mathrm{H}(\mathbf{2 2 4})$

$R=15$-crown-5; $R^{1}=C_{n} H_{2 n+1} O(n=4,6,8,10,12) ; R^{2}=H ; L n=L n^{\prime}=E u, H o, L u ; M=H(225)$

$R=12$-crown-4; $R^{1}=C_{8} H_{17} \mathrm{O} ; R^{2}=H ; L n=L n^{\prime}=E u ; M=H$ (226)

$\mathrm{R}=18$-crown-6; $\mathrm{R}^{1}=\mathrm{C}_{8} \mathrm{H}_{17} \mathrm{O} ; \mathrm{R}^{2}=\mathrm{H} ; \mathrm{Ln}=\mathrm{Ln} n^{\prime}=\mathrm{Eu} ; \mathrm{M}=\mathrm{H}$ (227)

$R=H ; R^{1}=15-$ crown-5; $R^{2}=H ; L n=L n^{\prime}=S m, D y, T m, Y ; M=H(228)$

$R=R^{1}=H ; R^{2}=\left(C_{2} H_{5}\right) C H O(229) ; L n=L n^{\prime}=S m, G d, L u ; M=H$

(i) TCB or $n-\mathrm{C}_{8} \mathrm{H}_{17} \mathrm{OH}, 190-220{ }^{\circ} \mathrm{C}, 3-12 \mathrm{~h}$

\section{Scheme 49.}



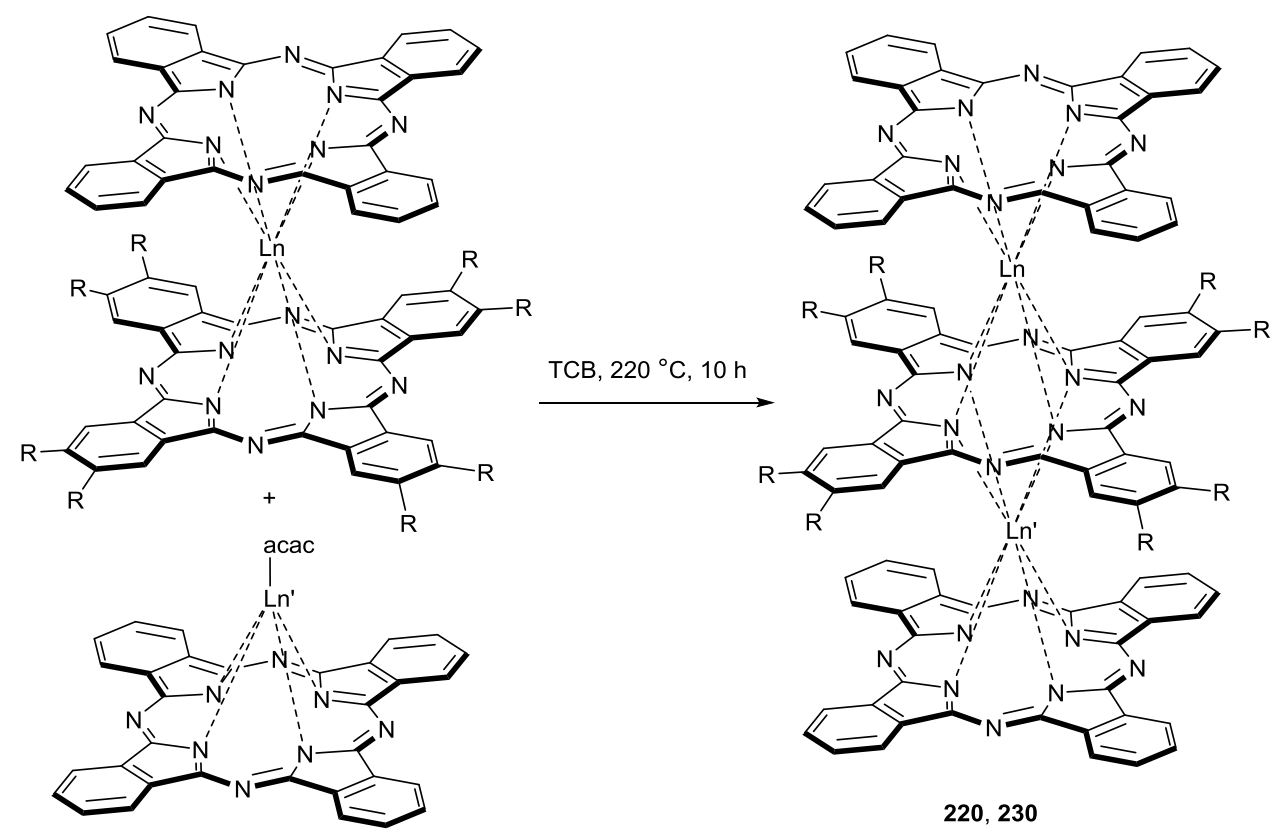

$\mathrm{R}=n-\mathrm{C}_{8} \mathrm{H}_{17} \mathrm{O} ; \mathrm{Ln} \mathrm{n}^{\prime}=\mathrm{Lu} ; \mathrm{Ln}=\mathrm{Gd}-\mathrm{Yb}(\mathbf{2 3 0})$

Scheme 50. 

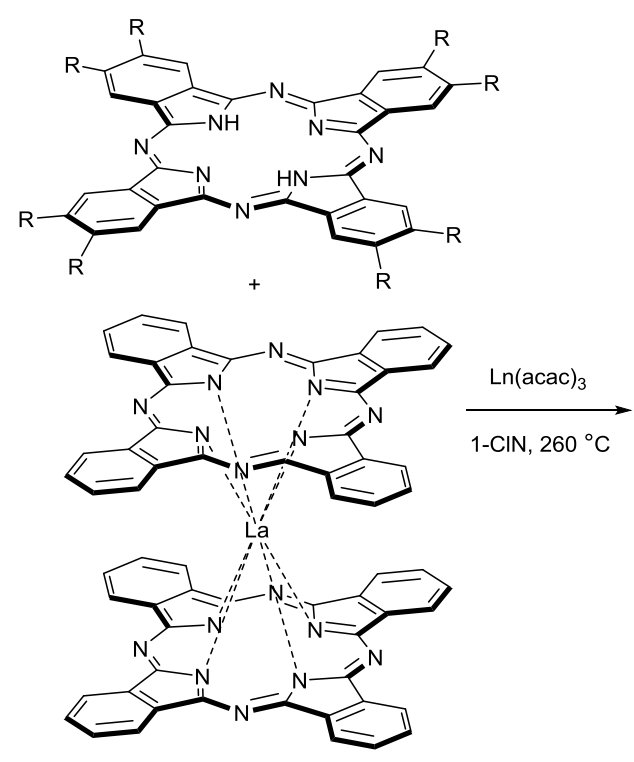

$R=15-$ crown-5; $\operatorname{Ln}=\mathrm{Sm}, \mathrm{Tb}, \mathrm{Dy}, \mathrm{Tm}, \mathrm{Y}[310]$
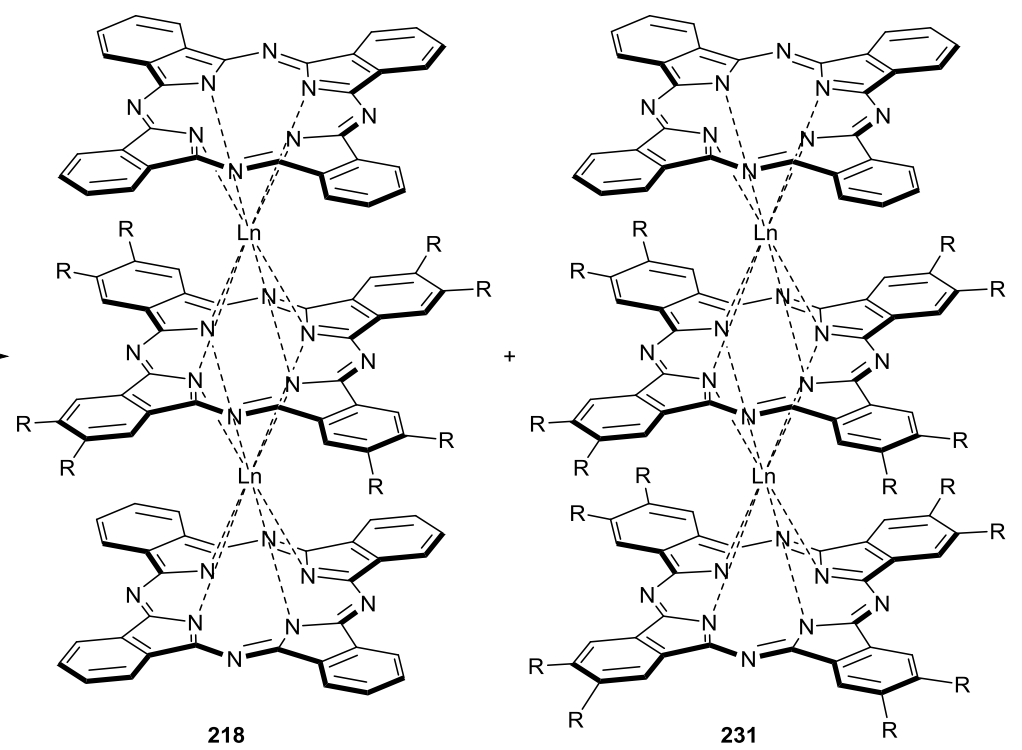
$\mathrm{Ln}=\mathrm{Nd}, \mathrm{Eu}, \mathrm{Ho}, \mathrm{Er}, \mathrm{Yb}$ [311]

\section{Scheme 51.}



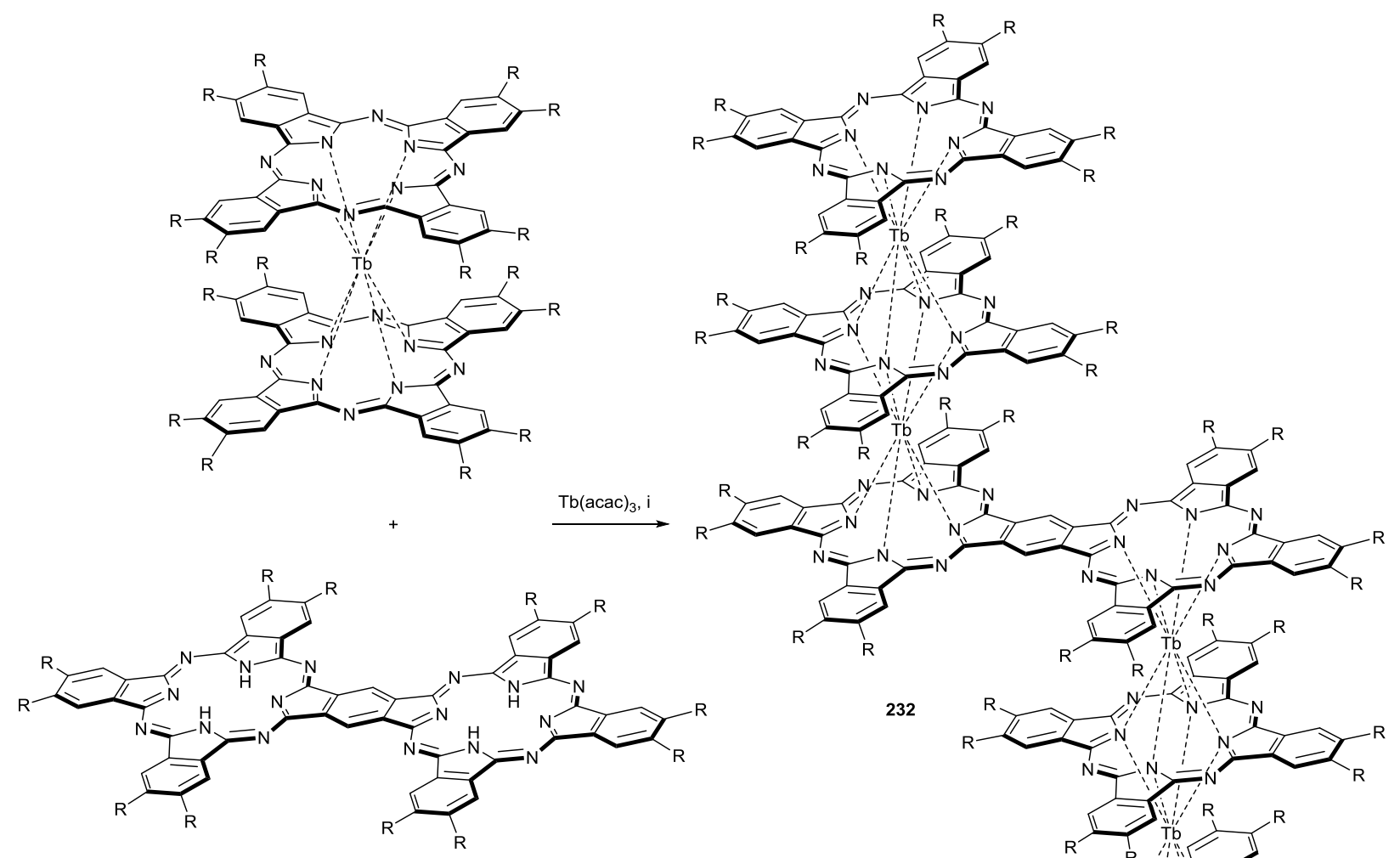

(i) $n-\mathrm{C}_{6} \mathrm{H}_{13} \mathrm{OH}$, reflux, $6 \mathrm{~h}$

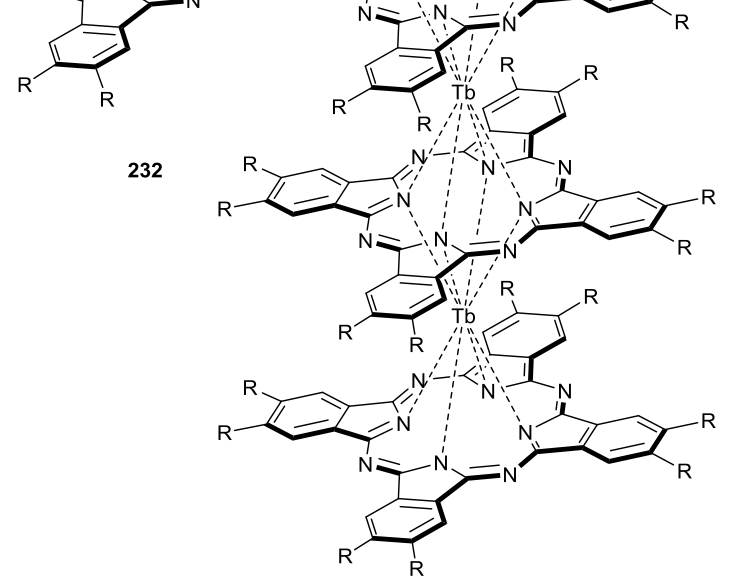

\section{Scheme 52.}



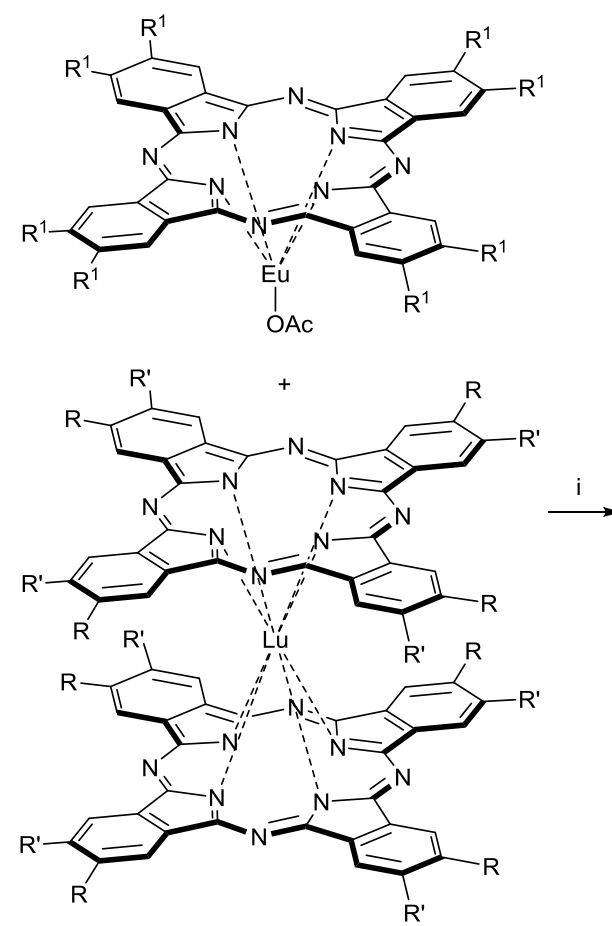

$\mathrm{R}=\mathrm{R}^{\prime}=n-\mathrm{Bu}(\mathbf{2 3 3}) ; \mathrm{R}=\mathrm{H} ; \mathrm{R}^{\prime}=$ tert $-\mathrm{Bu}(\mathbf{2 3 4})$

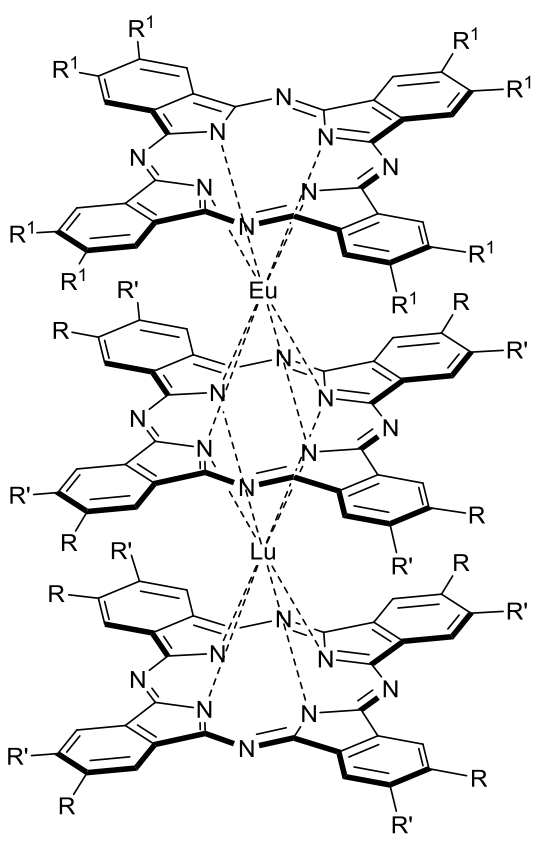

$\mathrm{R}^{1}=n-\mathrm{Bu}(\mathbf{a}), \mathrm{Cl}(\mathbf{b}), \mathrm{H}(\mathbf{c})$

(i) TCB- $n-\mathrm{C}_{16} \mathrm{H}_{33} \mathrm{OH}(50: 1), 220^{\circ} \mathrm{C}, 30 \mathrm{~min}$

\section{Scheme 53.}




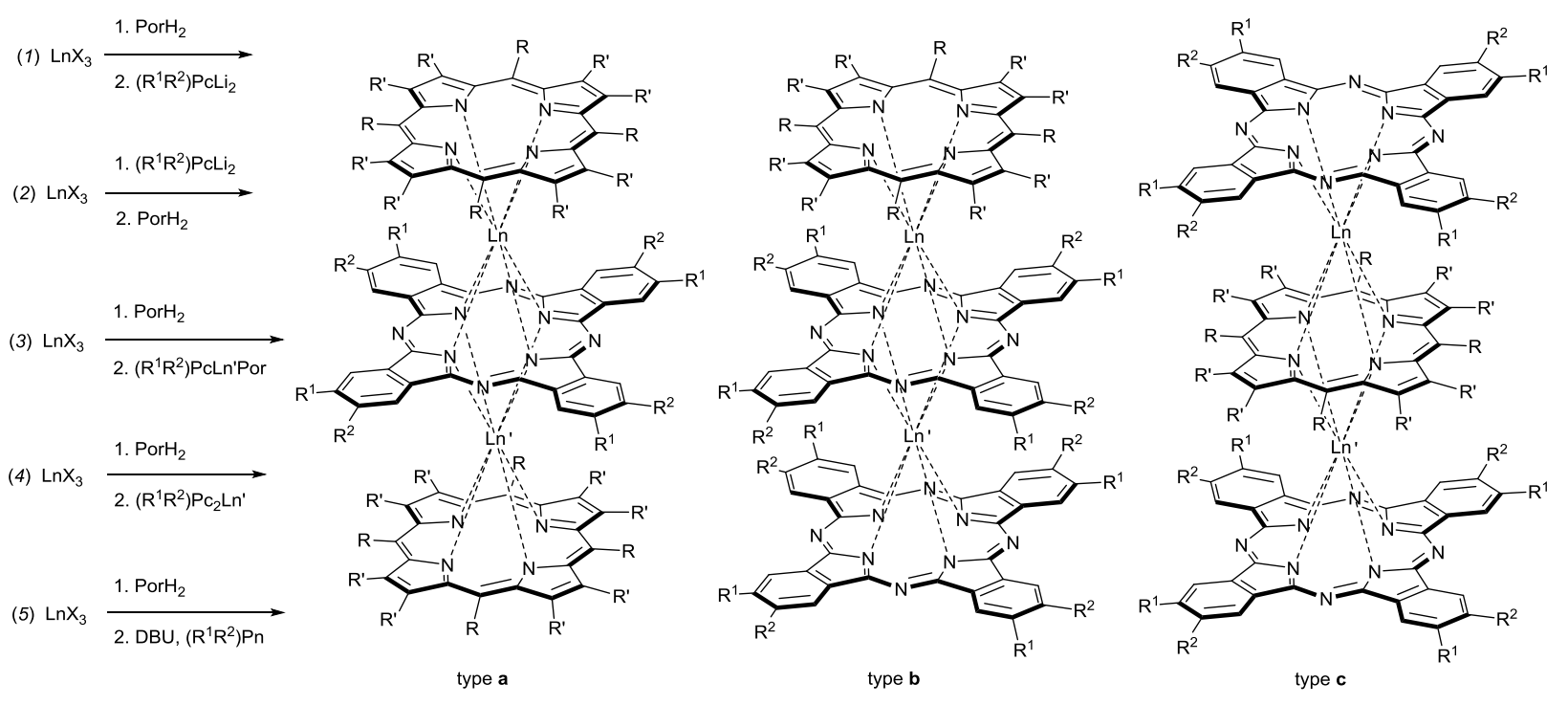

Scheme 54. 

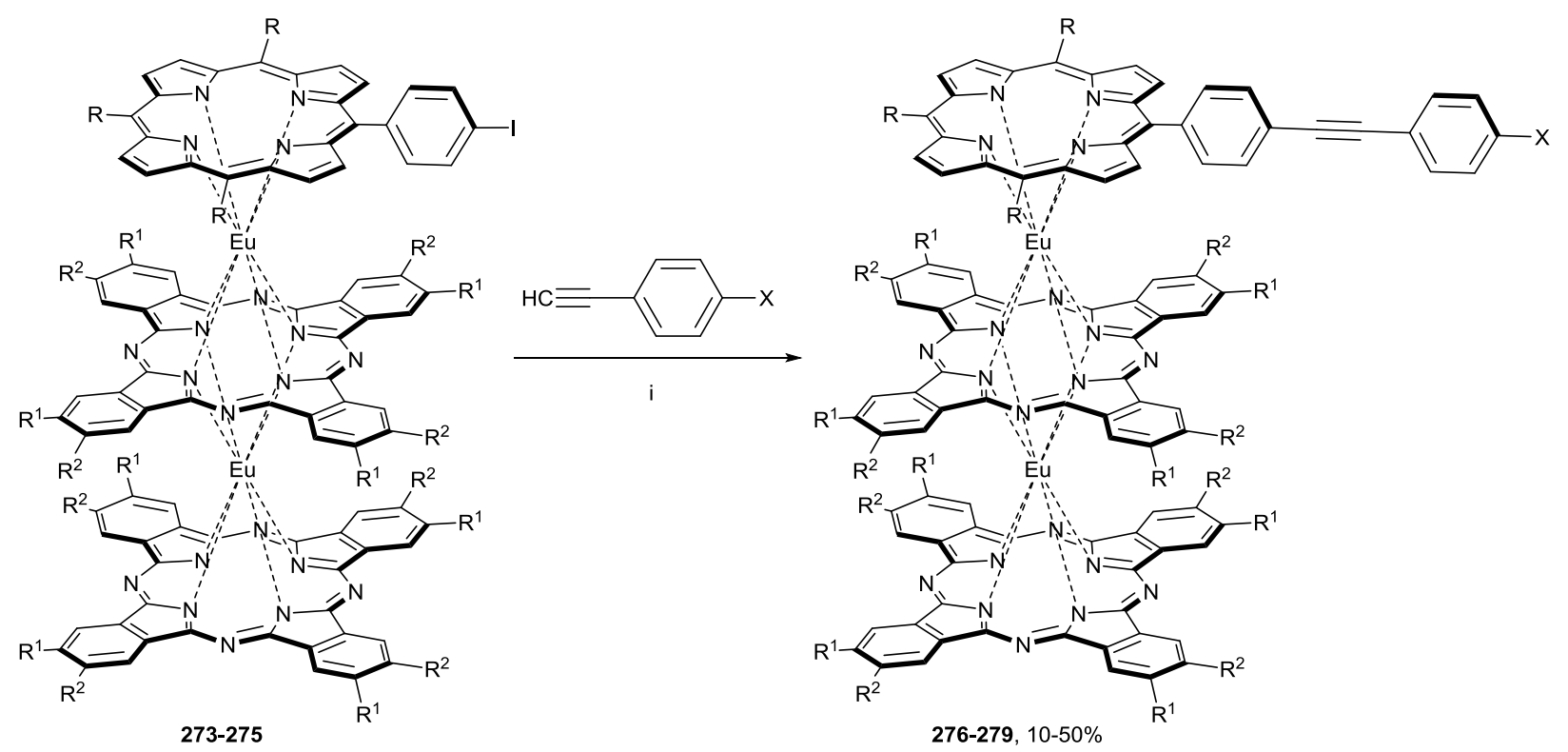

$\mathrm{R}=p-\mathrm{MeC}_{6} \mathrm{H}_{4} ; \mathrm{R}^{1}=\mathrm{R}^{2}=\mathrm{H}(\mathbf{2 7 3}) ; \mathrm{X}=\mathrm{AcS}(\mathbf{2 7 6}),\left[p-\left(\mathrm{AcSCH}_{2}\right) \mathrm{C}_{6} \mathrm{H}_{4}\right]_{3} \mathrm{C}$ (277)

$\mathrm{R}=n-\mathrm{C}_{5} \mathrm{H}_{11} ; \mathrm{R}^{1}=\mathrm{R}^{2}=\mathrm{Me}(\mathbf{2 7 4}) ; \mathrm{X}=\operatorname{AcS}(\mathbf{2 7 8})$

$\mathrm{R}=n-\mathrm{C}_{5} \mathrm{H}_{11} ; \mathrm{R}^{1}=\mathrm{H} ; \mathrm{R}^{2}=$ tert-Bu (275); $\mathrm{X}=\mathrm{AcS}(279)$

(i) 1: $\mathrm{Pd}\left(\mathrm{PPh}_{3}\right)_{2} \mathrm{Cl}_{2}, \mathrm{Cul},(i-\mathrm{Pr})_{2} \mathrm{EtN}, \mathrm{THF}, 30^{\circ} \mathrm{C}, 20 \mathrm{~h}$

2: $\mathrm{Pd}_{2}(\mathrm{dba})_{3}, \mathrm{P}(\mathrm{o} \text {-tol })_{3},(i-\mathrm{Pr})_{2} \mathrm{EtN}$, toluene, $35^{\circ} \mathrm{C}, 44 \mathrm{~h}$

\section{Scheme 55.}



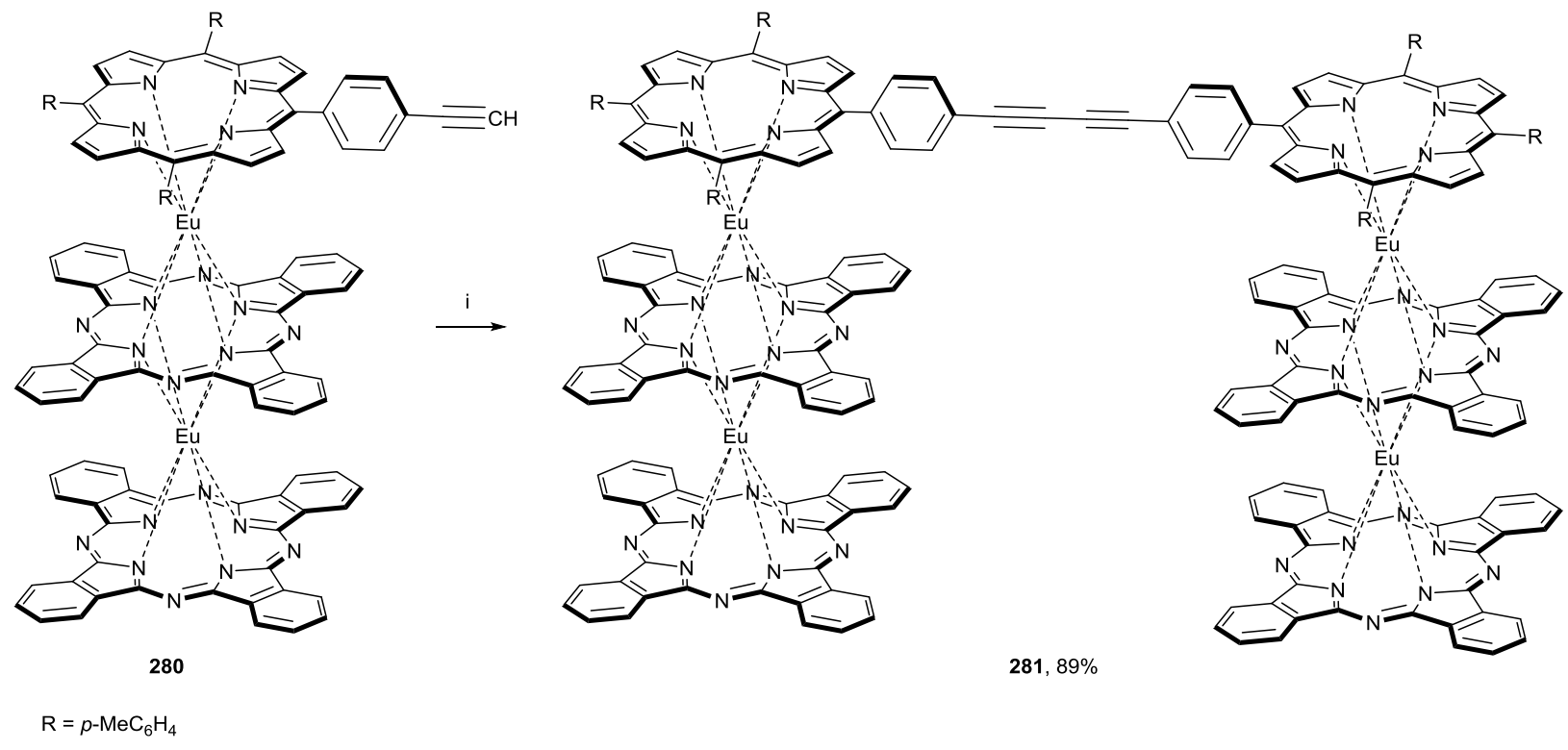

(i) $\mathrm{Pd}\left(\mathrm{PPh}_{3}\right)_{2} \mathrm{Cl}_{2}, \mathrm{Cul}, \mathrm{I}_{2},(i-\mathrm{Pr})_{2} \mathrm{NH}$, toluene, $25^{\circ} \mathrm{C}, 20 \mathrm{~h}$

Scheme 56.

181 
(1) $\operatorname{Ln}(\mathrm{acac})_{3} \underset{\text { 2. } \mathrm{NcLi}_{2}}{\stackrel{\mathrm{PorH}_{2}}{\longrightarrow}}$

(2) $\mathrm{Ln}(\mathrm{acac})_{3} \underset{\text { 2. NcLnPor }}{\stackrel{\text { 1. } \mathrm{PorH}_{2}}{\longrightarrow}}$
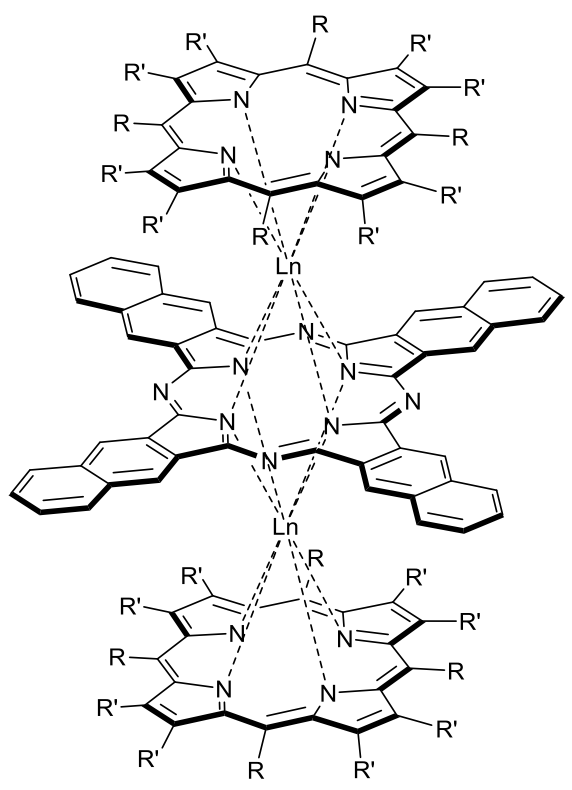

$\mathrm{R}=\mathrm{C}_{5} \mathrm{H}_{11} ; \mathrm{R}^{\prime}=\mathrm{H} ; \mathrm{Ln}=\mathrm{Eu}(\mathbf{2 8 8})$

(1) $288,3 \%$

$\mathrm{R}=\mathrm{H} ; \mathrm{R}^{\prime}=\mathrm{Et} ; \mathrm{Ln}=\mathrm{Nd}, \mathrm{Eu}(\mathbf{2 8 9})$

(2) $289,46-63 \%$

\section{Scheme 57.}




\section{Graphical Abstract}

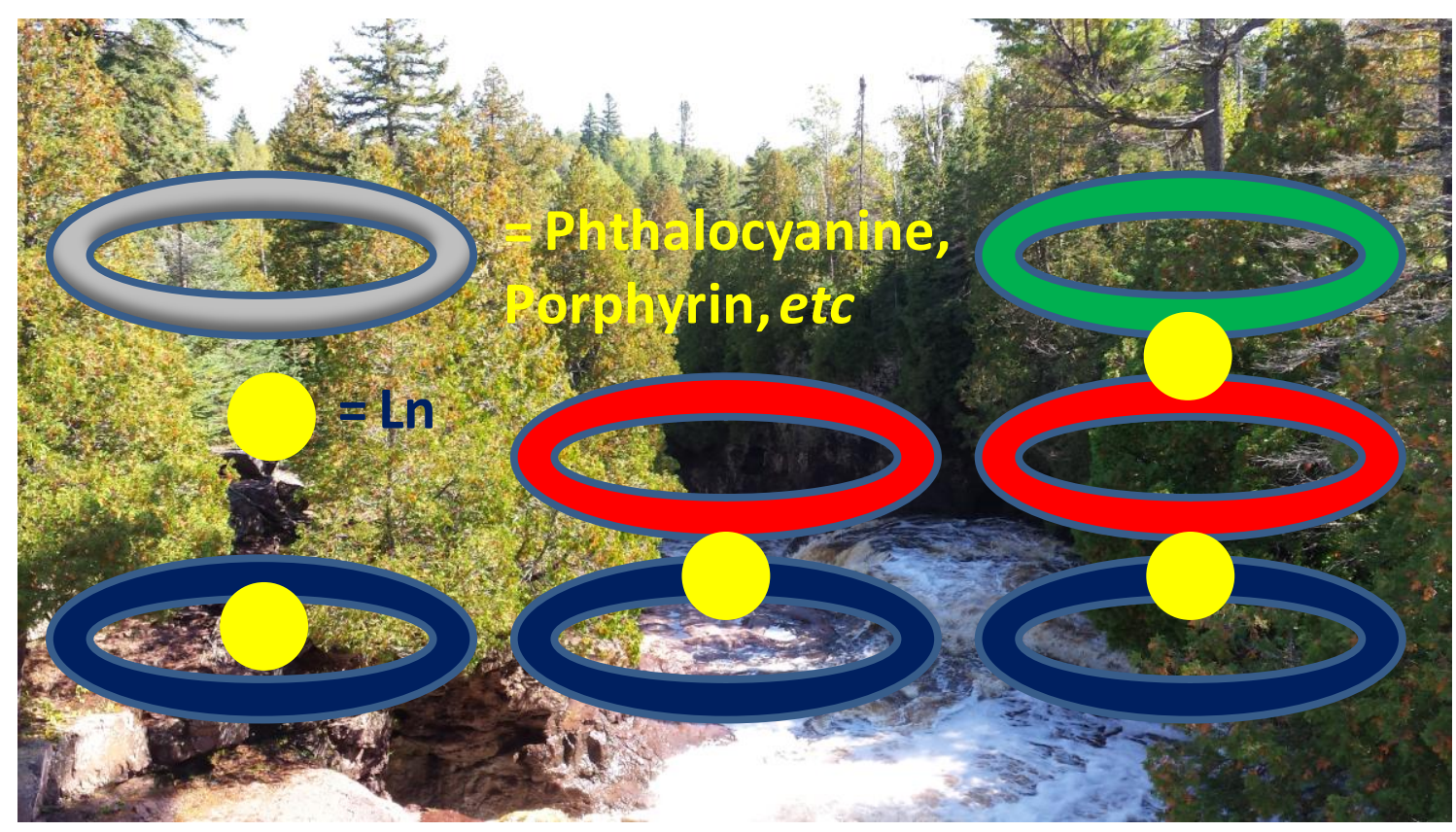

